\title{
Thermodynamics and emission modeling of liquefied natural gas (LNG) tanks and fueling stations
}

\author{
Cesar Augusto Sandoval Leon
}

Follow this and additional works at: https://researchrepository.wvu.edu/etd

\section{Recommended Citation}

Sandoval Leon, Cesar Augusto, "Thermodynamics and emission modeling of liquefied natural gas (LNG) tanks and fueling stations" (2015). Graduate Theses, Dissertations, and Problem Reports. 7125.

https://researchrepository.wvu.edu/etd/7125

This Dissertation is protected by copyright and/or related rights. It has been brought to you by the The Research Repository @ WVU with permission from the rights-holder(s). You are free to use this Dissertation in any way that is permitted by the copyright and related rights legislation that applies to your use. For other uses you must obtain permission from the rights-holder(s) directly, unless additional rights are indicated by a Creative Commons license in the record and/ or on the work itself. This Dissertation has been accepted for inclusion in WVU Graduate Theses, Dissertations, and Problem Reports collection by an authorized administrator of The Research Repository @ WVU.

For more information, please contact researchrepository@mail.wvu.edu. 
THERMODYNAMICS AND EMISSION MODELING OF LIQUEFIED NATURAL GAS (LNG) TANKS AND FUELING STATIONS

\author{
César Augusto Sandoval León \\ Dissertation submitted to the \\ Statler College of Engineering and Mineral Resources \\ at West Virginia University \\ in partial fulfillment of the requirements \\ for the degree of \\ Doctor of Philosophy \\ in \\ Mechanical Engineering \\ W. Scott Wayne, Ph.D., Chair \\ Nigel Clark, Ph.D. \\ Hailin Li, Ph.D. \\ Gregory Thompson, Ph.D. \\ Avinash Unnikrishnan, Ph.D. \\ Department of Mechanical and Aerospace Engineering \\ Morgantown, West Virginia \\ 2015
}

Keywords: LNG, Fueling Stations, Cryogenic Tanks, Thermal Stratification, Emissions, BOG, Venting, Vapor Return, Thermodynamics

(C) 2015 Sandoval León, César Augusto 


\section{AbSTRACT \\ THERMODYNAMICS AND EMISSION MODELING \\ OF LIQUEFIED NATURAL GAS (LNG) TANKS AND \\ FUELING STATIONS}

\section{César Augusto Sandoval León}

In this work a thermodynamics and emissions model of liquefied natural gas (LNG) tanks and fueling stations was developed, allowing for the calculation of methane $\left(\mathrm{CH}_{4}\right)$ emitted from tanks and the prediction of methane emissions in future scenarios. The detailed dynamic thermodynamic model determined the thermodynamic state (pressure, temperature, specific volume) and properties (enthalpy, internal energy, specific heat, etc.) of the liquid and vapor phase methane in the storage tank in order to determine the rate of LNG boil off and venting. The model employed differential forms of the energy balance and mass balance and thermodynamic property relations and data to describe the evolution of liquid and vapor quantity, state and properties with time as a function of fueling station activity. In addition, the temperature inside the storage tank was determined by two approaches: a homogeneous or a stratified distribution, where the homogeneous model assumed a uniform saturated temperature throughout the tank and the stratified model determined a temperature profile in the tank. The model accounted for varying ambient conditions, varying mass flow of LNG into and out of the tank as a result of refueling the tank, fuel dispensing, recirculation to chill dispensing equipment, return of vapor from vehicle tanks for vapor balancing, and release of boil off gas (BOG) to maintain safe tank operating pressure. Furthermore, this work could be adapted to develop a comprehensive model for LNG vehicle fuel tanks.

The model was validated with experimental data acquired by the Center for Alternative Fuels, Engines, and Emissions (CAFEE) of West Virginia University (WVU) from vehicle tanks and at LNG fueling stations in the United States. The complete LNG Fueling Station Model achieved an average error of -0.36 psia/day $(1.13 \%)$ in the rate of pressure change with respect to time using the stratified approach and an average error of $-1.67 \mathrm{psia} /$ day $(-10.43 \%)$ using the homogeneous approach. Two LNG fueling station tanks 
of 15,000 gallons and 25,000 gallons capacity were used. For fueling stations both approaches presented cases of over prediction and under prediction. The stratified approach had an error in $d P / d t$ between -8.00 psia/day (-39.03\%) and $2.75 \mathrm{psia} / \mathrm{day}$ (28.23\%). The homogeneous approach had an error in $d P / d t$ between -7.49 psia/day (-36.55\%) and 2.15 psia/day (17.38\%). Validation of pressure rise in vehicle tanks achieved an average error of $-1.01 \mathrm{psia} /$ day $(-2.64 \%)$ using the stratified approach and $14.56 \mathrm{psia} /$ day $(204.25 \%)$ using the homogeneous approach. Two LNG vehicle tanks of 120 gallons and 150 gallons capacity were used. For vehicle tanks the homogenous approaches always over predicted and the stratified approach presented cases of over prediction and of under prediction. The stratified approach had an error in $d P / d t$ between -6.31 psia/day (-44.90\%) and 4.13 psia/day (21.40\%). The homogeneous approach had an error in $d P / d t$ between 2.35 psia/day (12.16\%) and 39.48 psia/day (883.96\%). 


\section{DEDICATION}

I would like to dedicate this work to my family, my mom Emérita, my grandma Ana, and my brother Jairo, for giving me their support and strength to accomplish this stage of my life, and especially for helping and encouraging me during this process. 


\section{ACKNOWLEDGEMENTS}

I would like to thank my advisor Dr. Scott Wayne for giving me the opportunity to work with him, for his support, patience, dedication, and help in this work. Also, I would like to thank the members of my graduate committee, Dr. Clark, Dr. Li, Dr. Thompson, and Dr. Unnikrishnan, for their valuable help and advice. I also want to give thanks to all of the team members of CAFEE at WVU, and all my friends for their company and advice. I want to give special thanks to John Hailer for providing the heat transfer modules used in this work. Finally, I thank God for giving me the strength and health to accomplish this stage of my life.

Support was provided by the Environmental Defense Fund (EDF), Cummins, Cummins-Westport, Royal Dutch Shell, the American Gas Association, Chart Industries, Clean Energy, the International Council on Clean Transportation, PepsiCo, Volvo Group, Waste Management, and Westport Innovations. Funding for EDF's methane research series, including the West Virginia University study, was provided for by Fiona and Stan Druckenmiller, Heising-Simons Foundation, Bill and Susan Oberndorf, Betsy and Sam Reeves, Robertson Foundation, Alfred P. Sloan Foundation, TomKat Charitable Trust, and the Walton Family Foundation. 


\section{TABLE OF CONTENTS}

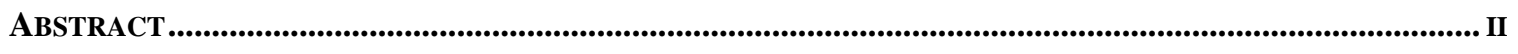

DEDICATION ..................................................................................................................................... IV

ACKNOWLEDGEMENTS............................................................................................................................... V

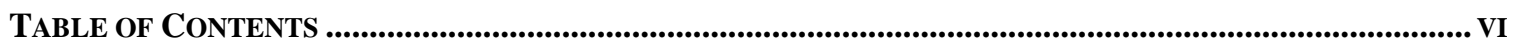

LIST OF FIGURES ................................................................................................................................................. IX

LIST OF TABLES...........................................................................................................................................XIX

LIST OF SYMBOLS......................................................................................................................................................XXI

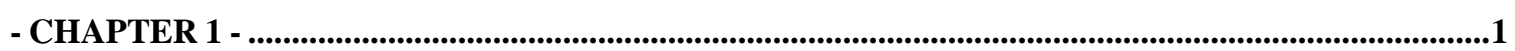

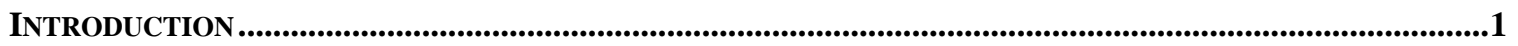

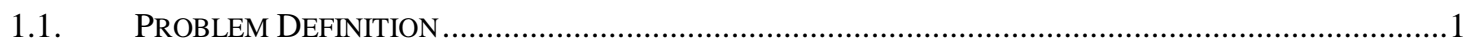

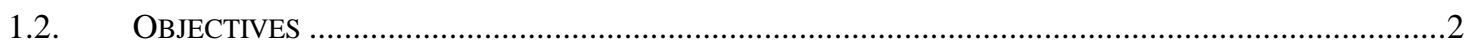

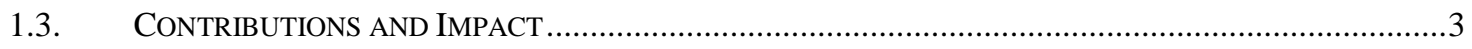

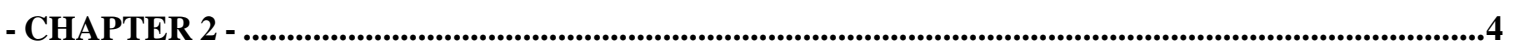

BACKGROUND \& LITERATURE REVIEW ...................................................................................4

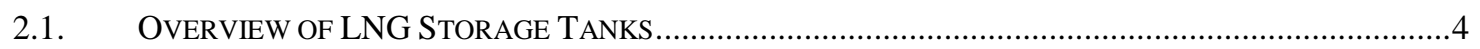

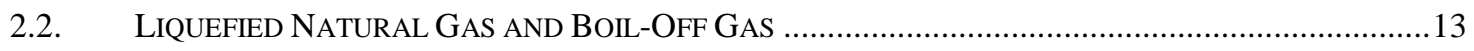

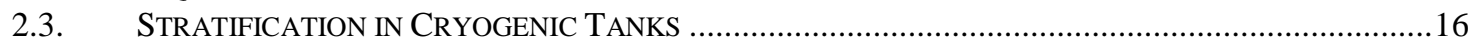

- CHAPTER 3 - ..........................................................................................................................................................21

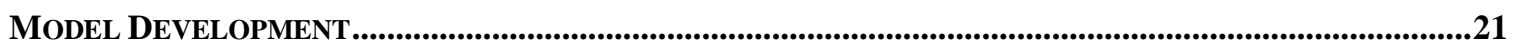

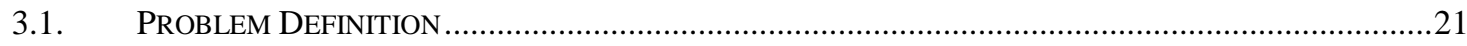

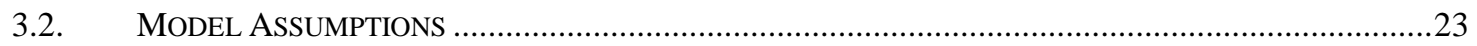

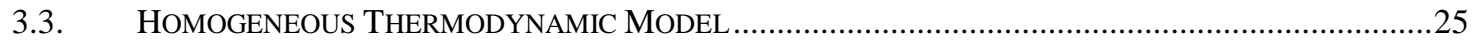

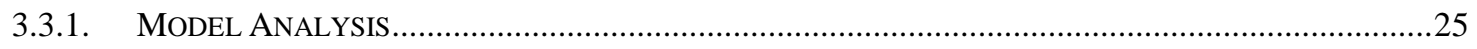

3.3.2. PREDICTION OF HOMOGENEOUS TEMPERATURE AND PRESSURE IN THE LNG TANK .....................28

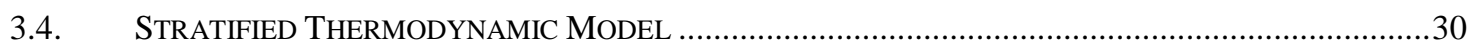

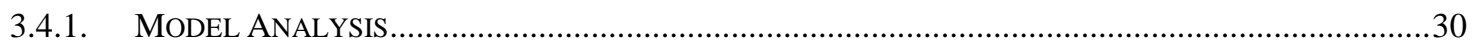

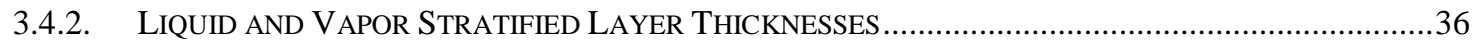

3.4.3. LIQUID AND VAPOR STRATIFIED LAYER TEMPERATURES .........................................................

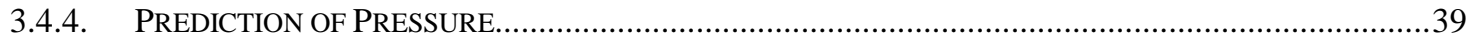

3.4.5. MASS BALANCE AND THERMAL CORRECTION FOR STRATIFICATION ……................................42

3.5. VENTING MODEL FOR CALCULATION OF LNG VAPOR MASS RELEASED....................................44

3.6. FUELING AND VAPOR RETURN FROM VEHICLE FUEL TANKS ......................................................46

3.7. BLOCK DIAGRAM OF THE LNG FUELING STATION MODEL........................................................4

3.8. MODEL IMPLEMENTATION IN MATLAB/SIMULINK …….....................................................50

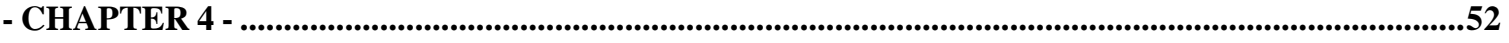

DATA ACQUISITION, RESULTS, AND DISCUSSION .........................................................................................52

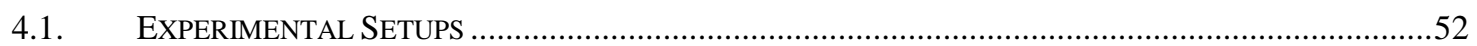

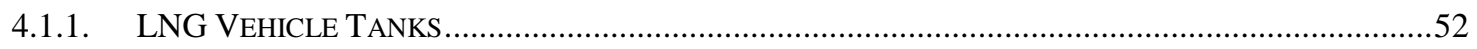

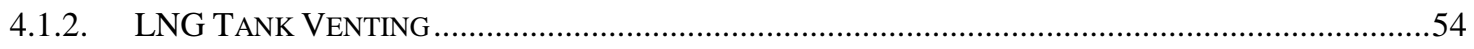

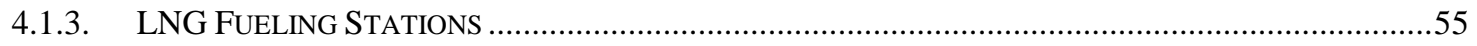


4.2. Hypothetical Hold Time Simulation using the Two Thermodynamic ApProaches with

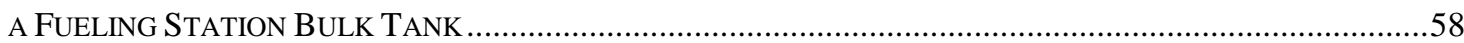

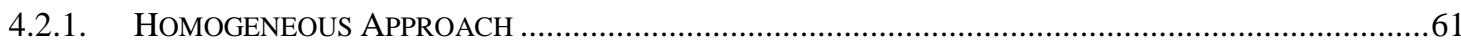

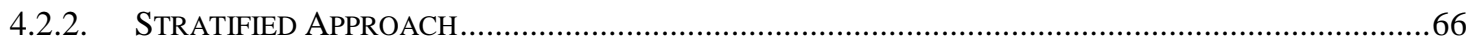

4.2.3. COMPARISON BETWEEN THE TWO THERMODYNAMIC APPROACHES USING A HYPOTHETICAL

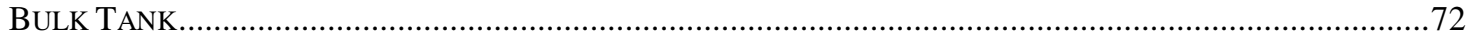

4.3. MODEL COMPARISON WITH EXPERIMENTAL HOLD TIME OF VEHICLE TANKS ..............................78

4.3.1. MODELING RESUlts FOR LNG VEHICLE TANKS WITHOUT INTERNAL FUEL PUMP ORGANIZED BY

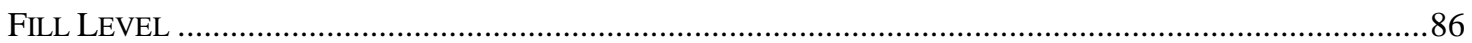

4.3.2. MODELING RESULTS FOR LNG VEHICLE TANKS WITH INTERNAL FUEL PUMP ORGANIZED BY

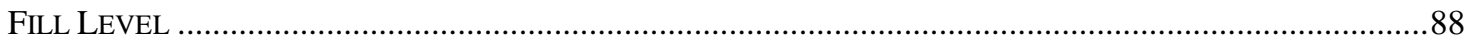

4.3.3. ANALYSIS OF HOLD TIME EXPERIMENTS AND SIMULATIONS WITH LNG VEHICLE TANKS ..........90

4.4. VENTING MODEL COMPARISON WITH EXPERIMENTAL TANK BOIL OFFS..................................101

4.5. MODEL COMPARISON WITH FUELING STATIONS WITH LNG VEHICLES REFUELING ..................109

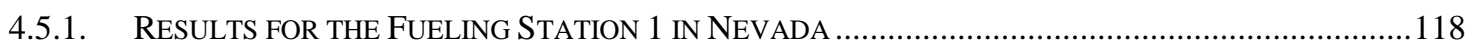

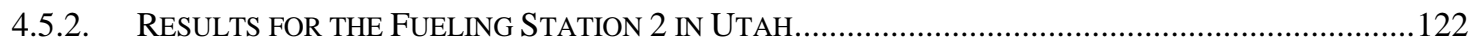

4.5.3. ANALYSIS OF AUdiTS AND SiMULATIONS OF FUELING STATIONS WITH LNG VEHICLES

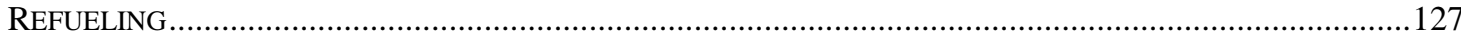

4.6. UNCERTAINTY AND SENSITIVITY ANALYSIS OF THE LNG FUELING STATION MODEL ...............137

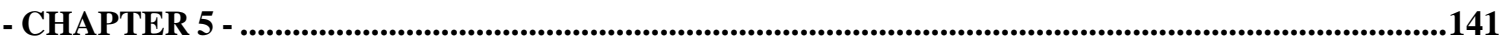

APPLICATIONS AND PREDICTIONS USING THE LNG FUELING STATION MODEL ........................................141

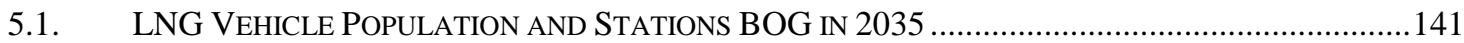

5.2. CHARACTERISTICS OF THE REPRESENTATIVE LNG STATION USED .........................................143

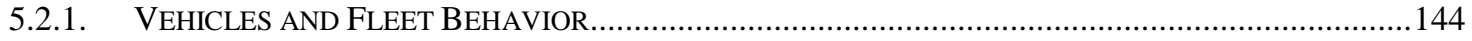

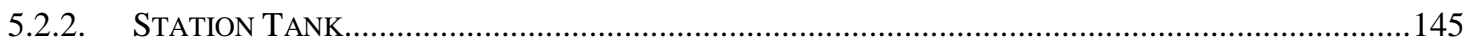

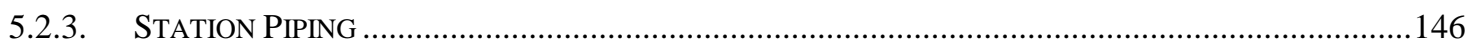

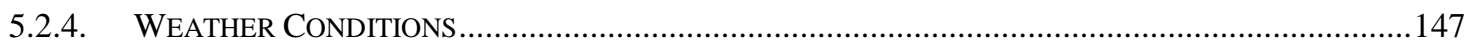

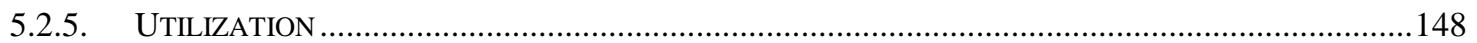

5.3. SimUlation OF BOG FROM A LNG FUELING STATION TANK WITH VEHICLES REFUELING ......149

- CHAPTER 6 - .....................................................................................................................................................151

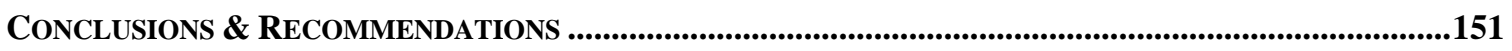

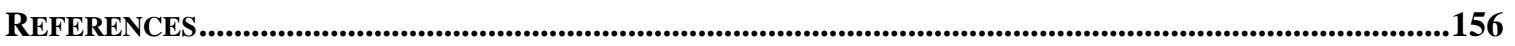

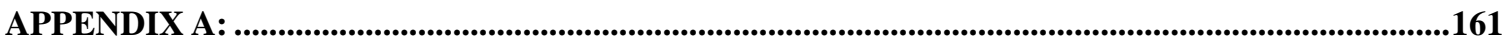

RESUlts OF EXPERIMENTAL HOLd TIME FOR LNG Vehicle TANKS Without INTERNAL Fuel PUMP

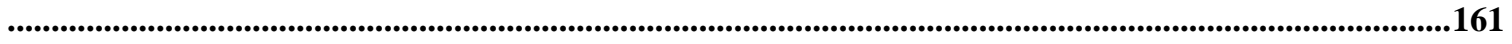

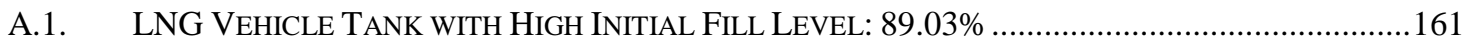

A.2. LNG VEHICLE TANK WITH LOW INITIAL FILL LEVEL: 10.81\% ..............................................165

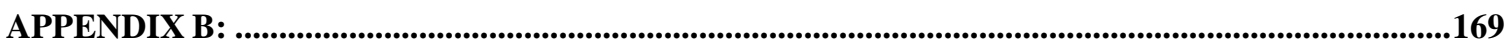

Results Of EXPERIMENTAL HOLd Time For LNG Vehicle TANKS With INTERNAL Fuel PUMP....169

B.1. LNG VEHICLE TANK WITH MIDDLE INITIAL FILL LEVEL: 48.77\% ……….............................169

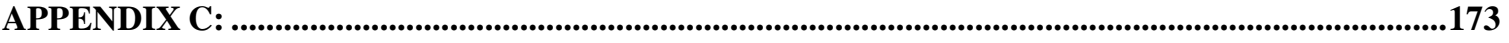

RESULTS OF LNG FUELING STATION 1 IN NEVADA WITH VEHICLES REFUELING ....................................173

C.1. LNG FUELING STATION 1 - SEGMENT 1 with 86.88\% INITIAL FiLL LEVEL ..............................173

C.2. LNG FuELING STATION 1 - SEgment 2 with OfFLOAD PUMP EFFECT.....................................178 


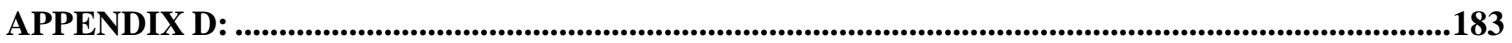

RESULTS OF LNG FUELING STATION 2 IN UTAH WITH VEHICLES REFUELING ....................................183

D.1. LNG FUELING STATION 2 - SEGMENT 1A WITH VAPOR REMOVED FAST ................................183

D.2. LNG FUELING STATION 2 - SEGMENT 2 WITH 62.83\%INITIAL FILL LEVEL.............................188

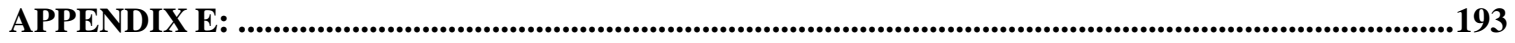

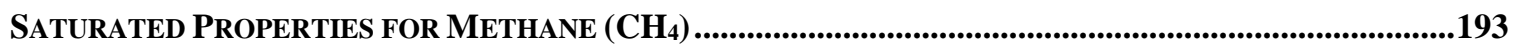

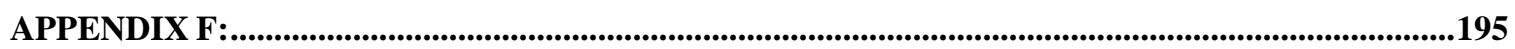

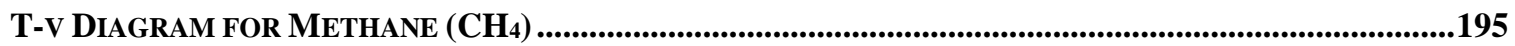

APPENDIX G : .......................................................................................................................196

T-P Diagram for Methane $\left(\mathrm{CH}_{4}\right)$ In the Typical Pressure Range Of a LNG Tank...................196 


\section{LIST OF FIGURES}

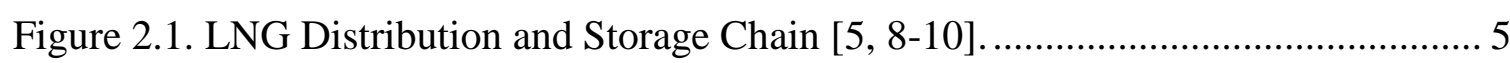

Figure 2.2. Variation of Apparent Thermal Conductivity (k) with Cold Vacuum Pressure

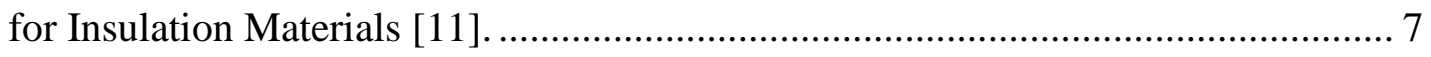

Figure 2.3. Schematic of Some Cryogenic Tank Support Structure Arrangements [7]. ... 9

Figure 2.4. Schematic of LNG Storage Tank Plumbing Connections [10]. .................... 10

Figure 2.5. Schematic of LNG Vehicle Tank Showing Typical Connections [16]......... 12

Figure 3.1. Control Volume Representation of an LNG Tank Station.......................... 22

Figure 3.2. Simplified Schematic of LNG Dispenser Module [14].............................. 23

Figure 3.3. Stratified Temperature Profile and Stratified Layers Inside an LNG Tank. .. 30

Figure 3.4. Velocity and Temperature Profiles in the Turbulent Free-Convection Boundary

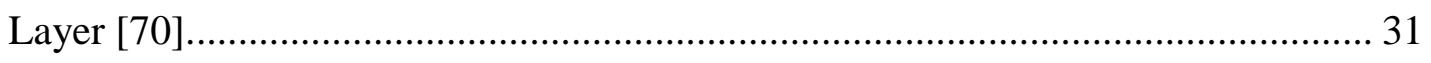

Figure 3.5. Boundary Layer Nomenclature. ..................................................... 32

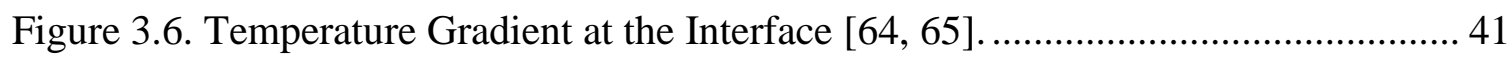

Figure 3.7. Control Volume Representation of the Simplified Sub-Model of an LNG

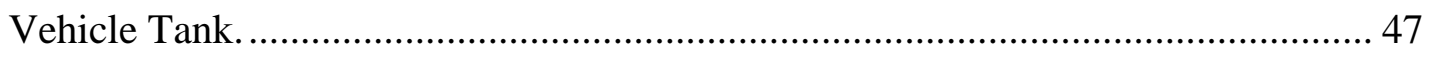

Figure 3.8. Block Diagram of the LNG Fueling Station Model using the Homogeneous

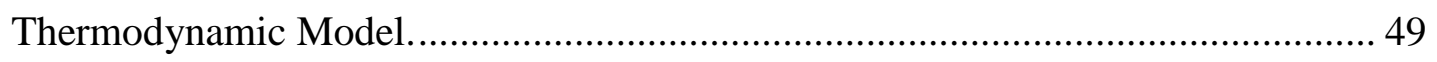

Figure 3.9. Block Diagram of the LNG Fueling Station Model using the Stratified

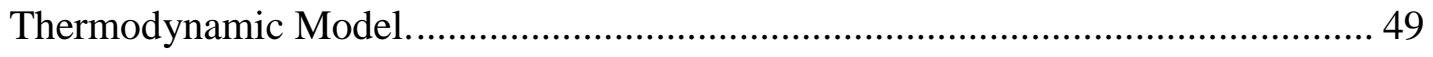


Figure 3.10. Simulink Implementation of the LNG Fueling Station Model using the Homogeneous Thermodynamic Model. 51

Figure 4.1. Lateral View of Filled LNG Vehicle Tank without Internal Fuel Pump after Attachment to the Data Acquisition System. 53

Figure 4.2. Front View of Filled LNG Vehicle Tank with Internal Fuel Pump after Attachment to the Data Acquisition System. 53

Figure 4.3. Tank Wall Insulation Layers used with the Heat Transfer Model. 60

Figure 4.4. Simulated Pressure and Temperature for a Hold Time Simulation in a Fueling Station Tank using the Homogeneous Approach 62

Figure 4.5. Heat Transfer Leak Simulated and Weather Data for a Hold Time Simulation in a Fueling Station Tank using the Homogeneous Approach. 63

Figure 4.6. Simulation Variables for a Hold Time Simulation in a Fueling Station Tank using the Homogeneous Approach. 64

Figure 4.7. Temperature Map for a Hold Time Simulation in a Fueling Station Tank using the Homogeneous Approach. 65

Figure 4.8. Simulated Pressure and dP/dt for a Hold Time Simulation in a Fueling Station Tank using the Stratified Approach. 67

Figure 4.9. LNG and Vapor Masses for a Hold Time Simulation in a Fueling Station Tank using the Stratified Approach. 67

Figure 4.10. Total Heat Transfer Leak Simulated and Weather Data for a Hold Time Simulation in a Fueling Station Tank using the Stratified Approach. 68

Figure 4.11. Total Heat Transfer Leak Used for the Vapor and Liquid Regions for a Hold Time Simulation in a Fueling Station Tank using the Stratified Approach. 69 
Figure 4.12. Heat Transfer Leak Distribution Through each Section of the Tank for a Hold Time Simulation using the Stratified Approach. 70

Figure 4.13. Temperature Map for a Hold Time Simulation in a Fueling Station Tank using

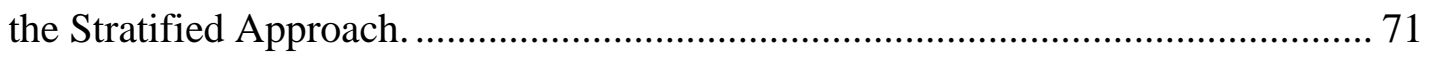

Figure 4.14. Simulated Pressure and dP/dt for a Hold Time Simulation in a Fueling Station

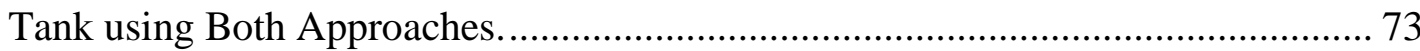

Figure 4.15. LNG and Vapor Mass Comparison for a Hold Time Simulation in a Fueling Station Tank using Both Approaches. ............................................................... 73

Figure 4.16. Total Heat Transfer Leak Simulated and Weather Data for a Hold Time Simulation in a Fueling Station Tank using Both Approaches.............................. 74

Figure 4.17. Total Heat Transfer Leak Used for a Hold Time Simulation in a Fueling Station Tank for the Vapor and Liquid Regions using Both Approaches. 75

Figure 4.18. Heat Transfer Leak Distribution Through each Section of the Tank for a Hold Time Simulation using Both Approaches. ............................................................. 76

Figure 4.19. Temperature Map Comparisons for a Hold Time Simulation in a Fueling Station Tank using Both Thermodynamic Approaches. 77

Figure 4.20. Hold Time Experiment 6 with the Tank without an Internal Fuel Pump (150 gallons) Interpolated and Averaged Data in Red are Indicated. Initial Homogeneous Fill Level: $41.08 \%$ 79

Figure 4.21. Experiment 5 Day 14. Tank without Internal Fuel Pump. Example of Tank Oscillated Every 6 Hours for 120 Seconds. 80

Figure 4.22. Experiment 7. Tank without Internal Fuel Pump. Example of Pressure and Total Weight of the Tank Affected by Snow. 82

Figure 4.23. Experiment 7. Tank without Internal Fuel Pump. Example of Solar Loading Sensor (Pyranometer) Affected by Snow. 82 
Figure 4.24. Experiment 2. Fill Level: 89.03\%. Avg. Ambient Temperature: 289.63 K. 86

Figure 4.25. Experiment 5. Fill Level: 64.16\%. Avg. Ambient Temperature: 277.13 K. 86

Figure 4.26. Experiment 9. Fill Level: 58.06\%. Avg. Ambient Temperature: 285.17 K. 87

Figure 4.27. Experiment 3. Fill Level: 47.32\%. Avg. Ambient Temperature: 290.42 K. 87

Figure 4.28. Experiment 6. Fill Level: 41.08\%. Avg. Ambient Temperature: 272.02 K. 87

Figure 4.29. Experiment 4. Fill Level: 28.88\%. Avg. Ambient Temperature: 288.11 K. 87

Figure 4.30. Experiment 7. Fill Level: 26.77\%. Avg. Ambient Temperature: 269.52 K. 88

Figure 4.31. Experiment 8. Fill Level: 10.81\%. Avg. Ambient Temperature: 264.69 K. 88

Figure 4.32. Experiment 2. Fill Level: 48.77\%. Avg. Ambient Temperature: 276.54 K. 89

Figure 4.33. Experiment 5. Fill Level: 32.47\%. Avg. Ambient Temperature: 277.59 K. 89

Figure 4.34. Experiment 3. Fill Level: 24.19\%. Avg. Ambient Temperature: 278.49 K. 89

Figure 4.35. Experiment 4. Fill Level: 14.34\%. Avg. Ambient Temperature: 275.31 K. 89

Figure 4.36. Trend of Hold Time in the LNG Tanks Experiments $\mathrm{dP} / \mathrm{dt}$ (psia/day) vs Ambient Temperature and Fill Level...................................................................... 92

Figure 4.37. Experimental vs Simulated dP/dt for the LNG Vehicle Tanks. ................... 93

Figure 4.38. Error in Simulated dP/dt (psia/day) vs Fill Level (\%)................................. 94

Figure 4.39. Error in Simulated dP/dt (psia/day) vs Ambient Temperature (K). ............. 94

Figure 4.40. LNG Tanks Experimental dP/dt (psia/day) vs Ambient Temperature and Fill

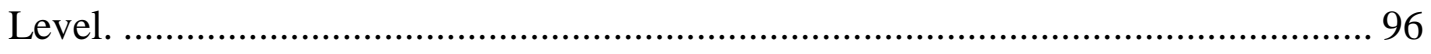

Figure 4.41. Heat Transfer Simulated (kJ/day) vs Fill Level (\%) for LNG Vehicle Tanks. 99 
Figure 4.42. Heat Transfer Simulated (kJ/day) vs Ambient Temperature (K) for LNG Vehicle Tanks. 100

Figure 4.43. Pressure Transient of LNG after Ventings. Experiment 3 with the Tank without an Internal Fuel Pump............................................................................ 102

Figure 4.44. Venting Comparison for Tank without Internal Pump (150 gallons) for

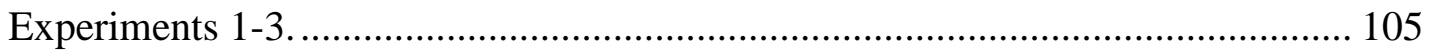

Figure 4.45. Venting Comparison for Tank without Internal Pump (150 gallons). Experiments 4-8 affected by PRV Problems .................................................... 105

Figure 4.46. Venting Comparison for Tank with Internal Pump (120 gallons)............. 106

Figure 4.47. Venting Comparison for Data Provided by Industry.............................. 106

Figure 4.48. Experimental (kg) vs Simulated (kg) LNG Vented................................. 107

Figure 4.49. Experimental LNG Vented (kg) vs Pressure Drop and Fill Level. ............ 108

Figure 4.50. Full Experimental Data for Fueling Station 1 in Nevada......................... 113

Figure 4.51. Offload Pump Effect at Fueling Station 1 in Nevada.............................. 114

Figure 4.52. Full Experimental Data for Fueling Station 2 in Utah. ........................... 116

Figure 4.53. Fueling Station 1 in Nevada. Segment 1. Initial Fill Level: 86.88\%......... 119

Figure 4.54. Fueling Station 1 in Nevada. Segment 2. Initial Fill Level: 90.85\%......... 119

Figure 4.55. Fueling Station 1 in Nevada. Segment 3. Initial Fill Level: 90.95\%......... 120

Figure 4.56. Fueling Station 1 in Nevada. Segment 4. Initial Fill Level: 91.70\%......... 120

Figure 4.57. Fueling Station 1 in Nevada. Segment 5. Initial Fill Level: 84.51\%........ 121

Figure 4.58. Fueling Station 1 in Nevada. Segment 6. Initial Fill Level: 91.54\%......... 121 
Figure 4.59. Fueling Station 2. Segment 1a. GenSet: On. Initial Fill Level: 86.99\% ... 122

Figure 4.60. Fueling Station. Segment 1b. GenSet: On. Initial Fill Level: 84.73\%...... 122

Figure 4.61. Fueling Station 2 in Utah. Segment 2. GenSet: On. Initial Homogeneous Fill Level: $62.83 \%$ 123

Figure 4.62. Fueling Station 2 in Utah. Segment 3. GenSet: On/Off. Initial Homogeneous Fill Level: $52.96 \%$. 123

Figure 4.63. Fueling Station 2 in Utah. Segment 4. GenSet: Off. Initial Homogeneous Fill Level: $38.66 \%$. 124

Figure 4.64. Fueling Station 2 in Utah. Segment 5. GenSet: Off/On. Initial Homogeneous Fill Level: 83.50\%. 124

Figure 4.65. Fueling Station 2 in Utah. Segment 6a. GenSet: On. Initial Homogeneous Fill Level: $73.33 \%$. 125

Figure 4.66. Fueling Station 2 in Utah. Segment 6b. GenSet: On. Initial Homogeneous Fill Level: $70.30 \%$. 125

Figure 4.67. Fueling Station 2 in Utah. Segment 7. GenSet: On. Initial Homogeneous Fill Level: $52.25 \%$. 126

Figure 4.68. Fueling Station 2 in Utah. Segment 8. GenSet: On. Initial Homogeneous Fill Level: $83.57 \%$. 126

Figure 4.69. Fueling Station 1 in Nevada. Segment 1. Comparison of Heat Transfer Magnitudes Estimated. 131

Figure 4.70. Fueling Station 2 in Utah. Segment 3. Showing Vehicles Not Recorded. . 133

Figure 4.71. Error in the LNG Fueling Stations Simulated dP/dt (psia/day)................ 136

Figure 5.1. Solar Loading and Ambient Temperature used in the Simulations.............. 148 
Figure 5.2. Total LNG Vented in a Fueling Station by \%Utilization. 150

Figure A.1. Hold Time Experiment 2 with LNG Vehicle Tank without Internal Fuel Pump. Simulated Pressure and dP/dt. Initial Homogeneous Fill Level: 89.03\% 161

Figure A.2. Hold Time Experiment 2 with LNG Vehicle Tank without Internal Fuel Pump. LNG and Vapor Mass Comparison 161

Figure A.3. Hold Time Experiment 2 with LNG Vehicle Tank without Internal Fuel Pump. Total Heat Transfer Leak Simulated and Weather Data. Average Ambient Temperature: $289.63 \mathrm{~K}$ 162

Figure A.4. Hold Time Experiment 2 with LNG Vehicle Tank without Internal Fuel Pump. Total Heat Transfer Leak Used for the Vapor and Liquid Regions. 163

Figure A.5. Hold Time Experiment 2 with LNG Vehicle Tank without Internal Fuel Pump. Initial Homogeneous Fill Level: 89.03\%. Temperature Map Comparisons. 164

Figure A.6. Hold Time Experiment 8 with LNG Vehicle Tank without Internal Fuel Pump. Simulated Pressure and dP/dt. Initial Homogeneous Fill Level: 10.81\% 165

Figure A.7. Hold Time Experiment 8 with LNG Vehicle Tank without Internal Fuel Pump. LNG and Vapor Mass Comparison. 165

Figure A.8. Hold Time Experiment 8 with LNG Vehicle Tank without Internal Fuel Pump. Total Heat Transfer Leak Simulated and Weather Data. Average Ambient Temperature: $264.69 \mathrm{~K}$ 166

Figure A.9. Hold Time Experiment 8 with LNG Vehicle Tank without Internal Fuel Pump. Total Heat Transfer Leak Used for the Vapor and Liquid Regions. 167

Figure A.10. Hold Time Experiment 8 with LNG Vehicle Tank without Internal Fuel Pump. Initial Homogeneous Fill Level: 10.81\%. Temperature Map Comparisons. 168

Figure B.1. Hold Time Experiment 2 with LNG Vehicle Tank with Internal Fuel Pump. Simulated Pressure and dP/dt. Initial Homogeneous Fill Level: 48.77\% 169 
Figure B.2. Hold Time Experiment 2 with LNG Vehicle Tank with Internal Fuel Pump. LNG and Vapor Mass Comparison. 169

Figure B.3. Hold Time Experiment 2 with LNG Vehicle Tank with Internal Fuel Pump. Total Heat Transfer Leak Simulated and Weather Data. Average Ambient Temperature: $276.54 \mathrm{~K}$ 170

Figure B.4. Hold Time Experiment 2 with LNG Vehicle Tank with Internal Fuel Pump. Total Heat Transfer Leak Used for the Vapor and Liquid Regions. 171

Figure B.5. Hold Time Experiment 2 with LNG Vehicle Tank with Internal Fuel Pump. Initial Homogeneous Fill Level: 48.77\%. Temperature Map Comparisons. 172

Figure C.1. Fueling Station 1 in Nevada. Segment 1. Simulated Pressure, dP/dt, and Fill Level. Initial Homogeneous Fill Level: 86.88\% 173

Figure C.2. Fueling Station 1 in Nevada. Segment 1. LNG and Vapor Mass Comparison. 174

Figure C.3. Fueling Station 1 in Nevada. Segment 1. Total Heat Transfer Simulated, Weather Data, and Vehicles Refueled. 174

Figure C.4. Fueling Station 1 in Nevada. Segment 1. Total Heat Transfer, Heat Transfer by the Vehicle Transactions, and Heat Leak into the Tank through Walls. 175

Figure C.5. Fueling Station 1 in Nevada. Segment 1. Heat Transfer Tank Leak into the Vapor and Liquid Regions. 176

Figure C.6. Fueling Station 1 in Nevada. Segment 1. Initial Homogeneous Fill Level: 86.88\%. Temperature Map Comparisons. 177

Figure C.7. Fueling Station 1 in Nevada. Segment 2. Simulated Pressure, dP/dt, and Fill Level. Initial Homogeneous Fill Level: 90.85\% 178

Figure C.8. Fueling Station 1 in Nevada. Segment 2. LNG and Vapor Mass Comparison. 
Figure C.9. Fueling Station 1 in Nevada. Segment 2. Total Heat Transfer Simulated, Weather Data, and Vehicles Refueled. 179

Figure C.10. Fueling Station 1 in Nevada. Segment 2. Total Heat Transfer, Heat Transfer by the Vehicle Transactions, and Heat Leak into the Tank through Walls. 180

Figure C.11. Fueling Station 1 in Nevada. Segment 2. Heat Transfer Tank Leak into the Vapor and Liquid Regions. 181

Figure C.12. Fueling Station 1 in Nevada. Segment 2. Initial Homogeneous Fill Level: 90.85\%. Temperature Map Comparisons. 182

Figure D.1. Fueling Station 2 in Utah. Segment 1a. GenSet: On. Simulated Pressure, dP/dt, and Fill Level. Initial Homogeneous Fill Level: 86.99\% 183

Figure D.2. Fueling Station 2 in Utah. Segment 1a. GenSet: On. LNG and Vapor Mass Comparison. 184

Figure D.3. Fueling Station 2 in Utah. Segment 1a. GenSet: On. Total Heat Transfer Simulated, Weather Data, and Vehicles Refueled. 184

Figure D.4. Fueling Station 2 in Utah. Segment 1a. GenSet: On. Total Heat Transfer, Heat Transfer by the Vehicle Transactions, and Heat Leak into the Tank through Walls. 185

Figure D.5. Fueling Station 2 in Utah. Segment 1a. GenSet: On. Heat Transfer Tank Leak into the Vapor and Liquid Regions. 186

Figure D.6. Fueling Station 2 in Utah. Segment 1a. GenSet: On. Initial Homogeneous Fill Level: $86.99 \%$. Temperature Map Comparisons. 187

Figure D.7. Fueling Station 2 in Utah. Segment 2. GenSet: On. Simulated Pressure, dP/dt, and Fill Level. Initial Homogeneous Fill Level: 62.83\% 188

Figure D.8. Fueling Station 2 in Utah. Segment 2. GenSet: On. LNG and Vapor Mass Comparison. 189 
Figure D.9. Fueling Station 2 in Utah. Segment 2. GenSet: On. Total Heat Transfer Simulated, Weather Data, and Vehicles Refueled. 189

Figure D.10. Fueling Station 2 in Utah. Segment 2. GenSet: On. Total Heat Transfer, Heat Transfer by the Vehicle Transactions, and Heat Leak into the Tank through Walls. 190

Figure D.11. Fueling Station 2 in Utah. Segment 2. GenSet: On. Heat Transfer Tank Leak into the Vapor and Liquid Regions...................................................................... 191

Figure D.12. Fueling Station 2 in Utah. Segment 2. GenSet: On. Initial Homogeneous Fill Level: $62.83 \%$. Temperature Map Comparisons. 192 


\section{LIST OF TABLES}

Table 2.1. R-Value of Selected Cryogenic Insulation [7]........................................... 7

Table 4.1. Parameters Monitored in the Experiments................................................... 52

Table 4.2. Initial LNG Bulk Tank Conditions for Simulations ................................... 58

Table 4.3. LNG Bulk Tank Dimensions and Heat Transfer Values Used in the Simulations

Table 4.4. Summary Results Bulk Tank with Homogeneous Approach ......................... 61

Table 4.5. Summary Results Bulk Tank with Stratified Approach .............................. 66

Table 4.6. Summary Results for a Hypothetical Bulk Tank with Both Thermodynamic

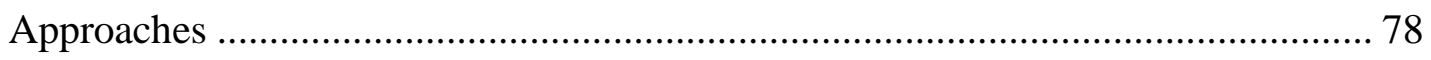

Table 4.7. Snow Weight on the LNG Vehicle Tanks ............................................... 81

Table 4.8. LNG Vehicle Tanks Dimensions and Heat Transfer Values Used in the Simulations 85

Table 4.9. Summary of Vehicle Tank Experiments Compared with Homogenous and

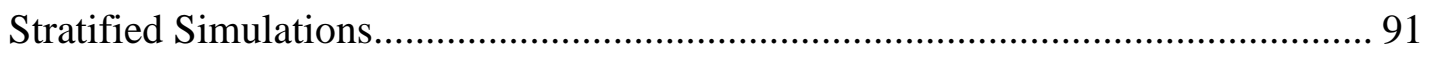

Table 4.10. Summary of Heat Transfer for Vehicle Tanks Compared with Homogenous

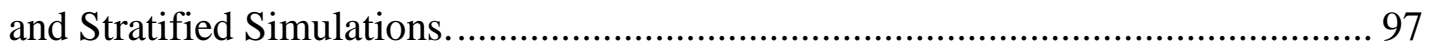

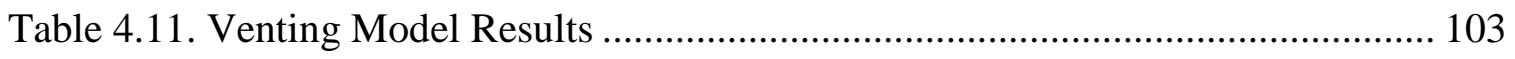

Table 4.12. Dimensions and Heat Transfer Values Used in the Simulations for the LNG Bulk Tanks at the Fueling Stations ............................................................. 110

Table 4.13. Average Ambient Pressure at Experimental Locations ............................. 111 
Table 4.14. Summary of Fleet Recorded at the LNG Fueling Stations 112

Table 4.15. Summary of Audit Stations Compared with Homogenous and Stratified Simulations. 130

Table 4.16. Manual and PRV Ventings during the LNG Fueling Stations Audited...... 135

Table 4.17. Uncertainty of the LNG Fueling Stations Model by Sensitivity of Variables with Measurement Errors............................................................................... 138

Table 4.18. Uncertainty of the LNG Fueling Stations Model by Sensitivity of the Fleet

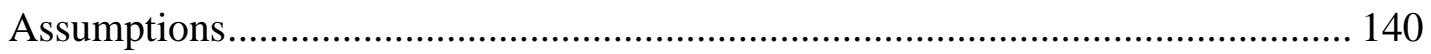

Table 5.1. Medium Projection of Heavy-Duty LNG Vehicle Population for the United

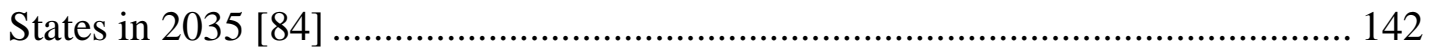

Table 5.2. Vehicle Characteristics for the Representative Station................................ 144

Table 5.3. Station Bulk Tank Parameters ................................................................. 145

Table 5.4. Station Bulk Tank Dimensions and Heat Transfer Values Used.................. 146

Table 5.5. Station Piping Dimensions................................................................. 147

Table 5.6. Solar Loading and Ambient Conditions ................................................. 148

Table 5.7. Simulation of LNG Vented in a Fueling Station. ...................................... 150 


\section{LIST OF SYMBOLS}

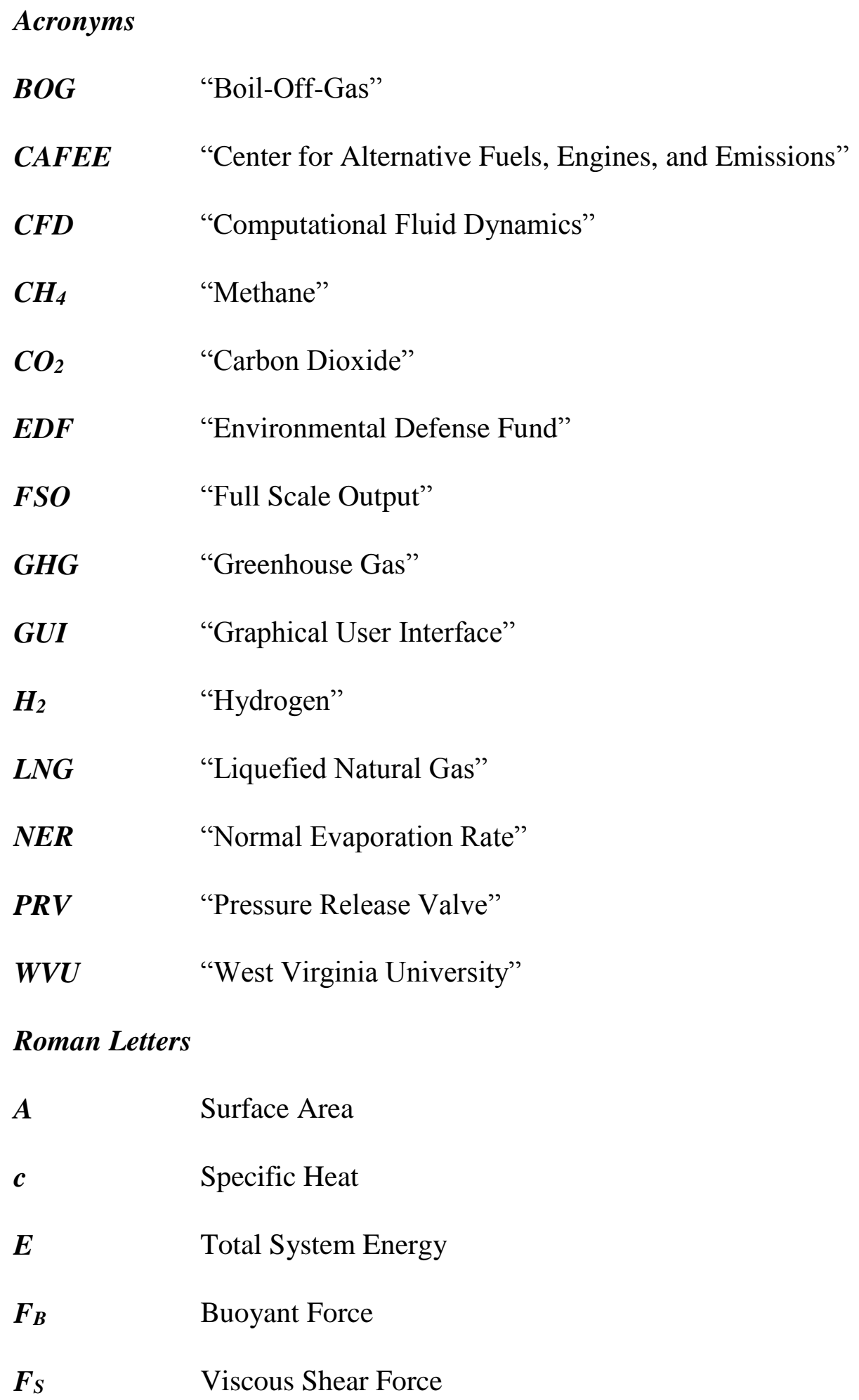




\begin{tabular}{ll}
$\boldsymbol{g}$ & Acceleration Field \\
$\boldsymbol{h}$ & Enthalpy, Height \\
$\boldsymbol{m}$ & Mass \\
$\boldsymbol{m}$ & Mass Flow Rate \\
$\boldsymbol{P}$ & Pressure \\
$\boldsymbol{P r}$ & Prandtl Number \\
$\boldsymbol{Q}$ & Heat Transfer \\
$\dot{\boldsymbol{Q}}$ & Heat Transfer Rate \\
$\boldsymbol{q}$ & Heat Flux \\
$\boldsymbol{R}$ & Tank Radius \\
$\boldsymbol{T}$ & Temperature \\
$\boldsymbol{t}$ & Time \\
$\boldsymbol{U}$ & Internal Energy, Boundary Layer Characteristic Velocity \\
$\boldsymbol{u}$ & Specific Internal Energy, Boundary Layer Local Velocity \\
$\boldsymbol{V}$ & Volume \\
$\boldsymbol{v}$ & Specific Volume, Kinematic Viscosity \\
$\boldsymbol{W}$ & Work \\
$\boldsymbol{x}$ & Distance from Bottom of Tank \\
$\boldsymbol{Z}$ & Distance from Tank Wall \\
\hline $\boldsymbol{B}$ & Depth in Stratified Layer \\
\hline & \\
\hline &
\end{tabular}

Greek letters

$\boldsymbol{\alpha} \quad$ Thermal Diffusivity

$\boldsymbol{\beta} \quad$ Coefficient of Volumetric Thermal Expansion 


\begin{tabular}{|c|c|}
\hline$\Delta$ & Increment \\
\hline$\delta$ & Boundary Layer Thickness \\
\hline$\varepsilon$ & Error Tolerance \\
\hline $\boldsymbol{\theta}$ & Boundary Layer Temperature Rise \\
\hline$\rho$ & Density \\
\hline$\tau$ & Shear Stress \\
\hline$\mu$ & Dynamic Viscosity \\
\hline$\chi$ & Vapor Quality \\
\hline \multicolumn{2}{|c|}{ Subscripts } \\
\hline$a$ & Adjusted \\
\hline ave & Average \\
\hline $\boldsymbol{B}$ & Bulk \\
\hline$f$ & Liquid \\
\hline$g$ & Vapor \\
\hline$i$ & Step Iteration \\
\hline in & Entering the Tank \\
\hline$m$ & Mean \\
\hline out & Exiting the Tank \\
\hline$s$ & Saturated \\
\hline$w$ & Wall \\
\hline
\end{tabular}




\section{- CHAPTER 1 -}

\section{INTRODUCTION}

\subsection{Problem Definition}

During the last decade liquefied natural gas (LNG) has been more widely adopted in the world, increasing the construction of LNG fueling stations and use of LNG commercial vehicles [1-4]. As well, due to the lower carbon content per unit energy of natural gas compared to diesel fuel when combusted in an internal combustion engine, use of natural gas in the heavy-duty transportation sector may offer climate change benefits. However, natural gas vehicles and their associated fueling infrastructure release fugitive methane, a significantly more potent greenhouse gas $(\mathrm{GHG})$ than carbon dioxide $\left(\mathrm{CO}_{2}\right)$, into the atmosphere which must be considered.

LNG is a cryogenic liquid stored around a temperature of $-162{ }^{\circ} \mathrm{C}\left(-260{ }^{\circ} \mathrm{F}\right)$ in well insulated pressurized cryogenic tanks. Since there is not perfect insulation, LNG gains heat expanding and evaporating some of the liquid which generates an increase of pressure in the tanks. In order to maintain tank integrity a pressure relief valve (PRV) releases some of the LNG vapor after reaching a maximum pressure. If the LNG vapor, consisting mainly of methane, is not mitigated a loss of fuel and release of methane $\left(\mathrm{CH}_{4}\right)$ to the atmosphere occurs increasing greenhouse gases. Furthermore, methane is potentially combustible and explosive when at a concentrations of 5-15\% mixed with air.

To predict the rate of LNG boil off and venting from a LNG tank the complex interactions between the different components of a LNG fueling station were modeled. Differential forms of the energy balance and mass balance, thermodynamic property relations and data were used to develop the detailed dynamic thermodynamic model. The characteristics of liquid and vapor flows into and out of the tank were included as a function of fueling station activity with respect to time to determine the dynamic evolution of liquid and vapor quantity, state and properties. Temperature inside the storage tank was determined by two temperature approaches: a homogeneous and a stratified approach. The 
homogeneous approach assumed a uniform saturated temperature throughout the tank and the stratified approach determined a temperature profile in the tank. Additionally, varying ambient conditions were used to determine the heat transfer through the tank shell and associated plumbing in the LNG fueling station.

\subsection{Objectives}

The use of natural gas has been more widely adopted in the heavy-duty transportation sector and may offer climate change benefits due to the lower carbon content per unit energy of natural gas compared to diesel fuel when combusted in an internal combustion engine. The methane released into the atmosphere by fueling infrastructure must be considered since is a significantly more potent GHG than $\mathrm{CO}_{2}$ and the publicly available data on methane emissions is limited. The methane released by LNG tanks is difficult to measure because of the magnitude of mass vented which saturates emissions sensors and for the potential danger of having electronic equipment around. Then, the overall objective of this dissertation was to quantify the current and future fugitive mass of methane released by LNG storage tanks and to estimate the climate change benefits by using natural gas in the growing heavy-duty transportation sector.

The specific task-based objectives of this work were as follows:

1. Develop a comprehensive thermodynamic and emission model of LNG tanks and fueling stations in MATLAB/Simulink to facilitate the calculation of methane emitted from tanks where the temperature inside the storage tank can use a homogeneous or stratified approach.

2. Validate the model with experimental data acquired by the Center for Alternative Fuels, Engines, and Emissions (CAFEE) team of West Virginia University (WVU). 
3. Model the Boil-Off Gas (BOG) vented from LNG tanks and compare it with experimental data to assess the accuracy of the model.

4. Predict the methane emissions for future scenarios as natural gas use in the heavy duty transportation sector expands as a function of fueling station (or vehicle) activity.

By achieving these objectives, the development of a thermodynamic and emission model for LNG tanks and fueling stations was possible. In addition, these modeling capabilities facilitated performing emission calculations. Furthermore, the thermodynamic and emission model for LNG tanks and fueling stations was validated to assess methane emitted based on different possible future scenarios.

\subsection{Contributions and Impact}

The main contributions of this work were the development of a thermodynamic LNG tank model, the modeling of the principal components involved in LNG fueling stations, and the integration of all in one comprehensive thermodynamic and emission model. Only one time was previously attempted in the literature but not at this detail and extended complexity. Additionally, the model allowed the simulation of different scenarios as a function of fueling station (or vehicle) activity. Moreover, the temperature inside the storage tank was determined by a homogeneous and a stratified temperature distribution approach, where the homogeneous model assumed the saturated temperature and the stratified approach determined a temperature profile in the tank. Furthermore, the work completed could be adapted to develop a comprehensive model for LNG vehicle fuel tanks or used with other cryogenic liquids such as hydrogen or nitrogen. 


\section{- CHAPTER 2 -}

\section{BACKGROUND \& LITERATURE REVIEW}

This chapter will provide background and a review of the published literature concerning LNG storage tanks, BOG calculations and modeling, and temperature stratification in cryogenic tanks.

\subsection{Overview of LNG Storage Tanks}

The distribution and storage chain for LNG is shown in Figure 2.1, where LNG storage tanks are designed base on application, fuel needs, and site environment [5]. On top of the chain are the tanks at production plants, which are not addressed in this work. These have large capacities between $100,000 \mathrm{~m}^{3}$ to $250,000 \mathrm{~m}^{3}$ (26 to 66 million gallons), keep the LNG near atmospheric pressure, and are typically above-ground or in-ground double walled "flat bottomed" tanks. Following in the chain are the transport tankers that are double walled cryogenic tanker trucks or rail cars and help to move the LNG between the production plants and the fueling stations. Next, are the tanks at LNG fueling stations that typically are "shop built" double walled and can be selected to be installed vertically or horizontally. Vertical tanks generally are less expensive, have smaller footprints, and are better for priming pumps, at the expense of the more costly foundations [6]. Finally, LNG is dispensed into LNG vehicles with onboard double walled tanks attached to their frame. LNG vehicle tanks are installed horizontally and vary in capacity, as well, some vehicles are provided with two LNG tanks to expand their driving range.

Regardless of application, LNG storage tanks keep similar design characteristics [7]: insulation to minimize heat into the cryogenic liquid that will produce BOG, input and output of LNG in liquid and vapor form to and from the tank, pressure and fill level instrumentation, a pressure release valve to protect the integrity of the tank at higher pressures, and support the service conditions required including from vibrations, corrosion, wind, and seismic. 
a) Flat Bottomed Bulk Cryogenic LNG Storage Tanks at

Production Plants

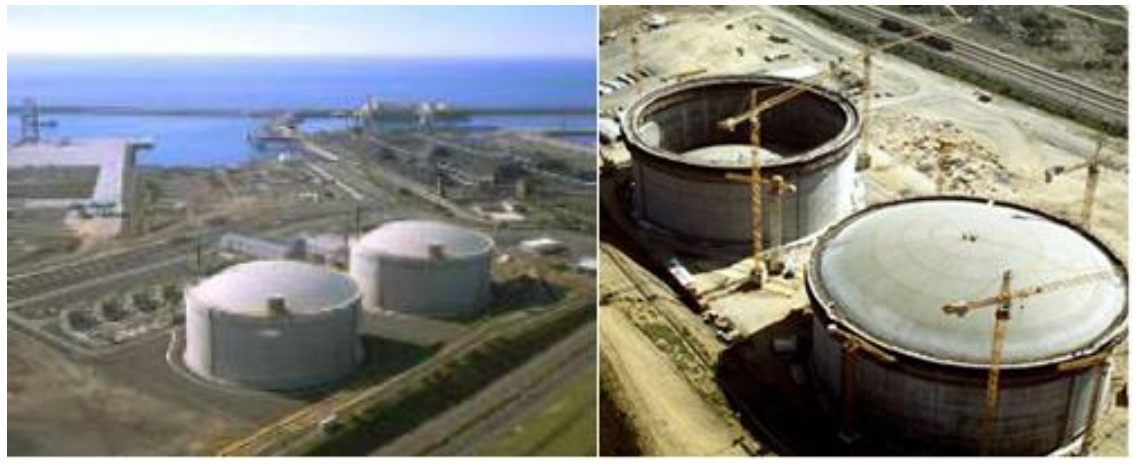

b) LNG

Transport

Tankers

c) Horizontal and Vertical LNG Storage

Tanks at Fueling Facilities
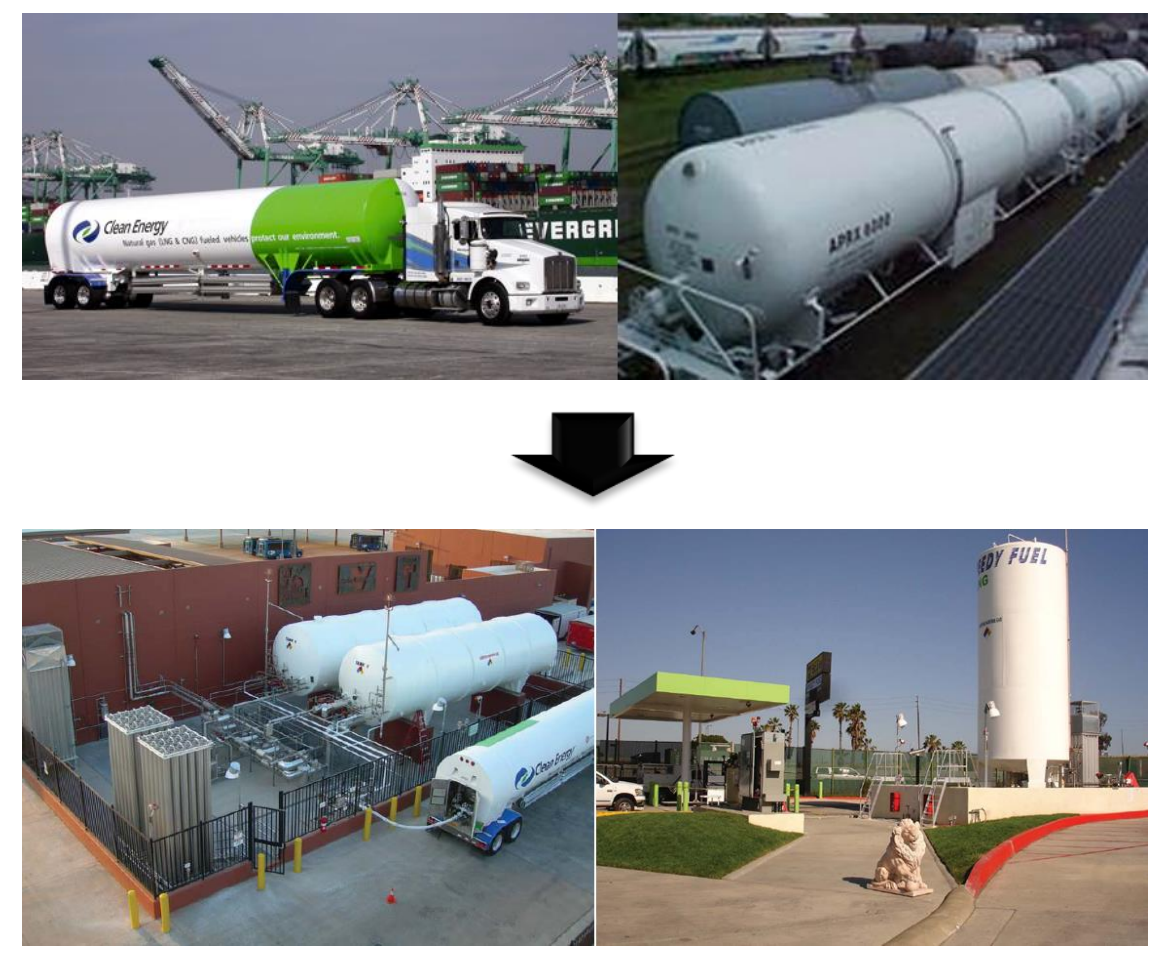

d) LNG Vehicle Fuel Tanks

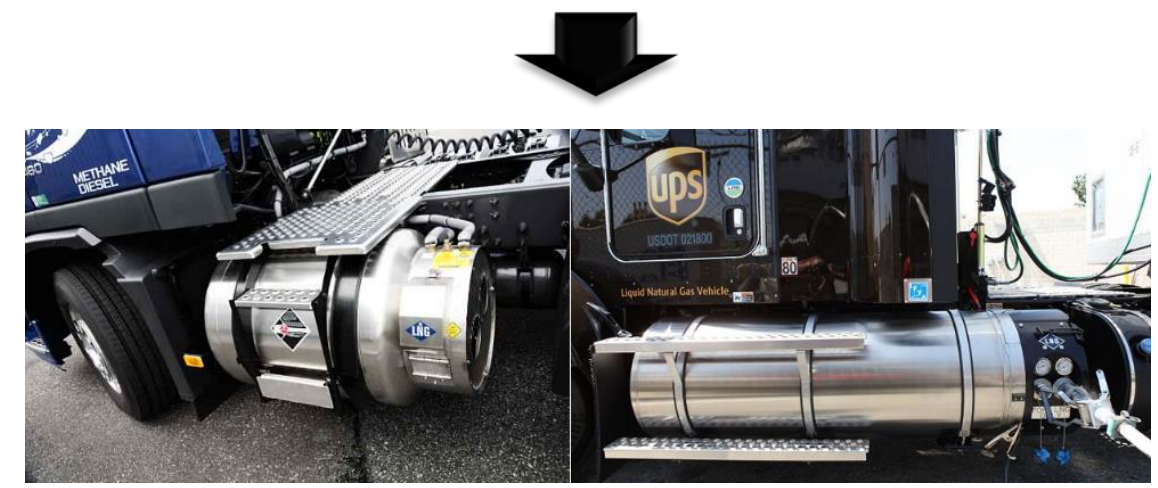

Figure 2.1. LNG Distribution and Storage Chain [5, 8-10]. 
At fueling stations, LNG is stored and dispensed as "saturated" or "unsaturated" fuel. Vehicles that have engines without an internal fuel pump in the tank require saturated LNG. Vehicles equipped with a tank with an internal fuel pump can operate on either saturated or unsaturated LNG. The difference between "saturated" and "unsaturated" LNG is fuel temperature. Unsaturated LNG is stored at $-160{ }^{\circ} \mathrm{C}\left(-256^{\circ} \mathrm{F}\right)$ with a low pressure down to 17 psia. Saturated LNG is warmer, -133 to $-123^{\circ} \mathrm{C}\left(-208\right.$ to $\left.-190{ }^{\circ} \mathrm{F}\right)$, which brings it to a higher saturation pressure in the storage tanks (90 to $150 \mathrm{psia}$ ). The main concern with cryogenic tanks is the difference between ambient temperature with the temperature of LNG stored in the tank, where ambient temperature is around $20^{\circ} \mathrm{C}\left(70{ }^{\circ} \mathrm{F}\right)$ which makes a difference of more than $140{ }^{\circ} \mathrm{C}\left(260^{\circ} \mathrm{F}\right)$ with the LNG inside a tank. This difference of temperature generates heat leak into the tank independent of the insulation used. Additional heat into the tank occurs by [7]:

- conduction (through the bracing between the inner and outer tank walls),

- conduction (through process piping crossing the inner and outer walls),

- convection (due to gas remaining in the annular space between the inner and outer walls which is usually pulled to a very high vacuum - less than 1 millionth of an atmosphere), and

- radiation (due to incident sunlight warming up the exterior of the tank).

The type of insulation material used in cryogenic tanks are various including: fiberglass, foam, Perlite, Aerogel, and Multilayer Insulation (MLI) also called Super Insulation (SI). At atmospheric pressure these materials are all poor insulators, but when vacuum increases their insulation capabilities increases and in the case of SI increases up to 100 times [7]. Values of thermal resistance (R-Value) for these insulation materials are shown in Table 2.1. Figure 2.2 shows the materials performance at different levels of vacuum [11].

The total thermal resistance of a LNG tank through the shell can be expressed using a parallel resistance network as [12]:

$$
R=\frac{1}{\frac{1}{R_{m}}+\frac{1}{R_{S}}}
$$

where $R_{m}$ is the thermal resistance of the multilayer super insulation and $R_{s}$ is the thermal resistance of the support structure connecting the inner and outer shells of the tank. 
Table 2.1. R-Value of Selected Cryogenic Insulation [7]

\begin{tabular}{l|c}
\hline \multicolumn{1}{c|}{ Insulation } & R-Value (m-K/W) \\
\hline Fiberglass without vacuum & 44 \\
Foam without vacuum & 58 \\
Powder without vacuum & 43 \\
Vacuum & 174 \\
Evacuated Perlite & 416 \\
Super Insulation under Vacuum & 1180 \\
\hline
\end{tabular}

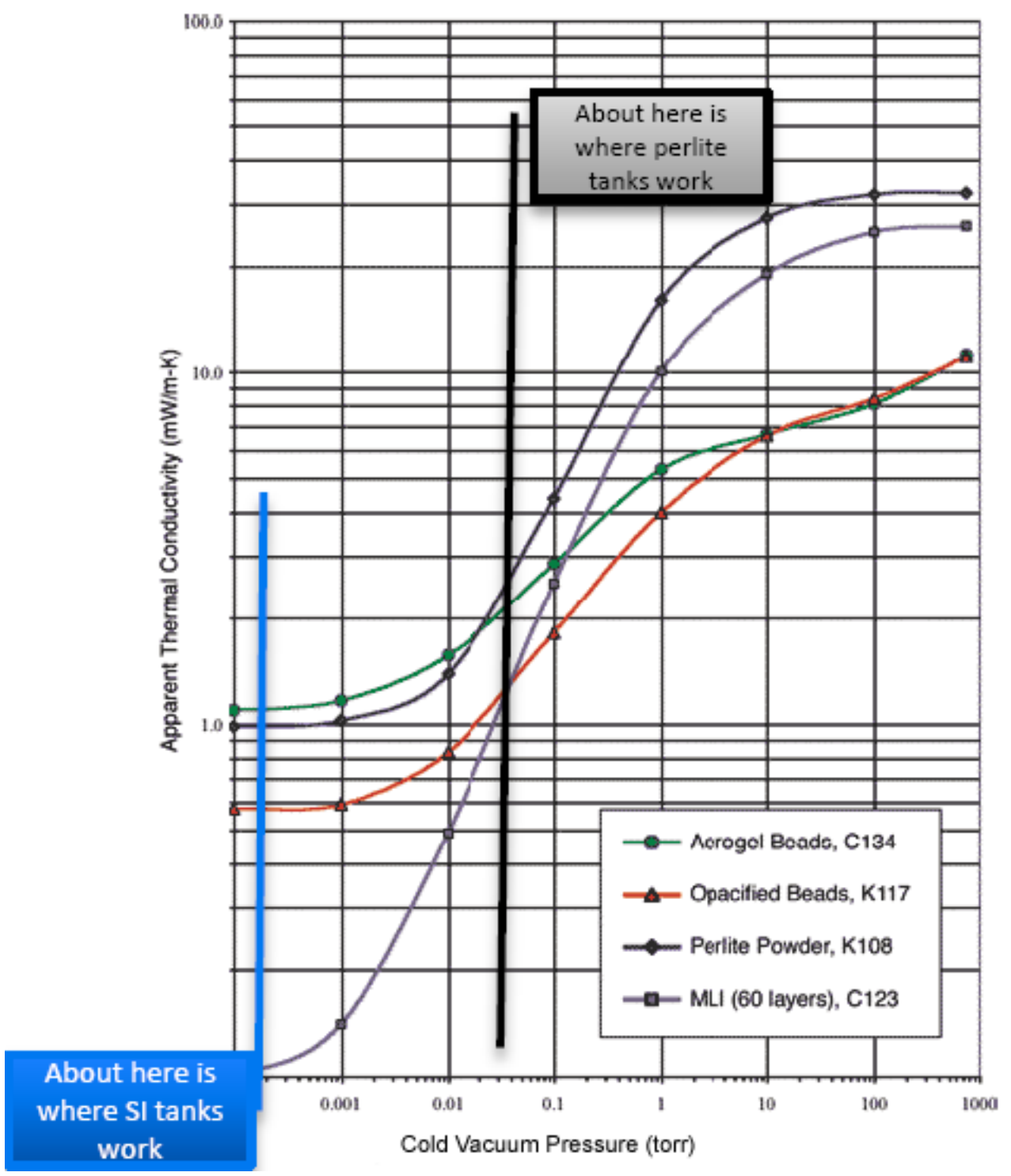

Figure 2.2. Variation of Apparent Thermal Conductivity (k) with Cold Vacuum Pressure for Insulation Materials [11]. 
The super insulation resistance can be estimated by $\left.R_{m}=\Delta h / k_{m} S\right)$ [13] and the support strut resistance can be estimated by $R_{s}=\Delta h /_{\left(k_{S} S_{S}\right)}[13]$ where $\Delta \mathrm{h}$ is the thickness of the super insulation, $\mathrm{k}_{\mathrm{m}}$ is the thermal conductivity of the super insulation, $\mathrm{k}_{\mathrm{s}}$ is the thermal conductivity of the support structure, $S$ is the surface area of the inner shell of the tank and $\mathrm{S}_{\mathrm{s}}$ is the surface area of the support structure. The heat flux across the shell of the LNG tank can then be approximated as [14]:

$$
q=\frac{\Delta T}{R}=\frac{\Delta T\left(k_{m} S+k_{s} \gamma S\right)}{\Delta h}=\frac{\Delta T\left(k_{m}+k_{s} \gamma\right) \beta V}{\Delta h}
$$

where $\Delta T$ is the temperature differential between the inner and outer tank surfaces, $\gamma=$ $S_{S} / S$ is the ratio of the support structure area to the inner shell surface area and $\beta=S / V$ is the ratio of inner shell surface area to tank volume defined as the area density of the tank. For a plain tube the area density is $\beta=4 / D$ where $D$ is the diameter of the tube [14]. The thermal conductivity of super insulation, $k_{m}$, is on the order of $5 \times 10^{-5} \mathrm{~W} / \mathrm{mK}^{[15]}$ and the conductivity of $1 \%$ chrome steel at $0^{\circ} \mathrm{C}, k_{s}$, is $43 \mathrm{~W} / \mathrm{mK}$ a difference of nearly six orders of magnitude [14]. Consequently, the ratio of support structure area to total tank surface area must be as low as possible in order to minimize the heat leak rate into the tank.

Different support arrangements are used by type of LNG tank application and four typical arrangements of supports used in cryogenic tanks are illustrated in Figure 2.3. Each arrangement is selected by a trade-off between support strength, heat leak, and manufacturing challenge based in the application needs of the cryogenic tank as mobile equipment, a stationary vertical or horizontal tank, or for both needs [7]. Then, the construction of the tank, type of insulation, integrity of the vacuum in the annulus, arrangement of support bracing between the inner and outer shells of the tank and the ratio of support junction area to the total tank surface area affect the heat leak rate of the tank. 


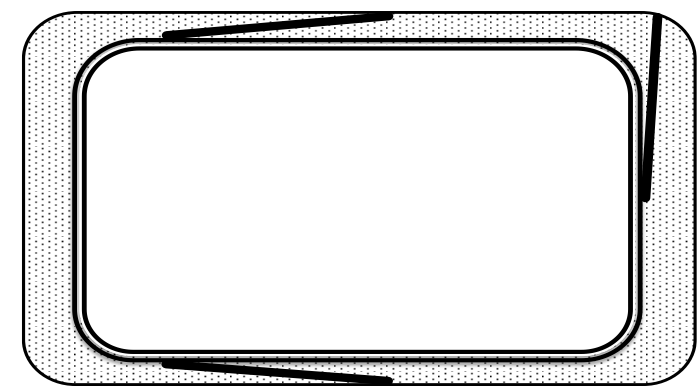

a) Most often used on mobile equipment. The cone support is probably the strongest, but has the highest heat leak.

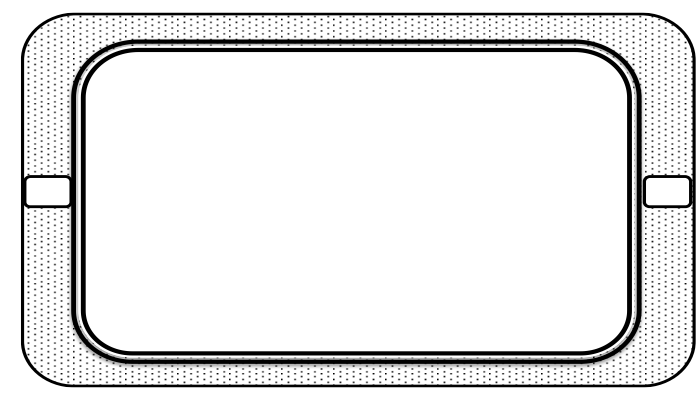

c) Used on mobile equipment and stationary tanks. A trunnion support is very effective, but is a real design and manufacturing challenge on mobile equipment.

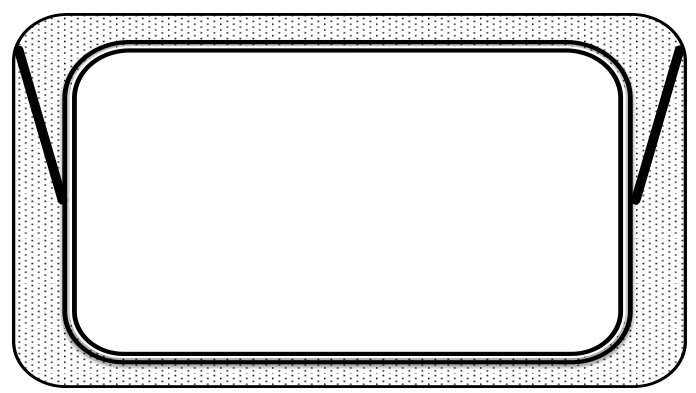

b) Most often used on stationary tanks. Straps between the inner and outer shell are a common support system.

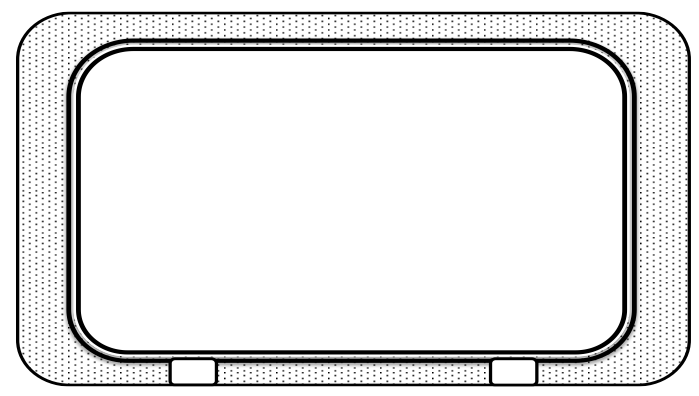

d) Used on mobile equipment and stationary tanks. Insulating bottom supports very effective, but hard to design for mobile equipment.

Figure 2.3. Schematic of Some Cryogenic Tank Support Structure Arrangements [7].

Another source of heat leak into cryogenic tanks is through piping crossing the insulation to reach the vapor or liquid regions in the tank. Plumbing connected to the liquid region of the tank includes vapor locks to prevent excessive heat leak into the liquid. As well, plumbing extending from the tank can act as fins increasing the heat leak. Figure 2.4 shows a schematic of typical plumbing connections for a LNG storage tank. Typical connections include:

- Fill lines - Tanks can be filled from either the top or bottom.

○ Top filling with cold liquid recondenses vapor in the ullage volume reducing pressure accordingly. Top filling is one strategy often used to manage venting of BOG.

○ Bottom filling increases pressure in the tank. 
- Vent lines - used to release BOG to maintain safe operating pressures within the tank.

- BOG may be vented to the atmosphere, or mitigated to power auxiliary equipment such as on site generators, or reliquefied.

- Product withdrawal line - these may exist to withdraw liquid product or vapor product.

- In fueling stations when LNG is dispensed to vehicle tanks, some LNG is initially recirculated to cool down pipes.

- Pressure control system - may include regulators and vaporizers to supply product at adequate pressures for the refueling application.

\begin{tabular}{ll} 
A1 & Fill connection \\
V1 & Bottom fill valve \\
V2 & Top fill valve \\
V28 & Valve, fill line drain \\
\hline LFD & Liquid outlet (VT3 - VT9) \\
LI & Level indicator \\
PBU & Pressure building vaporizer \\
PI & Pressure indicator \\
RG1 & Pressure control valve / Economizer \\
S1 & Safety valves, inner vessel \\
S2 & Vacuum safety valve \\
S5 & Thermal relief valve \\
V3 & Isolation valve, bottom filling \\
V4 & Isolation valve, top filling \\
V5 & Valve, vapor vent, gas outlet \\
V6 & Valve, trycock \\
V9 & Valve, external vaporizer \\
V12 & Vacuum pump down \\
V14 & Valve, safety relief section \\
V22.1 & Valve, liquid outlet (VT11 - VT60) \\
V50 & Valve, LI vapor phase \\
V51 & Valve, LI liquid phase \\
V52 & Valve, LI equalization \\
\hline
\end{tabular}

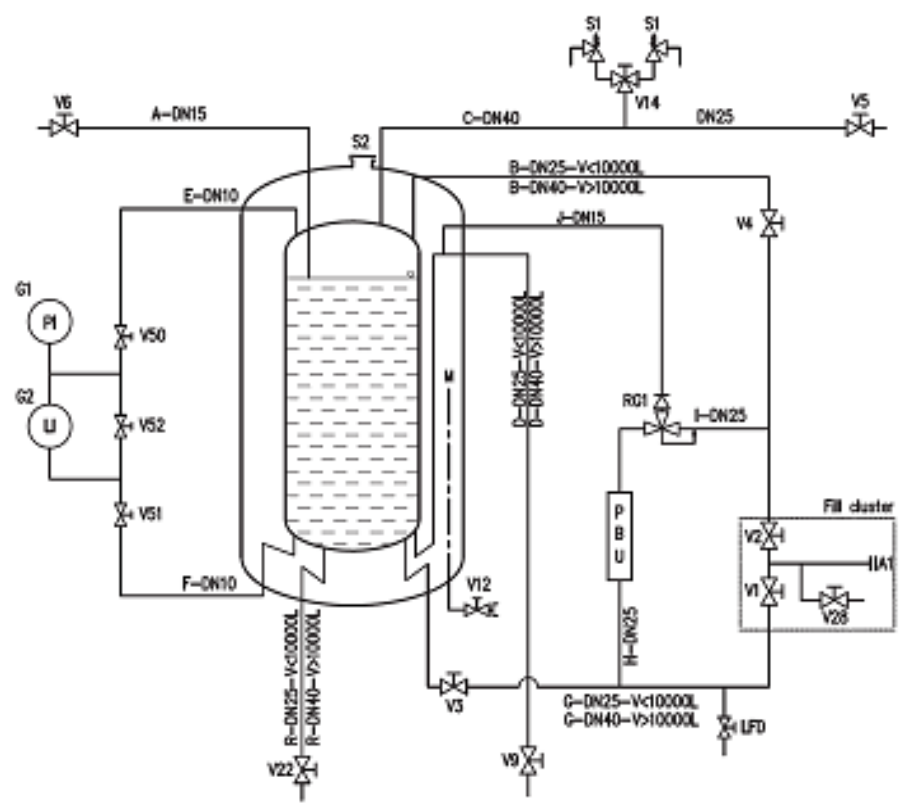

Figure 2.4. Schematic of LNG Storage Tank Plumbing Connections [10].

Additionally, both vehicle tanks and station tanks experience heat gain due to operational processes. Storage tanks at fueling stations can experience heat gain from vapor that is returned to the station from vehicle tanks during refueling, and as a result of recirculation of LNG to pre-cool the dispensing equipment and fueling hose prior to dispensing fuel. Figure 2.5 shows a schematic of a LNG vehicle fuel tank showing typical connections. A vehicle tank model can be developed using the information provided in this 
work, however, a comprehensive vehicle tank model that can simulate a driving cycle was not implemented. A simplified vehicle tank model was developed to interact with the fueling station model and simulate interaction of the station and vehicles. Nevertheless, the storage tank model developed can simulate the hold time of vehicle tanks. Additional connections and characteristics of vehicle tank are:

- The tank includes a separate ullage volume to accommodate LNG expansion and boil-off.

○ Typically the ullage volume holds around a $10 \%$ of the gross tank volume.

- Tanks must include at least one vapor release valve to prevent over-pressurizing and keep integrity of the tank due to pressure rise with LNG temperature increase.

○ Tanks may include multiple relief valves set to open at different pressures.

- A manual relief valve is included and may be used to vent the tank prior to maintenance or in case of failure of the PRV.

- The tank also includes a liquid fuel delivery line.

- Some tanks may have an internal liquid supply pump to deliver fuel to the engine such as that for a dual fuel compression ignition engine.

- The economizer regulator (present in vehicle tanks without internal fuel pump) allows boil off gas vapor to be withdrawn to reduce pressure in the tank.

○ The economizer line is connected to the liquid fuel delivery line such that a combined vapor/liquid flow is supplied to the evaporator (heat exchanger).

○ The presence of the economizer valve can lead to weathering of the LNG which increases the content of heavier hydrocarbons, most notably ethane, as the pure methane gas is withdrawn to reduce tank pressure. 


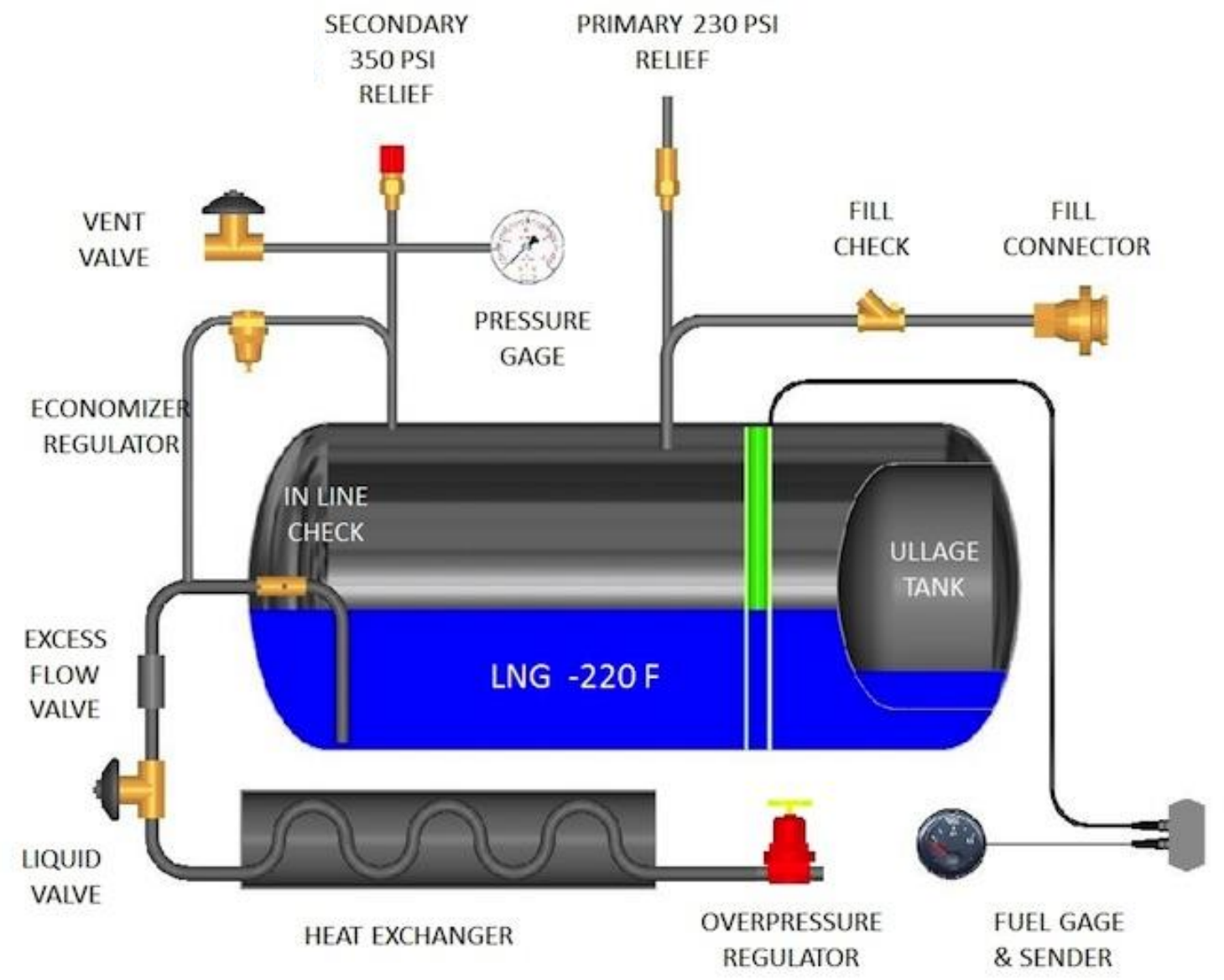

Figure 2.5. Schematic of LNG Vehicle Tank Showing Typical Connections [16].

Manufactures of cryogenic tanks report performance of their tanks by the normal evaporation rate (NER). The NER of cryogenic tanks is usually specified in percent per day of evaporated product at atmospheric pressure [7]. Larger vacuum insulated tanks have an NER between $0.07 \%$ and $0.15 \%$ per day; therefore, a 15,000 gallon LNG storage tank will evaporate approximately 15 gallons of LNG per day [7]. Larger tanks have lower heat leak rates because the surface area to volume ratio is smaller. In addition, a moving tank will have longer hold times than a stationary tank due to mixing of the LNG. In a stationary tank the liquid will stratify with warmer liquid rising to the top. The pressure in a stratified tank is determined by the warmest liquid at the top of the tank. Manufactures report that a large stationary cryogenic tank may experience a pressure rise of 3 to 5 psi per day compared to a moving road tanker with a pressure rise on the order of 1.5 psi per day [7]. These manufacture specifications are limited to hold times of the tank without any heat 
gain due to operational processes and interaction with other components, thus the actual BOG generated and the pressure rise in a tank is higher and hold times of LNG product are lower in actual service, which is part of the motivation of this work.

\subsection{Liquefied Natural Gas and Boil-Off Gas}

The boil-off gas from LNG cryogenic tanks has been a concern since the beginning of the commercial LNG industry in 1970s [17, 18]. Numerous researchers have approached several topics related to LNG and BOG including: advantages and disadvantages [19-21], production and infrastructure [22-27], applications for trucks and buses [28-31], handling [32-38], and safety [39-44]. However, not many comprehensive analytical and dynamic thermodynamic models of BOG rate have been developed [14], [45], and [46].

One of the first times that BOG was discussed was in 1970 by Pleban [17]. He reported to the National Aeronautics and Space Administration (NASA) the BOG effects of LNG in wing tanks for a super-sonic transport (SST) up to 3.5 aircraft cruise Mach. The mission simulation was such that the wing tanks and LNG followed the events: fuel fill and ground hold time, takeoff, climb to cruise, cruise (at Mach 2.7, 3.0, or 3.5), descent, landing, and refuel for the next mission if required. He used the wing tank technologies of the time and did an analytical heat transfer analysis with insulation thicknesses varying from 0.5 to 2 in $(1.27$ to $5.08 \mathrm{~cm})$ concluding that BOG losses of less than 1.5 percent were possible for cruise Mach numbers up to 3.5 with an insulation thickness of 1 in $(2.54 \mathrm{~cm})$ and flights less than 165 minutes.

One static approach to calculate BOG in LNG bulk storage tanks at production facilities was described by Adom et al. in 2010 [47]. They used the Lee-Kesler-Plocker (LKP) and the Starling modified Benedict-Webb-Rubin (BWRS) empirical models to simulate the compressibility factor, enthalpy and hence heat leakage at various pressures to determine the factors that affect the BOG in typical production facilities LNG tanks from $140 \mathrm{Ml}$ to $200 \mathrm{Ml}$ (37 to $53 \mathrm{Mgal}$ ) capacities. The structures of LNG tanks determine the heat leakage through these tanks, in this way small tanks gain more heat per kg fuel from the environment due to their large surface area to volume ratio compared to large tanks. Heat leakage was calculated through the roof, side, and bottom of the LNG tanks. Adom 
et al. calculated that at operating pressure of 200 mbar (2.9 psi) LNG tanks around these capacities reached BOG levels of 0.05 vol\%/day [47]. They did simulations between 50 to 300 mbar (0.7 to $4.4 \mathrm{psi}$ ). As well, they determined that as the methane fraction increases in the methane composition of the LNG, the BOG volume also increases.

Another static approach calculating the BOG in fueling stations was described by Sedlaczek in 2008 [46]. He statically analyzed the total fuel loss rate in a LNG tank by the effect of the number of buses fuelled each day assuming different heat transfer values into the tank. He concluded that the total fuel loss can be decreased by increasing the number of buses fueled each day and that a LNG tank of 50,000 l (13,200 gal) with thermal conductance of $2 \mathrm{~W} / \mathrm{K}$ will lose $7 \%$ of fuel delivered when fuelling 4 busses per day, and when fueling 31 buses every day will lose only $1 \%$ of fuel.

For liquid hydrogen $\left(\mathrm{H}_{2}\right)$ a dynamic storage study in cryogenic vehicle tanks was developed by the researchers of the Argonne National Laboratories (ANL) in 2008 [48]. A thermodynamic model was presented for dynamic behavior of $\mathrm{H}_{2}$ in insulated pressure vessels during refueling, discharging, and dormancy. The model characterized the behavior of stored $\mathrm{H}_{2}$ at different initial tank temperatures. Illustrations were shown presenting the transitioning of stored $\mathrm{H}_{2}$ between the liquid, and gaseous states during the discharge process. The critical point for $\mathrm{H}_{2}$ is 13.15 bar (190.7 psi) and $33.19 \mathrm{~K}$, where the states are: supercritical fluid if its pressure and temperature are above this point, subcooled liquid if its temperature is below the saturation temperature at the prevailing pressure, and superheated gas if its temperature is above the saturation temperature at the prevailing pressure. As well, dormancy as a function of the initial state of stored $\mathrm{H}_{2}$ was discussed. Even though LNG and $\mathrm{H}_{2}$ are both cryogenic liquids their properties are significantly different, however, their evaporative behavior with changes of temperature and the thermodynamic analysis developed by the researchers at ANL can be expanded to LNG modeling.

An analysis of temperature and pressure changes in LNG cryogenic tanks was described in 2004 by Chen et al. [14]. This is the only effort found related to the current work developed, where a comprehensive approach for a fueling station was addressed. However, the work developed here is significantly more extended and detailed than the work by Chen et al., as shown in Chapter 3. Chen et al. analyzed diverse mechanisms that 
may contribute to BOG of LNG in station storage tanks concluding that the main factor is the heat leak through the shell of storage tank. As well, to reduce heat leak rate in LNG tanks special strut design can be used. To analyze the different mechanisms of heat leak into the LNG fuel they developed a thermodynamic and heat transfer model simulating the evolution of properties and compositions of LNG fuel inside the tanks. Additionally, they proposed to use an electricity generator to consume the ullage gas when the tank pressure is high and to consume the fuel when the tank pressure is low since in most cases, the minimum throughput capacity of a liquefier is above the boil-off rate. For example, for a 13,000 gallon LNG tank a total of 3.9 gallon will be boiled-off each day assuming a boiloff rate of $0.03 \%$ per day when a liquefier size ranges from 200 to 8000 gallon/day (gpd). Moreover, one of the limitations of this work is the lack of experimental data for validation of their model. Only one hold time simulation was correlated with experimental data of a LNG fueling station tank without filling and venting during 5 days, where the only experimental data points were the initial and final pressure and level of LNG in the tank. From their experimental and simulated data points a percentage error of $-37.8 \%$ can be calculated for the increase of pressure with respect to time $(\Delta P / \Delta t)$, over predicting the pressure in the tank. Another series of simulations was provided by Chen et. al to show the effect of venting rate with respect to the number of buses using a station, and varying the thermal conductance of a tank as 1,2 , and $5 \mathrm{~W} / \mathrm{K}$. Their simulations concluded that increasing the number of buses using a station will considerably decrease the total amount of fuel loss by venting. For example, with a thermal conductance of $2 \mathrm{~W} / \mathrm{K}$ and two buses using the station per day the total fuel loss was $4.3 \%$, instead of a total of $3.9 \%$ when four buses are filled each day.

A comprehensive dynamic BOG model for LNG during marine transportation was developed by Dimopoulos and Frangopoulos in 2008 [45], accounting for the variation of BOG mass flow, composition, and thermodynamic properties during the voyage. The model described the LNG quantity and composition with time employing coupled nonlinear vapor-liquid phase equilibrium thermodynamic equations and differential conservation equations. The fugacity of the species was used for vapor-liquid equilibrium (VLE) conditions which is equivalent and more convenient than the Gibbs free energy. The detailed dynamic BOG production model was implemented using MATLAB and Simulink. 
A range of 6 to $10 \%$ variation during a voyage was found in quantity of BOG and the thermodynamic properties of LNG, having a significant impact in the operation modes and fuel consumption of the energy system.

\section{3. $\quad$ Stratification in Cryogenic Tanks}

The phenomenon of thermal stratification in cryogenic tanks results since the energy increased inside a cryogenic tank by heat transfer through the walls is not uniformly distributed in the liquid and vapor, causing higher temperatures in the top layers of both regions. This heat transfer and increase of temperature in the vapor region will increase the pressure and cause some of the liquid to evaporate. Lately, this topic has been approached mostly with Computational Fluid Dynamics (CFD) for the cryogenic tanks which require heavy computer calculations and limit modeling of the complex interactions with other components that make up a fueling station. Some of the CFD work about cryogenic stratification include storage of liquid hydrogen [49-53], liquid nitrogen [54-56], and LNG $[57,58]$. On the other hand, only the work from three groups was found with experimental measurements of temperature profiles in cylindrical cryogenic tanks. One group compared experimental data with theoretical models for the pressure rise [59] and two groups validated the profiles using CFD [60-62]. In a similar way, only three other groups were found that developed analytical and theoretical models to calculate thermal stratification [63-67], however, their validation was based on experimental data of pressure rise from the cryogenic tanks. Nevertheless, the homogeneous and stratification models described as part of the complete LNG Station Model developed in this work were validated comparing to pressure rise data from LNG tanks for vehicles and fueling stations acquired by WVU.

Only three works measuring the thermal stratification that occurs inside cryogenic tanks was found during this research, for liquid nitrogen and none for LNG. One, was by Seo and Jeong in 2010 [59] who acquired experimental data of temperature profiles using liquid nitrogen following the pressure trends at various heat leaks and liquid levels of 10, $30,50,70$, and $90 \%$. They used a small vertical cylindrical tank of $21.3 \mathrm{~cm}$ in height by $20.1 \mathrm{~cm}$ in diameter with an internal volume of 6.751 (1.78 gal). The tank was instrumented from the top with six thermocouples at intervals of $3 \mathrm{~mm}$ followed by nine thermocouples 
at intervals of $20 \mathrm{~mm}$. The closer distance between thermocouples in the top of the tank was intended to capture the thermal stratification in the vapor with more resolution, since this one is expected to have more considerable changes than in the liquid. Seo and Jeong also proposed a thermal diffusion model that was able to predict the pressure rise trends in the tank at 30 and 50\% fill level. However, their model presented limitations with other fill levels. Additionally, they presented a thermal equilibrium model which was useful to predict only the trend for the $10 \%$ fill level experiment.

Another work measuring the thermal stratification was by Li et al. in 2010 [60]. They measured the pressure rise and thermal stratification in the liquid region only, without taking any temperature measurements in the vapor region. Their goal was to characterize performance of the tank when the vacuum in the multi-layer insulation was lost and to compare their results with a two-dimensional CFD model. For this, liquid nitrogen was used in a cylindrical tank with volume of 1751 (46.2 gal) with an inner diameter of $45 \mathrm{~cm}$ and height of $95 \mathrm{~cm}$. A total of 14 thermocouples were installed in the liquid region in five layers, where the top four layers had three thermocouples and the bottom layer had two thermocouples. Thermocouples were installed at a minimum distance of $10 \mathrm{~cm}$ in order to have a negligible effect on the buoyancy-driven flow. Good temperature agreement was found between the predictions from the two-dimensional CFD model and experimental data, where the experiment lasted up to 640 minutes.

In 2013 and 2014 Ludwig and Dreyer presented their work which included ground experiments and CFD simulations for a cylindrical tank with liquid nitrogen, where either gaseous nitrogen or gaseous helium was injected as a pressurant gas at different temperatures [61, 62]. The tank of internal volume of 431 (11.36 gal) with an inner diameter of $29.6 \mathrm{~cm}$ and height of $65 \mathrm{~cm}$ was filled with liquid nitrogen to a $66 \%$ level. A pressure sensor was installed in the vapor region and a total of 14 silicon diodes were used to measure the temperatures inside the tank: four in the liquid region, four in the vapor region, four at the tank wall in the vapor region, one in the top wall of the tank, and one next to the diffuser that was injecting the pressurant gas. Experiments consisted of injecting a pressurant gas which pressurized the tank almost linearly until reaching a maximum desired pressure. When this pressure was reached, no more pressurant gas was injected and a relaxation period started where the tank pressure curve decreased asymptotically to a 
minimum pressure creating a total pressure drop. CFD simulations were performed with a 2D cylindrical mesh replicating the experiments and showing good agreement with the data.

For theoretical models, only three works addressing the stratification in cryogenic tanks were found. A simple three-node approach was developed by Riemer in 1986 [63] to test stratification in cryogenic tanks with no flow. The model results were compared with experimental pressure data acquired from a spherical tank with liquid methane. The threenode model consisted in a set of coupled differential thermodynamic equations at the vapor region, liquid region, and at the interface. The model was successfully correlated with the ground-based tank without flow following the pressure trend for a hold time test of up to 70 hours. Despite the outstanding results of this model, more details or extensions of this work were not found in the literature.

As part of a study by NASA, Arnett et al. developed in 1965 [64] and complemented in 1972 [65] a thermal stratification model to determine the selfpressurization of a closed liquid hydrogen tank. A cylindrical geometry with a cone on the top was assumed for the shape of the cryogenic tank, and a computer program of the model was implemented using Fortran IV and validated with experimental hold time tests performed by NASA. Experimental data was from ground tests and from the Centaur AC8 vehicle during a low-G coast phase, with measurement of pressure rise and temperature profiles that were unpublished. A description of the instrumentation used was made available by Lacovic in 1968 [68]. Ground test experiments were performed at the NASA Research Center in Cleveland, $\mathrm{OH}$ with a tank using liquid hydrogen and a few pressure experimental curves were shown in Arnett et al. [65] agreeing within 1.5\% of the absolute pressure, and within $4 \%$ for the low-G coast phase data, in simulations of less than 700 seconds. Longer simulations and experiments were not performed since cryogenic tanks of the time were poor in insulation and were reaching the maximum pressure in that limited window time. Nevertheless, when comparing the experimental and simulated temperature profiles a close agreement was not reflected. The initial profile for the simulations was assumed as uniform at the saturated temperature for the liquid and vapor region. Then, simulated final temperature profiles showed lower mean values of temperature than the experimental results, since the saturated assumption represented more mass of vapor and 
extra internal energy. Arnett et al. [65] concluded that for determining the pressure in the tank a precise knowledge of the temperature distribution in the vapor was not required and the value of the change in internal energy is the main factor independent of the distribution of the energy.

Gursu et al. in 1993 divided their developments into two main publications, a part 1 with model development, and a part 2 with the model results, respectively available in $[66,67]$. They developed three different pressure rise models to calculate selfpressurization and boil-off rates in cryogenic tanks using liquid hydrogen: a homogeneous, a surface-evaporation, and a thermal stratification model. The first two models were isothermal and assumed no temperature gradient inside the tank, while the last one calculated a temperature distribution based on and compared with Arnett et al. [64, 65]. The homogeneous model assumed that the temperature was uniform at all times in the entire tank. The surface-evaporation model neglected the temperature gradient, but assumed that all heat transfer entering the tank was used to evaporate liquid without changing the liquid phase temperature. Their isothermal models were compared with the experimental results of Aydelott and Spurckler in 1969 with a spherical tank using liquid hydrogen at 32\% and $80 \%$ fill levels [69], without being capable of predicting the pressure rise with enough accuracy. From their data the error in $(\Delta P / \Delta t)$ was calculated between $30 \%$ and $240 \%$. As expected, their results showed that the homogenous model was under predicting the pressure (since the vapor region in a real tank will have a higher temperature than the liquid region) and the surface-evaporation model was over predicting pressure rise (since the energy entering a real tank will increase the temperature of the liquid region as well). Additionally, they simulated the effects of ortho-para hydrogen conversion in the boil-off losses, with concentrations of 50\% and $75 \%$ ortho-hydrogen and with pure parahydrogen, concluding that higher concentrations of ortho-hydrogen will increase the pressure rate. The results by Arnett et al. [64, 65] were replicated in this work with the thermal stratification model using a cylindrical tank with a cone top, but the effects of different velocity and temperature profiles were additionally explored. For this, the power parameters of the temperature and velocity variations by Eckert and Jackson [70] (shown in Section 3.4.1) were changed from the original proposed values of $m / n=1 / 7$ and $p=$ 4. Simulations showed that the powers of $n$ and $m$ do not significantly influence the results; 
however, a power of $p$ used as 2 or 6 will deviate the experimental results. Finally, they simulated the effects in the pressure rise and boil-off of a tank when using cooling stations. The cooling stations were heat exchangers cooling the supports of the tank, showing that the increase of cooling stations will considerably decrease the pressure and boil-off rates, however, the optimal number of cooling stations needed to be balanced by economic considerations. 


\section{- CHAPTER 3 - \\ MODEL DEVELOPMENT}

This chapter will provide a theoretical approach and formulation for the development of the thermodynamics and methane emission model of LNG tanks and fueling stations using two approaches for the temperature inside the tank, a homogeneous approach where the saturated temperature is assumed and a stratified approach where a temperature profile in the tank is determined. The venting model development and interaction of all the components involved in the model are described as well.

\subsection{Problem Definition}

A LNG storage tank can be represented thermodynamically as a control volume which contains liquid and vapor as shown in Figure 3.1. Energy transfer occurs:

- through struts connecting the inner and outer shells of the tank, $\dot{\mathrm{Q}}_{\text {struts }}$,

- through extended surfaces (such as valves, lines, etc.) acting as fins, $\dot{\mathrm{Q}}_{\mathrm{fins}}$,

- by radiation from the sun and sky, $\dot{\mathrm{Q}}_{\text {radiation, }}$

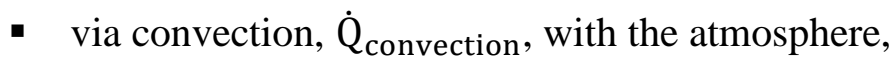

- and heat transfer through the evacuated insulation in the annulus, $\dot{\mathrm{Q}}_{\text {insulation, }}$

The methods for quantifying the heat leakage through the tank walls and plumbing connections were developed by John Hailer (M.S. student in Mechanical Engineering at WVU) and will be described in detail in his future publications, including his master thesis [71]. Heat input into the stored LNG may occur as the result of operation of pumping equipment used to supply LNG to the dispenser or to the engine of a vehicle, $\dot{Q}_{\text {pump. }}$. In addition, energy is added to and removed from the LNG as a result of the flow of liquid and vapor phase methane into and out of the tank. Figure 3.2 is a simplified schematic of an LNG dispenser showing the flow paths for circulation to cool the dispenser and fuel supply hose and the vapor return from the vehicle fuel tank. In the case of the fuel storage 
tanks at LNG fueling stations, mass flow into and out of the storage tank may occur as a result of:

- refueling the tank with LNG - this can be accomplished by either top filling $\left(\dot{\mathrm{m}}_{\mathrm{in}, \mathrm{f}, \mathrm{top}, \mathrm{fill}}\right)$, or bottom filling $\left(\dot{\mathrm{m}}_{\mathrm{in}, \mathrm{f}, \mathrm{bottom}, \mathrm{fill}}\right)$. Top filling collapses accumulated vapor reducing tank pressure while bottom filling generally increases the pressure in the tank,

- dispensing LNG to vehicles ( $\dot{\mathrm{m}}_{\text {out,f,dispensing }}$ ),

- return of methane vapor from the vehicle tank as a result of vapor balancing prior to LNG dispensing ( $\left.\dot{\mathrm{m}}_{\mathrm{in}, \mathrm{g}, \mathrm{vapor} \text { balancing }}\right)$,

- release of BOG to maintain safe tank pressure ( $\left.\dot{\mathrm{m}}_{\text {out,g,vent }}\right)$,

- recirculation of LNG to pre-cool the fuel dispensing equipment ( $\dot{\mathrm{m}}_{\text {out,f,recirculation }}$ and $\left.\dot{\mathrm{m}}_{\mathrm{in}, \mathrm{f}, \mathrm{recirculation}}\right)$.

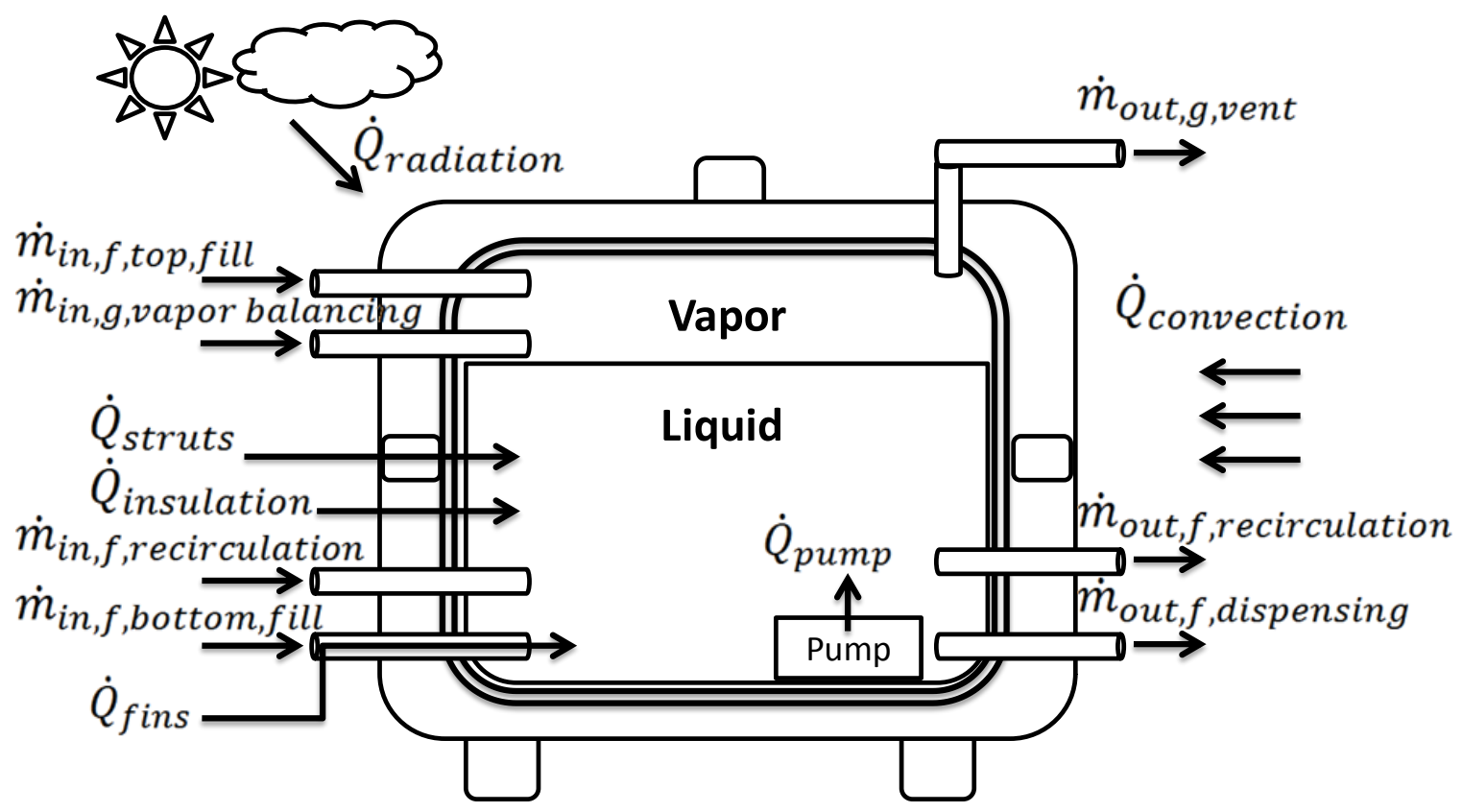

Figure 3.1. Control Volume Representation of an LNG Tank Station.

Figure 2.5 shows a schematic of a typical LNG vehicle fuel tank. In the case of vehicle fuel tanks, mass flow into and out of the tank results from:

- refueling with $\mathrm{LNG}$,

- removal of LNG to fuel the engine in response to the vehicle duty cycle, 
- release of boil-off vapor through the PRV to maintain safe tank pressure,

- flow of methane vapor through the economizer valve to the engine to maintain safe tank pressure, and

- removal of vapor as a result of vapor balancing prior to refueling.

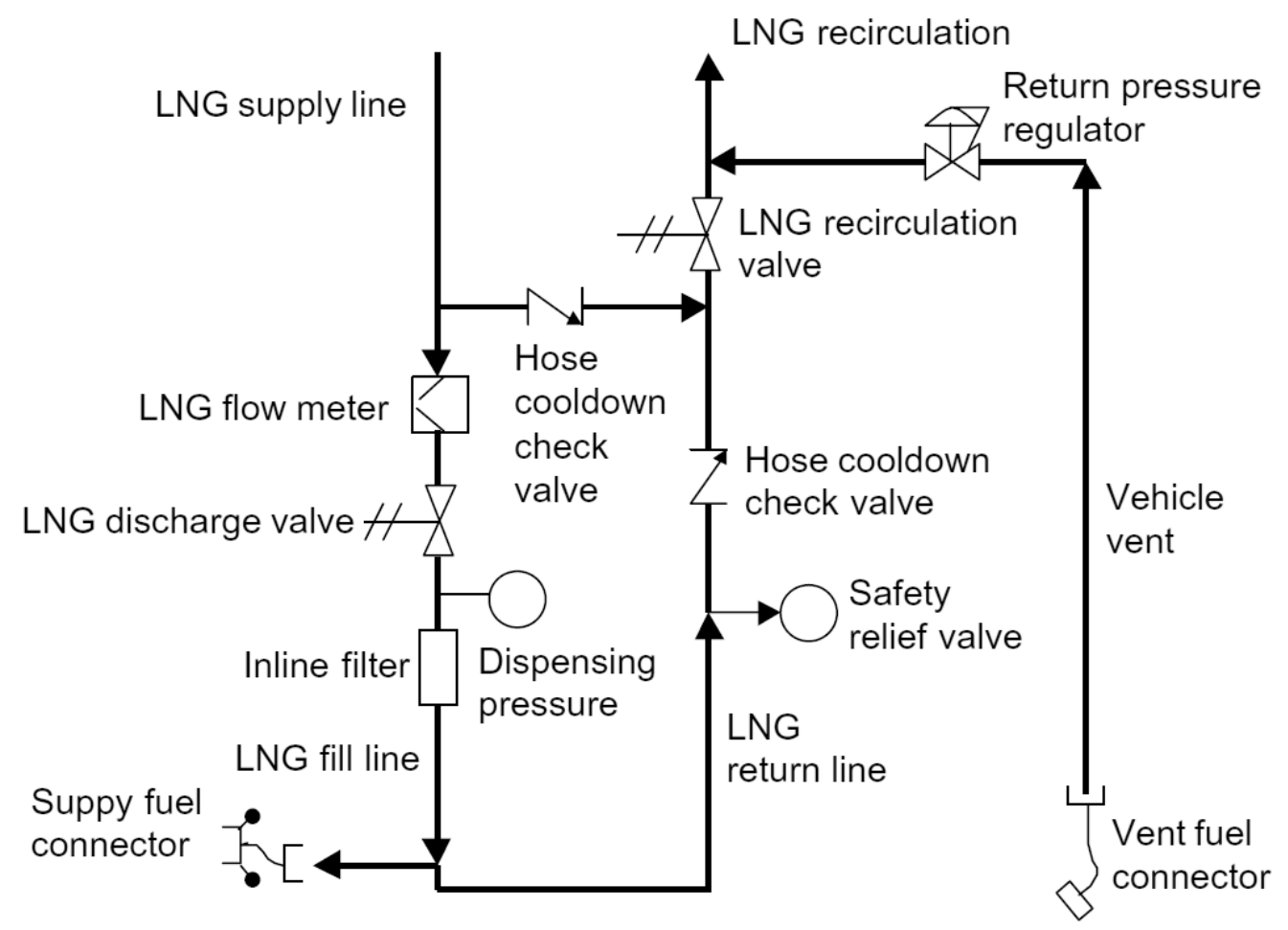

Figure 3.2. Simplified Schematic of LNG Dispenser Module [14].

\subsection{Model Assumptions}

The following thermodynamic assumptions were used for the thermodynamic model of the LNG storage tank:

- LNG composition is $100 \%$ methane $\left(\mathrm{CH}_{4}\right)$. The effects of other constituents such as ethane, propane, butane, and carbon dioxide were not considered.

- Evaporation of LNG only occurs at the surface of the liquid phase.

- During the process of evaporation, the vapor-liquid interface is in thermodynamic quasi-equilibrium. Fast occurring transient behaviors that may occur during refilling or dispensing operations were not considered. 
- Pressure in the tank is uniform.

- Temperature inside the tank may be modeled using two approaches: a homogeneous temperature where the saturated temperature is assumed and a stratified distribution where a temperature profile in the tank is determined.

- When the homogenous approach is used, the temperature and density of LNG is uniform and may be present in the tank as a liquid, vapor, or vapor-liquid mixture. If present as a mixture, the gas and liquid are in phase equilibrium (both phases are saturated).

- When the stratified approach is used a temperature profile is calculated where the vapor is considered with superheated properties and liquid with subcooled properties.

- Kinetic and potential energy is neglected since the tank system remains stationary and thus experiences no change in these energies. Energy flow of LNG flowing into and out of the tank is incorporated by the respective mass flow rates $(\dot{m})$.

- LNG is extracted or vented from the top of the tank as saturated gas and from the bottom of the tank as saturated liquid only.

- For vehicle tanks with an internal pump, the pump inside the tank is energized by external power and creates extra heat inside the tank $\left(\dot{Q}_{\text {pump }}\right)$. Work by the pump is neglected since it does not compress the LNG and is use for moving the fluid out of the tank, and this energy flow is included in the mass flow rate.

The uniform pressure assumption in both vapor and liquid regions of the LNG tank was a simplification to the thermodynamic model and is supported by the following calculations. The hydrostatic pressure difference between the surface and bottom of the liquid region for a typical LNG vehicle tank completely fueled (90\% fill level, around 60 cm (2 ft.) of liquid height) was estimated as less than half psi, and for a typical LNG bulk tank (90\% fill level, around 10 meter (33 ft.) of liquid height) was estimated around 5 psi. For the vapor region, the hydrostatic pressure difference between the top of the tank and the surface of the liquid for a LNG tank low in fuel was estimated as less than 1/1000 psi for a vehicle tank (10\% fill level, $60 \mathrm{~cm}$ ( $2 \mathrm{ft}$.) of vapor height), and less than 1/100 psi for 
a bulk tank (10\% fill level, $10 \mathrm{~m}$ (33 ft.) of vapor height). These pressure differences are small with respect to typical tank pressures: for the liquid region, $0.2-1.0 \%$ in a vehicle tank and $2-10 \%$ in a bulk tank, and less than $0.02 \%$ for the vapor region for both types of tanks.

Changes in kinetic and potential energy was neglected since the LNG bulk tanks remain stationary. This assumption extended to the LNG vehicle tanks used during this study which were under hold time conditions when the tanks remain stationary. Future research in this area including modeling of LNG vehicle tank under a driving cycle may not be able to neglect the kinetic and potential energies.

\subsection{Homogeneous Thermodynamic Model}

\subsubsection{Model Analysis}

The control volume illustrated in Figure 3.1 is described by the mass balance and energy balance. The mass balance for the tank control volume is expressed as:

$$
\begin{gathered}
\frac{\mathrm{d} m}{\mathrm{dt}}=\sum \dot{\mathrm{m}}_{\mathrm{in}}-\sum \dot{\mathrm{m}}_{\mathrm{out}} \\
\frac{\mathrm{dm}_{\mathrm{total}}}{\mathrm{dt}}=\dot{m}_{\mathrm{in}, \mathrm{f}, \mathrm{top}, \mathrm{fill}}+\dot{m}_{\mathrm{in}, \mathrm{f}, \mathrm{bottom}, \mathrm{fill}}+\dot{m}_{\mathrm{in}, \mathrm{f}, \text { recirculation }}+\dot{m}_{\mathrm{in}, \mathrm{g}, \text { vapor balancing }} \\
-\dot{m}_{\text {out }, \mathrm{f}, \text { dispensing }}-\dot{m}_{\text {out,f,recirculation }}-\dot{m}_{\text {out,g,vent }}
\end{gathered}
$$

where $\frac{\mathrm{dm}_{\text {total }}}{\mathrm{dt}}$ is the rate of change of mass in the tank and the total mass $\left(\mathrm{m}_{\text {total }}\right)$ can be calculated as the sum of the liquid $\left(m_{\mathrm{f}}\right)$ and vapor $\left(m_{g}\right)$ masses:

$$
\mathrm{m}_{\text {total }}=\mathrm{m}_{\mathrm{f}}+\mathrm{m}_{\mathrm{g}}
$$

The total volume of the tank $\left(V_{\text {total }}\right)$ is equal to the sum of the liquid and vapor LNG volumes, $\mathrm{V}_{\mathrm{f}}$ and $\mathrm{V}_{\mathrm{g}}$ respectively:

$$
\mathrm{V}_{\text {total }}=\mathrm{V}_{\mathrm{f}}+\mathrm{V}_{\mathrm{g}}
$$

Note that the total volume of the tank is constant. Furthermore, the average specific volume $\left(v_{\text {ave }}\right)$ of the LNG in the tank is the division of the total volume and total mass:

$$
v_{\text {ave }}=\frac{v_{\text {total }}}{m_{\text {total }}}
$$


Then, the calculation of the vapor quality $(x)$ of the LNG mixture (ratio of mass of vapor to mass vapor and liquid) using the specific volumes is:

$$
\begin{gathered}
x=\frac{\mathrm{m}_{\mathrm{g}}}{\mathrm{m}_{\mathrm{g}}+\mathrm{m}_{\mathrm{f}}}=\frac{\mathrm{m}_{\mathrm{g}}}{\mathrm{m}_{\text {total }}} \\
x=\frac{\mathrm{v}_{\text {ave }}-\mathrm{v}_{\mathrm{f}}}{\mathrm{v}_{\mathrm{g}}-\mathrm{v}_{\mathrm{f}}}
\end{gathered}
$$

As well, the LNG masses of vapor and liquid can be determined using the vapor quality as:

$$
\begin{gathered}
\mathrm{m}_{\mathrm{g}}=x \mathrm{~m}_{\text {total }} \\
\mathrm{m}_{\mathrm{f}}=(1-x) \mathrm{m}_{\text {total }}
\end{gathered}
$$

The energy balance for the tank control volume is expressed as:

$$
\frac{\mathrm{dE}_{\mathrm{cv}}}{\mathrm{dt}}=\dot{\mathrm{Q}}-\dot{\mathrm{W}}+\Sigma \dot{\mathrm{m}}_{\text {in }}\left(\mathrm{h}_{\text {in }}+\frac{\mathrm{v}_{\text {in }}^{2}}{2}+\mathrm{gz}_{\text {in }}\right)-\Sigma \dot{\mathrm{m}}_{\text {out }}\left(\mathrm{h}_{\text {out }}+\frac{\mathrm{v}_{\text {out }}{ }^{2}}{2}+\mathrm{gz}_{\text {out }}\right)
$$

The total energy of the control volume can be expressed as:

$$
E_{\mathrm{cv}}=\mathrm{U}+\mathrm{PE}+\mathrm{KE}
$$

where $\mathrm{U}$ is the total internal energy, and PE and $\mathrm{KE}$ are the potential and kinetic energy respectively. Kinetic and potential energy is neglected since the tank system remains stationary and thus experiences no change in these energies. Energy flow of LNG flowing into and out of the tank is incorporated by the respective mass flow rates $(\dot{m})$, therefore:

$$
\mathrm{E}_{\mathrm{cv}}=\mathrm{U}
$$

Assuming that there is no work ( $\dot{W})$, and that work by the pump is neglected since it does not compress the LNG and is used for moving the fluid out of the tank, and this energy flow is included in the mass flow rate and enthalpy. Then, the simplified energy balance of the LNG tank can be summarized as:

$$
\frac{\mathrm{dU}}{\mathrm{dt}}=\dot{\mathrm{Q}}+\Sigma \dot{\mathrm{m}}_{\text {in }} \mathrm{h}_{\text {in }}-\Sigma \dot{\mathrm{m}}_{\text {out }} \mathrm{h}_{\text {out }}
$$

where $\dot{Q}$ is the heat transfer rate, $\dot{m}$ is the mass flow rate, $\mathrm{h}$ is enthalpy, the subscripts "in" and "out" refer to the mass entering and exiting the tank respectively, and $\frac{\mathrm{dU}}{\mathrm{dt}}$ is the rate of change of internal energy in the control volume with respect to time. The average specific internal energy $\left(\mathrm{u}_{\mathrm{ave}}\right)$ can be calculated using the vapor quality and the specific internal energies $(u)$ found in methane property tables for liquid and vapor states at the tank temperature and pressure as: 


$$
\mathrm{u}_{\mathrm{ave}}=\mathrm{x}\left(\mathrm{u}_{\mathrm{g}}-\mathrm{u}_{\mathrm{f}}\right)+\mathrm{u}_{\mathrm{f}}
$$

and total internal energy (U) in the tank is equal to:

$$
\mathrm{U}=\mathrm{u}_{\mathrm{ave}} \mathrm{m}_{\text {total }}
$$

Introducing the mass flow terms, the complete energy balance of the LNG tank system is then:

$$
\begin{gathered}
\frac{\mathrm{dU}}{\mathrm{dt}}=\dot{\mathrm{Q}}+\dot{\mathrm{m}}_{\text {in,f,top,fill }} \mathrm{h}_{\text {in,f,top,fill }}+\dot{\mathrm{m}}_{\text {in,f,bottom,fill }} \mathrm{h}_{\text {in,f,bottom,fill }} \\
+\dot{\mathrm{m}}_{\text {in,f,recirculation }} \mathrm{h}_{\mathrm{in}, \mathrm{f}, \text { recirculation }}+\dot{\mathrm{m}}_{\text {in,g,vapor balancing }} \mathrm{h}_{\text {in,g,vapor balancing }} \\
-\dot{\mathrm{m}}_{\text {out,f,dispensing }} \mathrm{h}_{\text {out,f,dispensing }}-\dot{\mathrm{m}}_{\text {out,f,recirculation }} \mathrm{h}_{\text {out,f,recirculation }} \\
-\dot{\mathrm{m}}_{\text {out,g,vent }} \mathrm{h}_{\text {out,g,vent }}
\end{gathered}
$$

where $h$ are the respective enthalpies for the liquid or vapor at the saturated LNG state and depends of the temperature and pressure of the LNG in the tank or the LNG source. Calculation of the mass flow rates and enthalpies of the various flow streams will be discussed in subsequent sections.

The heat transfer rate $\dot{Q}$ is the sum of the total heat flux or energy transfer into the system by temperature differences between the tank and its ambient surroundings. LNG is stored at temperatures of $-162^{\circ} \mathrm{C}\left(-260^{\circ} \mathrm{F}\right)$ which is significantly colder than any environmental temperatures the tank experienced; therefore, there is always a heat flux into the LNG. Heat transfer into the LNG is the primary cause of BOG and comes from several sources. Heat transfer may originate from an internal pump $\left(\dot{\mathrm{Q}}_{\text {pump }}\right)$ in the case of some LNG tanks vehicles which used the pump to transfer the LNG to the engine. In contrast, bulk tanks used an external pump to transfer the LNG to the dispenser when fueling a vehicle. Additional heat leakage into the tank $\left(\dot{\mathrm{Q}}_{\text {heat leak }}\right)$ is the sum of the rest of heat components in Figure 3.1. The total heat added to the stored methane is then given by:

$$
\dot{\mathrm{Q}}=\dot{\mathrm{Q}}_{\text {heat leak }}+\dot{\mathrm{Q}}_{\text {pump }}
$$

The heat transfer module, developed by John Hailer and described in detail in his future publications, including his master thesis [71], calculated the heat leak rate and passed it into the thermodynamic module. The heat flux into the tank then influenced the temperature of the LNG liquid and vapor and their properties. 
Values for enthalpies and other thermophysical properties of methane at specific temperatures and pressures were determined using methane property tables [72-74]. Therefore, all of the initial conditions of the LNG tank (mass and volume of LNG liquid and vapor, vapor quality, average specific volume, average specific internal energy, and total internal energy) were determined using the previous equations assuming only the maximum volume capacity for the LNG tank, the initial temperature or pressure inside the tank, and the initial total LNG mass or initial LNG liquid or vapor mass.

\subsection{2. $\quad$ Prediction of Homogeneous Temperature and Pressure in the LNG Tank}

In order to determine the change of temperature and pressure in the LNG tank, the difference of total internal energy $\left(\frac{\mathrm{dU}}{\mathrm{dt}}\right)$ was used, where it can be discretized as:

$$
\begin{gathered}
\frac{\mathrm{dU}_{\mathrm{i}+1}}{\mathrm{dt}}=\frac{\mathrm{U}_{\mathrm{i}+1}-\mathrm{U}_{\mathrm{i}}}{\Delta \mathrm{t}} \\
\frac{\mathrm{dU_{i } + 1}}{\mathrm{dt}}=\frac{\mathrm{u}_{\mathrm{ave}, \mathrm{i}+1} \mathrm{~m}_{\text {total }, \mathrm{i}+1}}{\Delta \mathrm{t}}-\frac{\mathrm{u}_{\mathrm{ave}, \mathrm{i}} \mathrm{m}_{\text {total }, \mathrm{i}}}{\Delta \mathrm{t}}
\end{gathered}
$$

where subscript i represent the time step iteration of the LNG tank model simulation, from $\mathrm{i}=0$ (initial conditions) with unit increments until the end of the simulation, and $\Delta \mathrm{t}$ is the time difference or time step size:

$$
\Delta \mathrm{t}=\mathrm{t}_{\mathrm{i}+1}-\mathrm{t}_{\mathrm{i}}
$$

Combining the previous two equations with the simplified energy balance and calculating it for the next time step gives:

$$
\frac{\mathrm{dU} \mathrm{U}_{\mathrm{i}+1}}{\mathrm{dt}}=\dot{\mathrm{Q}}_{\mathrm{i}+1}+\sum \dot{\mathrm{m}}_{\mathrm{in}, \mathrm{i}+1} \mathrm{~h}_{\mathrm{in}, \mathrm{i}+1}-\sum \dot{\mathrm{m}}_{\mathrm{out}, \mathrm{i}+1} \mathrm{~h}_{\mathrm{out}, \mathrm{i}+1}=\frac{\mathrm{u}_{\mathrm{ave}, \mathrm{i}+1} \mathrm{~m}_{\text {total }, \mathrm{i}+1}}{\Delta \mathrm{t}}-\frac{\mathrm{U}_{\mathrm{i}}}{\Delta \mathrm{t}}
$$

where $i$ is the current time iteration and $i+1$ is the next time iteration. Solving the previous equation for the average specific internal energy at the next model simulation step $\left(\mathrm{u}_{\mathrm{ave}, \mathrm{i}+1}\right)$ gives:

$$
\begin{gathered}
\mathrm{u}_{\mathrm{ave}, \mathrm{i}+1}=\frac{\mathrm{dt}}{\mathrm{m}_{\text {total }, \mathrm{i}+1}}\left(\dot{\mathrm{Q}}_{\mathrm{i}+1}+\sum \dot{\mathrm{m}}_{\mathrm{in}, \mathrm{i}+1} \mathrm{~h}_{\mathrm{in}, \mathrm{i}+1}-\Sigma \dot{\mathrm{m}}_{\mathrm{out}, \mathrm{i}+1} \mathrm{~h}_{\mathrm{out}, \mathrm{i}+1}+\frac{\mathrm{U}_{\mathrm{i}}}{\Delta \mathrm{t}}\right) \\
\mathrm{u}_{\mathrm{ave}, \mathrm{i}+1}=\frac{1}{\mathrm{~m}_{\text {total }, \mathrm{i}+1}}\left(\Delta \mathrm{t}\left(\dot{\mathrm{Q}}_{\mathrm{i}+1}+\sum \dot{\mathrm{m}}_{\mathrm{in}, \mathrm{i}+1} \mathrm{~h}_{\mathrm{in}, \mathrm{i}+1}-\Sigma \dot{\mathrm{m}}_{\mathrm{out}, \mathrm{i}+1} \mathrm{~h}_{\text {out }, \mathrm{i}+1}\right)+\mathrm{U}_{\mathrm{i}}\right)
\end{gathered}
$$


From the conservation of mass equation, the total mass at the next step in the tank $\left(m_{\text {total, },+1}\right)$ was known since all the rates of LNG liquid and vapor masses $\left(\dot{\mathrm{m}}_{\mathrm{in}, \mathrm{i}+1}\right.$ and $\dot{\mathrm{m}}_{\text {out,i+1 }}$, respectively) were either assumed or calculated by other sub-components of the model. The enthalpies of the flow streams $\left(\mathrm{h}_{\mathrm{in}, \mathrm{i}+1}\right)$ were also assumed or determined by other components of the overall model. Additionally, the time step size $(\Delta t)$ and the total internal energy at the current simulation step $\left(U_{i}\right)$ have already been calculated.

The heat transfer rate $\left(\dot{Q}_{i+1}\right)$ and the enthalpies of the LNG output masses $\left(h_{\text {out }, i+1}\right)$ were unknown. Nevertheless, these two variables could be approximated as the values at the current simulation step (i) since the time step was assumed to be small enough to yield only small changes in the temperature and pressure.

Consequently the previous equation can be approximate as:

$$
\mathrm{u}_{\text {ave }, \mathrm{i}+1}=\frac{1}{\mathrm{~m}_{\text {total }, \mathrm{i}+1}}\left(\Delta \mathrm{t}\left(\dot{\mathrm{Q}}_{\mathrm{i}}+\Sigma \dot{\mathrm{m}}_{\mathrm{in}, \mathrm{i}+1} \mathrm{~h}_{\mathrm{in}, \mathrm{i}+1}-\Sigma \dot{\mathrm{m}}_{\text {out }, \mathrm{i}+1} \mathrm{~h}_{\text {out }, \mathrm{i}}\right)+\mathrm{U}_{\mathrm{i}}\right)
$$

Then, the previous equation and the average specific volume in the next step $\left(v_{\mathrm{ave}, \mathrm{i}+1}\right)$ could be used to predict the next temperature and pressure in the LNG tank:

$$
v_{\text {ave }, i+1}=\frac{v_{\text {total }}}{m_{\text {total }, i+1}}
$$

To predict the next temperature and pressure in the LNG tank the values of the last two equations were used to solve consecutively for the vapor quality of the LNG vaporliquid mixture in the next step $\left(\mathrm{x}_{\mathrm{i}+1}\right)$ by two methods: using the specific volume $\left(\mathrm{x}_{\mathrm{v}, \mathrm{i}+1}\right)$ and using the internal energy $\left(\mathrm{x}_{\mathrm{u}, \mathrm{i}+1}\right)$ :

$$
\begin{aligned}
& x_{v, i+1}=\frac{v_{a v e, i+1}-v_{f, i+1}}{v_{g, i+1}-v_{f, i+1}} \\
& x_{u, i+1}=\frac{u_{a v e, i+1}-u_{f, i+1}}{u_{g, i+1}-u_{f, i+1}}
\end{aligned}
$$

Since the correct specific volumes and internal energies of liquid and vapor states are at the next unknown temperature and pressure an iterative technique was implemented to determine the temperature at the next time step. Convergence was achieved when:

$$
\left|\mathrm{x}_{\mathrm{u}, \mathrm{i}+1}-\mathrm{x}_{\mathrm{v}, \mathrm{i}+1}\right| \leq \varepsilon
$$

where $\varepsilon$ is a small maximum value error such as $\varepsilon=10^{-6}$. At this point the future temperature has been predicted and the entire model was updated with the new pressure and new current thermophysical properties to repeat the modeling process. 


\section{4. $\quad$ Stratified Thermodynamic Model}

\subsubsection{Model Analysis}

The stratified thermodynamic model calculated the temperature profiles of vapor and liquid inside a LNG tank, solving the turbulent boundary layer equations for a cylindrical tank with symmetry around the vertical axis as the one shown in Figure 3.3. This development was based in the work proposed by Arnett et al. [64, 65]. However, they used Parahydrogen as fuel and a cylinder with a cone shape at the top for the cryogenic tank. Furthermore, in this work Arnett's model was improved by allowing flow of liquid and vapor into and out of the tank, adding hold time simulation capability, and the use of a stratified heat transfer distributed through the vapor and liquid layers.

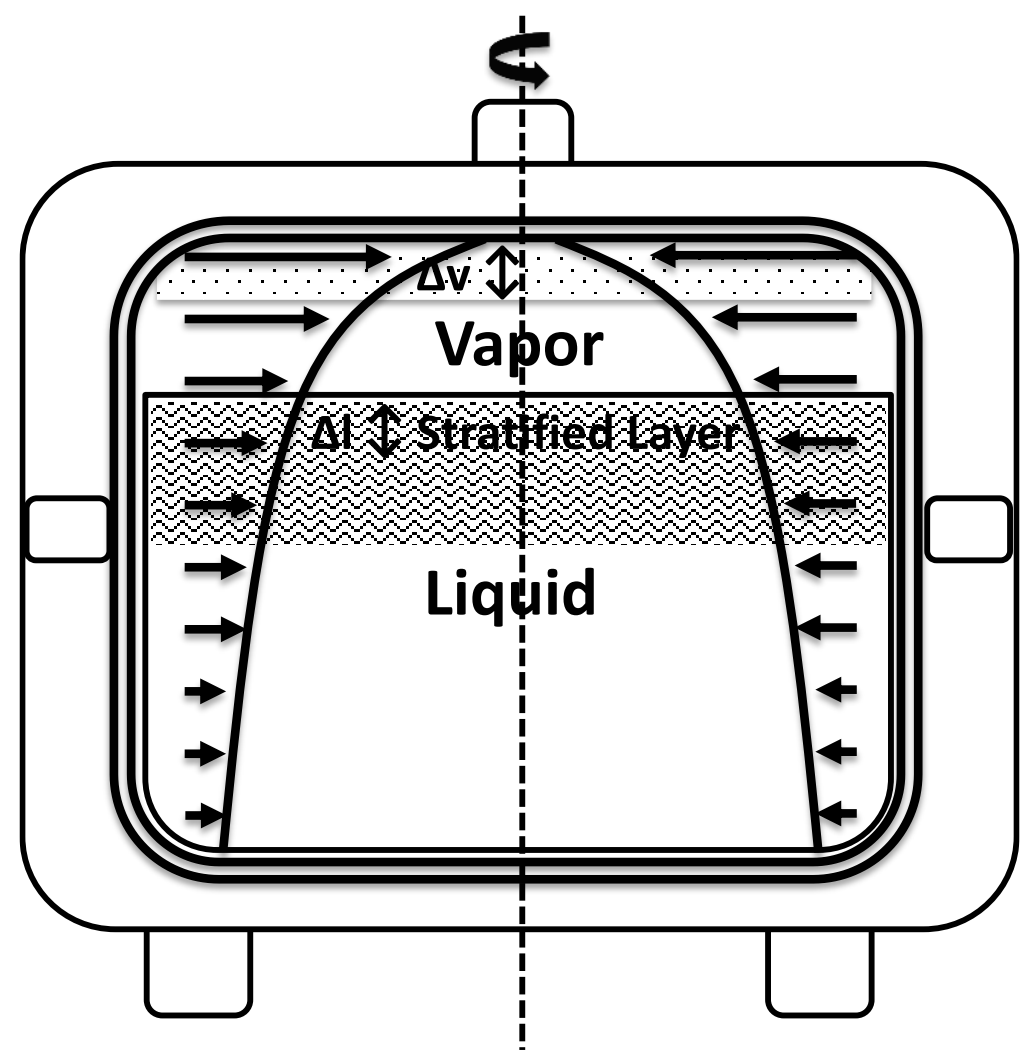

Figure 3.3. Stratified Temperature Profile and Stratified Layers Inside an LNG Tank. 
Assumptions in addition to the ones described in Section 3.2 were:

- Heat transferred through the tank walls moves toward the top of the tank via a free convection boundary layer.

- Initial temperature of vapor and liquid LNG is at saturated conditions.

- Temperature at the liquid surface determines the tank pressure.

- Thickness of the temperature and velocity boundary layers is assumed the same, since methane has a Prandtl number close to unity (between 0.8 and 1.2).

Initially, a Momentum-Force balance equation was described. For this, a free convection turbulent boundary layer was assumed since after a short distance of travel the LNG has a higher Grashof number $\left(G r \geq 10^{11}\right)$. Then, the temperature and velocity variations proposed by Eckert and Jackson [70] were used. These profiles can be seen in Figure 3.4 and are defined by the following two equations for temperature and velocity, respectively:

$$
\begin{gathered}
\frac{\theta}{\theta_{w}}=1-\left(\frac{y}{\delta}\right)^{1 / 7} \\
\frac{u}{\mathrm{U}}=\left(\frac{y}{\delta}\right)^{1 / 7}\left(1-\frac{y}{\delta}\right)^{4}
\end{gathered}
$$

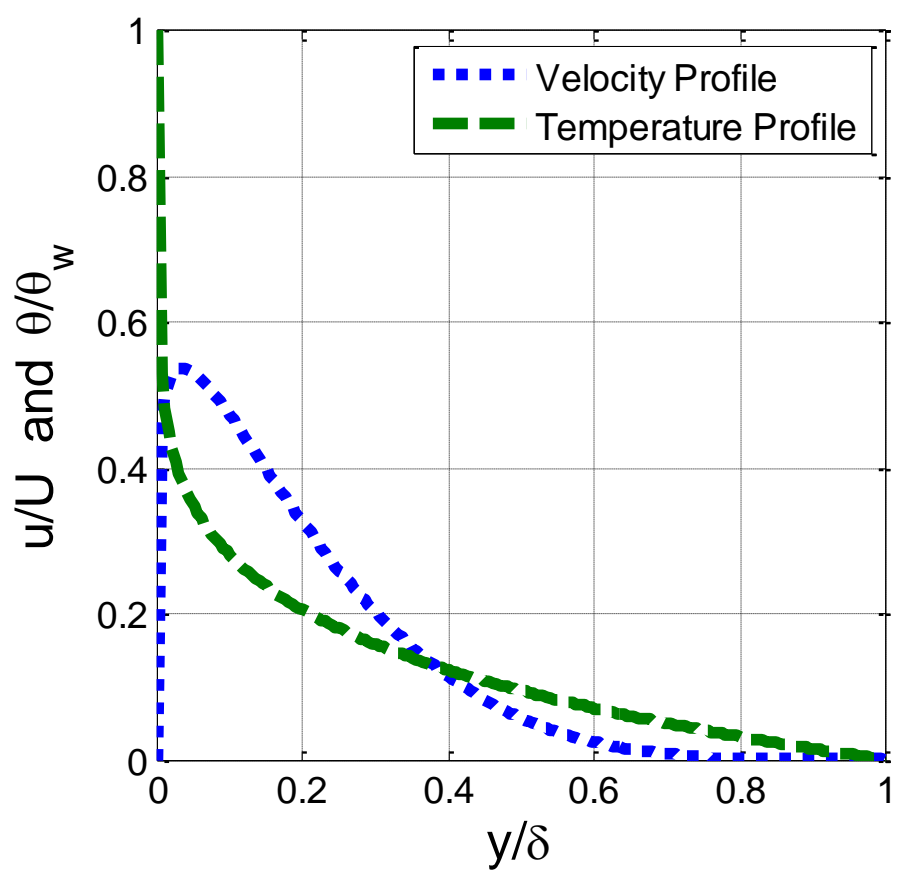

Figure 3.4. Velocity and Temperature Profiles in the Turbulent Free-Convection Boundary Layer [70]. 
where $\theta=T-T_{B}$ is the temperature rise, $\theta_{w}=T_{W}-T_{B}$ is the increase in wall temperature $\left(T_{W}\right)$ over the bulk liquid $\left(T_{B}\right), u$ is the local velocity, $U$ is the characteristic velocity, $y$ is the perpendicular distance from the wall, and $\delta$ is the boundary layer thickness.

A section of the tank is shown in Figure 3.5 with the nomenclature assumed for the mathematical model. At a distance $x$ from the bottom of the tank two planes ( $a$ and $b$ ) are located normal to the tank axis bounding a fluid element of thickness $\Delta \mathrm{x}$ with a heat transfer $\mathrm{q}_{\mathrm{w}}$.

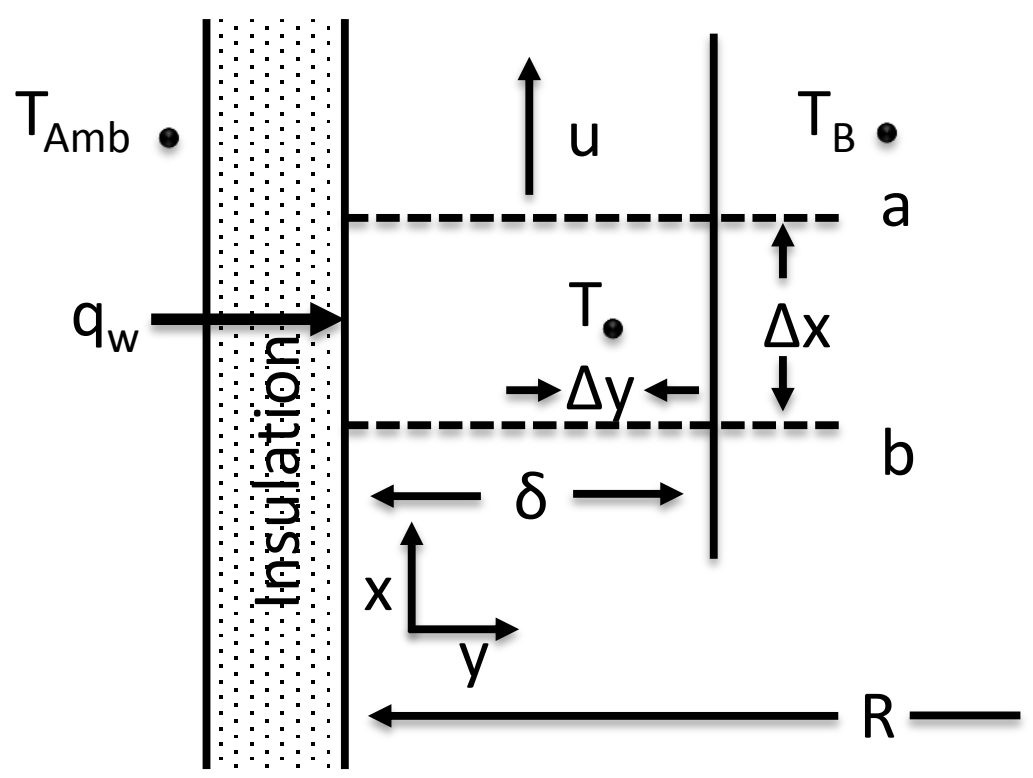

Figure 3.5. Boundary Layer Nomenclature.

The change in momentum flow for a circular cross section is equal to the forces acting on the section, the vertical buoyant force $\left(F_{B}\right)$ and the viscous shear force $\left(F_{v}\right)$ as:

$$
\frac{d}{d x}(\dot{m} u) \mathrm{dx}=F_{B}+F_{v}
$$

where the momentum flow can be described as:

$$
\frac{d}{d x}(\dot{m} u) \mathrm{dx}=\frac{d}{d x}\left(\int_{0}^{\delta} 2 \pi \rho(R-y) u^{2} d y\right) d x
$$

the parallel component of the vertical buoyant force $\left(F_{B}\right)$ is:

$$
F_{B}=2 \pi g \int_{0}^{\delta}(R-y)\left(\rho_{B}-\rho\right) d y d x
$$

and the viscous shear force $\left(F_{v}\right)$ acting parallel to the tank wall and opposite to the flow is:

$$
F_{v}=-\tau_{w} 2 \pi R d x
$$


where $\rho_{B}$ is the density at the bulk temperature $\left(T_{B}\right), \rho$ is the density, $R$ is the radius of the tank, and $g$ is the acceleration field.

Using the previous definitions of forces and momentum flow, and the approximations of $\frac{\rho}{\rho_{B}} \cong 1$ and $\rho_{B}-\rho \cong \beta \rho_{B} \theta$ since the wall and bulk temperature difference is expected to be small, and introducing the volumetric coefficient of expansion $\beta$. Then:

$$
\frac{d}{d x}\left(\rho_{B} \int_{0}^{\delta}(R-y) u^{2} d y\right)=\rho_{B} \beta g \int_{0}^{\delta} \theta(R-y) d y-\tau_{w} R
$$

Replacing the temperature rise and local velocity and then evaluating the previous integrals gives:

$$
\begin{gathered}
\frac{d}{d x}\left(\rho_{B} \int_{0}^{\delta}(R-y) U^{2}\left(\frac{y}{\delta}\right)^{2 / 7}\left(1-\frac{y}{\delta}\right)^{8} d y\right)= \\
\rho_{B} \beta g \int_{0}^{\delta} \theta_{w}\left(1-\left(\frac{y}{\delta}\right)^{1 / 7}\right)(R-y) d y-\tau_{w} R \\
\frac{d}{d x}\left(\rho_{B}\left(0.052315 R \delta U^{2}-0.006539 \delta^{2} U^{2}\right)\right)= \\
\rho_{B} \beta g\left(\frac{R \delta \theta_{w}}{8}-\frac{\delta^{2} \theta_{w}}{30}\right)-\tau_{w} R
\end{gathered}
$$

Following the work of Arnett et al. [64, 65], the shear stress at the wall $\tau_{w}$ was substituted by the Blasius correlation [75] to relate with other quantities as:

$$
\tau_{w}=0.0228 \rho_{B} U^{2}\left(\frac{v}{U \delta \cos (\gamma)}\right)^{1 / 4}
$$

This assumption is valid for both sections of a tank with a cylindrical part and a top part with a cone of angle $\gamma$. Since the angle $\gamma$ in a cylindrical section is zero, Equation 3.38 was simplified for this work as:

$$
\tau_{w}=0.0228 \rho_{B} U^{2}\left(\frac{v}{U \delta}\right)^{1 / 4}
$$

The wall temperature increase was found as well following Arnett et al. [64, 65] by using the Reynolds analogy [75] for viscous shear stress and conductive heat transfer, the Prandtl number correction by Colburn [76], and the Blasius correlation as:

$$
\theta_{w}=\frac{q_{m} \operatorname{Pr}^{2} / 3}{0.0228 c \rho_{B} U}\left(\frac{U \delta}{v}\right)^{1 / 4}
$$

where $q_{m}$ is the mean heat flux term, $\operatorname{Pr}$ is the Prandtl number, $c$ is the specific heat, and $v$ is the kinematic viscosity. 
A first main equation was obtained after performing the differentiations of the momentum equation and using the substitutions for shear stress and temperature increase at the wall:

$$
\frac{d U}{d x}=A(\delta, U)+B(\delta, U) \frac{d \delta}{d x}
$$

where $A$ and $B$ are defined below:

$$
\begin{gathered}
A(\delta, U)=\frac{52.399 g \beta q_{m} \operatorname{Pr}^{2} / 3 \delta^{1 / 4}\left(1-\frac{4}{15 R}\right)}{\rho_{B} c v^{1 / 4} U^{7 / 4}\left(1-\frac{\delta}{8 R}\right)}-\frac{0.2179 v^{1 / 4} U^{3 / 4}}{\delta^{5 / 4}\left(1-\frac{\delta}{8 R}\right)}-\frac{U}{2 R\left(1-\frac{\delta}{8 R}\right)} \frac{d R}{d x} \\
B(\delta, U)=-\frac{U\left(1-\frac{\delta}{4 R}\right)}{2 \delta\left(1-\frac{\delta}{8 R}\right)}
\end{gathered}
$$

This equation corroborates with Arnett et al. [64, 65] without their term for the angle $\gamma$ of the cone at the top of the tank.

A second main equation was derived by performing an energy balance in the circular cross section equating the heat flux through the wall to the heat flow change across the section, following to Arnett et al. [64, 65]. Then, on plane $b$ (Figure 3.5) the thermal energy entering the fluid is:

$$
\int_{0}^{\delta} 2 \pi \rho c \theta(R-y) u d y
$$

and the thermal energy change through plane $a$ (Figure 3.5) is:

$$
\frac{d}{d x}\left(\int_{0}^{\delta} 2 \pi \rho_{B} c \theta(R-y) u d y\right) d x
$$

Additionally, in the boundary layer at $y=\delta$ the mass flow entering and leaving is considered to be in equilibrium with the bulk temperature $\left(T_{B}\right)$, therefore $\theta=0$ and no heat flows through this boundary. Heat entering into the section is then through the wall at $y=0$ as:

$$
2 \pi R q_{w} d x
$$

where $q_{w}$ is the local wall heat flux.

Comparing the previous definitions of thermal energies and substituting $\rho=\rho_{B}$ gives:

$$
\frac{d}{d x}\left(2 \pi \rho_{B} c \int_{0}^{\delta} \theta(R-y) u d y\right) \mathrm{dx}=2 \pi R q_{w} d x
$$

Substituting the temperature rise and local velocity and then evaluating the previous integral results in: 


$$
\begin{gathered}
\frac{d}{d x}\left(\rho_{B} c \int_{0}^{\delta} \theta_{w}\left(1-\left(\frac{y}{\delta}\right)^{1 / 7}\right)(R-y) U\left(\frac{y}{\delta}\right)^{1 / 7}\left(1-\frac{y}{\delta}\right)^{4} d y\right)=R q_{w} \\
\frac{d}{d x}\left(\rho_{B} c \theta_{w} U \delta(0.036631 R-0.004785 \delta)\right)=R q_{w}
\end{gathered}
$$

The second main equation was obtained after performing the differentiations of the thermal energy equation and using the substitutions for shear stress and temperature increase at the wall:

$$
\frac{d \delta}{d x}=C(\delta, U)+D(\delta, U) \frac{d U}{d x}
$$

where $C$ and $D$ are defined below:

$$
\begin{gathered}
C(\delta, U)=\frac{1}{\left(1-0.2352 \frac{\delta}{R}\right)}\left(\frac{0.4979 v^{1 / 4} q_{w}}{q_{m} \operatorname{Pr}^{2} / 3 U^{1 / 4} \delta^{1 / 4}}-\frac{4 \delta}{5 q_{m}}\left(1-0.1306 \frac{\delta}{R}\right) \frac{d q_{m}}{d x}-\frac{4 \delta}{5 R} \frac{d R}{d x}\right) \\
D(\delta, U)=-\frac{\delta\left(1-0.1306 \frac{\delta}{R}\right)}{5 U\left(1-0.2352 \frac{\delta}{R}\right)}
\end{gathered}
$$

which corroborate with Arnett et al. $[64,65]$ work without their term for the cone angle $\gamma$ at the top of the tank.

Finally, a third main equation was derived similar to Arnett et al. [64, 65] by equating the rate of heat transported across the horizontal plane $b$ (Figure 3.5) and the rate of heat entering the fluid through the tank wall below the plane as:

$$
2 \pi \rho_{B} c \int_{0}^{\delta} \theta(R-y) u d y=q_{m} A(x)
$$

where $A(x)$ is the surface area of the tank at distance $x$ from the bottom of the tank. It is assumed that all energy entering the tank stays in the boundary layer and is carried upward.

Replacing the temperature rise and local velocity and then evaluating the previous integral results in:

$$
\begin{gathered}
2 \pi \rho_{B} c \int_{0}^{\delta} \theta_{w}\left(1-\left(\frac{y}{\delta}\right)^{1 / 7}\right)(R-y) U\left(\frac{y}{\delta}\right)^{1 / 7}\left(1-\frac{y}{\delta}\right)^{4} d y=q_{m} A(x) \\
\rho_{B} c \theta_{w} U \delta(0.230159 R-0.030065 \delta)=q_{m} A(x)
\end{gathered}
$$

Therefore, the third main equation which corroborate with Arnett et al. [64, 65] was obtained, after using the substitutions for shear stress and temperature increase at the wall:

$$
U=E(\delta, x)
$$

where $E$ is defined as: 


$$
E(\delta, x)=\left(\frac{v^{1 / 4} A(x)}{10.095 \operatorname{RPr}^{2} / 3 \delta^{5} / 4\left(1-0.1306 \frac{\delta}{R}\right)}\right)^{4}
$$

Solution for the three previous coupled main equations was achieved by using the iterative Newton's Method. A similar procedure like the one by Arnett et al. [64, 65] was used where an initial value of boundary layer thickness $\left(\delta_{1}\right)$ at $x_{1}$ is assumed calculating the respective characteristic velocity $\left(U_{1}\right)$. Then $(d U / d x)$ and $(d \delta / d x)$ are evaluated, and the iterative procedure is repeated assuming a new boundary layer thickness until the error $(\varepsilon)$ tends to zero before calculating the stratified layer thicknesses and temperature profiles in the liquid and vapor regions, as described in the following sections. A small maximum value error such as $\varepsilon=10^{-6}$ was used. Error $\left(\varepsilon=\left|\frac{\Delta U}{\Delta x}-\frac{d U}{d x}\right|\right)$ was calculated by evaluating a new characteristic velocity $\left(U_{2}=U\left(\delta_{1}, x_{2}\right)\right)$ using the third main equation with an incremental change in $x\left(\Delta x=x_{2}-x_{1}\right)$ and defining $\Delta U=U_{2}-U_{1}$.

Initial conditions and input parameters necessary for the model were the tank dimensions, LNG properties and fill level, initial pressure and PRV value, heat transfer in each layer of the tank, and number of layers desired in the stratified region of liquid and of vapor. Local heat transfer values were recalculated every time step of the simulation of the LNG Fueling Station Model with the Heat Transfer Model provided using the output from the previous time step of the Stratified Thermodynamics Model with the respective temperature profiles calculated for the liquid and vapor regions.

\subsubsection{Liquid and Vapor Stratified Layer Thicknesses}

A dual logic was implemented in order to improve convergence of the stratification model, calculating small time steps in the beginning and larger time steps afterward. The initial logic was to assume a stratified layer thickness for the liquid region and calculate the time needed for the boundary layer flow to occupy this volume. For this, a similar procedure like the one by Arnett et al. [64, 65] was used where at any horizontal plane the volume flow rate $(\dot{V})$ parallel to the wall is calculated by integrating across the boundary layer and substituting the velocity profile: 


$$
\begin{gathered}
\dot{V}=\int_{0}^{\delta} 2 \pi(R-y) u d y \\
\dot{V}=\int_{0}^{\delta} 2 \pi(R-y) U\left(\frac{y}{\delta}\right)^{1 / 7}\left(1-\frac{y}{\delta}\right)^{4} d y \\
\dot{V}=2 \pi U\left(0.1464 R \delta-0.02723 \delta^{2}\right)
\end{gathered}
$$

The incremental time $(\Delta t)$ for a boundary layer volume flow to occupy an arbitrary small volume $(\Delta V)$ immediately above the horizontal plane can be determined as:

$$
\Delta t=\Delta V /\left(\int_{0}^{\delta} u d A\right)_{x}
$$

and since:

$$
\dot{V} \Delta t=\pi R^{2} \Delta Z
$$

Then, solving for $\Delta t$ gives the following equation which corroborate with Arnett et al. $[64,65]$ without including their term for the cone of angle $\gamma$ for the top of the tank:

$$
\Delta t=\frac{R \Delta Z}{0.2927 \delta U\left(1-0.1860 \frac{\delta}{R}\right)}
$$

where $\Delta Z$ is an small vertical distance measured from the bottom of the stratified layer.

The logic developed was to assume a maximum time step size for the boundary layer flow to occupy this volume and calculate in a similar way the stratified layer thickness for the liquid region as:

$$
\Delta Z=\frac{0.2927 \delta U}{R}\left(1-0.1860 \frac{\delta}{R}\right) \Delta t
$$

The sum of all the time increments for all of the arbitrary volume increments determine the total time $(t)$ needed for the stratified layer to occupy the volume above the plane:

$$
t=\sum \Delta t
$$

These equations apply in the liquid and vapor regions in the tank. Thickness in the vapor stratified layer is calculated by an iterative method using the time previously determined for the assumed thickness of the liquid stratified layer. Thicknesses in the liquid and vapor stratified layers are recalculated every time step of the Stratified Thermodynamics Model. 


\subsection{3. $\quad$ Liquid and Vapor Stratified Layer Temperatures}

Once the time needed to occupy the volumes of the liquid and vapor stratified layers, and the respective thicknesses are calculated the amount of energy entering the stratified layers and distributions are determined. The total thermal energy $(Q)$ entering during the time $t$ through the wetted wall is:

$$
Q=q_{m} A_{l} t
$$

where $A_{l}$ is the area of the liquid wetted wall. Based on the experimental experience of Arnett et al. $[64,65]$ with stratified layer temperature gradients, it was assumed that this energy $(E)$ is distributed vertically in the following exponential form:

$$
E(Z)=m Z^{n}
$$

where $Z$ is the vertical distance from the bottom of the stratified layer, and $m$ and $n$ are constants. Therefore, the energy stored in an infinitesimal stratified layer of liquid is:

$$
d Q=\pi R^{2} E(Z) d Z
$$

Replacing with the exponential form of energy, integrating, and solving yields:

$$
\begin{gathered}
Q=\pi R^{2} \int_{0}^{\Delta} m Z^{n} d Z \\
Q=\pi R^{2} m \frac{\Delta^{n+1}}{n+1}
\end{gathered}
$$

where $\Delta$ represents the incremental vertical distance.

Solving for $m$ and using the definition of thermal energy entering through the wetted wall gives:

$$
m=\frac{q_{m} A_{l} t}{\pi R^{2}} \frac{(n+1)}{\Delta^{n+1}}
$$

As well, the temperature of the layer can be defined as:

$$
d Q=\pi R^{2} \rho c \theta_{Z} d Z
$$

Then, replacing $m$ in the energy and solving for the temperature profile over the liquid stratified layer $\left(\theta_{Z}\right)$ results in [64, 65]:

$$
\theta_{Z}=\frac{q_{m} A_{l} t(n+1)}{\pi \rho c R^{2} \Delta}\left(\frac{Z}{\Delta}\right)^{n}
$$

The constant value for the exponent $n$ can be entered in the model, however, the value of 2 was used since it was determined empirically by Arnett et al. [64, 65] and other values did not show a particular effect on the pressure rise of the tank. 
The temperature profile over the vapor stratified layer $\left(\theta_{Z v}\right)$ was calculated by a different method. In this case, the vapor stratified thickness is divided into small vertical increments $\left(\Delta Z_{v}\right)$ and all the energy entering through the wall into the vapor region during the incremental time due to boundary layer flow is assumed to be uniformly distributed in this increment. Energy entering the vapor region $\left(E_{Z v}\right)$ through the wall below the current small layer is assumed to be uniformly divided between the previous layers, until the entire depth of the vapor stratified layer is covered. Consequentially, temperature in each vapor layer is obtained as follows $[64,65]$ :

$$
\theta_{Z v}=\frac{E_{Z v}}{\pi \rho c R^{2} \Delta Z_{v}}
$$

\subsubsection{Prediction of Pressure}

In order to predict the pressure in the LNG tank a mass balance is evaluated at the interface of liquid and vapor coupling the results between both regions and estimating if mass has been evaporated or condensated, following to the approach by Arnett et al. [64, 65]. The total mass contained in the liquid or vapor regions can be calculated using the mass at each differential volume layer as:

$$
\mathrm{d} m=\pi R^{2} \rho(\theta, P) d Z
$$

where $\pi R^{2} d Z$ is the volume of each layer, and the density $\rho(\theta, P)$ is a function of the local temperature and pressure in the tank. Temperature $(\theta)$ in each layer had been calculated using the methodology described in the previous Section 3.4.3, and it is assumed to be saturated during the initial iteration of the model. Consecutive iterations uses the temperature profile calculated in the previous iteration. Pressure $(P)$ in the tank is determined by the saturated temperature at the liquid surface. For subsequent model iterations the properties are assumed in the vapor region as superheated and in the liquid region as subcooled. Appendix F shows the different isobars used. The total mass for the vapor region at iteration $i\left(m_{v, i}\right)$ is then calculated by:

$$
m_{v, i}=\pi R^{2} \int_{0}^{h_{i}} \rho\left(\theta_{Z v, i}, P_{i}\right) d Z
$$

where $h_{i}$ is the height of the vapor region at the current iteration from the interface to the top of the tank, and $P_{i}$ is assumed corresponding to the saturation pressure for the temperature at the liquid surface. 
The new calculated vapor mass is compared with the vapor mass of the previous iteration $\left(m_{v, i-1}\right)$, if the new mass is larger than the previous mass it is because some evaporation of liquid happened in order to achieve equilibrium between the two regions. If the new vapor mass is smaller condensation of some vapor into the liquid happened. If the case of equal masses occurs a new calculation of the stratified layer is performed. This can be summarized with the following equalities:

$$
\begin{array}{cc}
m_{v, i}>m_{v, i-1} & \text { Evaporation } \\
m_{v, i}=m_{v, i-1} & \text { Equilibrium } \\
m_{v, i}<m_{v, i-1} & \text { Condensation }
\end{array}
$$

The effects of evaporation and condensation are illustrated in Figure 3.6 a and b, respectively, where $Z_{1}$ is the depth in the stratified layer over which evaporation or condensation affects temperature, $T_{l}$ is the liquid temperature in the stratified layer, and $T_{S}$ is the temperature of liquid affected by evaporation or condensation.

In the evaporation case, a new mass of vapor $\left(m_{v, T_{S}}\left(\theta_{Z v, i}, P_{S}\right)\right)$ is calculated using the temperature profile of vapor with the saturated pressure at the new temperature $\left(P_{s}=P\left(T_{s}\right)\right)$. Then, this mass of vapor is compared with respect to an adjusted mass $\left(m_{a}\right)$ :

$$
m_{a}=m_{v, i-1}+\Delta m_{v}
$$

The mass evaporated $\left(\Delta m_{v}\right)$ is estimated using the energy contained in the surface layer of liquid $\left(E_{l}\right)$ that is used for evaporating liquid [64, 65]:

$$
E_{l}=\pi \rho_{B} c R^{2} \int_{0}^{Z_{1}}\left(T_{l}-T_{s}\right) d Z
$$

divided by the latent heat of evaporation $\left(L_{v}\right)$ as:

$$
\Delta m_{v}=E_{l} / L_{v}
$$

An iterative technique is implemented to determine the equilibrium of the two masses by looking for the saturation temperature corresponding to the vapor region pressure in equilibrium with the liquid surface temperature. Convergence is achieved when:

$$
\left|m_{\mathrm{v}, \mathrm{T}_{s}}-m_{\mathrm{a}}\right| \leq \varepsilon
$$




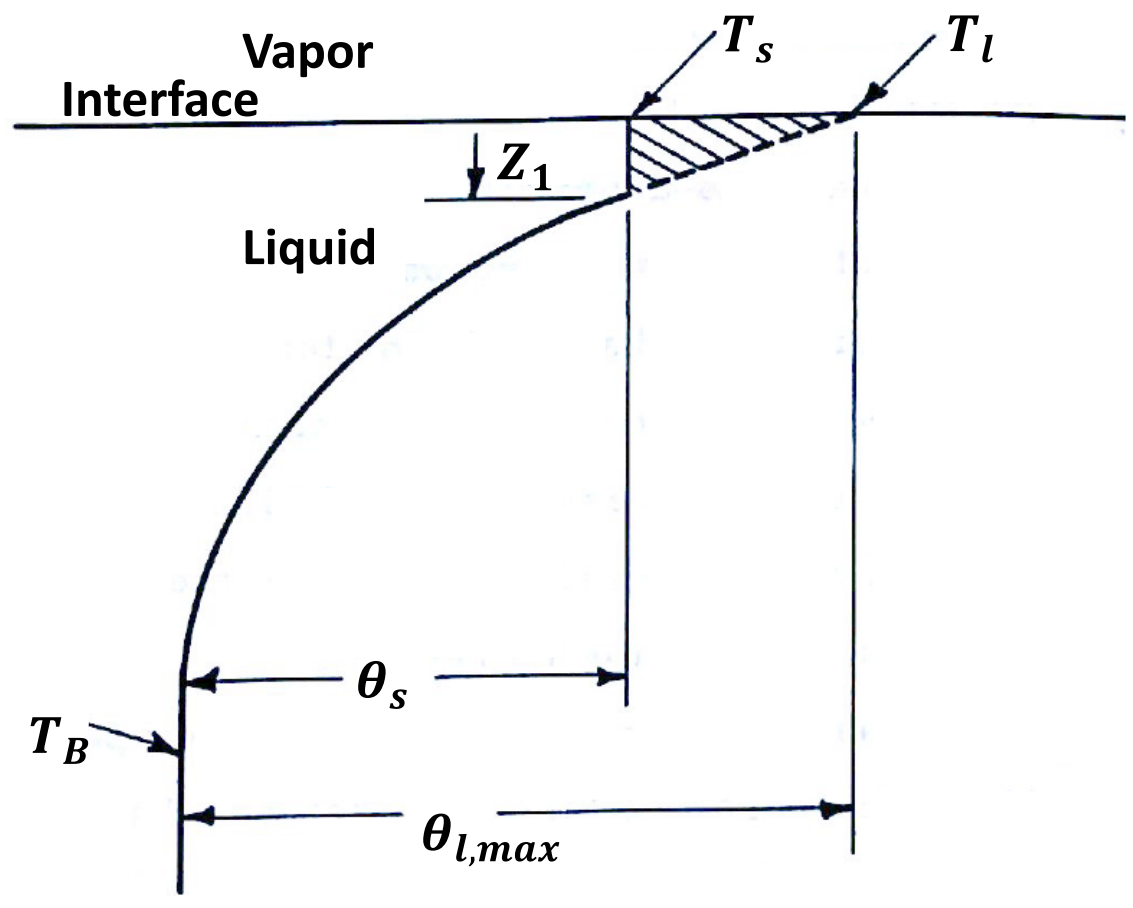

a. Evaporation

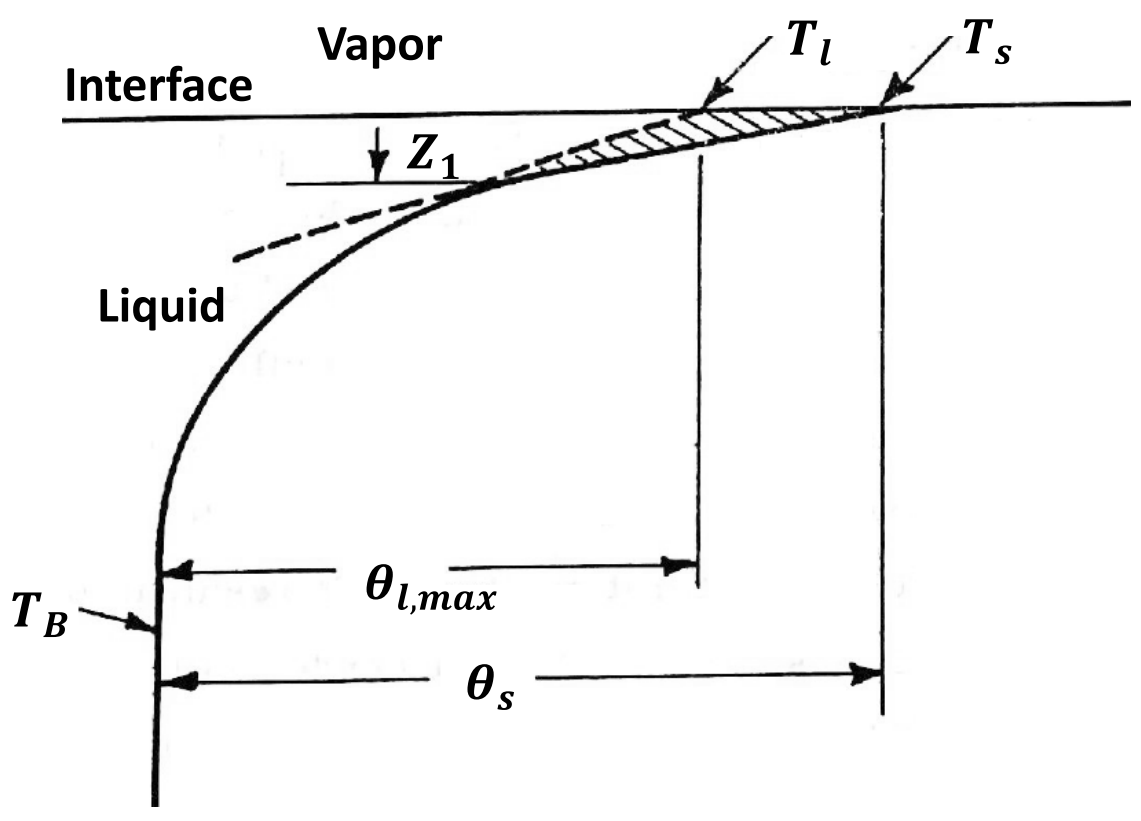

b. Condensation

Figure 3.6. Temperature Gradient at the Interface $[64,65]$. 
where $\varepsilon$ is a small maximum value error such as $\varepsilon=10^{-6}$. At this point the future pressure has been predicted and the entire model is updated with the new pressure and a new liquid stratification depth is selected to repeat the whole modeling process.

A similar procedure is followed for the condensation case, a new temperature $T_{S}$ higher than $T_{l}$ is selected. However, it was found by Schmidt et al. [77] that the liquid temperature gradient produced by condensation is not constant. Therefore, their following error function relation is used:

$$
\frac{T_{s, \max }-T_{S}}{T_{s, \max }-T_{B}}=\frac{2}{\sqrt{\pi}} \int_{0}^{\varphi} e^{-\lambda^{2}} d \lambda
$$

where $\varphi=\frac{Z}{2 \sqrt{\alpha t}}, \alpha$ is the thermal diffusivity, and $T_{s, \max }$ is the assumed temperature at the interface. The mass evaporated $\left(\Delta m_{v}\right)$ is estimated as before using the energy contained in the surface layer of liquid $\left(E_{l}\right)$, nevertheless, the integration is carried only up to the depth where $T_{l}=T_{s}$. As well, since it is assumed that $T_{s}>T_{l}$, the energy and mass evaporated are negative, as expected in a condensation.

\subsubsection{Mass Balance and Thermal Correction for Stratification}

The previous sections of the Stratification Model were reiterated calculating the evaporation or condensation happening inside the tank, the changes in pressure, and the temperature profiles for vapor and liquid regions. The goal of this part of the model was to use all this information and account for dynamic changes in liquid and vapor and to add the capability for hold time simulations. Note that these were some of the limitations in the Arnett et al. [64, 65] development, and were some of the improvements and extensions provided in this work. For this, a new fill level was provided with the corresponding new mass of vapor and liquid in the tank based on operational transactions that occurred as vapor returned and LNG dispensed. The equivalent changes in the stratification were determined, in order to adjust the stratified temperature profiles. The change of energy in the tank was calculated later based on the new mass distribution and new stratification thicknesses. 
Mass balance equations were implemented similar to the ones used in the Homogeneous Model and explained in Section 3.3.1, to track any changes in the masses of liquid and vapor in the tank. It was assumed that any vapor or liquid removed from the tank leaves at saturation conditions at the current tank pressure, and that the masses added were at known temperatures. Also, any volume emptied by the mass of liquid $\left(\mathrm{m}_{\text {out,liquid }}\right)$ and or mass of vapor $\left(\mathrm{m}_{\text {out,vapor }}\right)$ in the tank gets occupy by saturated vapor which was evaporated during the next time step $\left(\mathrm{m}_{\text {evaporated }}\right)$. Condensation happened when the mass of vapor added into the tank $\left(\mathrm{m}_{\text {in,vapor }}\right)$ was bigger than the mass evaporated $\left(\mathrm{m}_{\text {evaporated }}\right)$. To compensate for the continual change of volume by evaporation, an iterative algorithm was implemented to calculate the net change of the fill level. These approximations were reasonable since the possible mass of liquid leaving the tank in a time step was very small (less than $0.5 \%$ ) compared to the capacity of the full tank. As well, it was considered reasonable to replace the volume of liquid emptied with saturated vapor since this small change occurs at the interface level.

Since the geometry of the tanks was known, the changes in liquid fill level $\left(\Delta h_{n}\right)$ were calculated using the density of the liquid and the total mass removed, which was liquid and/or vapor vented. The mass of vapor vented was replaced with mass evaporated from the liquid region changing the liquid fill level, therefore the density of the liquid was used. The total volume emptied was assumed to be replaced by evaporated liquid, as:

$$
\begin{gathered}
\Delta V_{\text {out,liquid }}=\frac{\mathrm{m}_{\text {out,liquid }}+\mathrm{m}_{\text {out }, \text { vapor }}}{\rho_{\text {liquid }}} \\
\Delta h_{n}=\frac{\Delta V_{\text {out }, \text { liquid }}}{\pi R^{2}}
\end{gathered}
$$

The mass of vapor occupied for this volume was calculated as:

$$
\mathrm{m}_{\text {evaporated }, n}=\Delta V_{\text {out }, \text { liquid }} \cdot \rho_{\text {vapor }}-\mathrm{m}_{\text {in,vapor }}
$$

Evaporated mass changed the liquid fill level creating an additional volume. The iterative method used similar equations and recalculated the additional amount of mass evaporated to fill this space with more vapor:

$$
\begin{gathered}
\Delta V_{\text {evaporated, } n}=\frac{\mathrm{m}_{\text {evaporated }, n}}{\rho_{\text {liquid }}} \\
\Delta h_{n+1}=\frac{\Delta V_{\text {evaporated }, n}}{\pi R^{2}}
\end{gathered}
$$




$$
\mathrm{m}_{\text {evaporated }, n+1}=\Delta V_{\text {evaporated }, n} \cdot \rho_{\text {vapor }}
$$

The process iterated until the change in the fill level converged as:

$$
\left|\Delta h_{n+1}-\Delta h_{n}\right| \leq \varepsilon
$$

where $\varepsilon$ was a small maximum value error such as $\varepsilon=10^{-6}$ and $\mathrm{n}$ was the iteration number of the method.

The net change of the fill level $\left(\Delta h_{n e t}\right)$ was calculated as the sum of all iterations and was applied to the stratification thicknesses at next iterations as:

$$
\Delta h_{n e t}=\sum \Delta h_{n}
$$

The use of these new thicknesses and masses allowed the stratification model to account for the thermal shifting by the dynamic changes in liquid and vapor. Temperature profiles at the next iteration were calculated in the stratification model using the heat leak entered into the tank and the updated thicknesses and masses estimated.

\subsection{Venting Model for Calculation of LNG Vapor Mass Released}

The LNG Tank Venting Model calculated the mass of vapor that needed to be removed from a LNG tank in order to drop the pressure from an initial pressure $\left(\mathrm{P}_{\text {pre }}\right)$ to a desired final pressure $\left(\mathrm{P}_{\mathrm{after}}\right)$. This component of the LNG station model was used to estimate the mass of vapor that was transferred from a vehicle tank to the station tank during vapor balancing. It was also used to estimate the mass of vapor released from the PRV in the event that the PRV activation pressure was reached.

The model assumed isothermal homogenous conditions within the tank during this venting stage. Additionally, potential and kinetic energy, work, and heat transfer were neglected.

The volume of the tank $\left(\mathrm{V}_{\text {tank }}\right)$, total initial mass of methane in the tank $\left(\mathrm{m}_{\text {total,pre }}\right)$ the initial pressure $\left(\mathrm{P}_{\text {pre }}\right)$, and the final pressure $\left(\mathrm{P}_{\text {after }}\right)$ needed to be provided as inputs to the calculations. These values were computed by separate components of the overall model.

The simplified energy balance for a LNG tank during discharge or filling can be summarized as: 


$$
\frac{\mathrm{dU}}{\mathrm{dt}}=\Sigma \dot{\mathrm{m}}_{\mathrm{in}} \mathrm{h}_{\mathrm{in}}-\Sigma \dot{\mathrm{m}}_{\mathrm{out}} \mathrm{h}_{\mathrm{out}}
$$

where $\dot{m}$ was the mass flow rate, $\mathrm{h}$ was enthalpy, the subscripts in and out refer to the mass entering and exiting the tank respectively, and $\frac{\mathrm{dU}}{\mathrm{dt}}$ was the rate of change of internal energy in the control volume with respect to time. In this simplified equation the potential and kinetic energy, work, and heat transfer have been neglected. A venting takes a short period between two to five minutes; therefore, the heat transferred into the LNG tank during the venting event was assumed insignificant. The average specific internal energy $\left(\mathrm{u}_{\mathrm{ave}}\right)$ was calculated using the vapor quality $(\mathrm{x})$ and the specific internal energies $(\mathrm{u})$ found in methane properties tables for liquid and vapor states at the tank temperature and pressure as:

$$
u_{\text {ave }}=x\left(u_{g}-u_{f}\right)+u_{f}
$$

and total internal energy (U) in the tank was equal to:

$$
U=u_{\text {ave }} m_{\text {total }}
$$

The previous energy balance equation was reformulated given that during venting no mass was assumed to enter the tank and the mass exiting was assumed to be vapor:

$$
u_{\text {ave,after }} m_{\text {total,after }}-u_{\text {ave,pre }} m_{\text {total,pre }}=-m_{\text {out }, g} h_{\text {out }, g}
$$

where the mass of vapor vented was calculated as:

$$
m_{\text {out }, g}=m_{\text {total,pre }}-m_{\text {total,after }}
$$

Using the last two equations, the total mass after venting was predicted as:

$$
m_{\text {total }, \text { after }}=\frac{\left(h_{\text {out }, g}-u_{\text {ave }, \text { pre }}\right)}{\left(h_{\text {out }, g}-u_{\text {ave }, \text { after }}\right)} m_{\text {total,pre }}
$$

where the enthalpy of vapor vented was approximated as the average between the known enthalpies before and after venting:

$$
h_{\text {out }, g}=\frac{h_{g, p r e}+h_{g, a f t e r}}{2}
$$

Since the correct average specific internal energy $\left(u_{\text {ave,after }}\right)$ was unknown an iterative technique was implemented to determine it using a guess of the total final mass $\left(\mathrm{m}_{\text {total,after,guess }}\right)$. Convergence was achieved when

$$
\left|m_{\text {total,after }}-m_{\text {total,after,guess }}\right| \leq \varepsilon
$$

where $\varepsilon$ was a small maximum value error such as $\varepsilon=10^{-6}$. At this point the mass of vapor vented was calculated as the difference of the initial and final total masses. 
The mass flow rate of BOG released through the vent valves ( $\left.\dot{\mathrm{m}}_{\text {out,g,vent }}\right)$ was defined then as the total mass vented in a time step size:

$$
\dot{m}_{\text {out }, \text { g,vent }}=\frac{m_{\text {out }, g}}{\Delta t}
$$

\subsection{Fueling and Vapor Return from Vehicle Fuel Tanks}

When LNG vehicles arrive at a fueling station their tank pressure was typically higher than the maximum pressure necessary for the LNG dispenser pump to work properly. For this reason, fueling stations were equipped with a system which removed the LNG vapor from vehicles tanks and returned it to the LNG bulk storage tank. This process reduced the pressure of the vehicle tank to a level that the LNG dispenser pump can overcome and allowed a faster LNG delivery flow. Although the vapor returned added heat

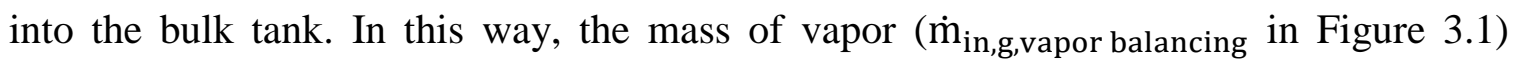

returned from the vehicle tank and the enthalpy $\left(h_{\text {in,g,vapor balancing }}\right)$ of that vapor must be determined during a typical refueling event in order to account for the effect of vapor return on boil-off rate of the fueling station bulk storage tank. The amount and properties of vapor returned to the fueling station were a function of the arriving conditions of the vehicle tank including: the amount of LNG in the fuel tank, the temperature and pressure conditions in the tank, vehicle driving activity, and environmental conditions in the area where the vehicle operates.

A simplified sub-model to estimate the mass and enthalpy of vapor returned from vehicle fuel tanks based on an average vehicle conditions upon arrival was developed. Further, the vehicle tank sub-model was capable of handling randomized LNG level, temperature and pressure in the vehicle tanks within user specified bounds and between different standard sizes of tanks, to emulate realistic vehicle arrivals at a fueling station.

The control volume representation of the vehicle fuel tank sub-model is shown in Figure 3.7 which has a single inlet where the LNG is introduced into the fuel tank and a single exit where the vapor flows back into the fueling station. It was assumed as a vessel of known volume containing a saturated mixture of liquid and vapor phase methane. The mass of liquid and pressure in the tank were known either as a user specified input or the result of the randomization routine. Thermodynamic properties of the contents of the 
vehicle fuel tank including enthalpy were determined from the saturated property tables using the saturated pressure provided. The heat transferred into the vehicle fuel tank during the refueling event was assumed insignificant, since returning vapor takes a short period between two to five minutes. Therefore, the tank was assumed to be adiabatic during this period of time.

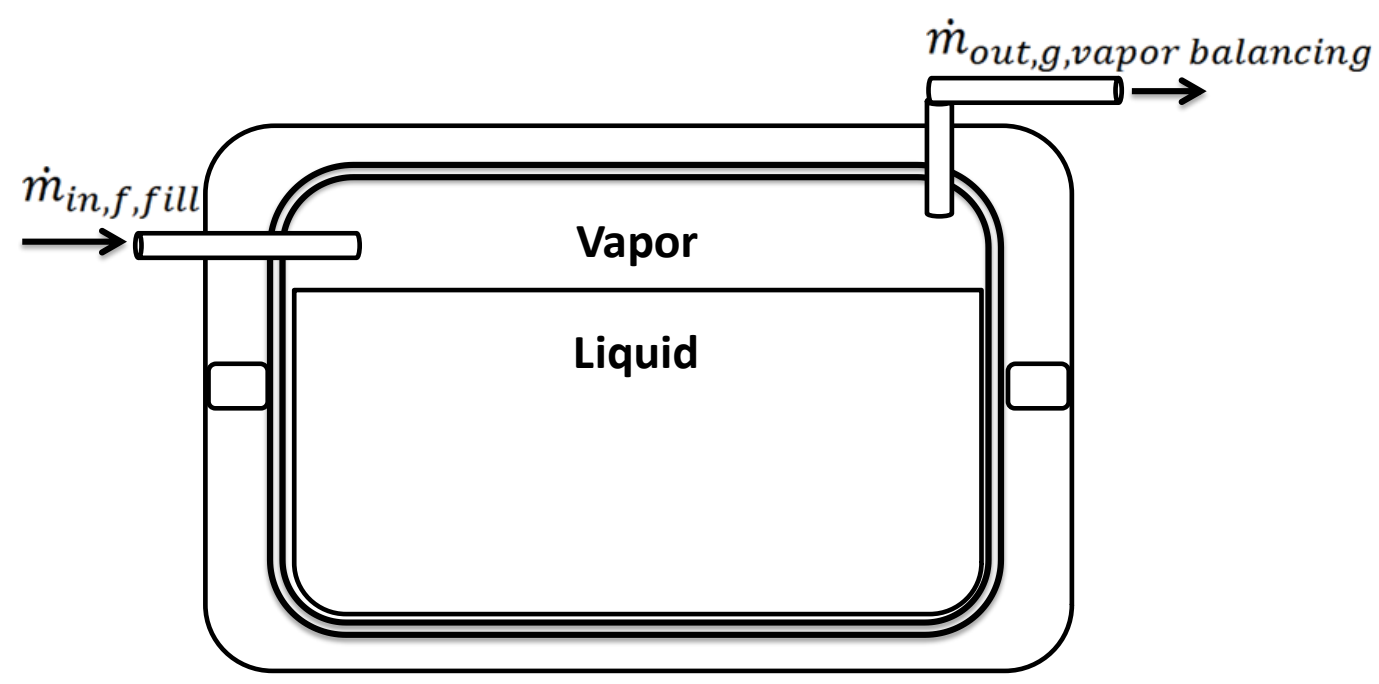

Figure 3.7. Control Volume Representation of the Simplified Sub-Model of an LNG Vehicle Tank.

The Venting Model described in the previous Section 3.5 was used to calculate the mass vented back from each vehicle tank that was fueled at the LNG station. The fuel dispensed to each vehicle tank (that was the liquid LNG removed from the bulk station tank) was calculated using the arrival conditions and the thermodynamic equations described in Section 3.3.

\subsection{Block Diagram of the LNG Fueling Station Model}

The interactions of all the components of the LNG fueling station model are shown in Figure 3.8 with the Homogeneous Thermodynamic Model and in Figure 3.9 with the Stratified Thermodynamic Model. Nevertheless, the interactions between the fueling station components and the two thermodynamic models are identical. The main two modules were: the Thermodynamic Model and the Heat Transfer Model. The Thermodynamics Model module interacted with the Tank Initial Conditions and Tank Usage blocks. The Tank Initial Conditions block provided information such as tank 
capacity, total LNG mass, and tank pressure. The Tank Usage block managed the LNG mass rates $(\dot{m})$ of vapor and liquid into and out of the tank.

In the interior of the Thermodynamics Model module there were four main concepts implemented when using the homogenous thermodynamic approach (Section 3.3). Three concepts were the equations that define the Tank Conditions (including masses of vapor and liquid, vapor quality, and internal energy), the Conservation of Mass Equation $\left(\frac{\mathrm{d} m}{\mathrm{dt}}=\right.$ $\left.\sum \dot{\mathrm{m}}_{\mathrm{in}}-\sum \dot{\mathrm{m}}_{\mathrm{out}}(3.1)\right)$, and the Energy Balance Equation $\left(\frac{\mathrm{dU}}{\mathrm{dt}}=\dot{\mathrm{Q}}+\sum \dot{\mathrm{m}}_{\mathrm{in}} \mathrm{h}_{\mathrm{in}}-\right.$ $\left.\Sigma \dot{\mathrm{m}}_{\text {out }} \mathrm{h}_{\text {out }}(3.13)\right)$. The fourth concept was the method to Determine the New Tank Pressure (Section 3.3.2), which fed the new tank pressure to the Tank Conditions block and was updated every time step. Furthermore, the pressure of the tank was used in the Pressure Release Valve block (Section 3.5) which fed the Tank Usage block with the information necessary to keep the tank below the maximum safe pressure. When using the stratified thermodynamic approach (Section 3.4) there were three main concepts implemented: the Liquid/Napor Stratified Layer Thicknesses (Section 3.4.2), the Liquid/Napor Stratified Layer Temperatures (Sections 3.4.3), and the method for the Prediction of Pressure (Section 3.4.4).

The Heat Transfer Model module provided the total heat leak rate $(\dot{Q})$ to the Energy Balance block inside the Thermodynamic Model module. To do this calculation the Heat Transfer Model module used the current information of LNG liquid level and temperature(s) from the Thermodynamic Model module, as well as the information provided from the Initial Conditions Heat Transfer block (including tank insulation thickness, cylindrical strut area ratio, and strut material conductivity) and the Ambient Conditions block (including ambient temperature, solar loading, and wind speed). In the case of the Stratified Thermodynamic model, the Heat Transfer Model calculated a vector of heat leak rates into the LNG tank using the profile of LNG temperature profile (Section 3.4.3). Details of the Heat Transfer Model developed by John Hailer will be available in his future publications, including his master thesis [71]. 


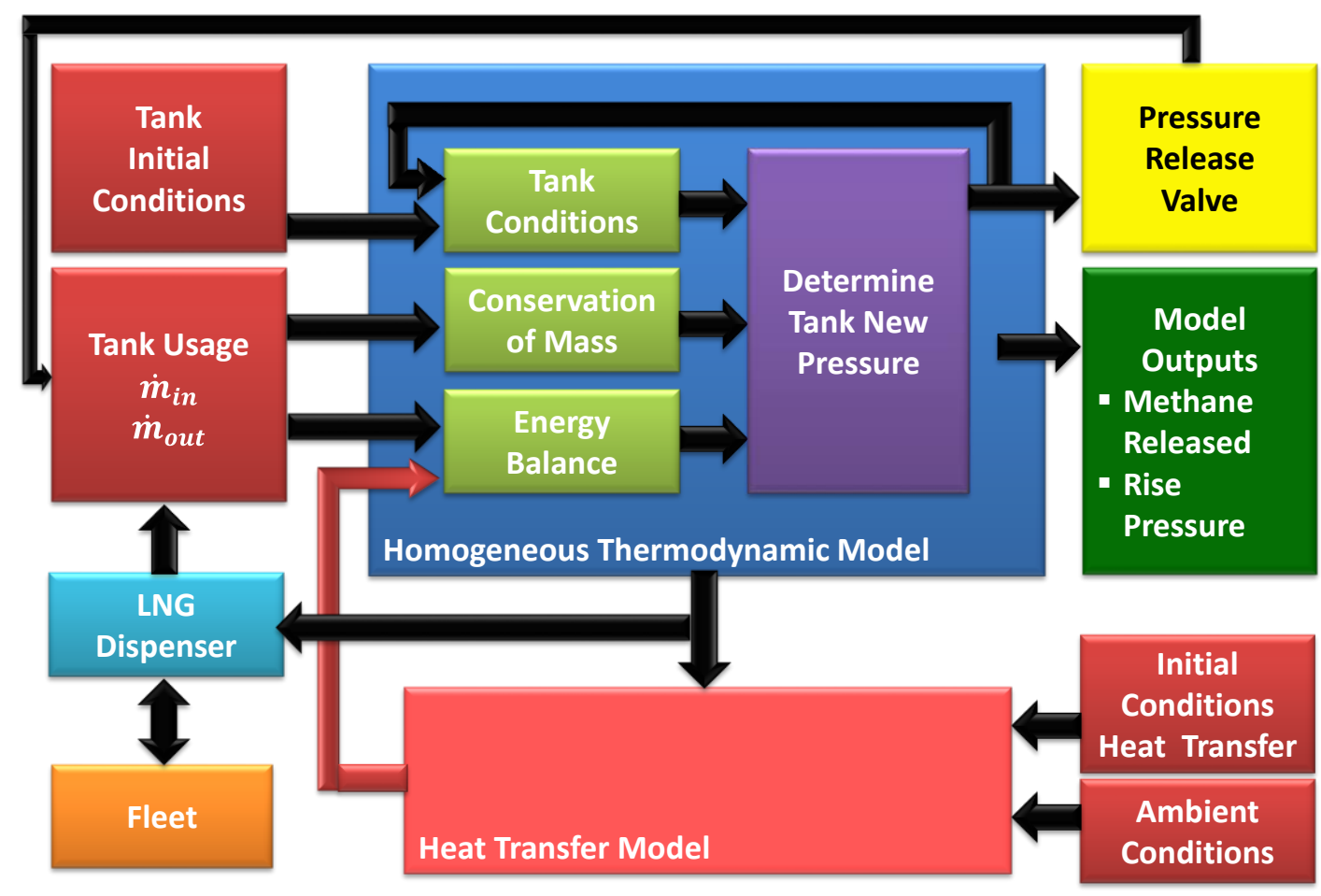

Figure 3.8. Block Diagram of the LNG Fueling Station Model using the Homogeneous Thermodynamic Model.

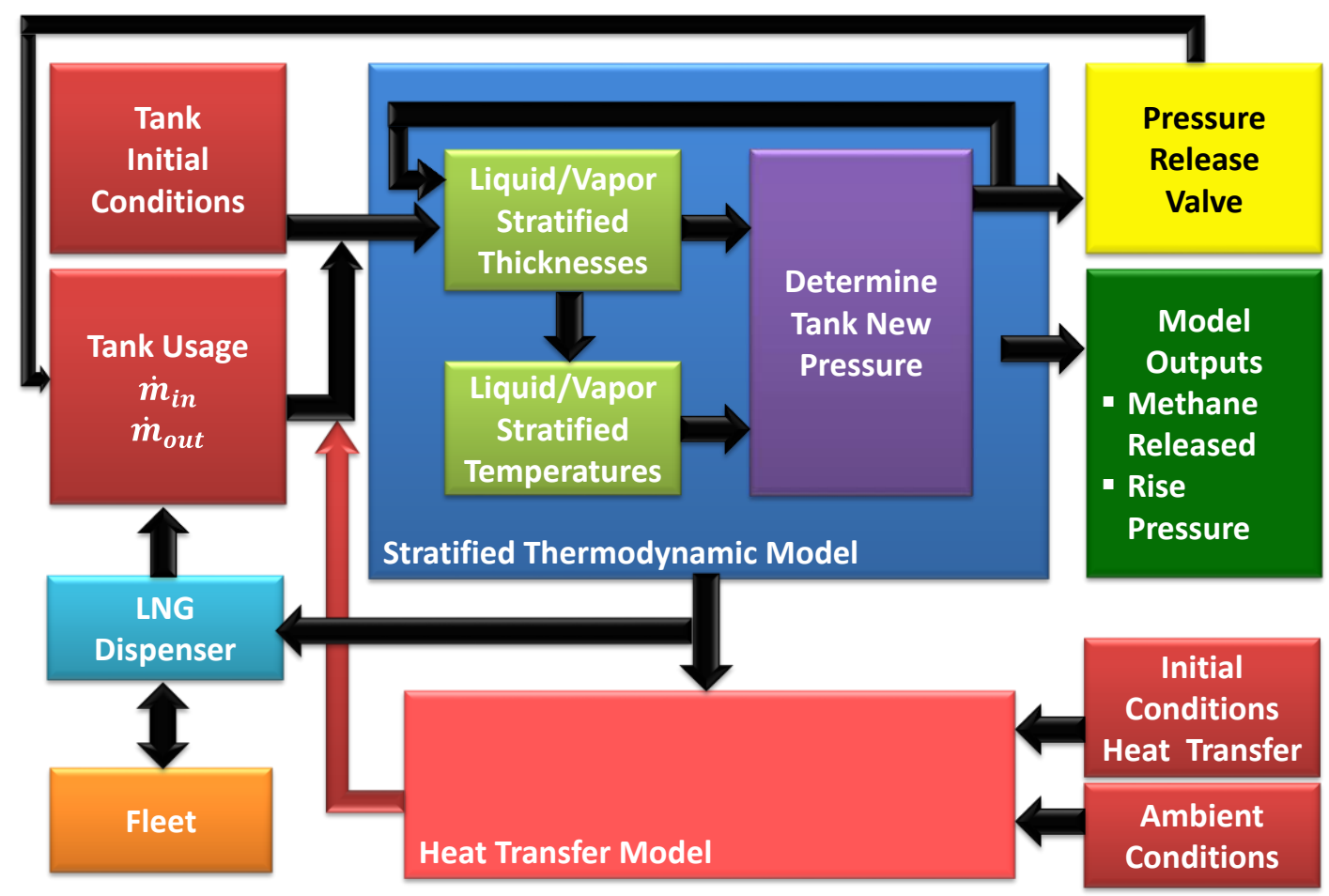

Figure 3.9. Block Diagram of the LNG Fueling Station Model using the Stratified Thermodynamic Model. 
In addition, there was the Fleet and the LNG Dispenser blocks (Section 3.6) which interacted with each other providing mass rate $(\dot{m})$ information from the vehicles tanks to the Tank Usage block and used the overall information from the Thermodynamics Model module. Further, the Fleet block had the capability to provide to the overall LNG fueling station model the arrival of vehicles between randomized user specified bounds.

Finally, the Model Outputs block included calculations of the total methane released or vented from the LNG fueling station tank and the evolution of its pressure.

\subsection{Model Implementation in MATLAB/Simulink}

The model was implemented in Simulink with the help of some scripts in MATLAB and follows the same logical structure shown in the block diagram of Figure 3.8 and Figure 3.9, for the homogeneous and stratified approaches respectively. The full LNG Fueling Station model in Simulink is shown in Figure 3.10 where the Homogeneous Thermodynamic Model is being used. The blocks for the Heat Transfer Model, Pressure Release Valve, LNG Dispenser, Vehicle Fleet Consumption, and Initial Conditions for each main module including the Ambient Conditions and Tank Dimensions can be seen in Figure 3.10 .

Variables inside the initialization blocks are directly imported from information typed into a MATLAB initialization script file. Details about the simulation variables used are described in Chapter 4. Additionally, the model used blocks for visualization and saving of the simulation data. 


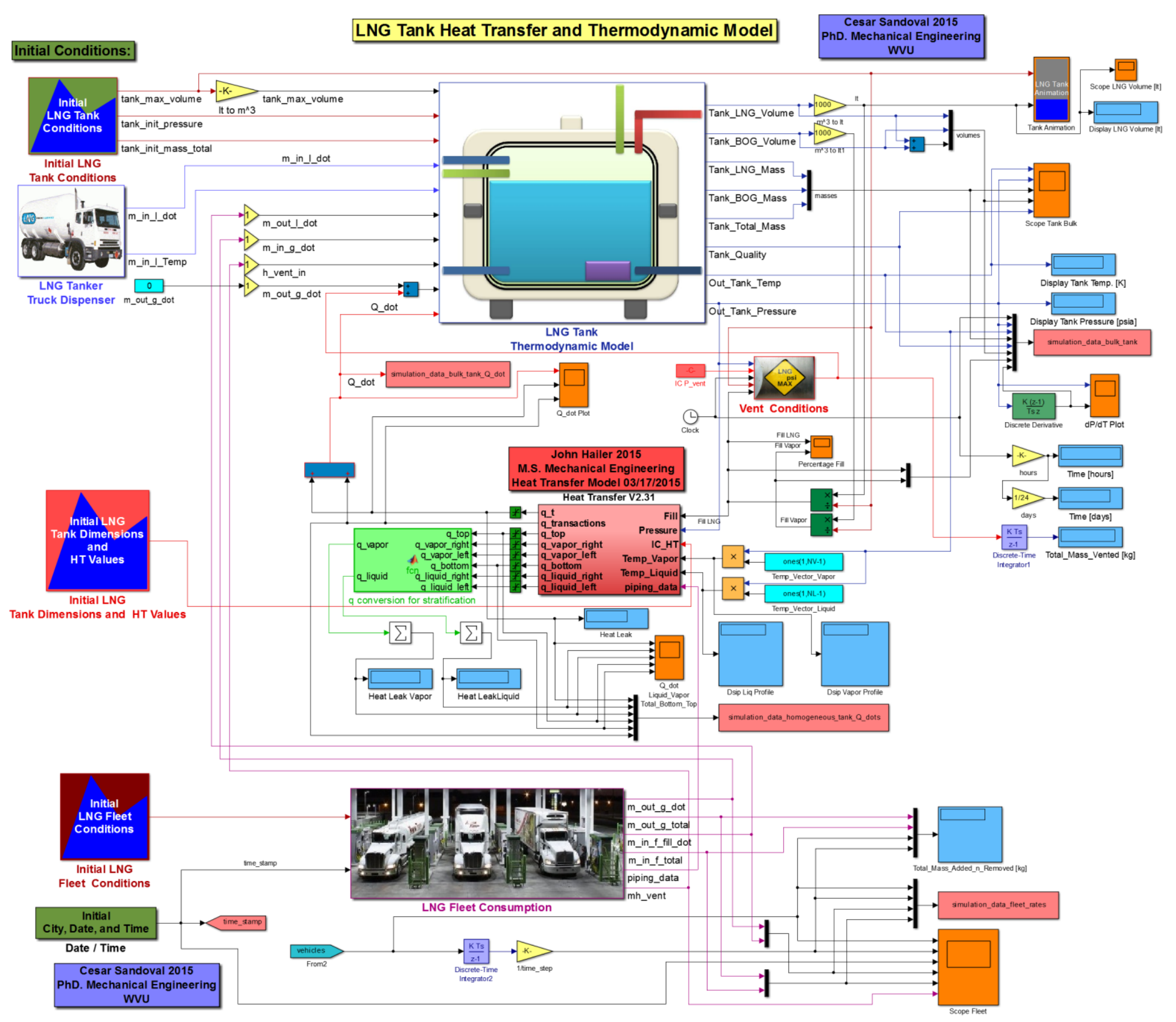

Figure 3.10. Simulink Implementation of the LNG Fueling Station Model using the Homogeneous Thermodynamic Model. 


\section{- CHAPTER 4 -}

\section{DATA ACQUiSition, RESUlts, AND DiscusSION}

This chapter describes the experimental setup used to acquire the data from the LNG tanks and shows the results of the LNG fueling stations model. The modeling components were validated with respect to experimental data acquired by the Center for Alternative Fuels, Engines, and Emissions (CAFEE) team of WVU with LNG vehicle tanks with internal fuel pump and without internal fuel pump and at LNG fueling stations in the United States. An uncertainty and sensitivity analysis of the model was performed based on the sensitivity of the more influential parameters in the LNG fueling station model.

\subsection{Experimental Setups}

\subsubsection{LNG Vehicle Tanks}

The CAFEE team at WVU setup a LNG Vehicle Tank experiment in their Westover, WV laboratory. The experiment consisted of continuous data collection of a LNG vehicle tank for hold time monitoring, where the data acquired was used to validate parts of the model developed. Two identical continuous data collection systems were implemented at WVU's laboratory. Figure 4.1 shows a LNG tank without internal fuel pump attached to one of the systems and Figure 4.2 shows the LNG tank with internal fuel

pump used in the second system. Parameters monitored were recorded at $1 \mathrm{~Hz}$ and are shown in Table 4.1.

Table 4.1. Parameters Monitored in the Experiments

\begin{tabular}{l}
\hline Time \\
Tank surface temperature (top) \\
Tank solar loading (top) \\
Tank surface temperature (bottom) \\
Tank solar loading (bottom) \\
Tank pressure \\
Tank weight \\
Ambient temperature \\
\hline
\end{tabular}




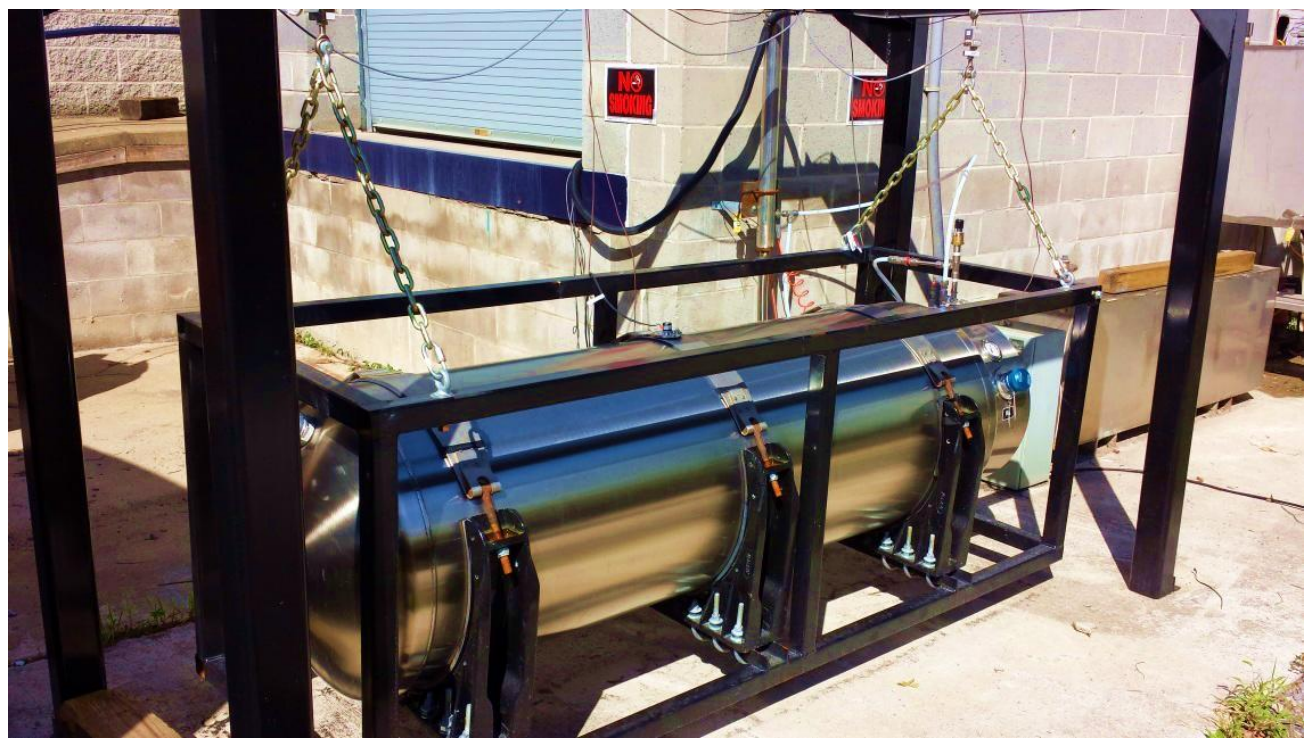

Figure 4.1. Lateral View of Filled LNG Vehicle Tank without Internal Fuel Pump after Attachment to the Data Acquisition System.

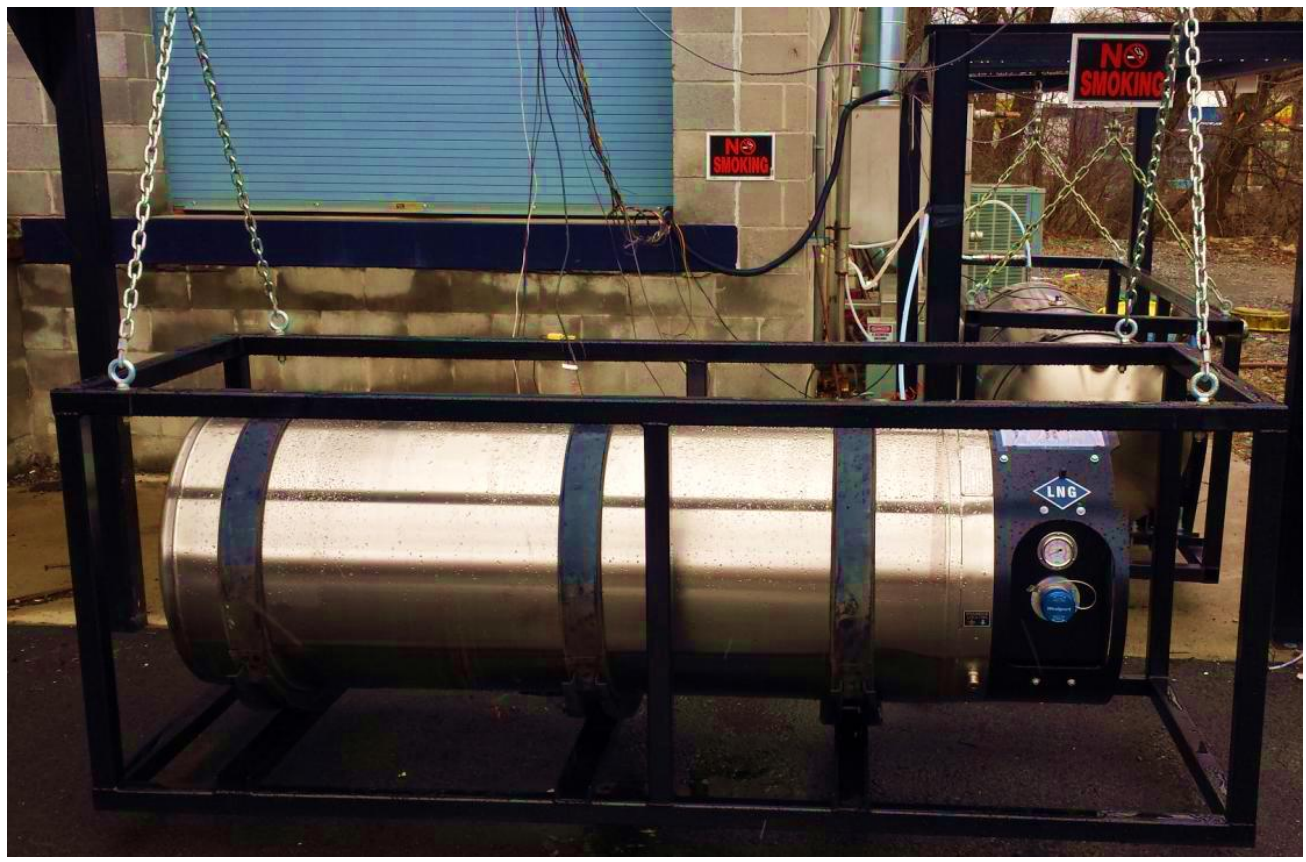

Figure 4.2. Front View of Filled LNG Vehicle Tank with Internal Fuel Pump after Attachment to the Data Acquisition System. 
The tank pressure was measured with a pressure transducer (Omega) of 0-500 psia range with accuracy of $+/-0.25 \%$ full scale output (FSO), which yields an accuracy of $+/$ 1.25 psia. The tank weight was measured with two S-Beam load cells of $1500 \mathrm{lb}$ weight range with an accuracy of $+/-0.03 \% \mathrm{FSO}$, where the corresponding uncertainty of both sensors and differencing was $+/-0.90 \mathrm{lb}(0.41 \mathrm{~kg})$. Temperatures were measured with $\mathrm{K}-$ Type thermocouples with uncertainty of $+/-4.0^{\circ} \mathrm{F}\left(+/-2.2^{\circ} \mathrm{C}\right)$ or an error of $0.75 \%$ FSO. Solar loadings on the tanks were measured with two pyranometers (Campbell Scientific LI-200X) which monitored sun and sky radiation intensity up to $3000 \mathrm{~W} / \mathrm{m}^{2}$ with an uncertainty of $+/-90 \mathrm{~W} / \mathrm{m}^{2}$ or $+/-3 \%$ FSO.

A total of 14 experiments using LNG vehicle tanks took place during the period of September 2013 to April 2014, nine with a 150 gallon tank without an internal fuel pump and five with a 120 gallon tank with an internal fuel pump. The tanks were initially filled at a LNG fueling station up to the $90 \%$ level with LNG leaving a $10 \%$ ullage, then were transported to the WVU laboratory and monitored until the pressure rise activated the tank pressure release valve. When this first experiment was done the LNG tank was manually vented until the content reached a lower fill level of LNG, starting a new hold time experiment. This process was repeated for different fill levels and hold times experiments until reaching a $10 \%$ level of LNG. Additionally, three experiments with the 150 gallon tank without an internal fuel pump were performed with the tank oscillating (Experiments 5,6 , and 7), in order to examine the effects of thermal stratification inside the tanks. Tanks dimensions and insulation properties used are addressed in Section 4.3.

\subsection{2. $\quad$ LNG Tank Venting}

At the end of the previous hold times experiments the LNG vehicle tank was manually vented from the PRV setpoint down, eventually, to atmospheric pressure. During venting the same experimental setup was used acquiring continuously pressure and tank weight. Most of the manual ventings included multiple venting segments, in each segment the tank pressure was incrementally dropped and then the tank was allowed to "rest" before continuing to drop the pressure. A total of 13 venting sets were performed with the LNG vehicle tanks, eight for the 150 gallon tank without an internal fuel pump and five with the 
120 gallon tank with an internal fuel pump, for a total of 31 venting segments; twenty one and ten, respectively for each tank. Note that one of the previous 14 hold time experiments was not included in the venting sets, since the venting was not performed and instead a new hold time experiment was immediately started after a power outage of the acquisition system. Additionally, five extra data points were provided from the LNG tank manufactures, four of which performed similar venting experiments with a 105 gallon LNG vehicle tank without an internal fuel pump and one estimated the venting assuming the use of one of their 120 gallon tank with an internal fuel pump [78]. Mass vented was calculated as the subtraction of the initial and final experimental weight of the tank, making the uncertainty of mass vented equal to $+/-1.80 \mathrm{lb}(+/-0.82 \mathrm{~kg})$.

\subsubsection{LNG Fueling Stations}

Two LNG fueling stations located in the United States were visited during three week observation periods in 2014 gathering tank pressure data, records of fuel dispensing, and tanker refueling deliveries. This data was used for comparison with the full LNG fueling station model.

The first station was located in the state of Nevada and the 25,000 gallon tank was observed during a period of 21 days between March and April. Data were collected at a frequency of $0.5 \mathrm{~Hz}$ and the uncertainty of the station pressure transducer was determined to be $+/-1.885$ psi. The 21-day data set was subdivided each time the station was refueled providing a total of six periods between 32 and 98 hours in length. This station did not employ a venting mitigation strategy. Additionally, the owner/operators of the first station provided the WVU modeling team with station schematics and a breakdown of the

plumbing used at this station. This information included pipe lengths, diameters, and insulation types as vacuum jacketed, foam insulated, and bare metal.

The second station was located in the state of Utah with a 15,000 gallon tank which was observed during the month of June for a period of 21 days. This station employed a natural gas fired turbine for electricity generation to consume excess LNG boil off gas. Additionally, this station used a lower pressure limit of the bulk storage tank and periodically manually vented the station when venting mitigation control was not working 
properly. During the three weeks at Station Two a series of issues occurred with the electrical generator. The 21-day data set was subdivided each time the station was refueled and each time that a manual venting was observed getting a total of eight periods between 19 and 96 hours in length. Three tanker offloads were received while at this station. Only one period of the data collection was acquired for comparison with the model where the generator was off all the time and this period reached 50 hours in duration. It is noted then that this facility operated differently than the first station. For the second station, limited information was provided and plumbing lengths and characteristics were assumed to be similar to the first station and estimated by visual inspection. As well, pressure transducer uncertainty was unknown and uncertainty from Station One was utilized instead. Furthermore, both stations used cool down recirculation for their pipes. Station One kept a constant recirculation in order to supply LNG to any vehicle arriving with a minimum waiting time. Station Two used recirculation only before fueling a vehicle increasing the waiting time of a vehicle before starting to refuel.

The maximum electrical generator fuel consumption rate at the second station was assumed based on turbine specification as $8.70 \mathrm{~kg} / \mathrm{h}$, since this showed a net full load power of $30 \mathrm{~kW}$ and efficiency of $27 \%$. Actual turbine operating demand and fuel consumption which are required to better understand its role in vapor withdraw and station tank performance were not known. However, after observing the pressure profile of the second station a constant load power of $100 \%, 50 \%$, and $25 \%$ were assumed and distributed around the seven segments when the generator was partially on use, assuming respectively a linear vapor consumption of $8.70,4.35$, and $2.18 \mathrm{~kg} / \mathrm{h}$. Nevertheless, vapor consumption is not necessarily linear with respect to power load.

Weather conditions, ambient temperature and solar loading on the tank were not measured at the two LNG fueling stations, however, hourly data from the closest National Oceanic and Atmospheric Administration (NOAA) weather stations were used. NOAA reports the uncertainty of their climate stations for ambient temperature as $+/-1{ }^{\circ} \mathrm{F}(+/-0.56$ $\left.{ }^{\circ} \mathrm{C}\right)$ with a $95 \%$ confidence in the range of -20 to $+115^{\circ} \mathrm{F}\left(-29\right.$ to $\left.+46{ }^{\circ} \mathrm{C}\right)[79]$. Nevertheless, Watts et al. $[80,81]$ found that $89 \%$ of the stations fail to meet the National Weather Service's own siting requirement that stations must be 30 meters (about 100 feet) or more away from an artificial heating or radiating/reflecting heat source. This means that the 
stations produce unreliable data by NOAA's own definition where $64.4 \%$ of the stations reported an error greater than $3.6^{\circ} \mathrm{F}\left(2^{\circ} \mathrm{C}\right)$ and $6.2 \%$ an error of more than $9{ }^{\circ} \mathrm{F}\left(5^{\circ} \mathrm{C}\right)[80$, 81]. Based on Watts et al. findings, distance of the weather station, the heat-absorbing surfaces such as asphalt and concrete, and the artificial heating sources as vehicles and electrical generators an uncertainty of $+/-9^{\circ} \mathrm{F}\left(+/-5^{\circ} \mathrm{C}\right)$ was used.

Both fueling stations recorded storage tank pressure electronically, however, only Station One automatically recorded LNG level and fuel dispensing information. Therefore, data from vehicle refueling events were manually logged in parallel for both station. LNG level at the bulk tank of Station Two was only manually observed from the gauge at the beginning and end of the three fueling offloads and at four of the manual ventings.

For Station One a total of 768 fuel transactions for a total of 685 vehicles occurred and were provided. It was noted that on some occasions multiple vehicles used separate transactions to complete the vehicle refueling. WVU personnel observed $67 \%$ (458) of those refueling vehicles and were able to obtain complete data sets on $53.3 \%$ (365) vehicle refueling events. The remaining 46.7\% (320) vehicle refueling events were approximated using averages of the actual transactions observed. The key parameters collected from each refueling event were vehicle tank level and pressure upon arrival, and vehicle tank pressure after fueling. The station was not capable of delivering fuel to vehicles with tank pressures exceeding $150 \mathrm{psig}$. The stations were equipped such that vehicle tanks could be vented back to the station to reduce pressure and allow refueling. In a similar way, a total of 427 transactions for a total of 221 vehicles refueling events were observed at Station Two. Some of the vehicle refueling events at Station Two were not observed and were not accounted, which affected the LNG station model simulations. A summary of the vehicle refueling events observed at both stations is provided in Table 4.14.

The full station model was compared against fourteen time periods from two LNG fueling stations. As it will be noted in Section 4.5, performance of the model presented closer results with Station One than with Station Two, which is expected due the lack of precise information about the second station. Additionally, at Station Two when the station was modeled during the period with generator off the maximum error was smaller than during the periods when the generator was operating. 


\subsection{Hypothetical Hold Time Simulation using the Two Thermodynamic Approaches with a Fueling Station Bulk Tank}

A fueling station bulk storage tank was simulated in order to compare the results with the typical value of at least 30 days for hold time in fueling stations tanks. The two thermodynamic approaches developed were used and results are shown in detail for this example. A comparison between the results of both approaches is shown in Section 4.2.3. A hypothetical vertical bulk tank of 15,600 gal (59,044 1) capacity was selected assuming an $80 \%$ LNG fill level (20\% ullage). The initial pressure was assumed at 90 psig (104.7 psia) and the typical maximum release pressure for station tanks was used at 160 psig (174.7 psia). Ambient pressure at the location selected (elevation of 0 meter ( $0 \mathrm{ft}$.) above sea level) was assumed as $14.7 \mathrm{psi}$ and all pressure results are shown in psia units. The total mass of LNG in the tank was calculated using the previous assumed conditions for a total of $17,800 \mathrm{~kg}$, where saturated conditions were initially assumed. A summary of the parameters selected is shown in Table 4.2, and the tank dimensions and heat transfer parameters assumed are shown in Table 4.3. Parameters were selected based on manufacturer literature, materials property tables, and assumptions for cryogenic tanks by Chen et al. [14]. Additionally, per the confidentially agreement with the LNG tank manufactures that provided information for this work, all values reported that are not in public documentation were randomly adjusted between $\pm 5 \%$ and $\pm 20 \%$.

Table 4.2. Initial LNG Bulk Tank Conditions for Simulations

\begin{tabular}{|c|c|c|c|}
\hline Variable Name & Value & Units & Reference \\
\hline Tank Volume Capacity & 59,044 & I & $\begin{array}{l}\text { Manufacture } \\
\text { Literature }\end{array}$ \\
\hline Relief Valve Pressure & 174.7 & psia & $\begin{array}{l}\text { Manufacture } \\
\text { Literature }\end{array}$ \\
\hline Initial Tank Pressure & 104.7 & psia & Assumed Value \\
\hline Initial Total Tank Mass & 17,800 & $\mathrm{~kg}$ & Assumed Value \\
\hline
\end{tabular}


Weather data was obtained for New York City from NOAA for the full year of 2010, since elevation above sea level is around 0 meter ( $0 \mathrm{ft}$.) and ambient pressure is around 14.7 psi. The simulation ran from September until October until the bulk tank reached the maximum pressure allowed, confirming the hold time of over 30 days. The homogeneous approach reached venting after 723 hours (30.13 days) and the stratified approach after a total of 773 hours (32.21 days). Detailed results from both approaches and comparison between them are described in the following sections.

Table 4.3. LNG Bulk Tank Dimensions and Heat Transfer Values Used in the Simulations

\begin{tabular}{|c|c|c|c|}
\hline Variable Name & Value & Units & Reference \\
\hline Outside Diameter & 2.8956 & $\mathrm{~m}$ & $\begin{array}{c}\text { Manufacturer } \\
\text { Literature }\end{array}$ \\
\hline Insulation Thickness & 0.0792 & $\mathrm{~m}$ & $\begin{array}{c}\text { Assumption based } \\
\text { on Chen et al. }\end{array}$ \\
\hline External Shell Layer Thickness & 0.0032 & $\mathrm{~m}$ & $\begin{array}{c}\text { Assumption based } \\
\text { on Chen et al. }\end{array}$ \\
\hline Internal Shell Layer Thickness & 0.0222 & $\mathrm{~m}$ & $\begin{array}{c}\text { Assumption based } \\
\text { on Chen et al. }\end{array}$ \\
\hline Length/Height of Tank & 13.3350 & $\mathrm{~m}$ & $\begin{array}{c}\text { Manufacturer } \\
\text { Literature }\end{array}$ \\
\hline Top Area Ratio & $8.65 e-5$ & $(-)$ & $\begin{array}{c}\text { Assumption based } \\
\text { on Chen et al. }\end{array}$ \\
\hline Cylindrical Area Ratio & $8.65 e-5$ & $(-)$ & $\begin{array}{c}\text { Assumption based } \\
\text { on Chen et al. }\end{array}$ \\
\hline Bottom Area Ratio & $8.65 e-5$ & $(-)$ & $\begin{array}{c}\text { Assumption based } \\
\text { on Chen et al. }\end{array}$ \\
\hline Insulation Conductivity (MLI) & $5.00 e-5$ & $\mathrm{~W} /\left(\mathrm{m}^{*} \mathrm{~K}\right)$ & $\begin{array}{c}\text { Manufacturer } \\
\text { Literature }\end{array}$ \\
\hline Surface Absorptivity (White Paint) & 0.14 & $(-)$ & $\begin{array}{c}\text { Material Property } \\
\text { Tables }\end{array}$ \\
\hline
\end{tabular}

The bulk tank was assumed to be covered by white paint with absorptivity of 0.14 . Wall thickness was distributed as shown in Figure 4.3. Multilayer insulation (MLI) was assumed in the vacuum area with a thermal conductivity of $5 \cdot 10^{-5} \mathrm{~W} /(\mathrm{m} \cdot \mathrm{K})$. Internal and external layers, as well struts were assumed to be made of stainless steel which thermal conductivity is six orders of magnitude larger than MLI. Thermal conductivity at the 
internal and external shells were recalculated every time step using the current ambient and internal wall temperatures, respectively. Thermal conductivity through the struts were calculated as the mean thermal conductivity between the ambient and internal wall temperatures. Struts were assumed supporting the inner tank from the top, bottom, and sides (cylindrical region) defining the respective area ratios as the ratio between strut material to area of the tank. The area ratio was defined as the cross-sectional area of support material divided by the external surface area of the tank designed to statically support the vessel and LNG product in it. Since the location and distribution of the struts were unknown a representative area ratio was assumed for all the sections of the tank. These are all the parameters necessary for the Heat Transfer Model provided and are shown in Table 4.3.

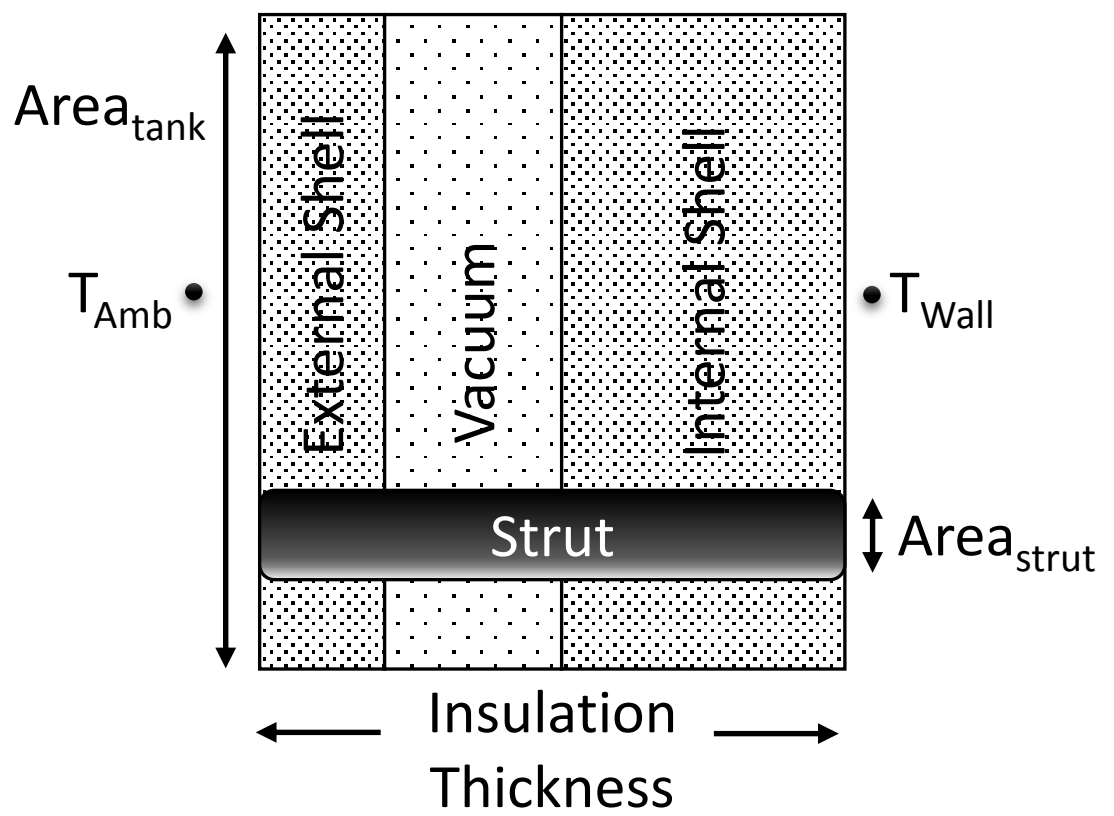

Figure 4.3. Tank Wall Insulation Layers used with the Heat Transfer Model.

The heat transfer model calculated independently the heat leaks thought the top and bottom of the tanks, and the heat leaks affecting the vapor and liquid regions. Heat leaks through the vapor and liquid regions were calculated using the temperature profiles which divided the regions in $\mathrm{N}_{V}$ and $\mathrm{N}_{\mathrm{L}}$ layers respectively. The homogeneous approach used the total heat transfer into the thermodynamic model as the sum of all the heat leaks estimated. The stratification approach distributed the top heat leak in equitable leaks entering each vapor region layer. Similarly, bottom heat leak was distributed in the liquid region layers. During all of the simulations, the same amount of 400 layers were used for both regions. 


\subsubsection{Homogeneous Approach}

The following figures show the simulation results for a hold time of a hypothetical bulk tank using the thermodynamic model with the homogeneous approach. Initial fill level was calculated as $80.30 \%$. It was observed from Figure 4.4 that the simulation reached venting after 723 hours (30.13 days), with an average pressure rise of $2.32 \mathrm{psia} / \mathrm{day}$. The average heat transfer estimated was $25.3 \mathrm{MJ} / \mathrm{day}$, as shown in Figure 4.5. A summary of the results is shown in Table 4.4. Temperature plot in Figure 4.4 show that the saturation temperature inside the tank increased during time due to the heat entering the tank. This caused liquid mass to evaporate increasing the vapor quality, as shown in Figure 4.6. Nevertheless, the fill level increased since the cryogenic LNG liquid expanded when rising temperature. A fluctuation was observed at the start of the $\mathrm{dP} / \mathrm{dt}$ plot in Figure 4.4, this was due to the sensibility of the initial divisions by a small difference of time (dt). The heat transfer average plotted in Figure 4.5 corresponded to the cumulative average since the beginning of the simulation until the current time, in this way does not follow the middle of the current heat transfer simulated but instead corresponded to a total average. Additionally, Figure 4.7 shows temperature map during the simulation appreciating the constant temperature effect in the whole tank profiles. Eight maps are shown at $0 \%, 10 \%$, $25 \%, 50 \%, 70 \%, 80 \%, 90 \%$, and $100 \%$ of the progression of the simulation.

Table 4.4. Summary Results Bulk Tank with Homogeneous Approach

\begin{tabular}{l|rc}
\hline \multicolumn{1}{c|}{ Homogeneous Simulation } & \multicolumn{1}{c}{ Value } & Units \\
\hline Avg. Ambient Temperature & 291.86 & $\mathrm{~K}$ \\
Avg. Solar Loading & 360.02 & $\mathrm{~W} / \mathrm{m}^{2}$ \\
\hline Avg. HT Vapor Region & 6.0 & $\mathrm{MJ} / \mathrm{day}$ \\
Avg. HT Liquid Region & 19.3 & $\mathrm{MJ} / \mathrm{day}$ \\
Avg. Total Heat Transfer & 25.3 & $\mathrm{MJ} / \mathrm{day}$ \\
\hline Initial Mass (kg) & 17,800 & $\mathrm{~kg}$ \\
Initial Homogeneous Fill & 80.30 & $\%$ \\
\hline Initial Pressure & 104.70 & $\mathrm{psia}$ \\
Pressure Rise & 70.01 & $\mathrm{psia}$ \\
Time & 30.17 & days \\
$\mathrm{dP} / \mathrm{dt}$ & 2.32 & psia/day \\
\hline
\end{tabular}



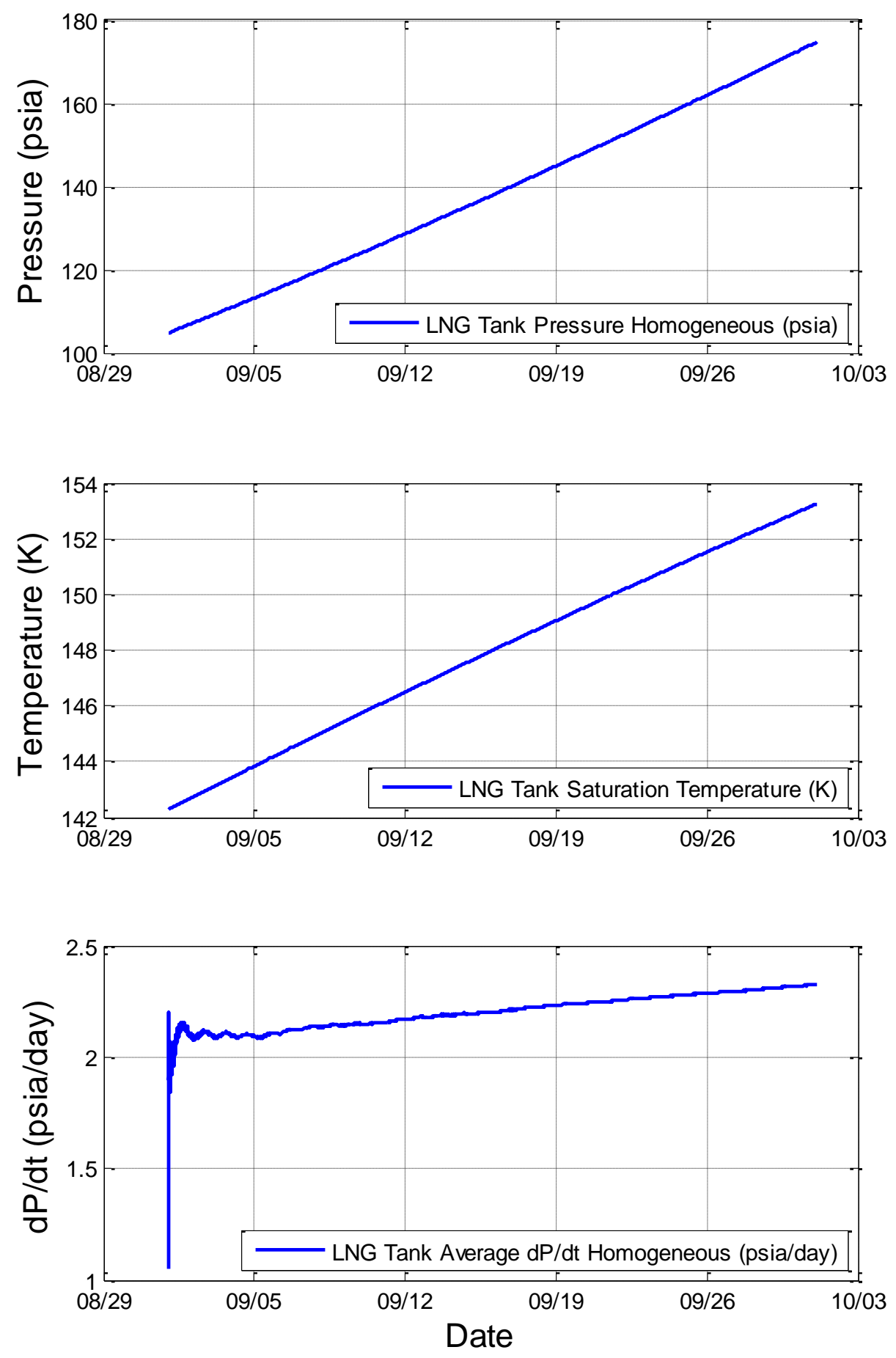

Figure 4.4. Simulated Pressure and Temperature for a Hold Time Simulation in a Fueling Station Tank using the Homogeneous Approach. 

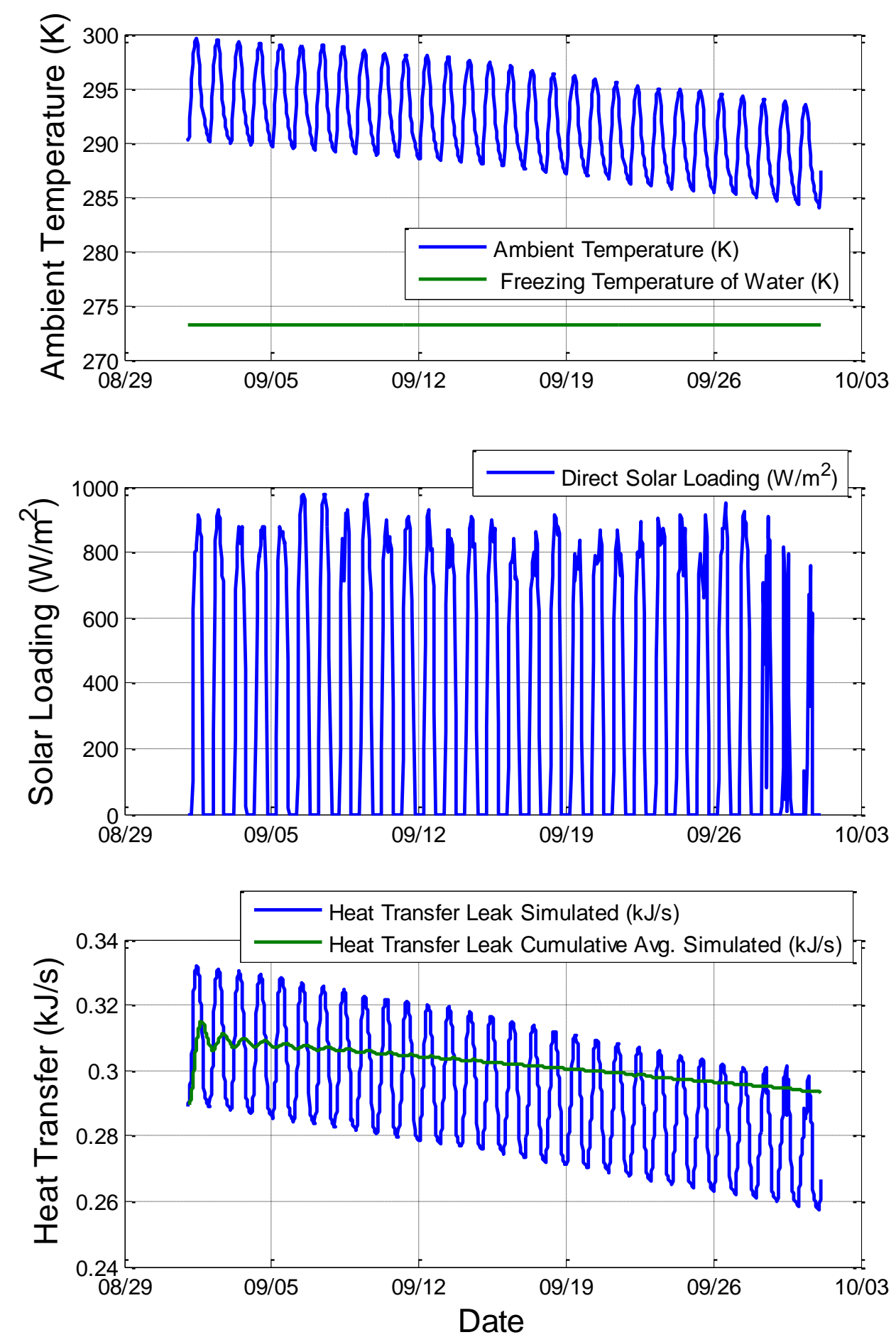

Figure 4.5. Heat Transfer Leak Simulated and Weather Data for a Hold Time Simulation in a Fueling Station Tank using the Homogeneous Approach. 

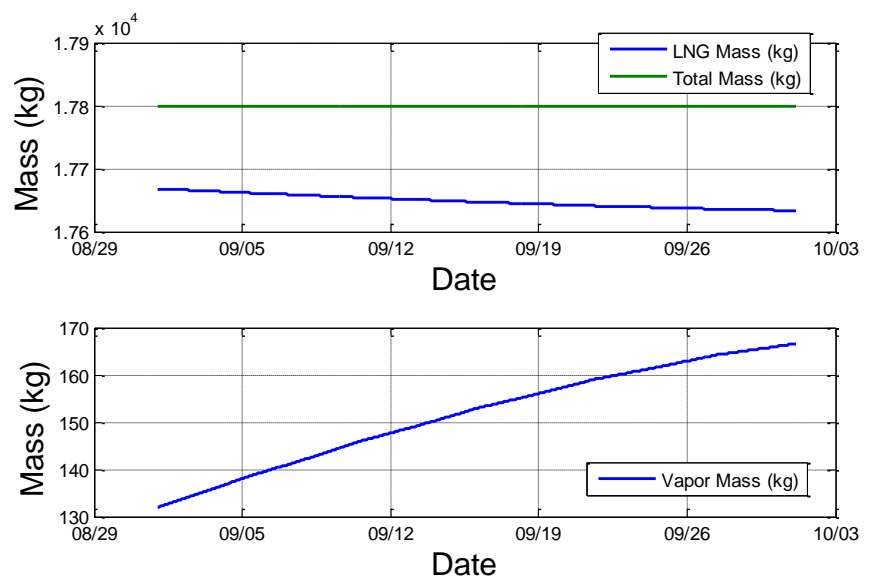

a. LNG and Vapor Masses
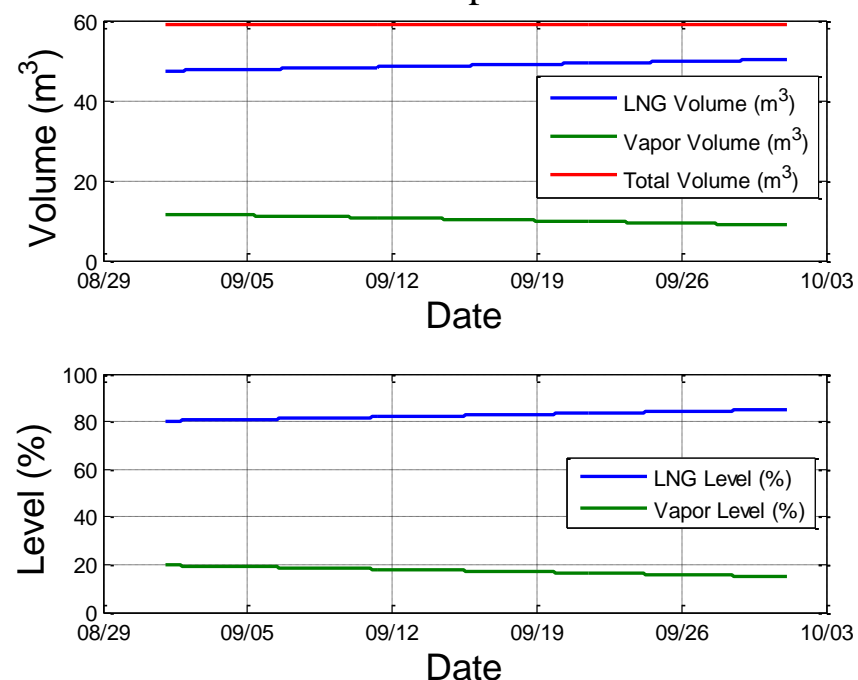

b. Volumes and Fill Level

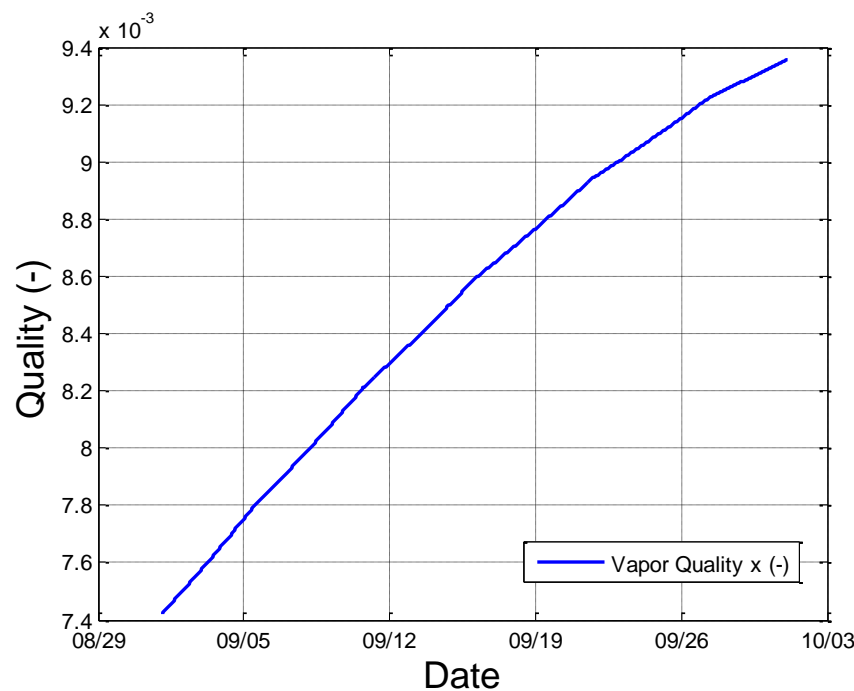

c. Vapor Quality

Figure 4.6. Simulation Variables for a Hold Time Simulation in a Fueling Station Tank using the Homogeneous Approach. 


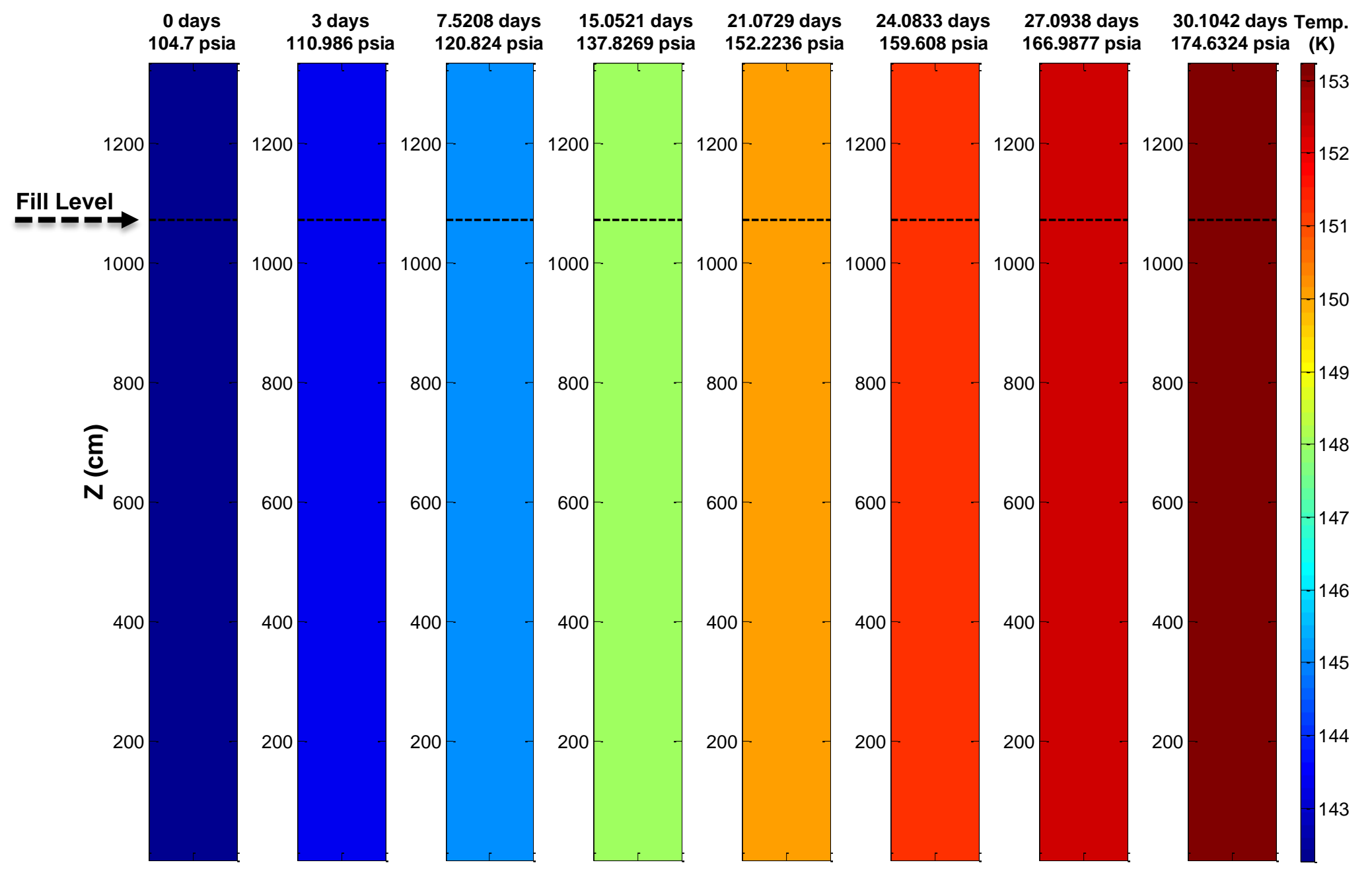

Figure 4.7. Temperature Map for a Hold Time Simulation in a Fueling Station Tank using the Homogeneous Approach. 


\subsection{2. $\quad$ Stratified Approach}

The previous hypothetical bulk tank was simulated under the same initial condition using the stratified approach in the thermodynamic model. Heat transfer was estimated for each of the 400 discretized layers in each of the two region, however, total heat transfer entering each region were reported. In this case, the simulation reached venting after 773 hours (32.21 days), with an average heat transfer into the whole tank estimated of 25.5 $\mathrm{MJ} /$ day, and average pressure rise of $2.17 \mathrm{psia} / \mathrm{day}$. An average heat transfer was calculated as $5.9 \mathrm{MJ} /$ day entering the vapor region and $19.6 \mathrm{MJ} /$ day entering the liquid region. Heat transfer estimated at the liquid region was 3.32 times bigger than at the vapor region when the fill level was $80.30 \%$, since the liquid region was 4.07 times larger than the vapor region. The stratification model applied the heat transfer into each discretized layer of the vapor region including the sum of the distributed heat transfer through the top surface. Similarly, heat transfer into the liquid region layers included the bottom heat leak. A summary of the results is shown in Table 4.5.

Table 4.5. Summary Results Bulk Tank with Stratified Approach

\begin{tabular}{l|rc}
\hline \multicolumn{1}{c|}{ Stratified Simulation } & \multicolumn{1}{c}{ Value } & Units \\
\hline Avg. Ambient Temperature & 291.86 & $\mathrm{~K}$ \\
Avg. Solar Loading & 360.02 & $\mathrm{~W} / \mathrm{m}^{2}$ \\
\hline Avg. HT Vapor Region & 5.9 & $\mathrm{MJ} / \mathrm{day}$ \\
Avg. HT Liquid Region & 19.6 & $\mathrm{MJ} / \mathrm{day}$ \\
Avg. Total Heat Transfer & 25.5 & $\mathrm{MJ} / \mathrm{day}$ \\
\hline Initial Mass (kg) & 17,800 & $\mathrm{~kg}$ \\
Initial Homogeneous Fill & 80.30 & $\%$ \\
\hline Initial Pressure & 104.70 & $\mathrm{psia}$ \\
Pressure Rise & 70.04 & $\mathrm{psia}$ \\
Time & 32.21 & $\mathrm{days}$ \\
$\mathrm{dP} / \mathrm{dt}$ & 2.17 & $\mathrm{psia} / \mathrm{day}$ \\
\hline
\end{tabular}

The following figures show the results using the stratified approach. Heat transfers estimated through the different sections of the tank are shown. It is noted that heat transfer values decreased over time since the difference of temperature between the inside tank wall and ambient temperature was reduced. Figure 4.11 shows the total heat transfer used in the vapor and liquid regions, and Figure 4.12 shows the heat transfer estimated through each 
side of the tank. Additionally, Figure 4.13 shows the temperature map during the simulation appreciating the temperature profile inside the tank where the vapor region had super heated vapor and liquid region had subcooled liquid. Eight maps are shown at $0 \%$, $10 \%, 25 \%, 50 \%, 70 \%, 80 \%, 90 \%$, and $100 \%$ of the progression of the simulation.
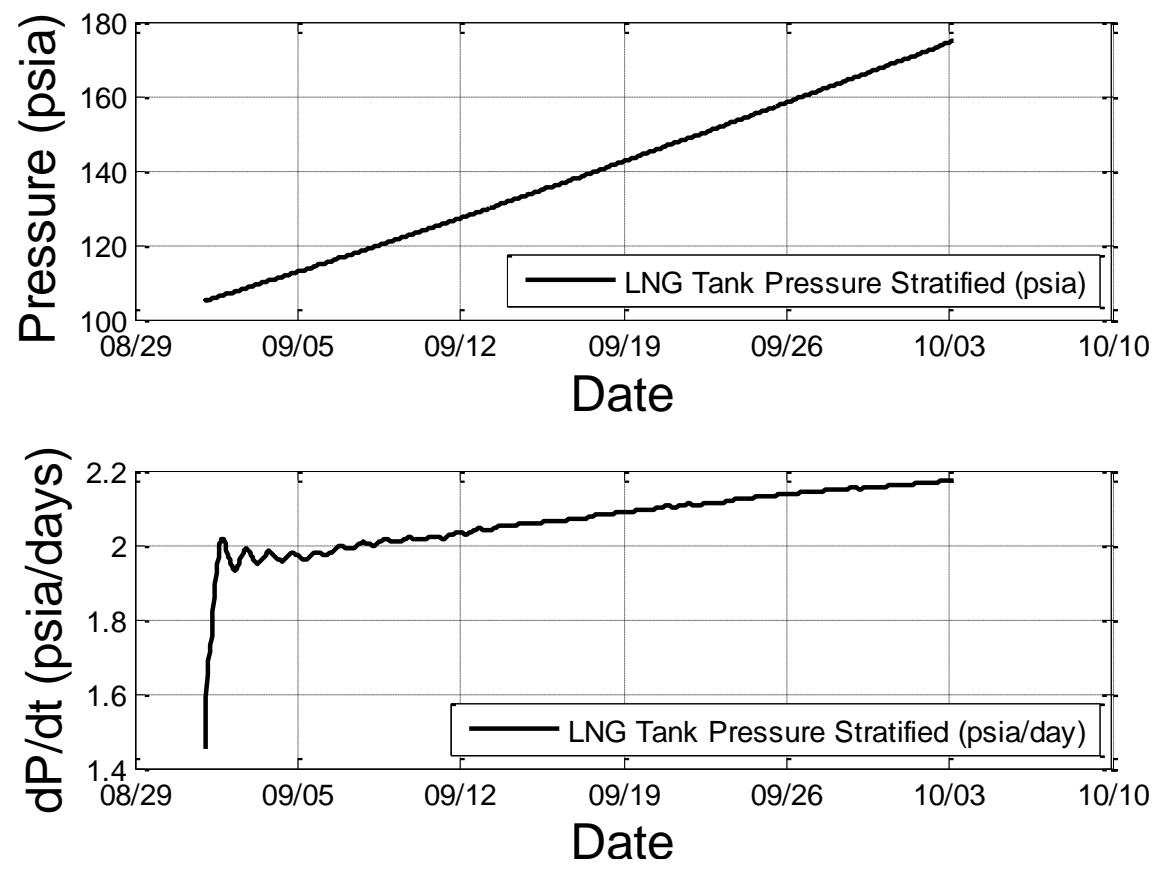

Figure 4.8. Simulated Pressure and dP/dt for a Hold Time Simulation in a Fueling Station Tank using the Stratified Approach.
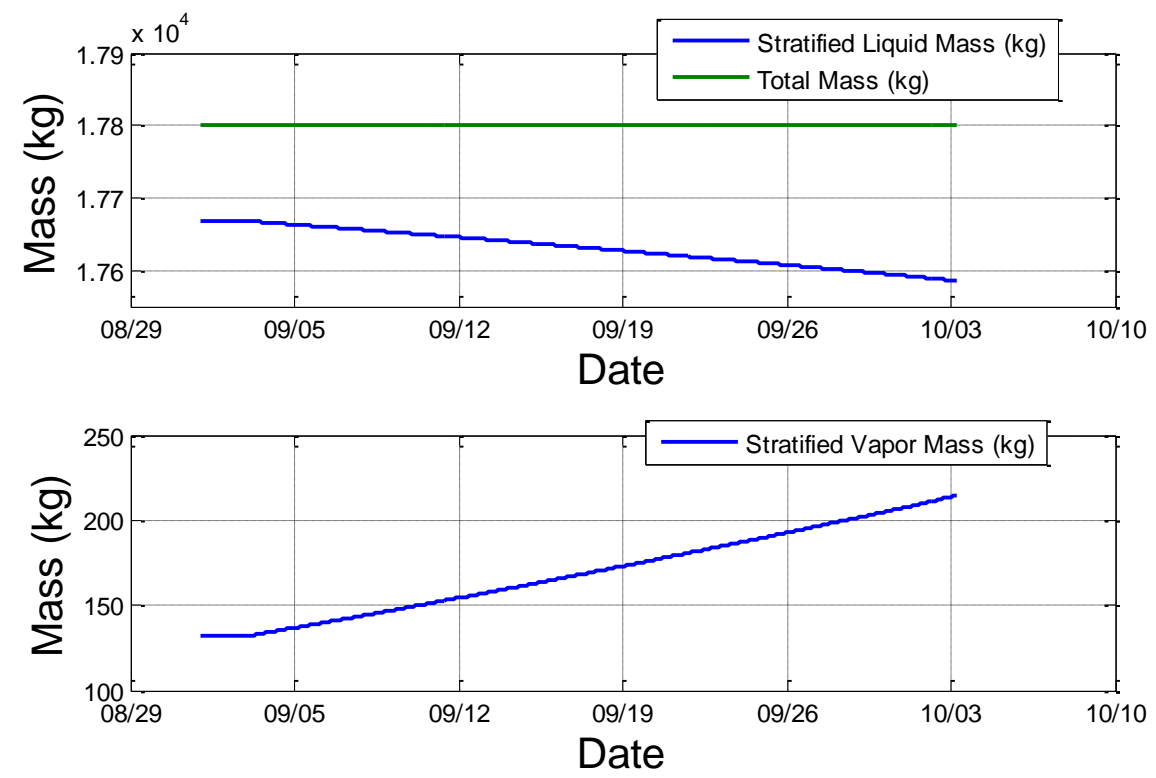

Figure 4.9. $\mathrm{LNG}$ and Vapor Masses for a Hold Time Simulation in a Fueling Station Tank using the Stratified Approach. 

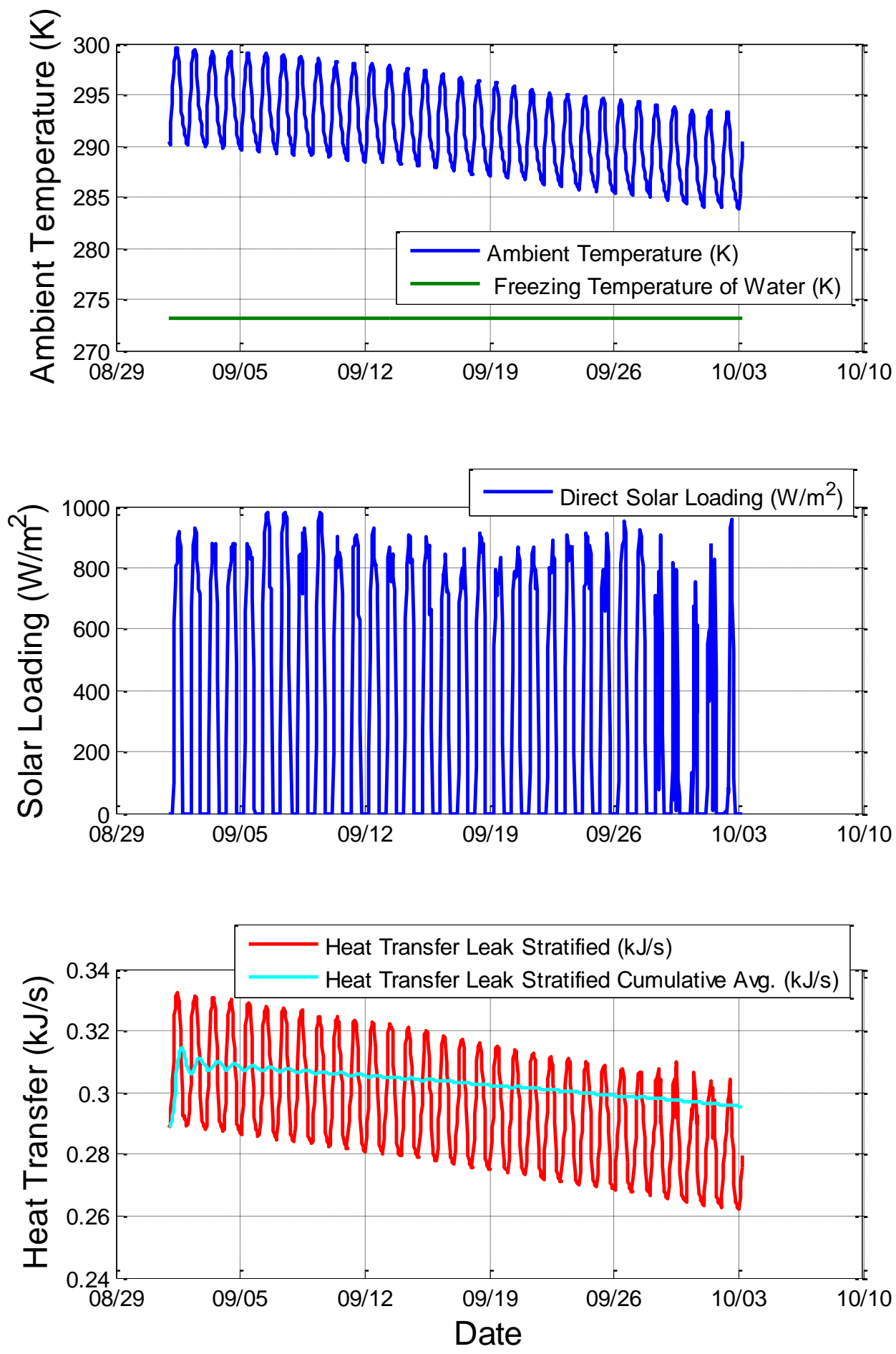

Figure 4.10. Total Heat Transfer Leak Simulated and Weather Data for a Hold Time Simulation in a Fueling Station Tank using the Stratified Approach. 

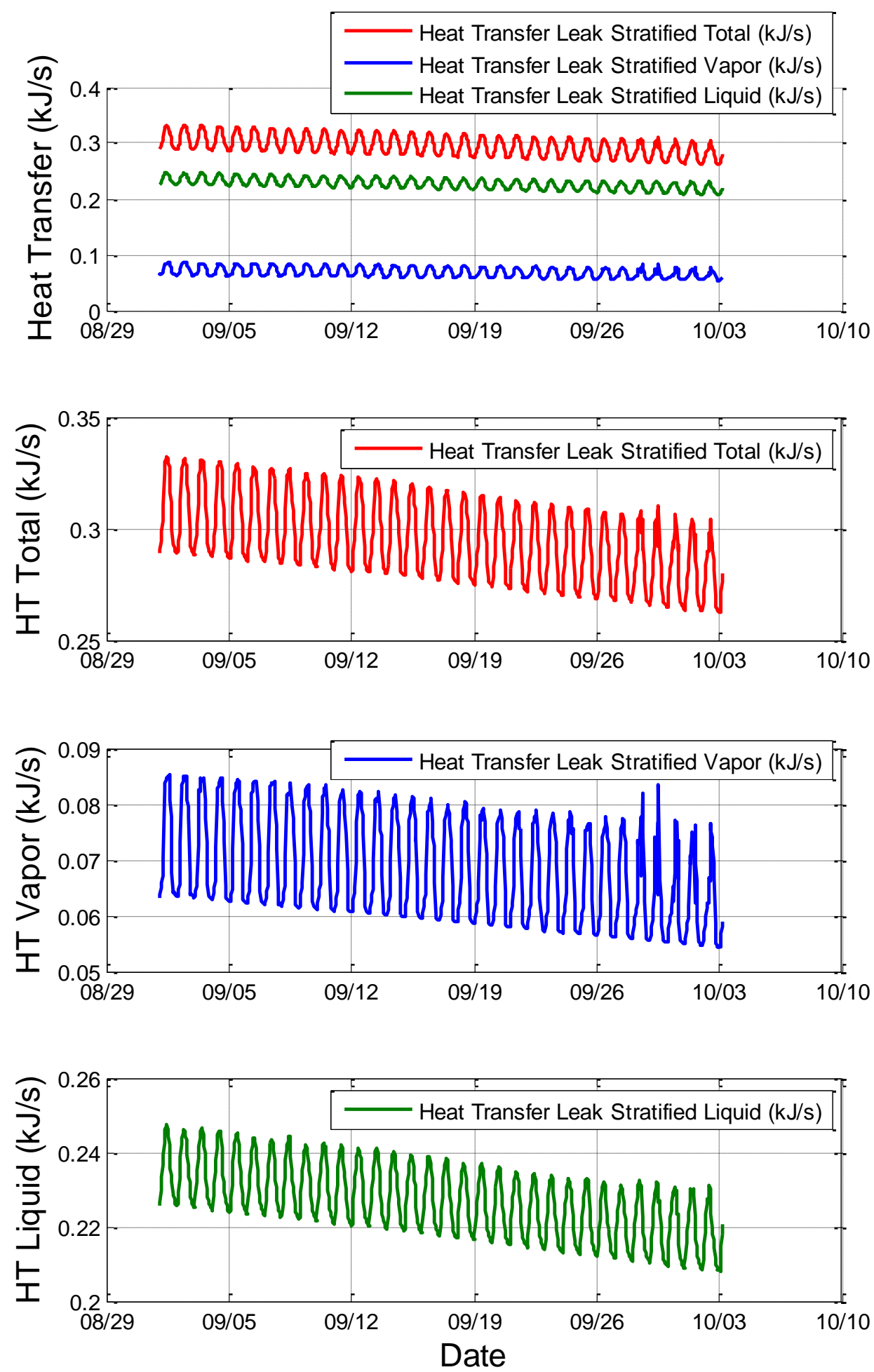

Figure 4.11. Total Heat Transfer Leak Used for the Vapor and Liquid Regions for a Hold Time Simulation in a Fueling Station Tank using the Stratified Approach. 

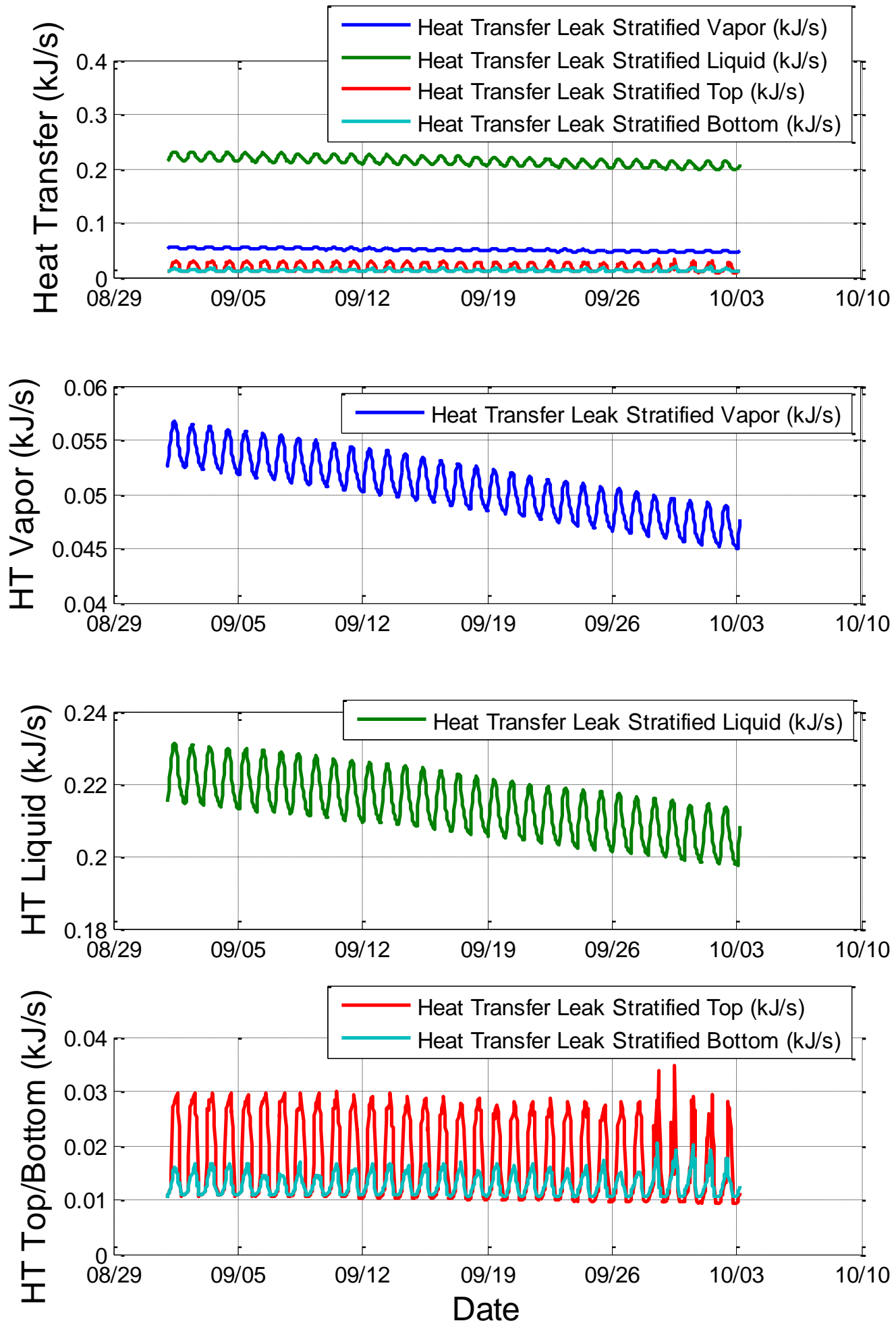

Figure 4.12. Heat Transfer Leak Distribution Through each Section of the Tank for a Hold Time Simulation using the Stratified Approach. 


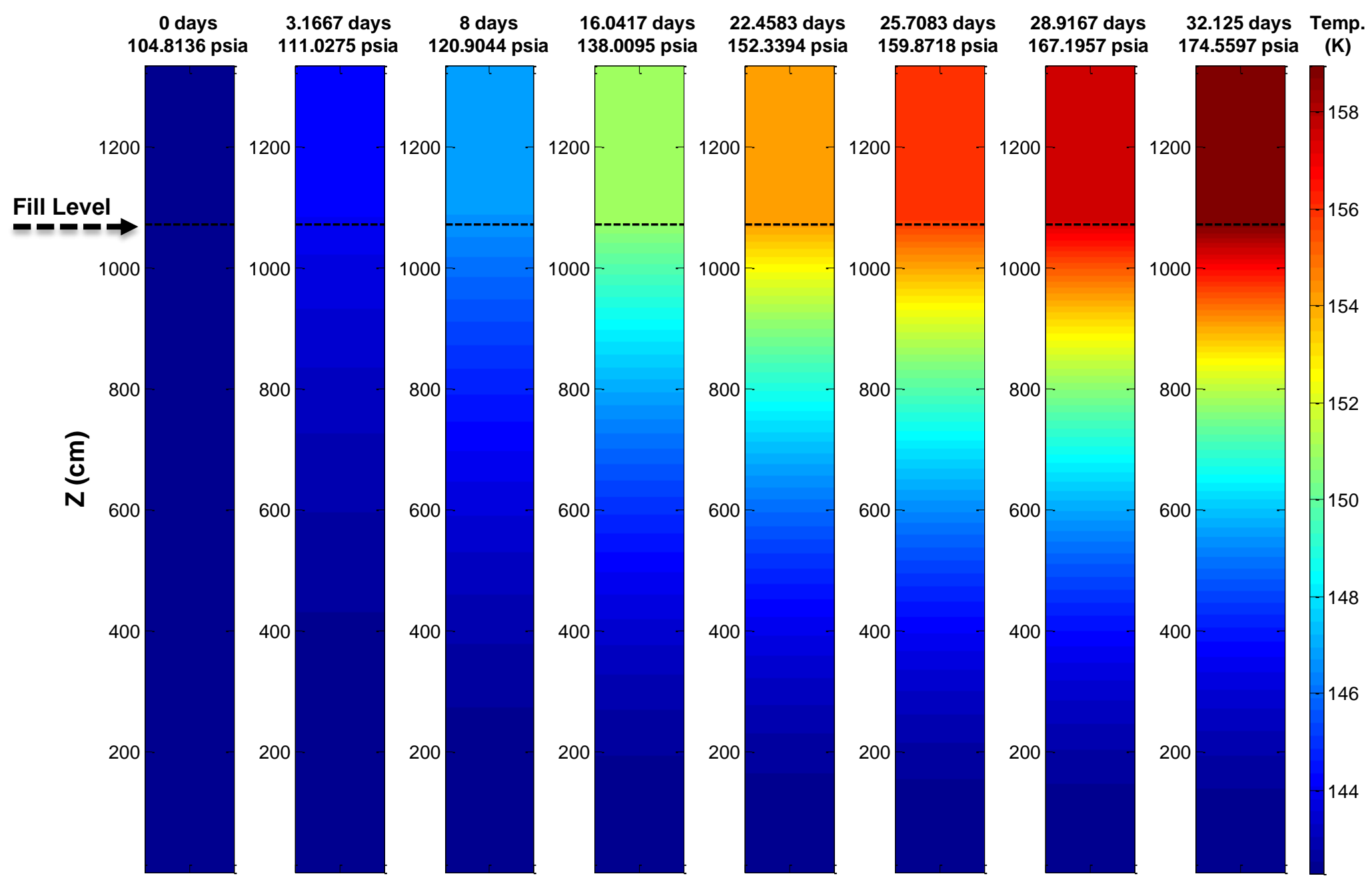

Figure 4.13. Temperature Map for a Hold Time Simulation in a Fueling Station Tank using the Stratified Approach. 


\subsubsection{Comparison between the Two Thermodynamic Approaches Using a Hypothetical Bulk Tank}

The following figures show a comparison between the simulations using the two approaches. The homogeneous approach reached venting after 723 hours (30.13 days) and the stratified approach after a total of 773 hours (32.21 days), estimating a dP/dt of 2.32 psia/day and $2.17 \mathrm{psia} /$ day respectively. The total average calculated heat transfer was smaller for the homogeneous approach, however, it was higher for the vapor region and lower for the liquid region than with the stratified approach. A summary of the results is shown in Table 4.6.

For the stratified approach the average temperature in the liquid region was lower than the saturated temperature since the basis of the approach assumed a subcooled stratifying liquid. Similarly, the average temperature in the vapor region was higher than the saturation temperature, keeping the vapor at super heated conditions which reduced the calculated heat transfer compared to that calculated for the same region with the homogeneous approach. As it will be shown in Section 4.3, the fill level has a strong effect on the performance between the two approaches and affects the average temperature of the regions and therefore the calculated heat transfer. The effects are more notable especially at lower fill levels.

Figure 4.15 shows the masses inside the tank, where the stratified approach estimated a higher amount of liquid evaporating than the homogeneous approach. Figure 4.17 shows the total average heat transfer used in the vapor and liquid regions. Figure 4.18 shows the heat leak calculated through each section of the tank. The heat transfer through the bottom of the tank was lower than from the top of the tank, given the higher direct sun radiation on top of the tank. Figure 4.19 shows a comparison of the temperature maps of both approaches where all of the color maps had been set between the minimum and maximum temperature calculated with the stratified approach. Eight maps are shown at $0 \%, 10 \%, 25 \%, 50 \%, 70 \%, 80 \%, 90 \%$, and $100 \%$ of the progression of the simulation. Higher temperatures were notable at the vapor region with the stratified approach and a clear temperature stratification was observed over the whole tank. The constant saturation temperatures were seen for the temperature map with the homogeneous approach. 

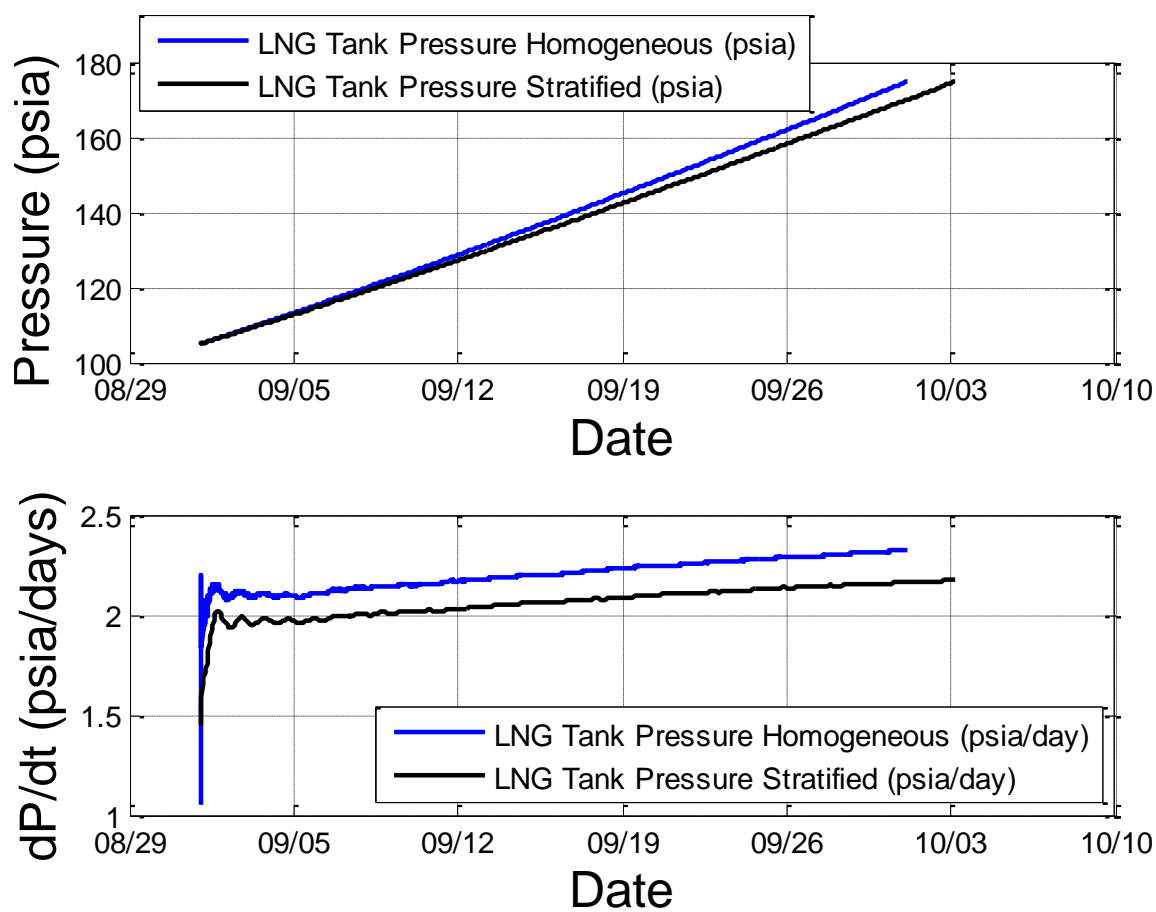

Figure 4.14. Simulated Pressure and dP/dt for a Hold Time Simulation in a Fueling Station Tank using Both Approaches.
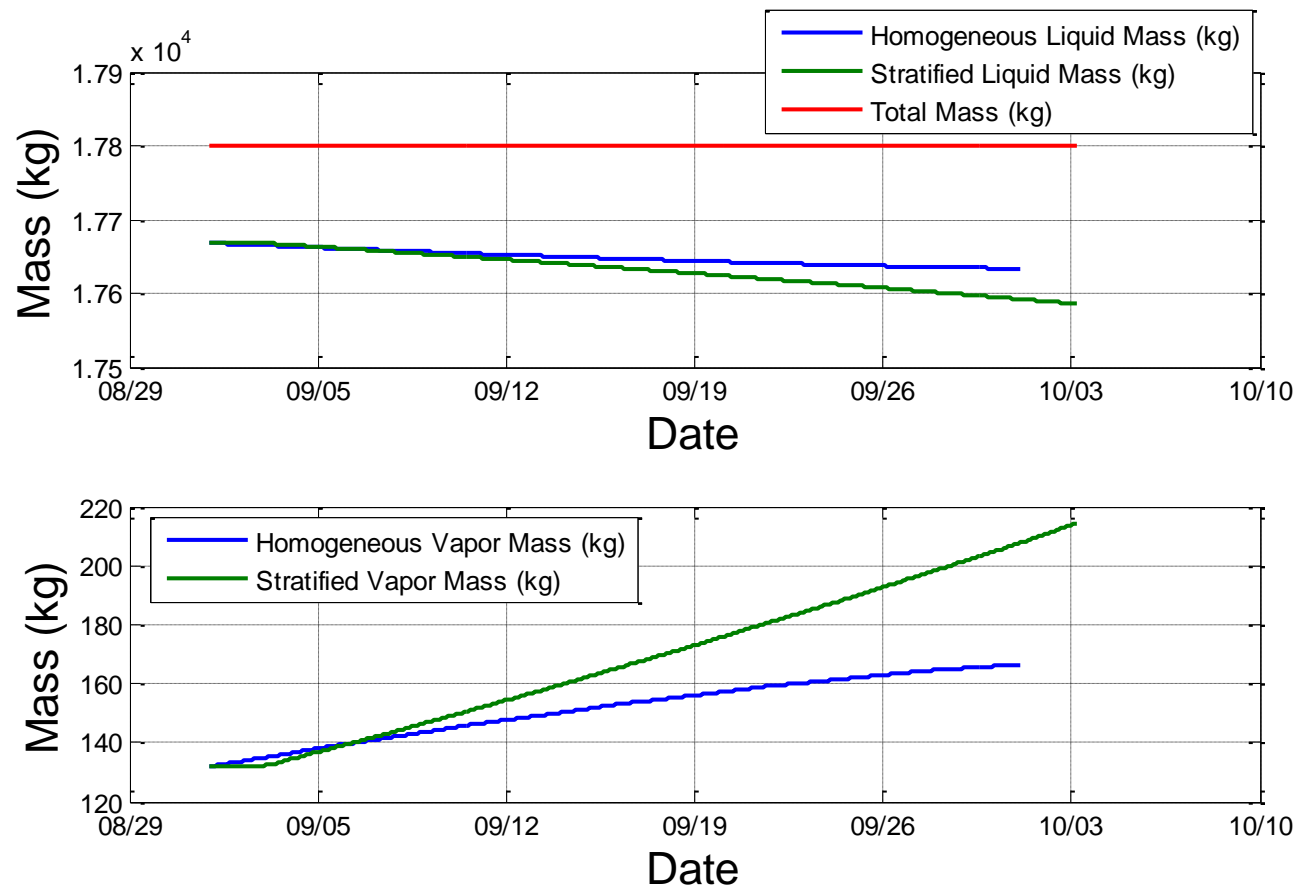

Figure 4.15. LNG and Vapor Mass Comparison for a Hold Time Simulation in a Fueling Station Tank using Both Approaches. 

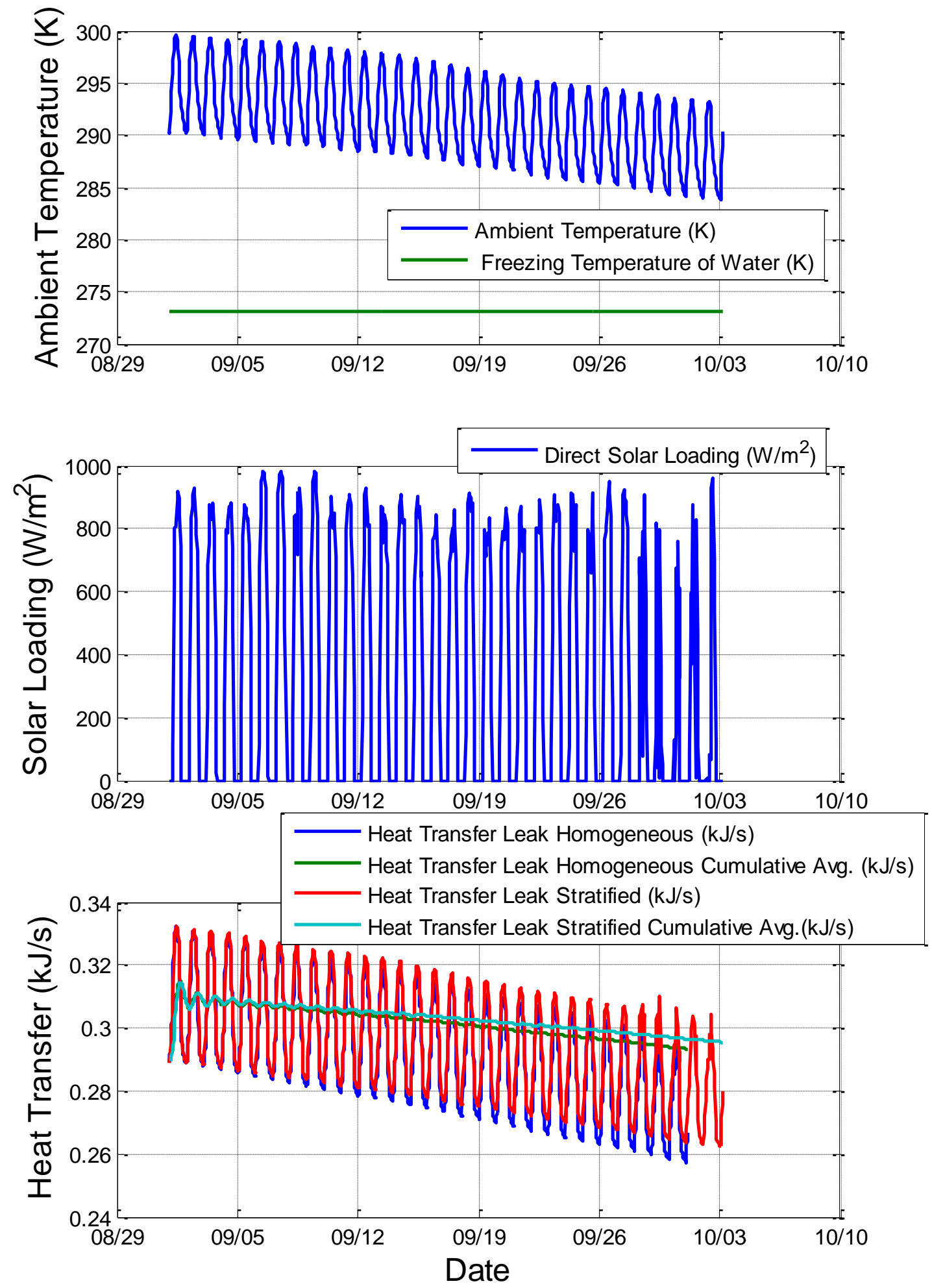

Figure 4.16. Total Heat Transfer Leak Simulated and Weather Data for a Hold Time Simulation in a Fueling Station Tank using Both Approaches. 

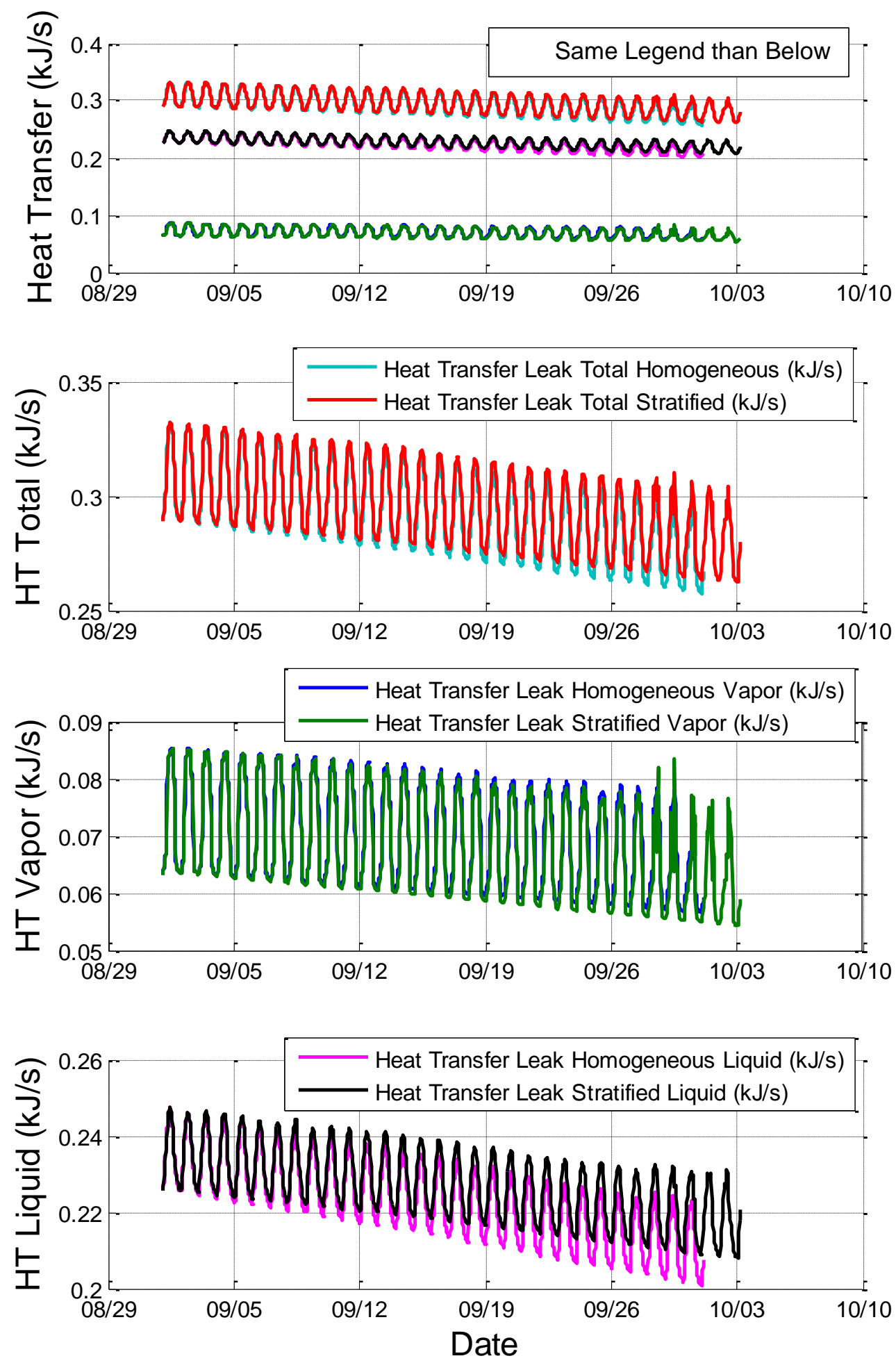

Figure 4.17. Total Heat Transfer Leak Used for a Hold Time Simulation in a Fueling Station Tank for the Vapor and Liquid Regions using Both Approaches. 

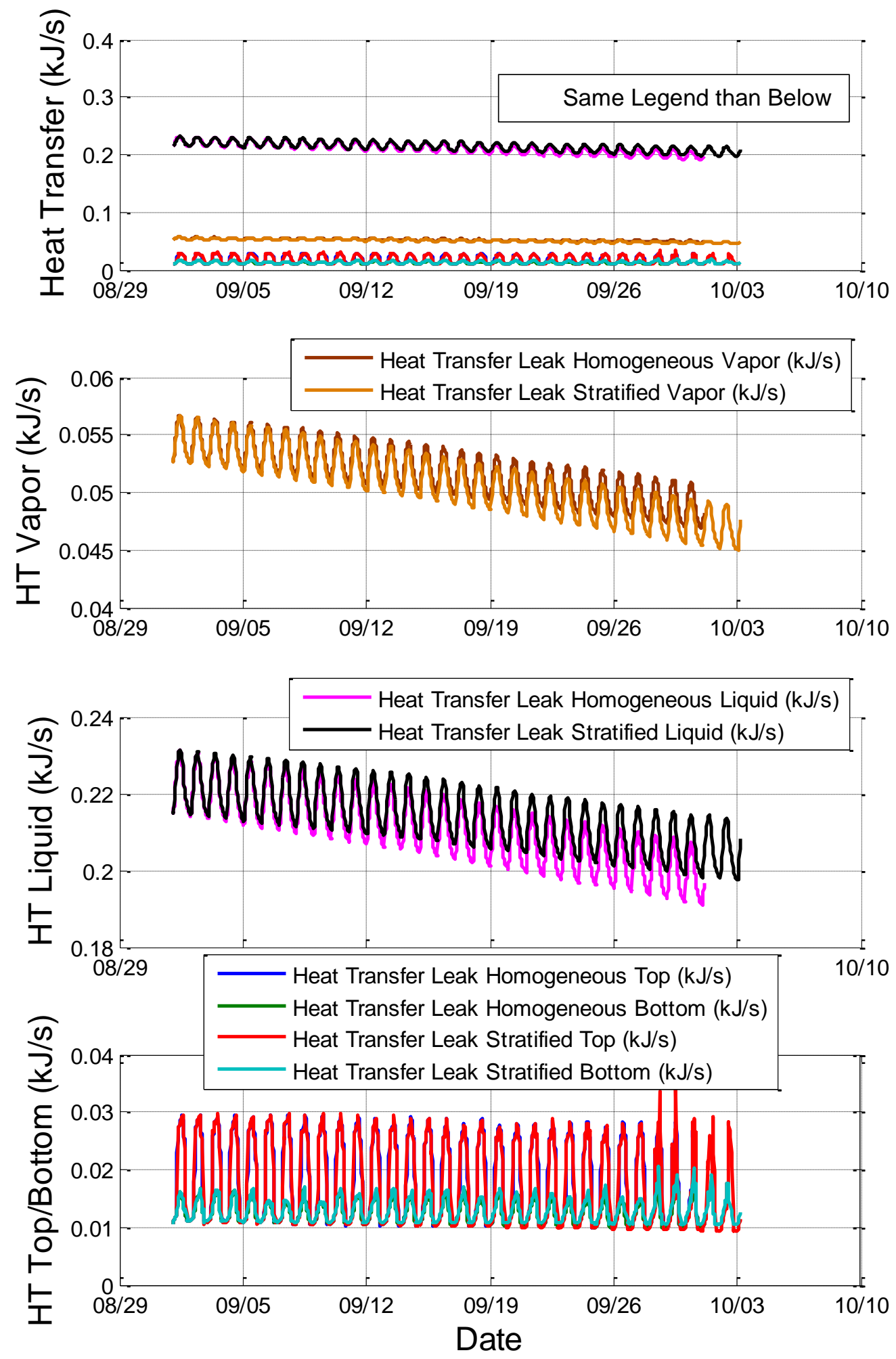

Figure 4.18. Heat Transfer Leak Distribution Through each Section of the Tank for a Hold Time Simulation using Both Approaches. 

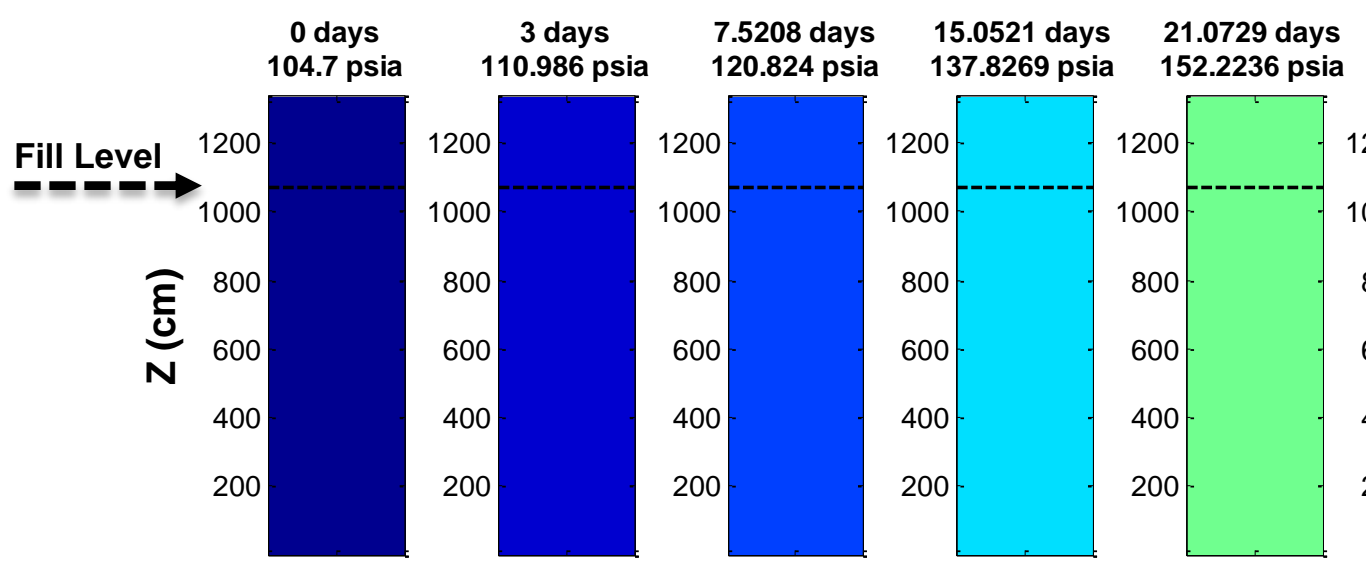

24.0833 days

$\begin{array}{ll}27.0938 \text { days } & 30.1042 \text { days Temp. } \\ 166.9877 \text { psia } & 174.6324 \text { psia }\end{array}$ 152.2236 psia

159.608 psia
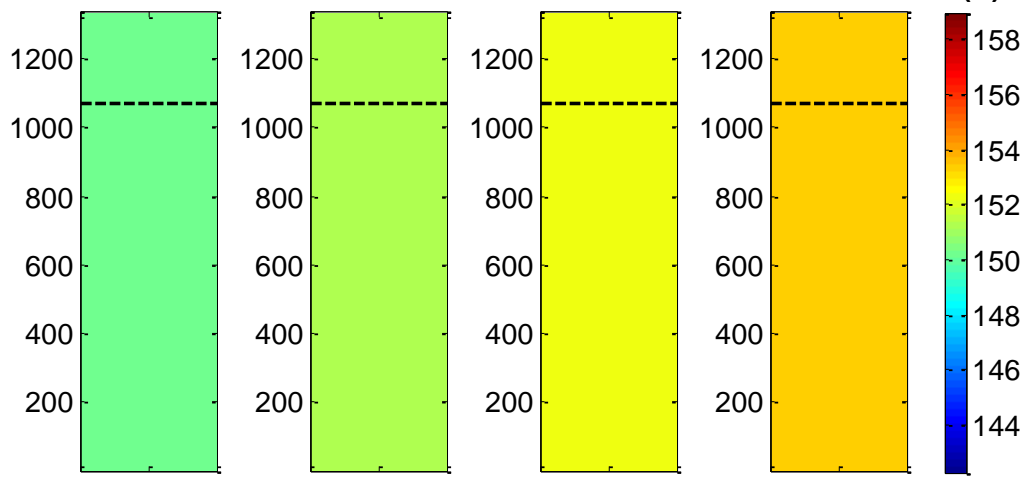

a. Homogeneous Approach.
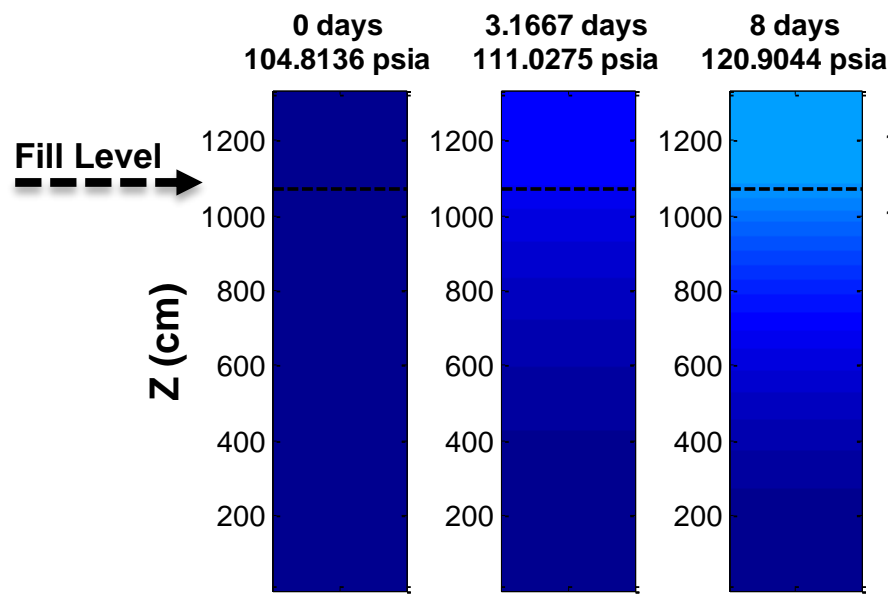

$\begin{array}{cc}16.0417 \text { days } & 22.4583 \text { days } \\ 138.0095 \text { psia } & 152.3394 \text { psia }\end{array}$

25.7083 days

28.9167 days

32.125 days Temp
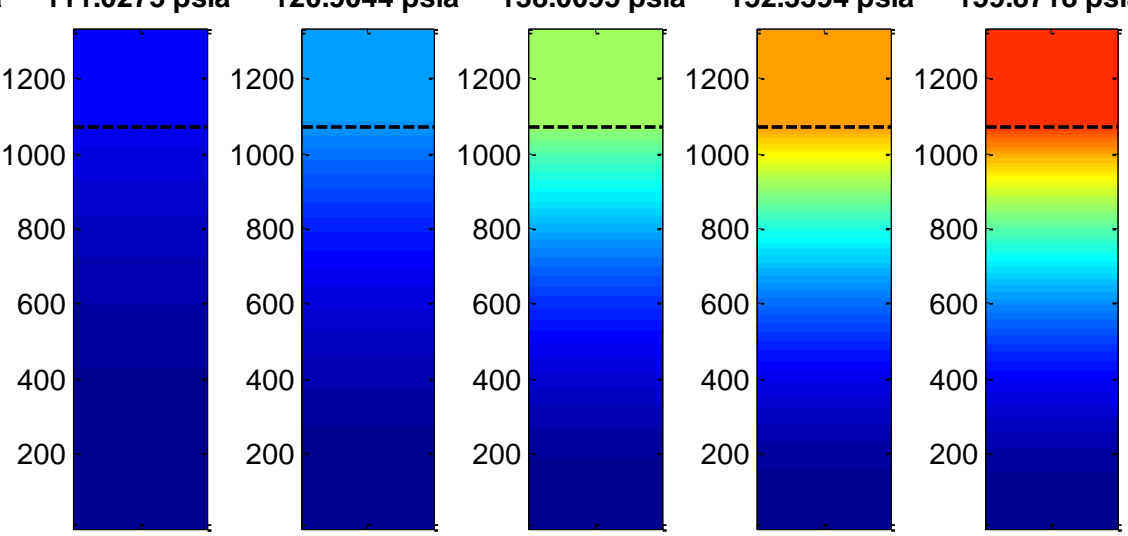

167.1957 psia

174.5597 psia (K)

b. Stratified Approach.
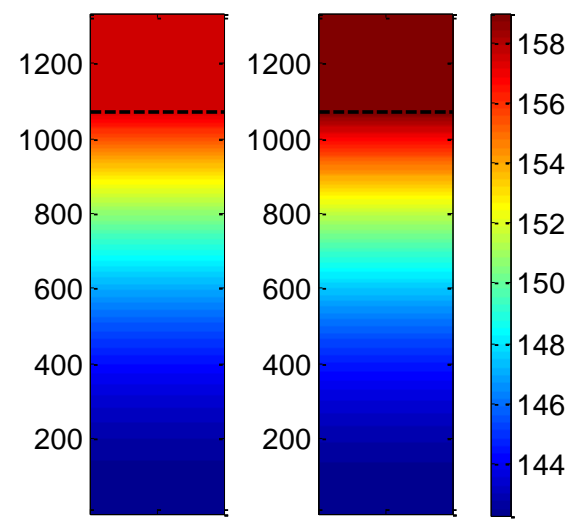

Figure 4.19. Temperature Map Comparisons for a Hold Time Simulation in a Fueling Station Tank using Both Thermodynamic Approaches. 
Table 4.6. Summary Results for a Hypothetical Bulk Tank with Both Thermodynamic Approaches

\begin{tabular}{l|rrc}
\hline \multicolumn{1}{c|}{ Simulation } & Homogeneous & Stratified & Units \\
\hline Avg. Ambient Temperature & 291.86 & 291.86 & $\mathrm{~K}$ \\
Avg. Solar Loading & 360.02 & 360.02 & $\mathrm{~W} / \mathrm{m}^{2}$ \\
\hline Avg. HT Vapor Region & 6.0 & 5.9 & $\mathrm{MJ} / \mathrm{day}$ \\
Avg. HT Liquid Region & 19.3 & 19.6 & $\mathrm{MJ} / \mathrm{day}$ \\
Avg. Total Heat Transfer & 25.3 & 25.5 & $\mathrm{MJ} / \mathrm{day}$ \\
\hline Initial Mass (kg) & 17,800 & 17,800 & $\mathrm{~kg}$ \\
Initial Homogeneous Fill & 80.30 & 80.30 & $\%$ \\
\hline Initial Pressure & 104.70 & 104.70 & $\mathrm{psia}$ \\
Pressure Rise & 70.01 & 70.04 & $\mathrm{psia}$ \\
Time & 30.17 & 32.21 & $\mathrm{days}$ \\
$\mathrm{dP} / \mathrm{dt}$ & 2.32 & 2.17 & $\mathrm{psia} / \mathrm{day}$ \\
\hline
\end{tabular}

\subsection{Model Comparison with Experimental Hold Time of Vehicle Tanks}

During the period of September 2013 to April 2014 a total of 14 experiments using LNG vehicle tanks took place, nine with a 150 gallon tank without an internal fuel pump and five with a 120 gallon tank with an internal fuel pump. Additionally, three experiments with the 150 gallon tank without an internal fuel pump were performed with the tank oscillating (Experiments 5, 6, and 7), in order to examine the effects of thermal stratification inside the tanks.

During the experiments intermittent data acquisition failures occurred stopping the acquisition system for periods between one hour and seven days. Failures included power outages and problems with fuses. Missing intervals of the solar loading data were replaced with the average of the values previously observed. The averages were calculated including known solar loading peaks during the daylight and zero solar loading during the night. Data loss of tank pressure and of ambient temperature were replaced with interpolated data using the observed data points. Public weather data was not used since the closer weather station was located around 10 miles away from the experimental setup and hourly data was not available, hourly data is released for download by NOAA after around four years. An 
example of the replaced data is shown in Figure 4.20 during experiment 6. The data replaced affected the estimated instant values of heat transfer, however, the heat transfer trend was conserved by the assumptions used to replace the data.
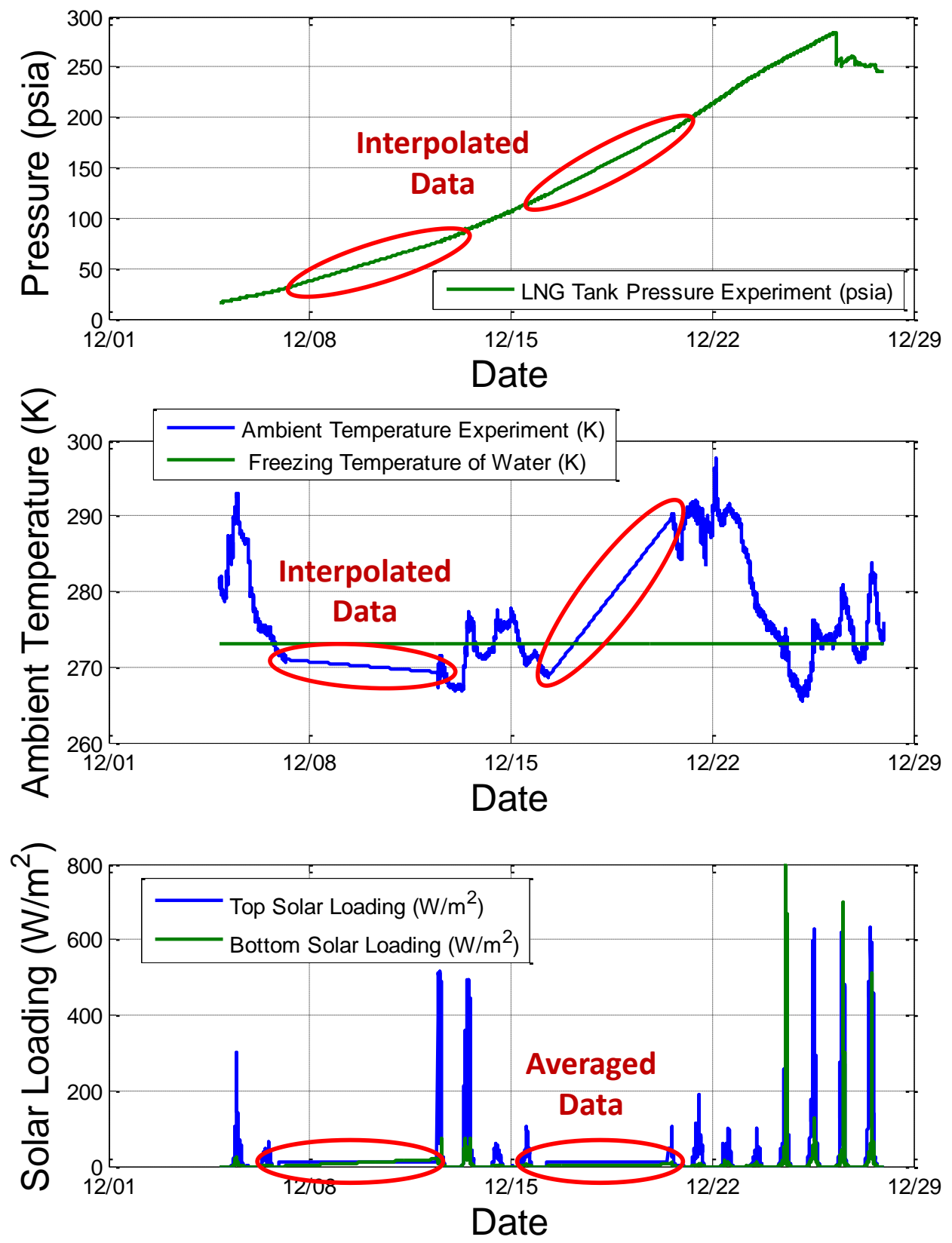

Figure 4.20. Hold Time Experiment 6 with the Tank without an Internal Fuel Pump (150 gallons) Interpolated and Averaged Data in Red are Indicated. Initial Homogeneous Fill Level: $41.08 \%$

Experiments 5 to 7 with the LNG vehicle tank without an internal fuel pump were performed oscillating the tank at varying frequencies and durations with a cam driven 
motor. The tank was pushed with the cam driven motor while attached by the hangers to the support frame. The oscillating motion occurred for 60 seconds every 6 hours after the 10th day of experiment 5. Experiment 6 was oscillated for 120 seconds every 6 hours, and experiment 7 was constantly oscillated, with the exception of the intermittent system failures. It was observed that oscillating the LNG tank caused the tank pressure to decrease, indicating to the existence of stratified liquid and superheated vapor. However, the pressure decreased an average of 1 psi and then subsequently rose back to the pressure trend. Figure 4.21 shows this effect with the four oscillations on day 14 of experiment 5 . In conclusion, the type of oscillations applied were not believed to be mixing the LNG back to the saturated conditions, and no significant effect was observed in the overall pressure trend of these experiments.
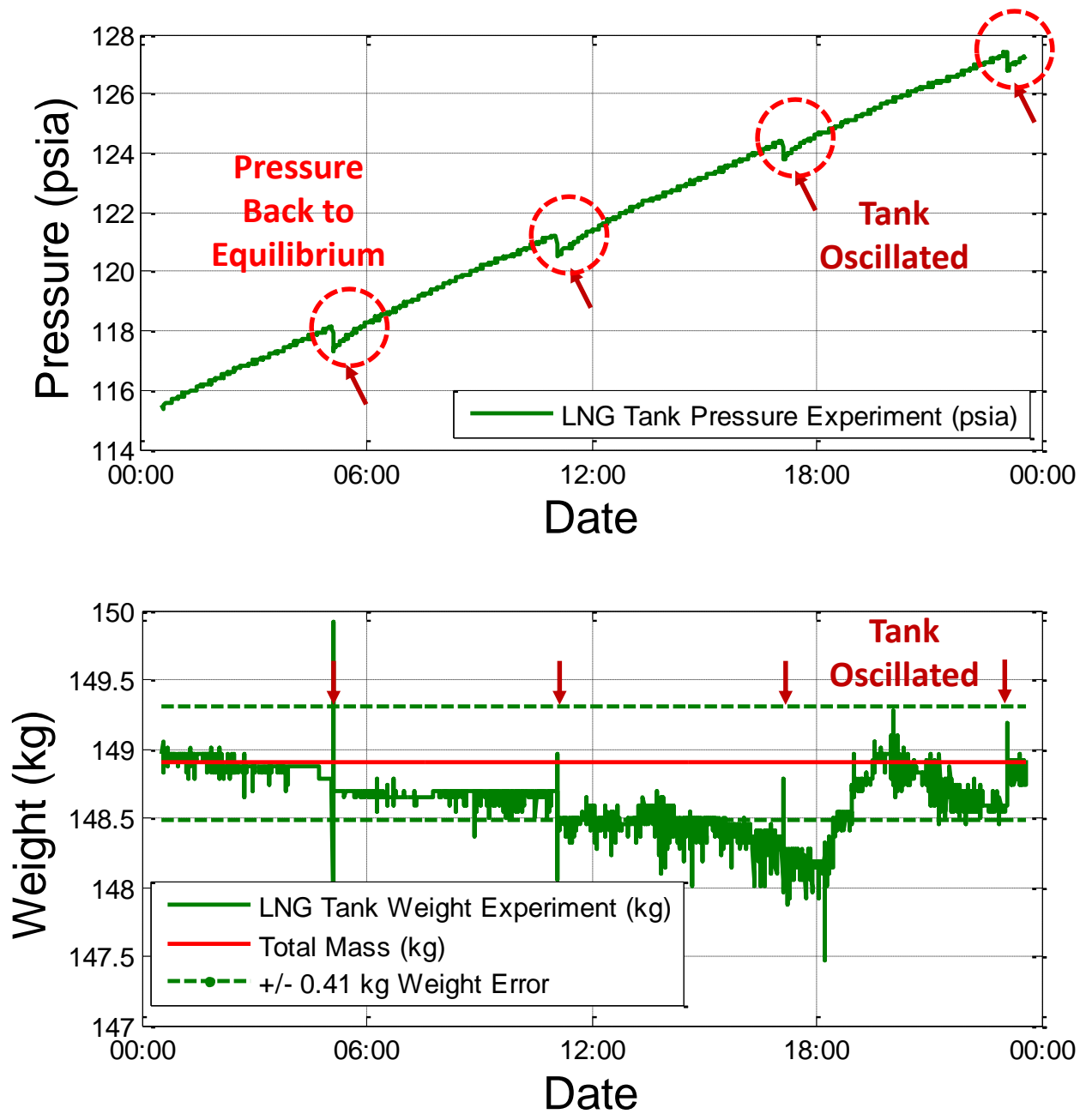

Figure 4.21. Experiment 5 Day 14. Tank without Internal Fuel Pump. Example of Tank Oscillated Every 6 Hours for 120 Seconds. 
Some of the experiments were affected by snow and this was observed in the experimental tank weight, as shown in Figure 4.22 for experiment 7. The snow density was assumed as 320,240 , and $160 \mathrm{~kg} / \mathrm{m}^{3}$ for heavy, average, and light snow respectively [82]. Then, the total weight of snow was estimated based on the dimensions of the tanks assuming that half of the surface area of the tanks were covered by snow. Results are shown in Table 4.7 for snow accumulation between 1" to 4 " $(0.0254$ to $0.1016 \mathrm{~m})$ of height. The snow calculations agreed with the extra weight between $10 \mathrm{~kg}$ and $50 \mathrm{~kg}$ observed in the tank data. This snowfall created an extra layer of insulation, keeping the tanks surface cooler, and protecting them from solar irradiation. Figure 4.23 shows the ambient temperature during experiment 7 and shows no measurement of solar radiation on top of tank since the top pyranometer was covered by snow. Additionally, the pressure rise profile changed during the days where snow was reported, significantly reducing the pressure rise of the tanks compared to the other experiments performed.

All of the experiments performed with the 120 gallon LNG tank with an internal fuel pump encountered some snow, affecting mostly the data acquired closer to the tank reaching venting conditions. Experiments 5 to 9 with the 150 gallon LNG tank without an internal fuel pump encountered some snow as well.

Table 4.7. Snow Weight on the LNG Vehicle Tanks

\begin{tabular}{cccc}
\hline Height of & \multicolumn{3}{c}{ Snow Weight on Tank (kg) } \\
\cline { 2 - 4 } Snow (m, in) & Heavy & Average & Light \\
\hline $\mathbf{0 . 0 2 5 4}\left(\mathbf{1}^{\prime \prime}\right)$ & 17.55 & 13.16 & 8.78 \\
$\mathbf{0 . 0 5 0 8 ( \mathbf { 2 } ^ { \prime \prime } )}$ & 35.10 & 26.33 & 17.55 \\
$\mathbf{0 . 0 7 6 2}\left(\mathbf{3}^{\prime \prime}\right)$ & 52.65 & 39.49 & 26.33 \\
$\mathbf{0 . 1 0 1 6}\left(\mathbf{4}^{\prime \prime}\right)$ & 70.20 & 52.65 & 35.10 \\
\hline
\end{tabular}




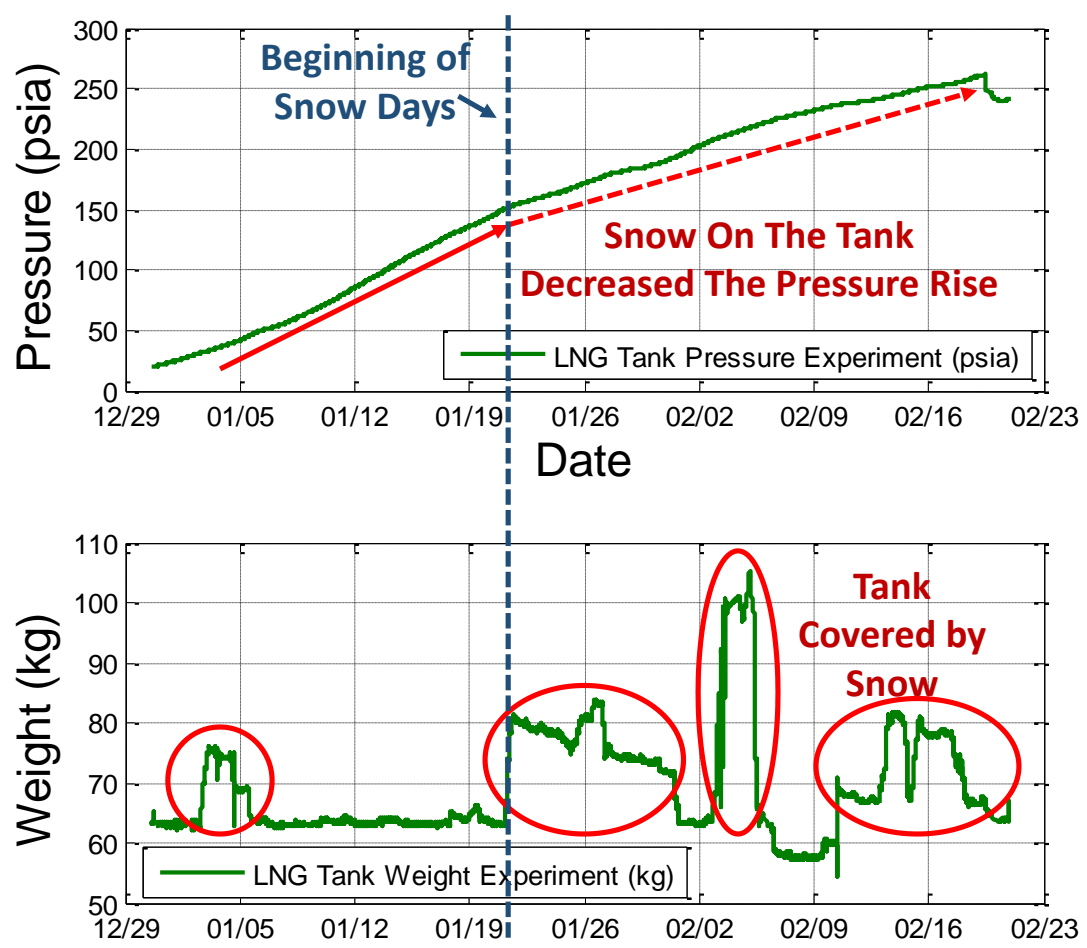

Figure 4.22. Experiment 7. Tank without Internal Fuel Pump. Example of Pressure and Total Weight of the Tank Affected by Snow.
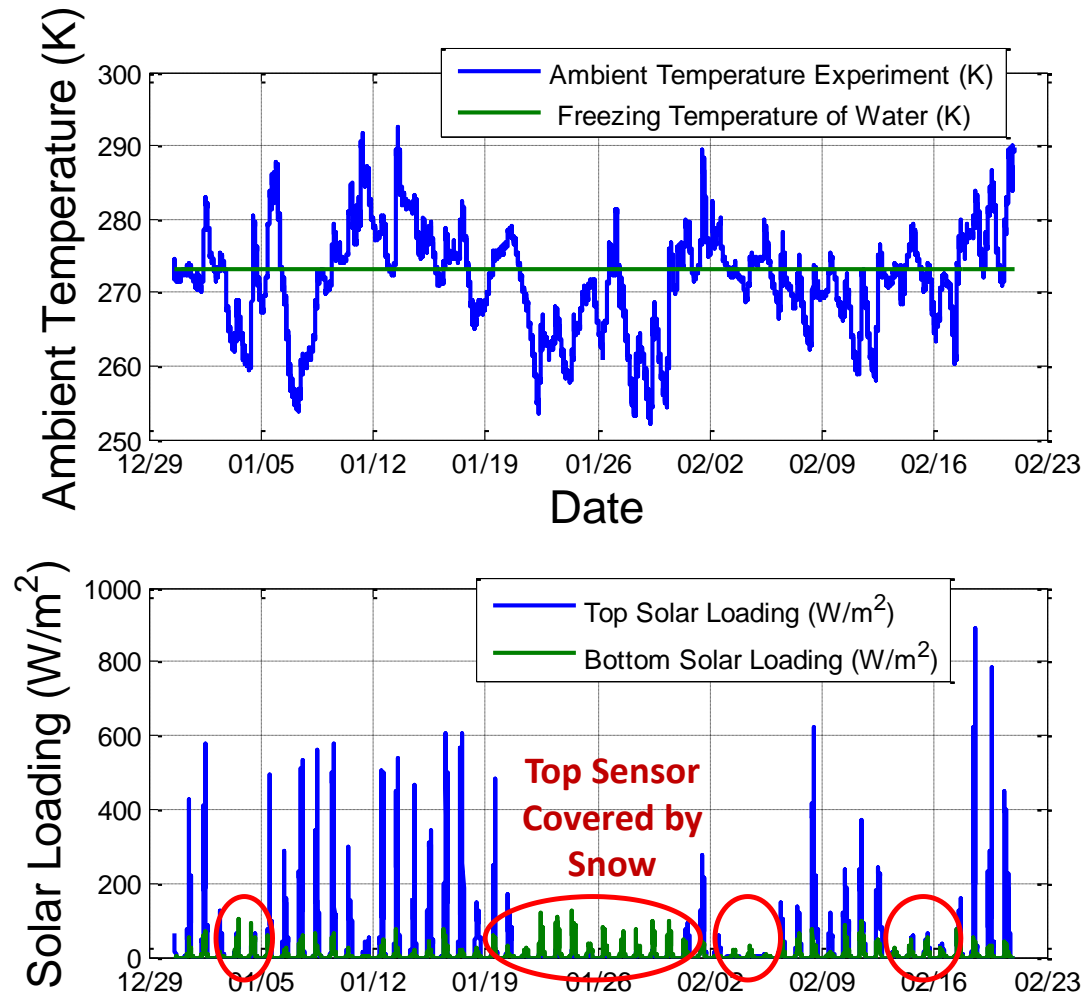

Figure 4.23. Experiment 7. Tank without Internal Fuel Pump. Example of Solar Loading Sensor (Pyranometer) Affected by Snow. 
Results from the LNG tank model using the homogeneous and stratified approaches were compared with the experimental hold time of the LNG vehicle tanks. Pressure rise results organized by fill level of the experiments are shown in the following two sections: Section 4.3.1 with the LNG vehicle tank without an internal fuel pump, and Section 4.3.2 with the tank with an internal fuel pump. Section 4.3.3 describes a detailed analysis of the results. Furthermore, detailed figures including the weather data, change of estimated masses, temperature maps, and heat transfer calculated for selected experiments are shown in Appendix A for the tank without an internal fuel pump, and in Appendix B for the tank with an internal fuel pump. Three experiments were selected showing detailed simulations with a high, a middle, and a lower initial fill level.

Experiments started at ambient pressure and continued until reaching venting pressure. However, it was noticed that PRVs tended to leak as pressure approached the PRV set point decreasing the pressure rise rates as tanks approached venting. Substantive releases of pressure by the PRV were observed in some cases as well. A clear behavior was not identified for the PRVs in vehicle tanks and a same vehicle tank started venting at different pressures. Simulations were stopped when the PRV set point was reached or at the time of the experimental venting. Simulations started at 20 psia in order to have a standard when comparing the results, with exception of experiment 2 with the tank without an internal fuel pump which started at 161.55 psia.

Both tanks were purged with ultra-high-purity nitrogen before the first LNG fueling and manufactures recommended practices were followed for the hot filling of the tanks. However, based on internal discussion with industry the tanks may have been over filled during the first experiment with each tank. Using the tank dimensions, tank pressure, and total tank weight, the initial homogeneous fill level was calculated as $105.20 \%$ for the first experiment with the LNG vehicle tank without an internal fuel pump and $103.70 \%$ for the tank with an internal fuel pump. The desired fill level after leaving a fueling station was around $90 \%$ fuel and a $10 \%$ ullage. Therefore, it was not possible to simulate the first experiment with each tank since the initial conditions did not follow the model assumptions. Fill levels of the tank without an internal fuel pump ranged from $89.03 \%$ down to $10.81 \%$, and from $48.77 \%$ down to $14.34 \%$ for the tank with an internal fuel pump. 
The vehicle tank dimensions and heat transfer values assumed for the simulations are shown in Table 4.8. Parameters were selected based on manufacturer literature, materials property tables, and assumptions for cryogenic tanks by Chen et al. [14]. Additionally, for confidentially with the LNG tank manufactures that provided information for this work all values reported that were not in the public documentation were altered. Note that the tank without an internal fuel pump was a 150 gallon series, however, the gross capacity of the one used was publically specified by the manufacture as 147 gallons (556.46 1). The relief valve pressure set point was selected as 244.4 psia for both tanks and the surface absorptivity for polished stainless steel of 0.37 was used. Multilayer insulation (MLI) was assumed in the vacuum area with a thermal conductivity of 5 . $10^{-5} \mathrm{~W} /(\mathrm{m} \cdot \mathrm{K})$. The internal layer, external layer, and struts were assumed to be made of stainless steel which thermal conductivity six orders of magnitude larger than MLI. The thermal conductivity of the internal and external shells were recalculated every time step using the current ambient and internal wall temperatures, respectively. The thermal conductivity through the struts were calculated as the mean thermal conductivity between the ambient and internal wall temperatures. The struts were assumed to support the inner tank from the top, bottom, and sides (cylindrical region). The area ratio was defined as the cross-sectional area of support material designed to statically support the vessel and LNG product in it divided by the external surface area of the tank. Since the location and distribution of the struts were unknown a representative area ratio was assumed for all of the sections of the tank.

The heat transfer model independently calculated the heat leaks through the top and bottom of the tanks, and the heat leaks affecting the vapor and liquid regions. Heat leaks through the vapor and liquid regions were calculated using the temperature profiles which divided the liquid and vapor regions in $\mathrm{N}_{V}$ and $\mathrm{N}_{\mathrm{L}}$ layers respectively. The homogeneous approach used the total heat transfer into the thermodynamic model as the sum of all the heat leaks. The stratification approach used the heat leaks estimated for each layer in the vapor and liquid regions. However, the top surface leak was equitably distributed and added into each of the vapor region layers. Similarly, heat leak through the bottom of the tank was equitably distributed into the liquid region layers. During all of the simulations 400 layers were used for both regions. 
The stratified approach was formulated for vertical tanks. Since the vehicle tanks were horizontal equivalent vertical tank dimensions were used. The height for both tanks was maintained as $0.66 \mathrm{~m}$. Equivalent radii were calculated conserving the tank volumes. Radii of $0.518 \mathrm{~m}$ and $0.466 \mathrm{~m}$ were calculated for the tank without an internal fuel pump and for the tank with an internal fuel pump, respectively.

Table 4.8. LNG Vehicle Tanks Dimensions and Heat Transfer Values Used in the Simulations

\begin{tabular}{|c|c|c|c|c|}
\hline Variable Name & $\begin{array}{c}\text { Tank without } \\
\text { Internal Fuel } \\
\text { Pump }\end{array}$ & $\begin{array}{c}\text { Tank with } \\
\text { Internal } \\
\text { Fuel Pump }\end{array}$ & Units & Reference \\
\hline Tank Volume Capacity & 556.46 & 450.00 & 1 & $\begin{array}{l}\text { Manufacture } \\
\text { Literature }\end{array}$ \\
\hline Relief Valve Pressure & 244.4 & 244.4 & psia & $\begin{array}{c}\text { Manufacture } \\
\text { Literature }\end{array}$ \\
\hline Outside Diameter & 0.66 & 0.66 & $\mathrm{~m}$ & $\begin{array}{c}\text { Manufacturer } \\
\text { Literature }\end{array}$ \\
\hline Insulation Thickness & 0.0206 & 0.0206 & $\mathrm{~m}$ & $\begin{array}{l}\text { Assumption based } \\
\text { on Chen et al. }\end{array}$ \\
\hline $\begin{array}{l}\text { External Shell Layer } \\
\text { Thickness }\end{array}$ & 0.0032 & 0.0032 & $\mathrm{~m}$ & $\begin{array}{c}\text { Assumption based } \\
\text { on Chen et al. }\end{array}$ \\
\hline $\begin{array}{l}\text { Internal Shell Layer } \\
\text { Thickness }\end{array}$ & 0.0048 & 0.0063 & $\mathrm{~m}$ & $\begin{array}{c}\text { Assumption based } \\
\text { on Chen et al. }\end{array}$ \\
\hline Length/Height of Tank & 2.285 & 2.160 & $\mathrm{~m}$ & $\begin{array}{c}\text { Manufacturer } \\
\text { Literature }\end{array}$ \\
\hline Top Area Ratio & $3.90 e-5$ & $3.90 e-5$ & $(-)$ & $\begin{array}{l}\text { Assumption based } \\
\text { on Chen et al. }\end{array}$ \\
\hline Cylindrical Area Ratio & $3.90 e-5$ & $3.90 e-5$ & $(-)$ & $\begin{array}{c}\text { Assumption based } \\
\text { on Chen et al. }\end{array}$ \\
\hline Bottom Area Ratio & $3.90 e-5$ & $3.90 e-5$ & $(-)$ & $\begin{array}{c}\text { Assumption based } \\
\text { on Chen et al. }\end{array}$ \\
\hline $\begin{array}{l}\text { Insulation Conductivity } \\
\text { (MLI) }\end{array}$ & $5.00 e-5$ & $5.00 e-5$ & $\mathrm{~W} /(\mathrm{m} * \mathrm{~K})$ & $\begin{array}{l}\text { Manufacturer } \\
\text { Literature }\end{array}$ \\
\hline $\begin{array}{l}\text { Surface Absorptivity } \\
\text { (Polished Stainless Steel) }\end{array}$ & 0.37 & 0.37 & $(-)$ & $\begin{array}{c}\text { Material Property } \\
\text { Tables }\end{array}$ \\
\hline
\end{tabular}

The last days of experiment 4 with the tank without an internal fuel pump were lost including the venting. The first thirteen days of the experiment were acquired. The 
simulation was stopped upon reaching the maximum experimental pressure of 227.4 psia. The same occurred with experiment 8 and 9 in which the maximum pressures observed were 32.2 psia and 144.6 psia, respectively. It was believe that the PRV was not behaving correctly and was replaced at the beginning of experiment 4. For the LNG tank with an internal fuel pump, it was noticed that the PRV started venting after reaching 209 psia during experiment 4 and after 120 psia during experiment 5.

\subsection{1. $\quad$ Modeling Results for LNG Vehicle Tanks without Internal Fuel Pump Organized by Fill Level}

The following figures show the results using the LNG vehicle tank without an internal fuel pump. Results using the homogeneous and stratified approaches were compared with the experimental hold time acquired. Pressure rise results have been organized by the initial fill level of the experiments. Section 4.3.3 describes a detailed analysis of the results. Furthermore, detailed figures including the weather data, change of estimated masses, temperature maps, and calculated heat transfer for selected experiments are shown in Appendix A. Two experiments were selected showing detailed simulations with a high, and a lower initial fill level.

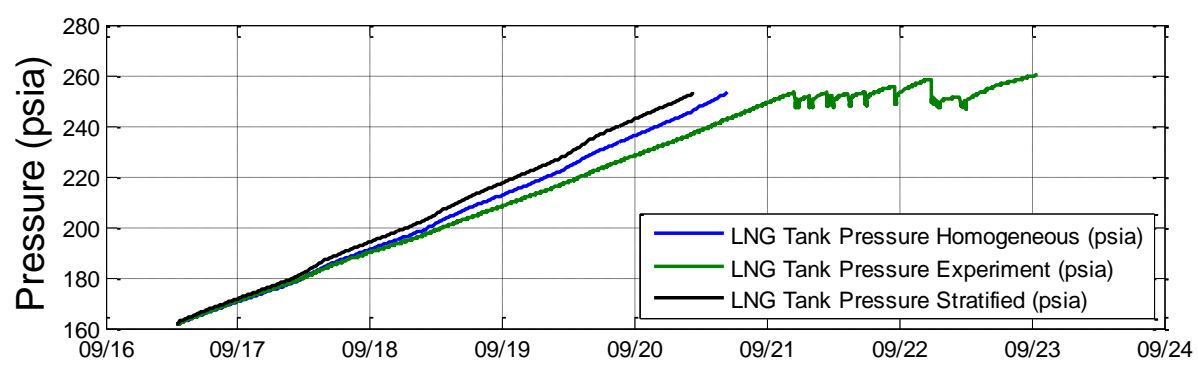

Figure 4.24. Experiment 2. Fill Level: 89.03\%. Avg. Ambient Temperature: $289.63 \mathrm{~K}$

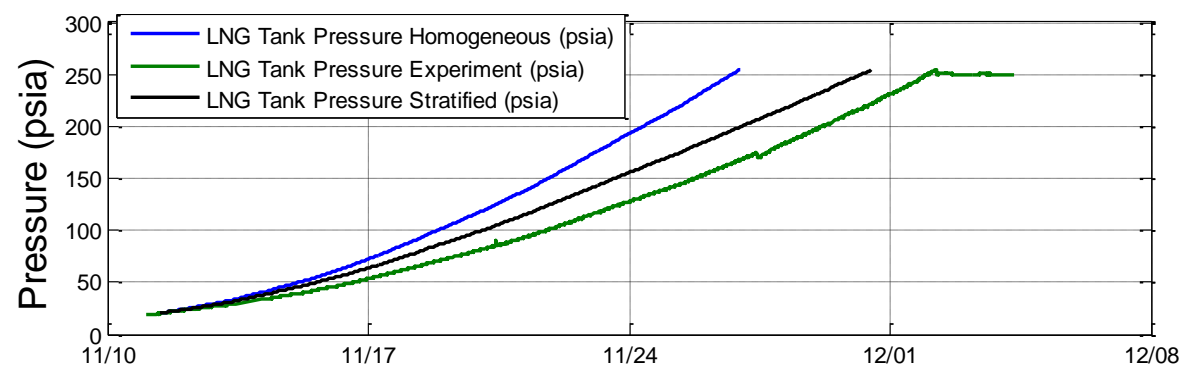

Figure 4.25. Experiment 5. Fill Level: 64.16\%. Avg. Ambient Temperature: $277.13 \mathrm{~K}$ 


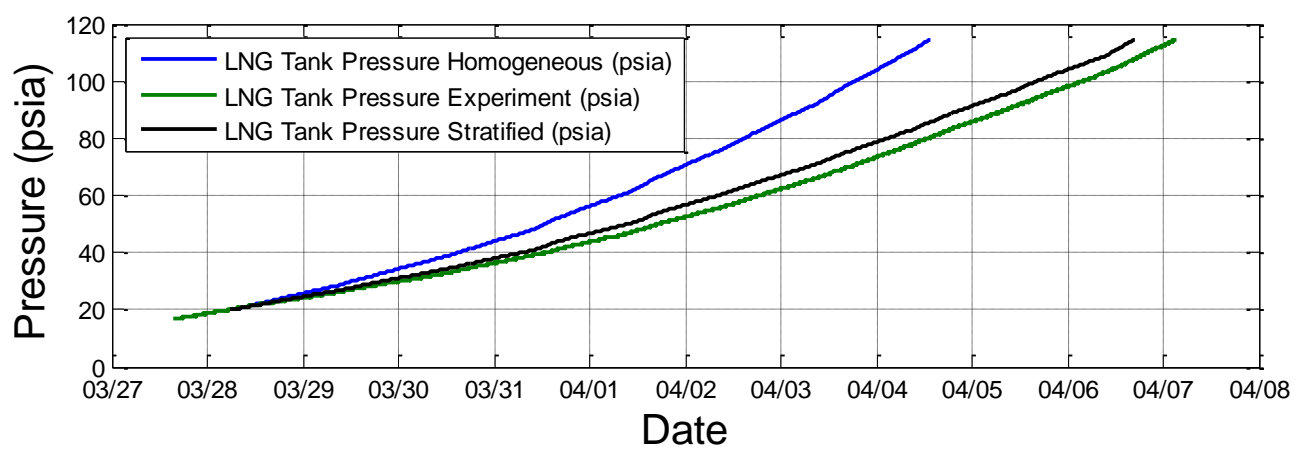

Figure 4.26. Experiment 9. Fill Level: 58.06\%. Avg. Ambient Temperature: 285.17 K

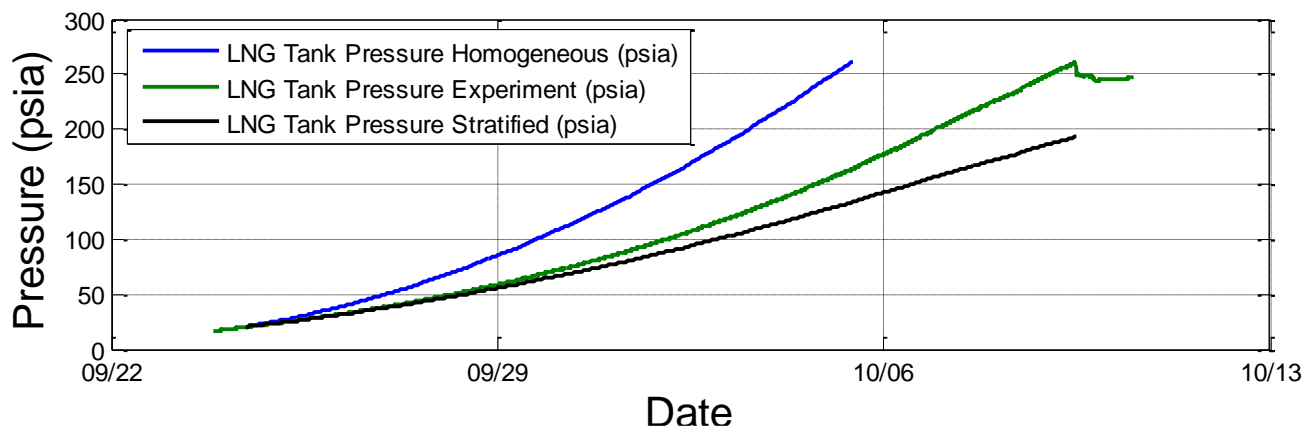

Figure 4.27. Experiment 3. Fill Level: 47.32\%. Avg. Ambient Temperature: $290.42 \mathrm{~K}$

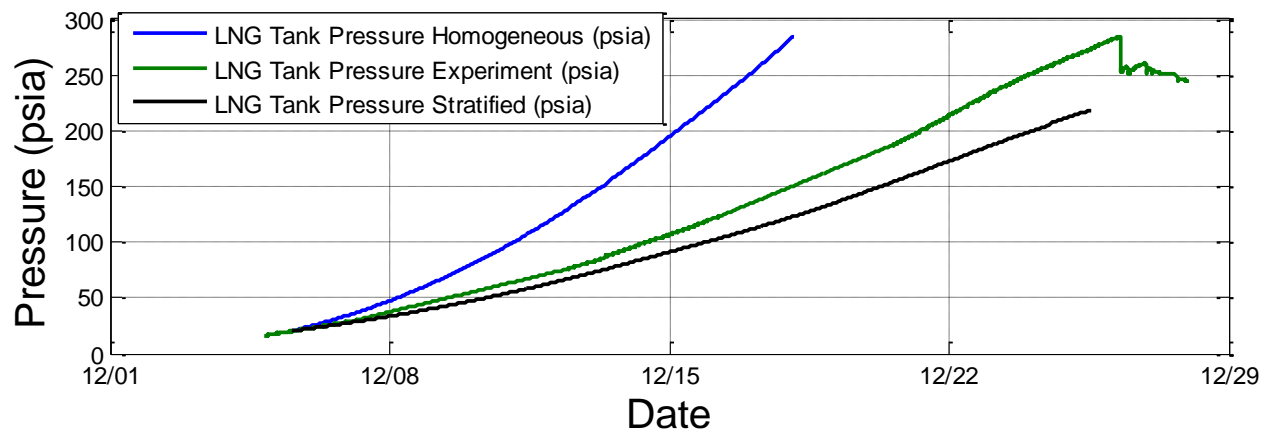

Figure 4.28. Experiment 6. Fill Level: 41.08\%. Avg. Ambient Temperature: $272.02 \mathrm{~K}$

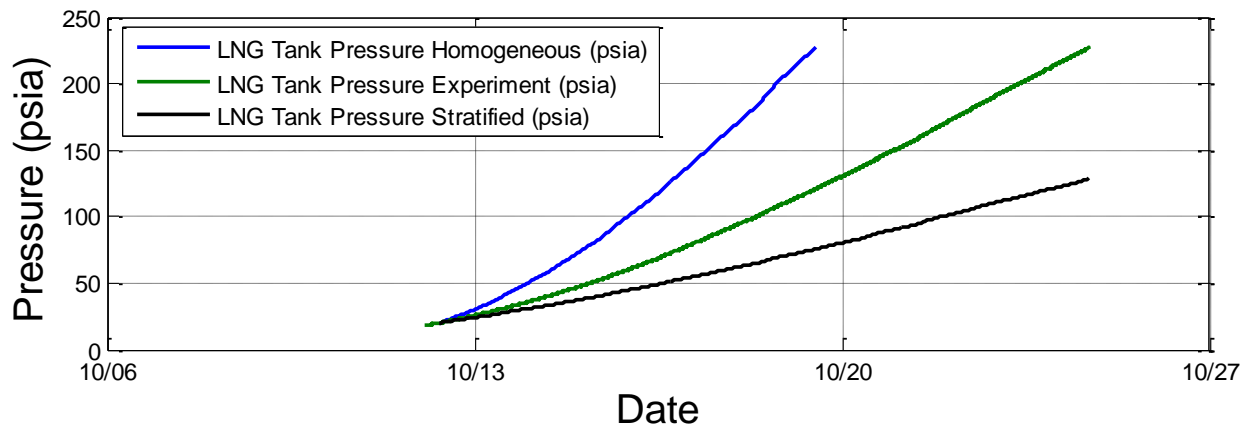

Figure 4.29. Experiment 4. Fill Level: $28.88 \%$. Avg. Ambient Temperature: $288.11 \mathrm{~K}$ 


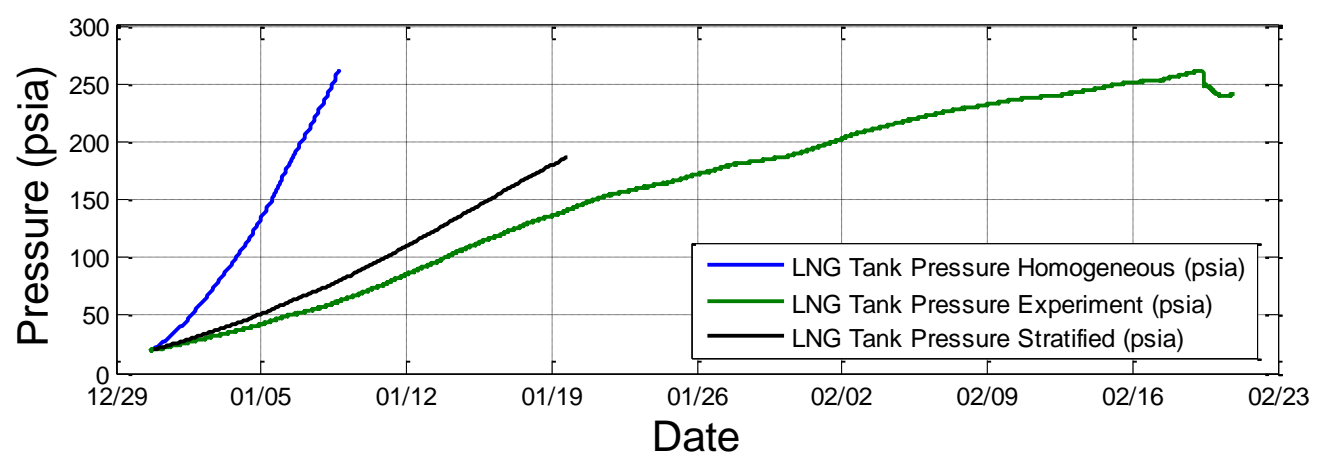

Figure 4.30. Experiment 7. Fill Level: 26.77\%. Avg. Ambient Temperature: $269.52 \mathrm{~K}$

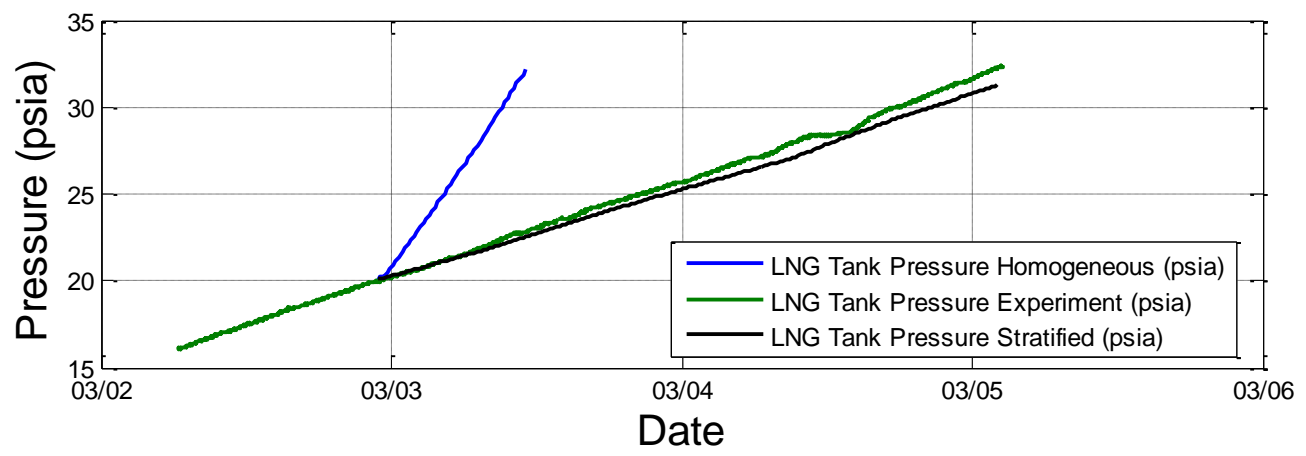

Figure 4.31. Experiment 8. Fill Level: 10.81\%. Avg. Ambient Temperature: $264.69 \mathrm{~K}$

\subsubsection{Modeling Results for LNG Vehicle Tanks with Internal Fuel Pump Organized by Fill Level}

The following figures show the results using the LNG vehicle tank with an internal fuel pump. Results using the homogeneous and stratified approaches were compared with the experimental hold time acquired. Pressure rise results have been organized by the initial fill level of the experiments. Section 4.3.3 describes a detailed analysis of the results. Furthermore, detailed figures including the weather data, change of estimated masses, temperature maps, and heat transfer calculated for a selected experiment is shown in Appendix B. One experiment was selected showing detailed results with a middle initial fill level. 


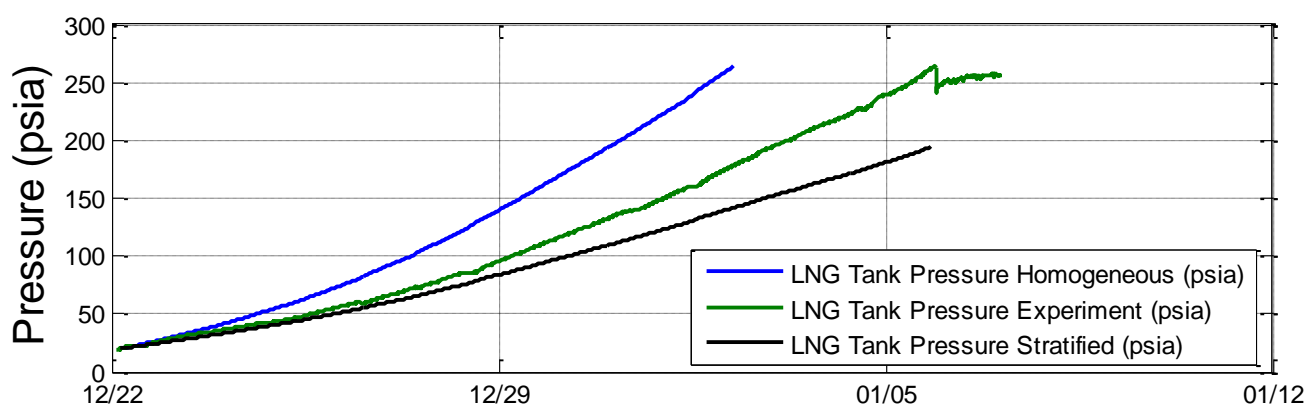

Figure 4.32. Experiment 2. Fill Level: 48.77\%. Avg. Ambient Temperature: $276.54 \mathrm{~K}$

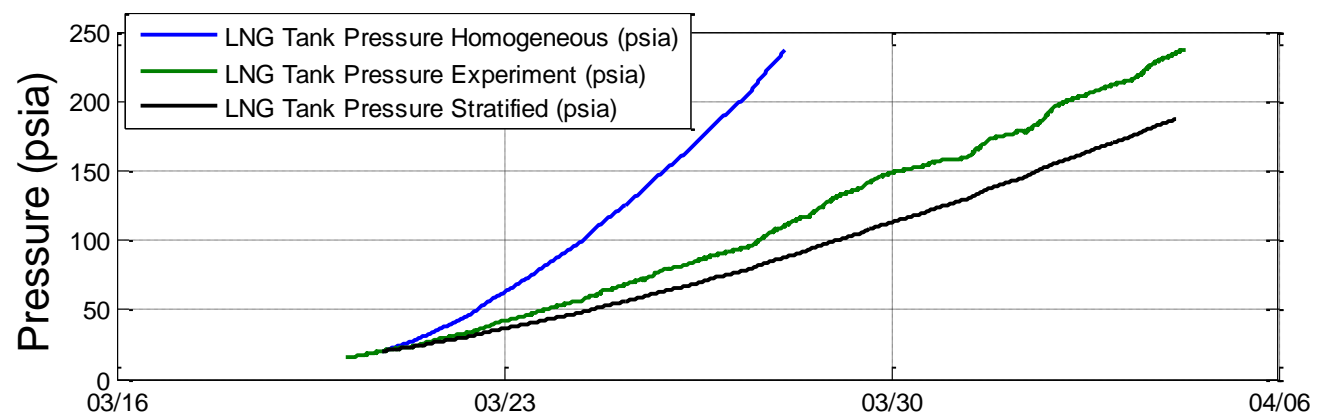

Figure 4.33. Experiment 5. Fill Level: $32.47 \%$. Avg. Ambient Temperature: $277.59 \mathrm{~K}$

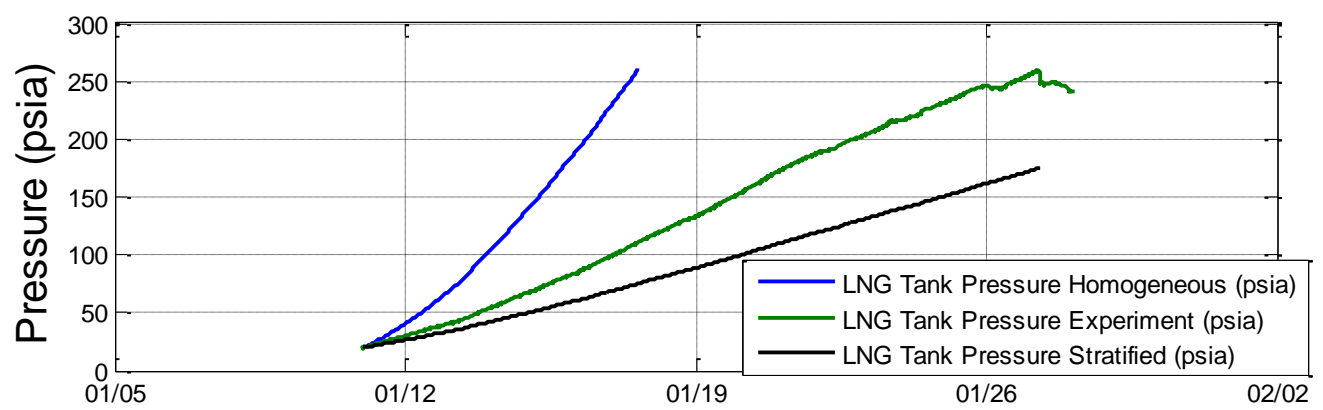

Figure 4.34. Experiment 3. Fill Level: 24.19\%. Avg. Ambient Temperature: 278.49 K

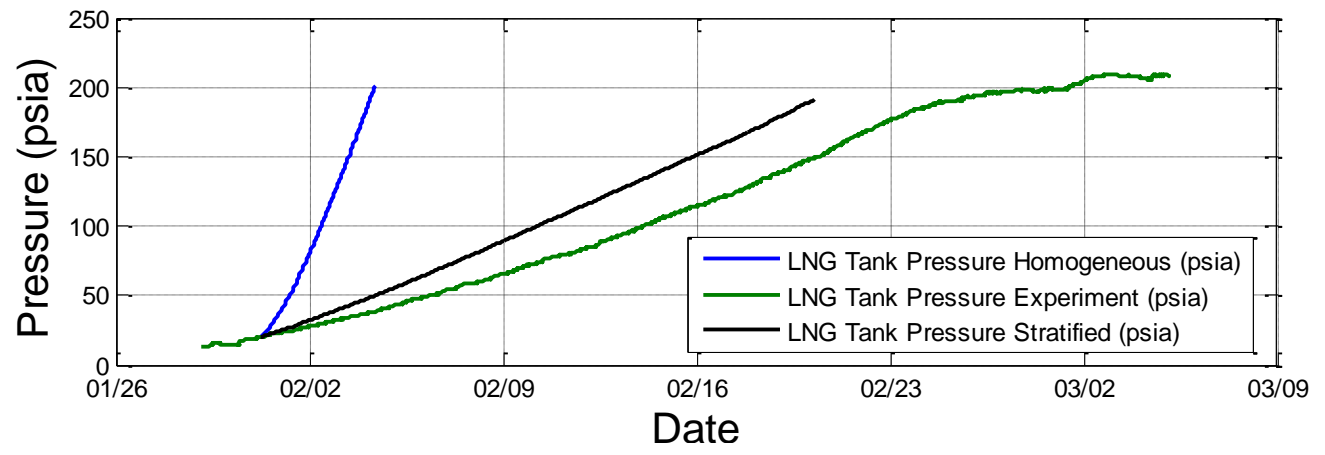

Figure 4.35. Experiment 4. Fill Level: 14.34\%. Avg. Ambient Temperature: $275.31 \mathrm{~K}$ 


\subsubsection{Analysis of Hold Time Experiments and Simulations with LNG Vehicle Tanks}

A summary of the vehicle tank experiments compared to the homogenous and stratified simulations is shown in Table 4.9. The rate of pressure rise with respect to time $(d P / d t)$ was calculated with an average error of -1.01 psia/day $(-2.64 \%)$ using the stratified approach and an average error of 14.56 psia/day (204.25\%) using the homogeneous approach. The stratified approach had an error in $d P / d t$ between -6.31 psia/day (-44.90\%) and 4.13 psia/day (21.40\%). The homogeneous approach had an error in $d P / d t$ between $2.35 \mathrm{psia} / \mathrm{day}(12.16 \%)$ and $39.48 \mathrm{psia} / \mathrm{day}(883.96 \%)$. From the results it was observed that the model performance was affected by the fill level of the experiments and by the overall ambient temperature.

The experimental $d P / d t$ was plotted separately in Figure 4.36 with respect to ambient temperature and with respect to fill level. It was seen that the experimental $d P / d t$ was higher at higher ambient temperatures, following a polynomial trend. This behavior was expected since the difference between the inside tank temperature and ambient temperature increased, which produced a higher heat transfer into the tank. The experimental $d P / d t$ was higher at higher fill levels, following a polynomial trend. This behavior was expected since the liquid region exhibited a lower temperature than the vapor region, therefore, when the fill level was higher (more liquid region) the average temperature in the overall tank stayed lower increasing the heat transfer into the tank.

A difference was observed in hold times between the LNG tank without an internal fuel pump and with an internal fuel pump, where the tank with an internal fuel pump had a lower hold time. Even though the internal fuel pump was not operated and was disconnected it had an effect on the pressure rise in the tank. It was believed that it acted as a fin, conducting heat into the tank. 
Table 4.9. Summary of Vehicle Tank Experiments Compared with Homogenous and Stratified Simulations.

\begin{tabular}{|c|c|c|c|c|c|c|c|c|c|c|c|c|c|c|c|c|c|c|}
\hline \multicolumn{2}{|c|}{ Experiment } & Start Dates & $\begin{array}{c}\text { Avg. } \\
\text { Ambient } \\
\text { Temp. ('K) }\end{array}$ & $\begin{array}{l}\text { Avg. Solar } \\
\text { Loading } \\
\left.\text { (W/m } \mathrm{m}^{2}\right)\end{array}$ & $\begin{array}{c}\text { Initial } \\
\text { Mass } \\
\text { (kg) }\end{array}$ & $\begin{array}{c}\text { Homog. } \\
\text { Fill } \\
(\%)\end{array}$ & $\begin{array}{c}\text { Initial } \\
\text { Pressure } \\
\text { (psia) }\end{array}$ & $\begin{array}{l}\text { Press. } \\
\text { Rise Exp. } \\
\text { (psia) }\end{array}$ & $\begin{array}{c}\text { Press. Rise } \\
\text { Homog. } \\
\text { (psia) }\end{array}$ & $\begin{array}{c}\text { Press. } \\
\text { Rise Strat. } \\
\text { (psia) }\end{array}$ & $\begin{array}{l}\text { Time } \\
\text { (days) }\end{array}$ & $\begin{array}{c}\mathrm{dP} / \mathrm{dt} \\
\text { Exp. } \\
\text { (psia/day) }\end{array}$ & $\begin{array}{c}\text { dP/dt } \\
\text { Homog. } \\
\text { (psia/day) }\end{array}$ & $\begin{array}{c}\mathrm{dP} / \mathrm{dt} \\
\text { Strat. } \\
\text { (psia/day) }\end{array}$ & $\begin{array}{c}\text { Error dP/dt } \\
\text { Homog. } \\
\text { (psia/day) }\end{array}$ & $\begin{array}{c}\text { Error dP/dt } \\
\text { Homog. } \\
(\%)\end{array}$ & $\begin{array}{c}\text { Error dP/dt } \\
\text { Strat. } \\
\text { (psia/day) }\end{array}$ & $\begin{array}{c}\text { Error dP/dt } \\
\text { Strat. } \\
\text { (\%) }\end{array}$ \\
\hline \multirow{9}{*}{$\begin{array}{c}\text { Tank } \\
\text { without } \\
\text { Internal Fuel } \\
\text { Pump } \\
\text { (150 gallons) }\end{array}$} & Exp 1 & 9/10/2013 & 292.21 & 98.78 & 203.80 & $105.20 \%$ & 182.10 & 59.99 & & & 2.86 & 21.01 & & & & & & \\
\hline & Exp 2 & 9/16/2013 & 289.63 & 117.77 & 176.86 & $89.03 \%$ & 161.55 & 75.41 & 84.58 & 91.55 & 3.91 & 19.31 & 21.65 & 23.44 & 2.35 & $12.16 \%$ & 4.13 & $21.40 \%$ \\
\hline & Exp 3 & 9/24/2013 & 290.42 & 82.32 & 110.40 & $47.32 \%$ & 20.00 & 144.12 & 241.14 & 113.54 & 11.02 & 13.08 & 21.88 & 10.30 & 8.80 & $67.32 \%$ & -2.77 & $-21.22 \%$ \\
\hline & Exp 4 & $10 / 12 / 2013$ & 288.11 & 68.18 & 67.90 & $28.88 \%$ & 20.00 & 100.82 & 207.36 & 55.55 & 7.18 & 14.05 & 28.89 & 7.74 & 14.84 & $105.68 \%$ & -6.31 & $-44.90 \%$ \\
\hline & Exp 5 & $11 / 10 / 2013$ & 277.13 & 43.80 & 149.23 & $64.16 \%$ & 20.00 & 147.61 & 234.09 & 178.83 & \begin{tabular}{|l|l|}
15.56 \\
\end{tabular} & 9.48 & 15.04 & 11.49 & 5.56 & $58.59 \%$ & 2.01 & $21.16 \%$ \\
\hline & Exp 6 & $12 / 5 / 2013$ & 272.02 & 21.14 & 96.02 & $41.08 \%$ & 20.00 & 130.63 & 265.01 & 103.24 & 12.59 & 10.37 & 21.04 & 8.20 & 10.67 & $102.86 \%$ & -2.17 & $-20.97 \%$ \\
\hline & Exp 7 & $12 / 30 / 2013$ & 269.52 & 29.62 & 63.05 & $26.77 \%$ & 20.00 & 42.13 & 241.85 & 59.58 & 8.98 & 4.69 & 26.93 & 6.64 & 22.24 & $474.00 \%$ & 1.94 & $41.41 \%$ \\
\hline & Exp 8 & $3 / 2 / 2014$ & 264.69 & 0.98 & 26.31 & $10.81 \%$ & 20.00 & 2.84 & 12.20 & 2.52 & 0.51 & 5.56 & 23.91 & 4.93 & 18.35 & $330.05 \%$ & -0.63 & $-11.32 \%$ \\
\hline & Exp 9 & $3 / 28 / 2014$ & 285.17 & 87.59 & 135.17 & $58.06 \%$ & 20.00 & 60.29 & 94.57 & 65.57 & 7.32 & 8.23 & 12.91 & 8.95 & 4.68 & $56.84 \%$ & 0.72 & $8.74 \%$ \\
\hline \multirow{5}{*}{$\begin{array}{c}\text { Tank } \\
\text { with Internal } \\
\text { Fuel Pump } \\
\text { (120 gallons) }\end{array}$} & $\operatorname{Exp} 1$ & $12 / 18 / 2013$ & & & 158.70 & $103.70 \%$ & 205.70 & & & & & & & & & & & \\
\hline & Exp 2 & $12 / 22 / 2013$ & 276.54 & 33.96 & 91.99 & $48.77 \%$ & 20.00 & 158.33 & 244.02 & 121.80 & 11.10 & 14.26 & 21.98 & 10.97 & 7.72 & $54.12 \%$ & -3.29 & $-23.07 \%$ \\
\hline & Exp 3 & $1 / 10 / 2014$ & 278.49 & 35.84 & 46.18 & $24.19 \%$ & 20.00 & 90.18 & 240.28 & 54.93 & 6.60 & 13.65 & 36.38 & 8.32 & 22.73 & $166.45 \%$ & -5.34 & $-39.09 \%$ \\
\hline & Exp 4 & $1 / 29 / 2014$ & 275.31 & 13.61 & 27.81 & $14.34 \%$ & 20.00 & 18.33 & 180.36 & 29.61 & 4.10 & 4.47 & 43.94 & 7.21 & 39.48 & $883.96 \%$ & 2.75 & $61.51 \%$ \\
\hline & Exp 5 & $3 / 20 / 2014$ & 277.59 & 96.38 & 61.60 & $32.47 \%$ & 20.00 & 90.83 & 217.01 & 67.77 & 7.30 & 12.44 & 29.72 & 9.28 & 17.28 & $138.92 \%$ & -3.16 & $-25.39 \%$ \\
\hline & 10.94 & $150.94 \%$ & -0.39 & $-0.71 \%$ \\
\hline \multicolumn{15}{|c|}{ Avg. Tank with Pump } & $\frac{21.80}{14.56}$ & $\begin{array}{l}310.86 \% \\
204.25 \%\end{array}$ & $\frac{-2.26}{-1.01}$ & $\frac{-6.51 \%}{-2.64 \%}$ \\
\hline
\end{tabular}


A direct comparison between the experimental and simulated results using both approaches is shown in Figure 4.37 for the two tanks. It was concluded that in general the stratified approach performed better than the homogeneous approach. The error difference between the experimental and the simulated rate of pressure rise with respect to time in psia/day is shown in Figure 4.38 and Figure 4.39. Figure 4.38 compared by fill level and Figure 4.39 compared by ambient temperature.
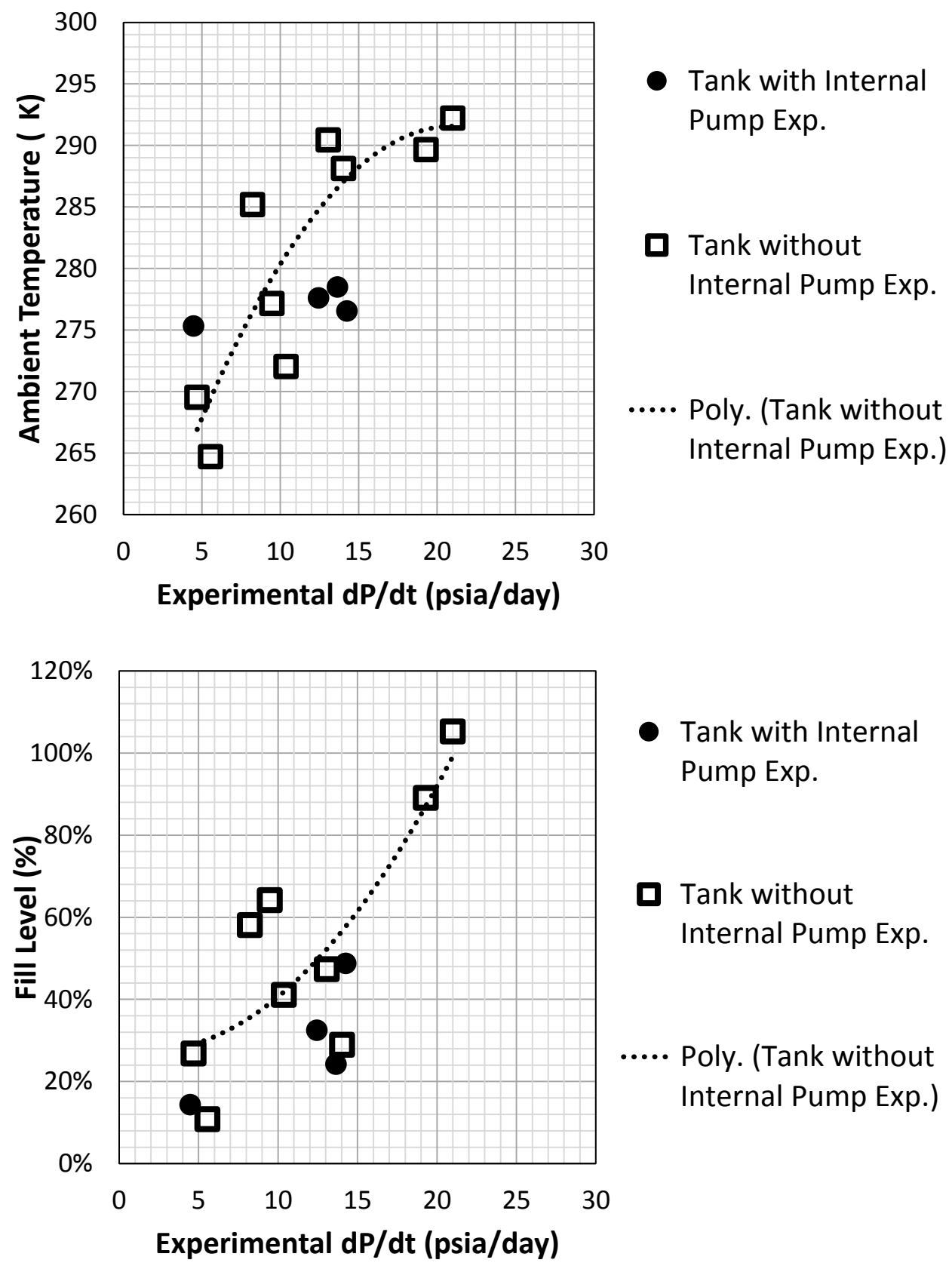

Figure 4.36. Trend of Hold Time in the LNG Tanks Experiments dP/dt (psia/day) vs Ambient Temperature and Fill Level. 


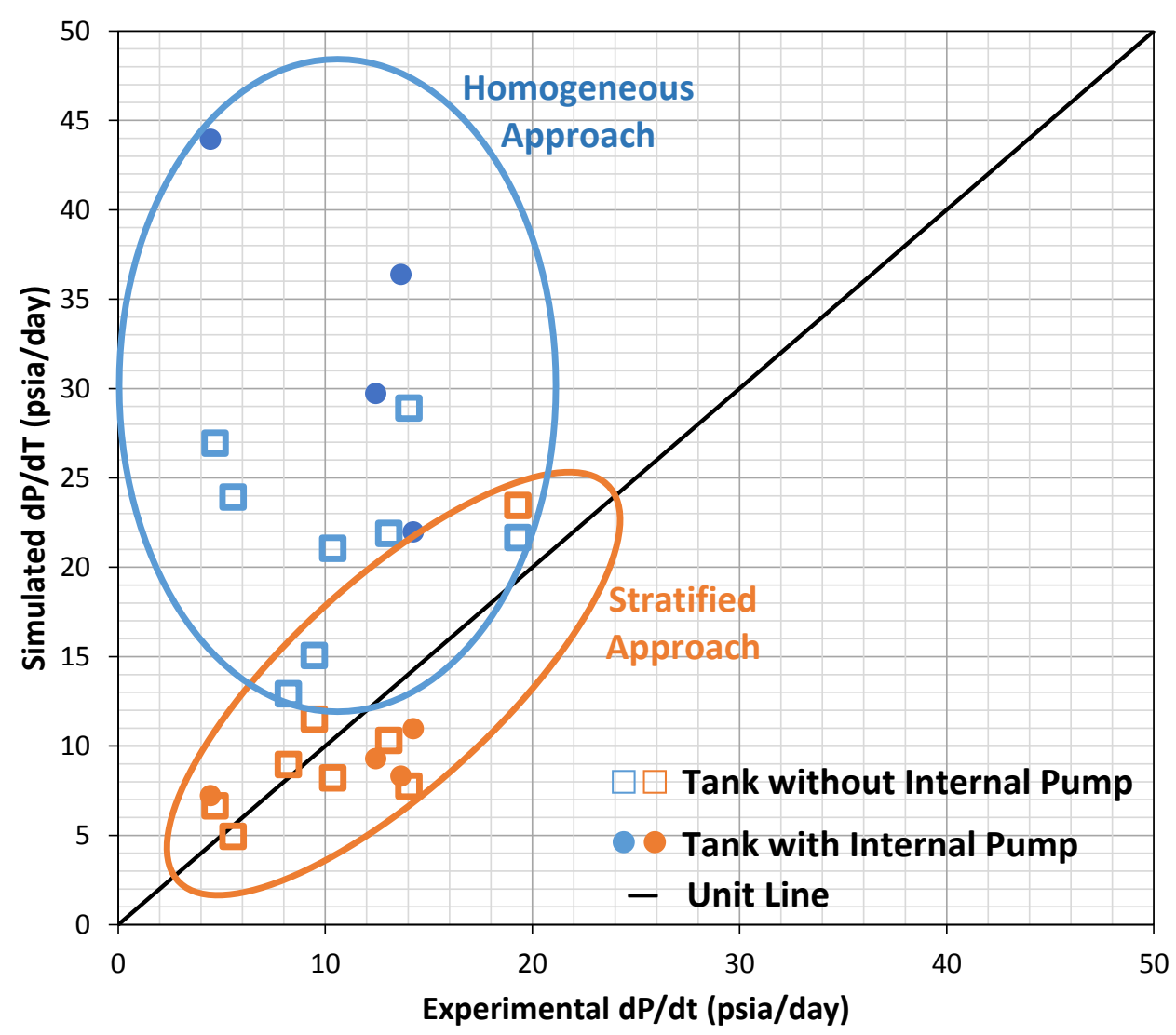

Figure 4.37. Experimental vs Simulated dP/dt for the LNG Vehicle Tanks.

It was concluded from Figure 4.38 that the homogeneous approach always over predicted the pressure rise and it gave better performance at higher fill levels, following an exponential trend. Over prediction was between $2.35 \mathrm{psia} /$ day and $39.48 \mathrm{psia} / \mathrm{day}$. On the other hand, the stratified approach tended to over predict the pressure rise at higher fill levels and under predict it at lower fill levels. A linear trend with zero crossing around a $50 \%$ fill level was observed. The stratified approach was bounded with an over prediction of $4.13 \mathrm{psia} / \mathrm{day}$ and an under prediction of $6.31 \mathrm{psia} / \mathrm{day}$. In general, the stratified approach error was smaller than the homogenous approach and the homogenous approach error increased exponentially at lower fill levels. Nevertheless, the homogenous approach presented better performance than the stratified approach when the fill level exceeded approximately $85 \%$. A clear trend was not observed from Figure 4.39 when comparing to ambient temperature and the experimental data points of $d P / d t$ were dispersed. However, when organizing the results by ambient temperature it was noted that in general the stratified approach resulted in a smaller error than the homogeneous approach. 


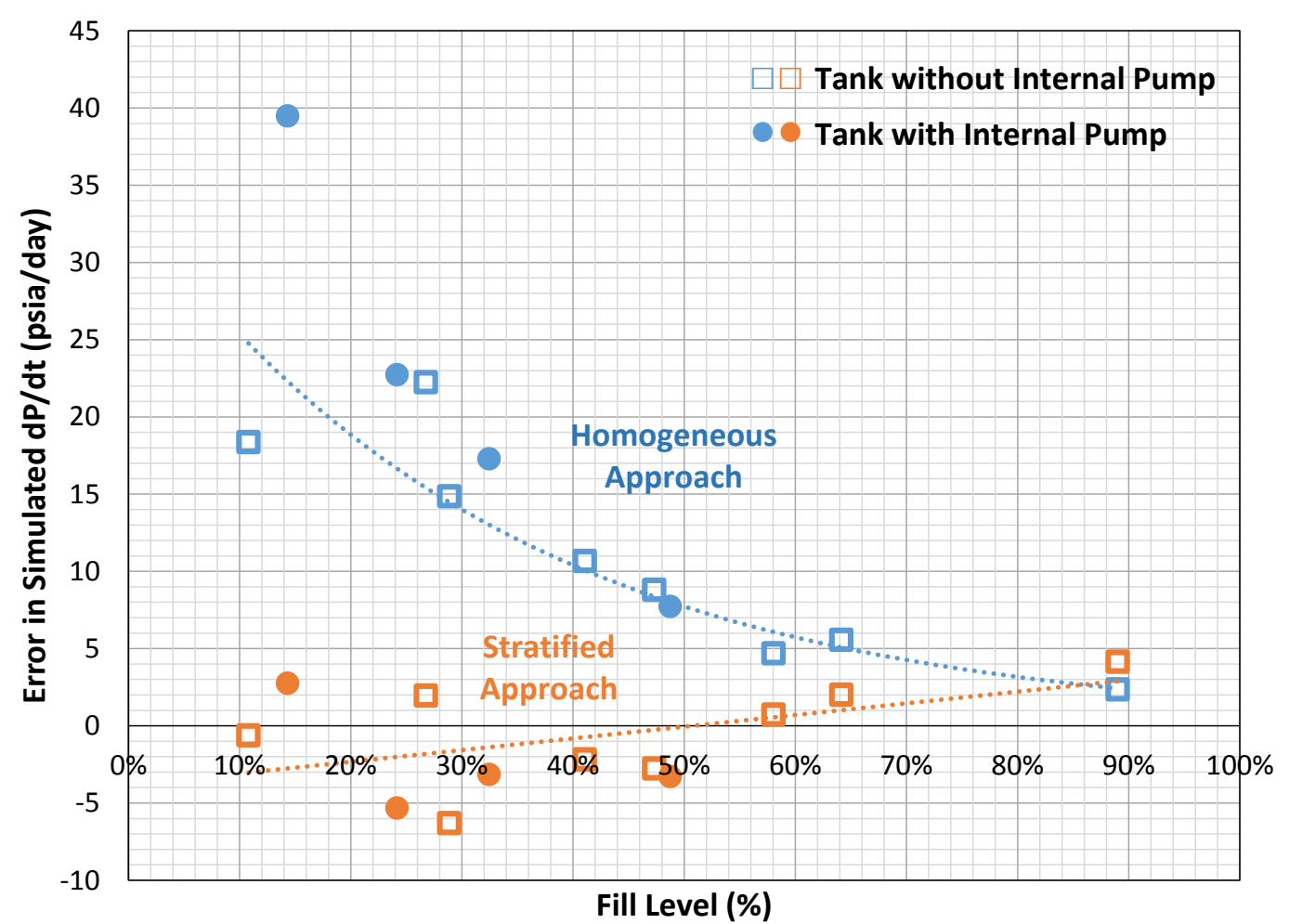

Figure 4.38. Error in Simulated dP/dt (psia/day) vs Fill Level (\%).

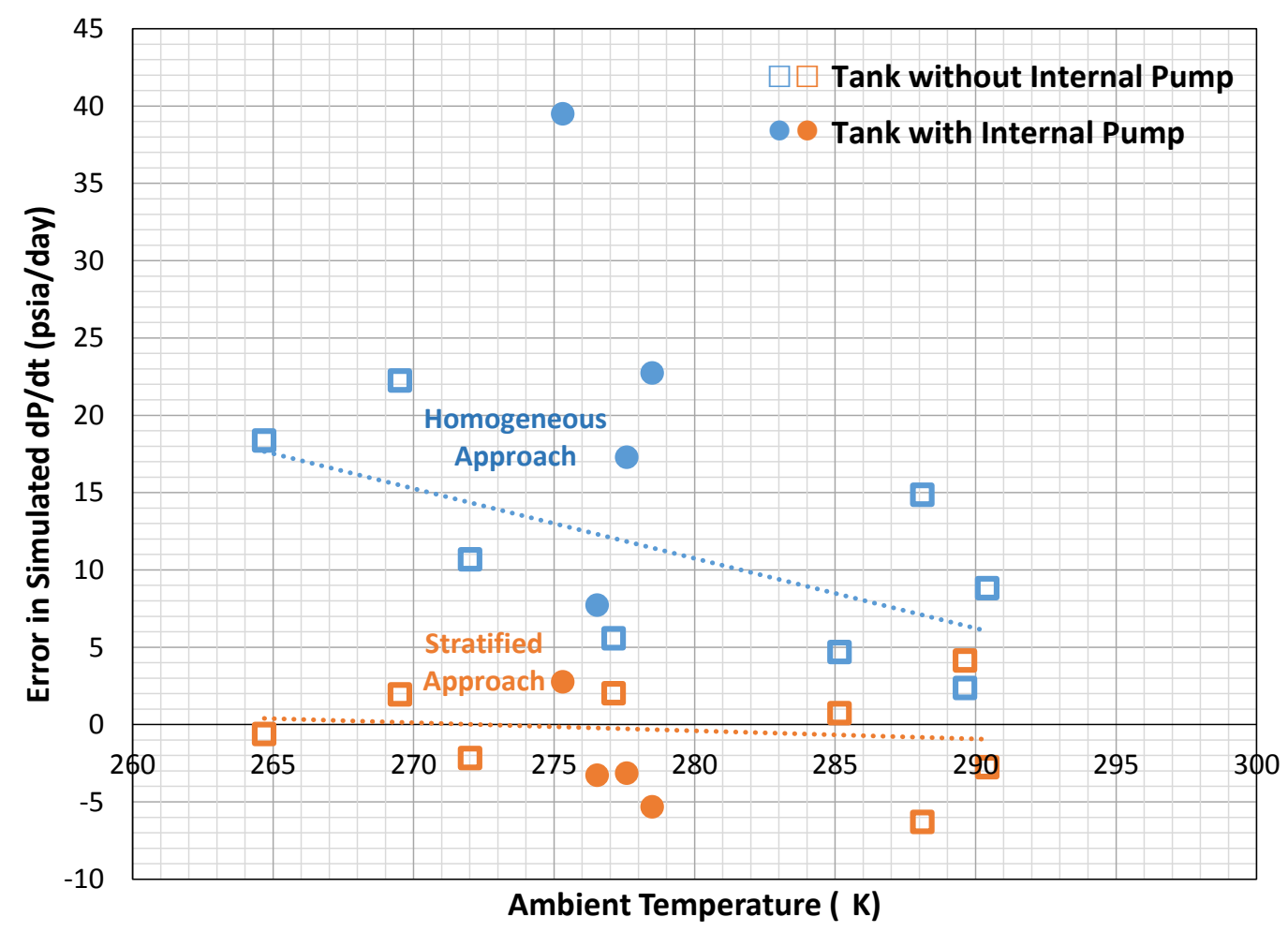

Figure 4.39. Error in Simulated dP/dt (psia/day) vs Ambient Temperature (K). 
A bubble diagram is shown in Figure 4.40 comparing the experimental and simulated $d P / d t$ for both tanks with respect to ambient temperature and fill level. Bubble size represented the $d P / d t$. The experimental values are indicated by dash lines. Homogeneous and stratified simulation results overlapped with the experimental results. This diagram allowed visualization of the mixed trends as a function of ambient temperature and fill level. The experimental $d P / d t$ increased at higher fill levels and at higher ambient temperatures. In this way, a small experimental $d P / d t$ was observed as $5.56 \mathrm{psia} /$ day for the minimum fill level of $10.81 \%$ when the minimum average temperature was $264.69 \mathrm{~K}$. The greatest experimental $d P / d t$ change was observed as $21.01 \mathrm{psia} /$ day for the tank without an internal fuel pump when the maximum average ambient temperature was $292.21 \mathrm{~K}$ and fill level was $105.20 \%$. The greatest experimental $d P / d t$ corresponded to the overfilled experiment 1 and was not simulated. Grey bubbles represented the homogenous approach. The increase of error for the homogeneous approach was observed when the fill level decreased. Orange and blue bubbles represented the stratified simulations for the tank with an internal fuel pump and without an internal fuel pump, respectively. The greater sizes of the experimental $d P / d t$ for the tank with an internal fuel pump were observed when compared to the experimental values from the tank without an internal fuel pump. It is believe that the internal fuel pump acted as a fin.

Finally, a summary of the heat transfer estimated by the homogeneous and stratified simulations is shown in Table 4.10. The distribution of heat transfer estimated for the liquid and vapor regions during the stratified simulations is included and the percentage with respect to the total heat transfer is compared. It was noted that the total heat transfer calculated using the two approaches was similar but the stratified simulations had a small increase compared to the homogeneous simulations. The total heat transfer was affected by the overall ambient temperature. The distribution of heat transfer between the vapor and liquid region was marked by the fill level of the experiments. 


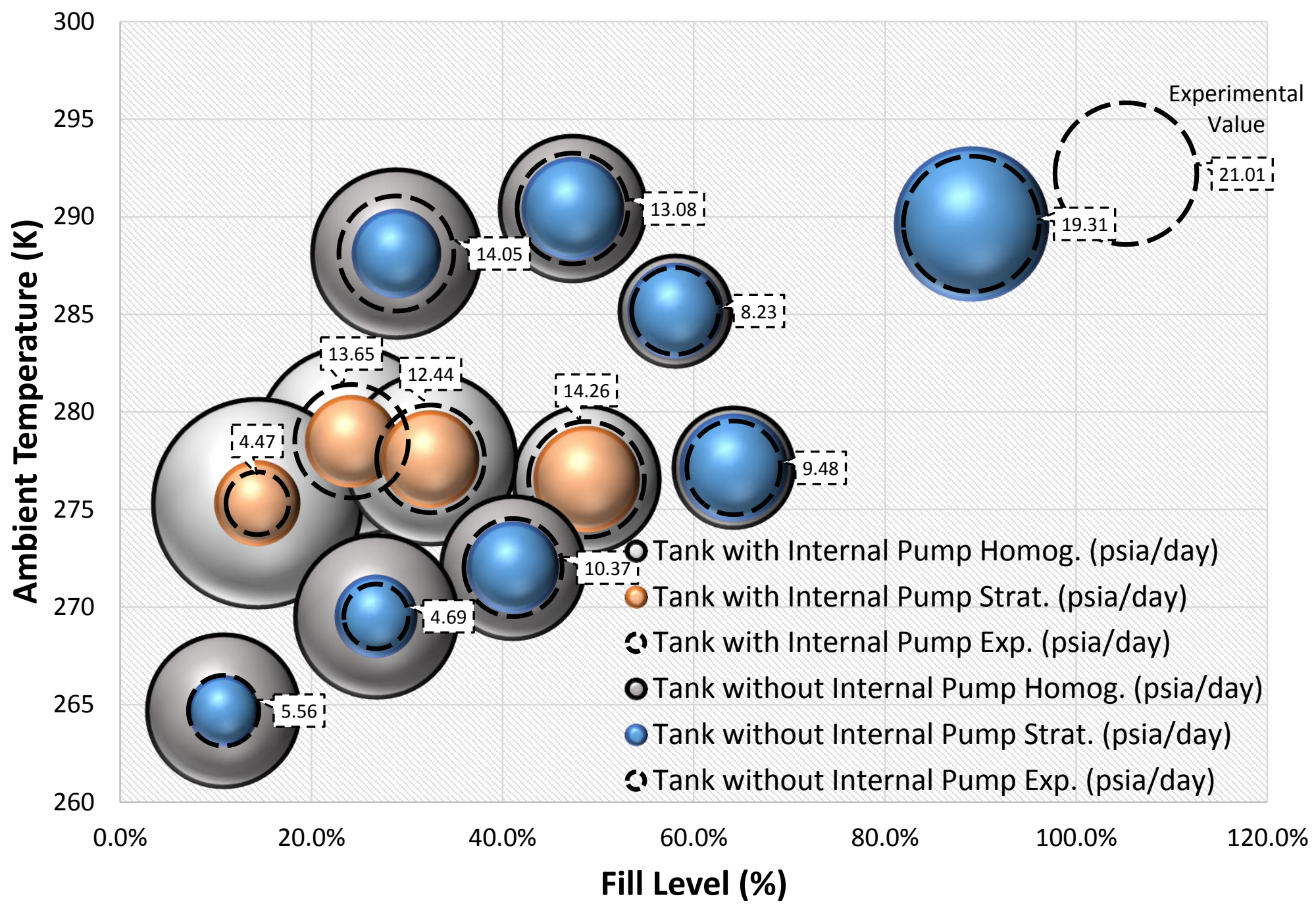

Figure 4.40. LNG Tanks Experimental dP/dt (psia/day) vs Ambient Temperature and Fill Level. 
Table 4.10. Summary of Heat Transfer for Vehicle Tanks Compared with Homogenous and Stratified Simulations.

\begin{tabular}{|c|c|c|c|c|c|c|c|c|c|c|c|c|}
\hline \multirow{2}{*}{\multicolumn{2}{|c|}{ Experiment }} & \multirow{3}{*}{$\begin{array}{l}\text { Start Dates } \\
9 / 10 / 2013 \\
\end{array}$} & \multirow{3}{*}{$\begin{array}{c}\text { Avg. } \\
\text { Ambient } \\
\text { Temp. }\left({ }^{\circ} \mathrm{K}\right) \\
292.21\end{array}$} & \multirow{3}{*}{$\begin{array}{l}\begin{array}{l}\text { Avg. Solar } \\
\text { Loading } \\
\left(\mathrm{W} / \mathrm{m}^{2}\right)\end{array} \\
98.78\end{array}$} & \multirow{3}{*}{$\begin{array}{c}\text { Initial } \\
\text { Mass } \\
\text { (kg) } \\
203.80\end{array}$} & \multirow{3}{*}{$\begin{array}{c}\text { Homog. } \\
\text { Fill } \\
(\%)\end{array}$} & \multirow{2}{*}{$\begin{array}{c}\text { Avg. HT } \\
\text { Homog. Sim } \\
\text { (kJ/day) }\end{array}$} & \multicolumn{2}{|c|}{$\begin{array}{l}\text { Avg. HT Strat. } \\
\text { Vapor Sim }\end{array}$} & \multicolumn{2}{|c|}{$\begin{array}{l}\text { Avg. HT Strat. } \\
\text { Liquid Sim }\end{array}$} & \multirow{2}{*}{$\begin{array}{l}\text { Avg. HT } \\
\text { Strat. Sim } \\
\text { (kJ/day) }\end{array}$} \\
\hline & & & & & & & & (kJ/day) & (\%) & (kJ/day) & $(\%)$ & \\
\hline \multirow{9}{*}{$\begin{array}{c}\text { Tank } \\
\text { without } \\
\text { Internal Fuel } \\
\text { Pump } \\
\text { (150 gallons) }\end{array}$} & Exp 1 & & & & & & & & & & & \\
\hline & $\operatorname{Exp} 2$ & $9 / 16 / 2013$ & 289.63 & 117.77 & 176.86 & $89.03 \%$ & 1828.15 & 298.20 & $16.13 \%$ & 1550.83 & $83.87 \%$ & 1849.04 \\
\hline & Exp 3 & $9 / 24 / 2013$ & 290.42 & 82.32 & 110.40 & $47.32 \%$ & 1967.02 & 999.97 & $49.60 \%$ & 1016.16 & $50.40 \%$ & 2016.13 \\
\hline & Exp 4 & $10 / 12 / 2013$ & 288.11 & 68.18 & 67.90 & $28.88 \%$ & 1925.35 & 1317.89 & $66.63 \%$ & 659.92 & $33.37 \%$ & 1977.81 \\
\hline & Exp 5 & $11 / 10 / 2013$ & 277.13 & 43.80 & 149.23 & $64.16 \%$ & 1746.22 & 618.12 & $34.32 \%$ & 1182.82 & $65.68 \%$ & 1800.94 \\
\hline & Exp 6 & $12 / 5 / 2013$ & 272.02 & 21.14 & 96.02 & $41.08 \%$ & 1631.77 & 916.87 & $54.46 \%$ & 766.60 & $45.54 \%$ & 1683.47 \\
\hline & Exp 7 & $12 / 30 / 2013$ & 269.52 & 29.62 & 63.05 & $26.77 \%$ & 1606.36 & 1126.66 & $67.83 \%$ & 534.29 & $32.17 \%$ & 1660.95 \\
\hline & Exp 8 & $3 / 2 / 2014$ & 264.69 & 0.98 & 26.31 & $10.81 \%$ & 1759.96 & 1490.96 & $84.33 \%$ & 277.13 & $15.67 \%$ & 1768.09 \\
\hline & $\operatorname{Exp} 9$ & $3 / 28 / 2014$ & 285.17 & 87.59 & 135.17 & $58.06 \%$ & 2010.30 & 849.43 & $41.53 \%$ & 1195.69 & $58.47 \%$ & 2045.11 \\
\hline \multirow{5}{*}{$\begin{array}{c}\text { Tank } \\
\text { with Internal } \\
\text { Fuel Pump } \\
\text { (120 gallons) }\end{array}$} & Exp 1 & $12 / 18 / 2013$ & & & 158.70 & $103.70 \%$ & & & & & & \\
\hline & Exp 2 & $12 / 22 / 2013$ & 276.54 & 33.96 & 91.99 & $48.77 \%$ & 1626.02 & 798.50 & $47.72 \%$ & 874.83 & $52.28 \%$ & 1673.33 \\
\hline & Exp 3 & $1 / 10 / 2014$ & 278.49 & 35.84 & 46.18 & $24.19 \%$ & 1648.62 & 1194.16 & $70.36 \%$ & 503.00 & $29.64 \%$ & 1697.16 \\
\hline & Exp 4 & $1 / 29 / 2014$ & 275.31 & 13.61 & 27.81 & $14.34 \%$ & 1621.00 & 1320.99 & $79.67 \%$ & 337.10 & $20.33 \%$ & 1658.09 \\
\hline & Exp 5 & $3 / 20 / 2014$ & 277.59 & 96.38 & 61.60 & $32.47 \%$ & 1707.00 & 1103.20 & $62.99 \%$ & 648.14 & $37.01 \%$ & 1751.35 \\
\hline
\end{tabular}


The average simulated heat transfer was plotted in Figure 4.41 with respect to fill level. It was observed that the total heat transfer entering the tank was higher at higher fill levels, following a linear trend. The heat transfer into the liquid region followed a linear trend increasing with the fill level. In the opposite way, the heat transfer into the vapor region followed a linear trend decreasing at higher fill levels. This behavior corroborated the previous findings stated where the $d P / d t$ increased with higher fill levels. The highest heat transfer entering the liquid region occurred with the tank without internal fuel pump when the fill level was $89.03 \%$. The heat transfer of $1.55 \mathrm{MJ} /$ day or $83.87 \%$ of the total heat transfer was estimated. For this simulation the heat transfer into the vapor region was $0.30 \mathrm{MJ} /$ day (16.13\%). Similarly, the minimum heat transfer into the liquid region occurred with the tank without internal fuel pump at $10.81 \%$ of fill level. Heat transfer into the liquid was $0.28 \mathrm{MJ} /$ day (15.67\%) and was $1.49 \mathrm{MJ} /$ day (84.33\%) into the vapor region.

The average heat transfer was plotted in Figure 4.42 with respect to ambient temperature. A polynomial trend was observed in the total heat transfer increasing at higher ambient temperatures. Heat transfer into the vapor and liquid regions were included in the figure; however, a clear trend was not observed and their distribution were strongly defined by the fill level in the tank. 


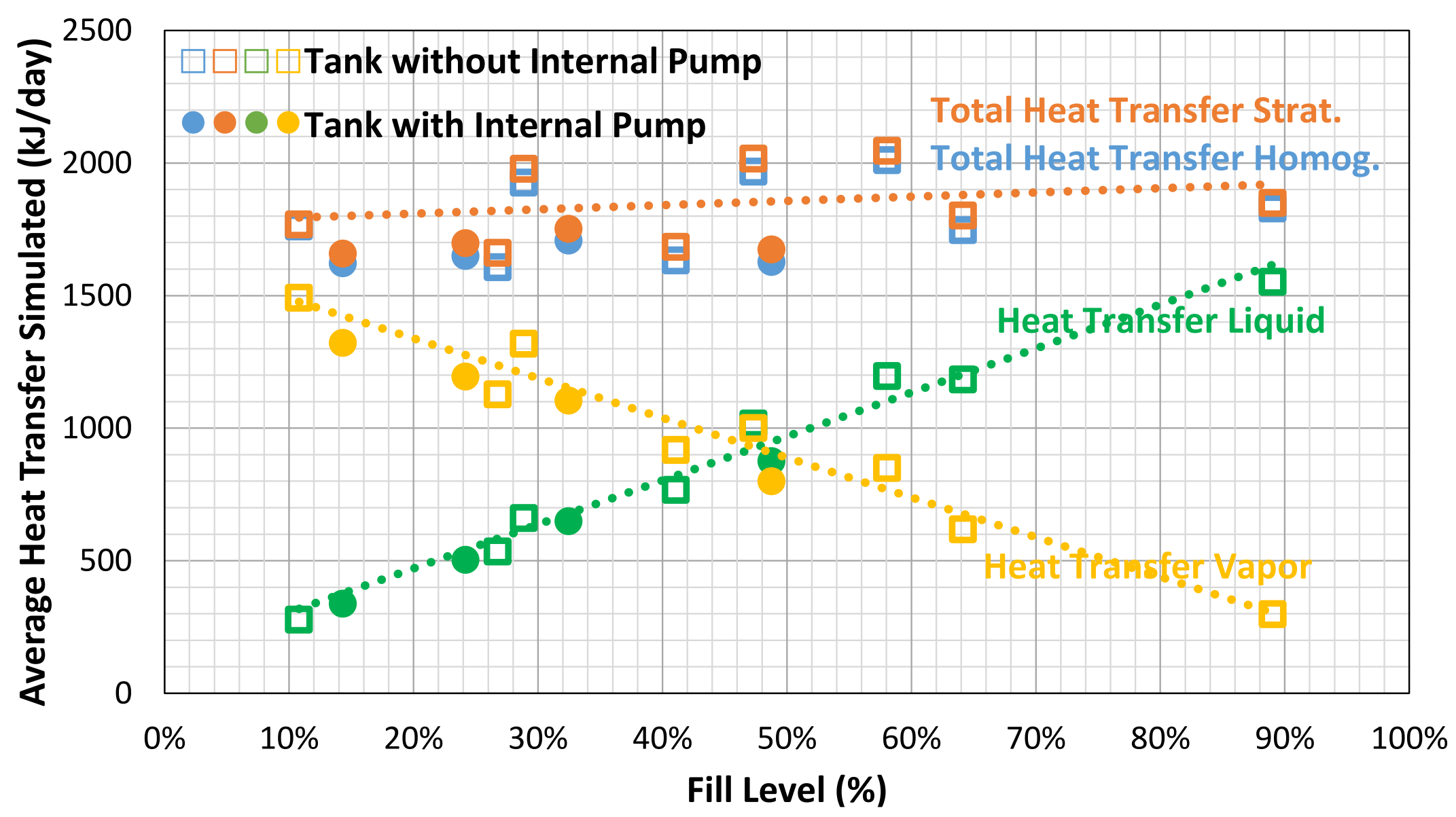

Figure 4.41. Heat Transfer Simulated (kJ/day) vs Fill Level (\%) for LNG Vehicle Tanks. 


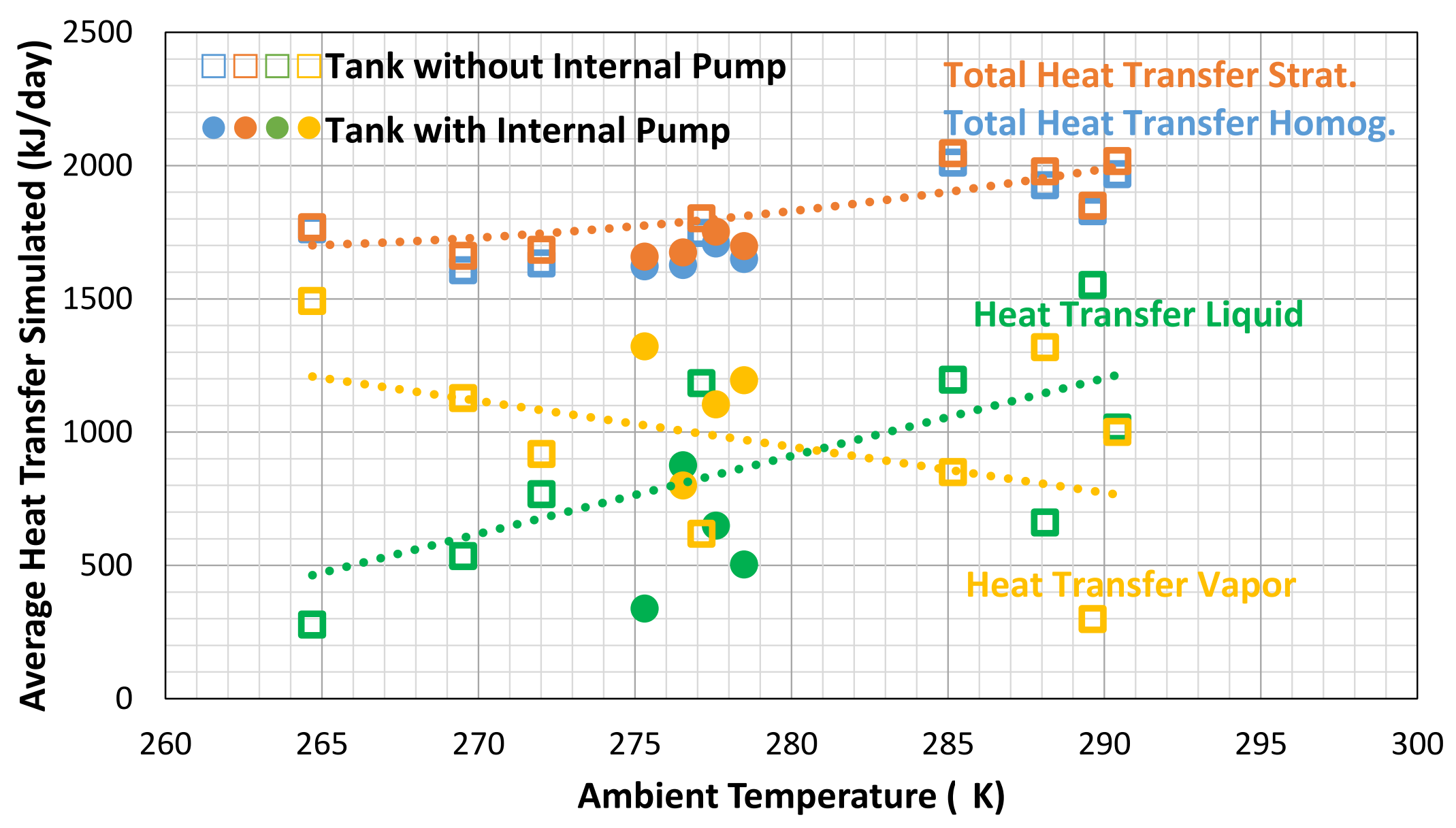

Figure 4.42. Heat Transfer Simulated (kJ/day) vs Ambient Temperature (K) for LNG Vehicle Tanks. 


\subsection{Venting Model Comparison with Experimental Tank Boil Offs}

A total of 13 venting experiments were performed with the LNG vehicle tanks at the WVU laboratory, eight with the 150 gallon tank without an internal fuel pump and five with the 120 gallon tank with an internal fuel pump. The venting experiments were divided into a total of 31 segments, twenty one with the tank without an internal fuel pump and ten with tank with an internal fuel pump. Additionally, information about five ventings were provided from the LNG tank manufactures. Tank manufactures performed four ventings with a 105 gallon LNG vehicle tank without an internal fuel pump and estimated one venting assuming the use of a 120 gallon tank with an internal fuel pump [78]. The mass of methane vented was calculated as the subtraction of the initial and final experimental tank weight, making the uncertainty of mass vented equal to $+/-1.80 \mathrm{lb}(+/-0.82 \mathrm{~kg})$. The weight error for the industry experiments was not provided, therefore the same uncertainty of $+/-1.80 \mathrm{lb}$ was used.

A short transient period was observed in the experimental tank pressure after a significant release of vapor from the vehicle tanks. During the transient the pressure initially had a lower peak before increasing into a new equilibrium pressure. After this brief thermodynamic transient the pressure continued increasing as a result of the heat leakage through the tank walls. For the venting simulations the final pressure was selected as the pressure after the venting transient. Figure 4.43 shows a comparison of the experimental pressure and the pressure simulated with the model for the experiment 3 with the LNG tank without an internal fuel pump. The recovery transients lasted for an average of 2 minutes after closing the PRV valve and the pressure dropped between 6 and 10 psia before settling at the new equilibrium pressure.

A summary of the vehicle tank experiments compared with the venting simulations is shown in Table 4.11. The mass of methane vented was estimated with an average error of $-0.10 \mathrm{~kg}(-1.46 \%)$ for both types of tanks. An average error of $-0.19 \mathrm{~kg}(-1.96 \%)$ was estimated for the tank without an internal fuel pump, $0.04 \mathrm{~kg}(0.09 \%)$ for the tank with an 
internal fuel pump, and $-0.18 \mathrm{~kg}(-3.45 \%)$ for the tanks experiments performed by the industry.

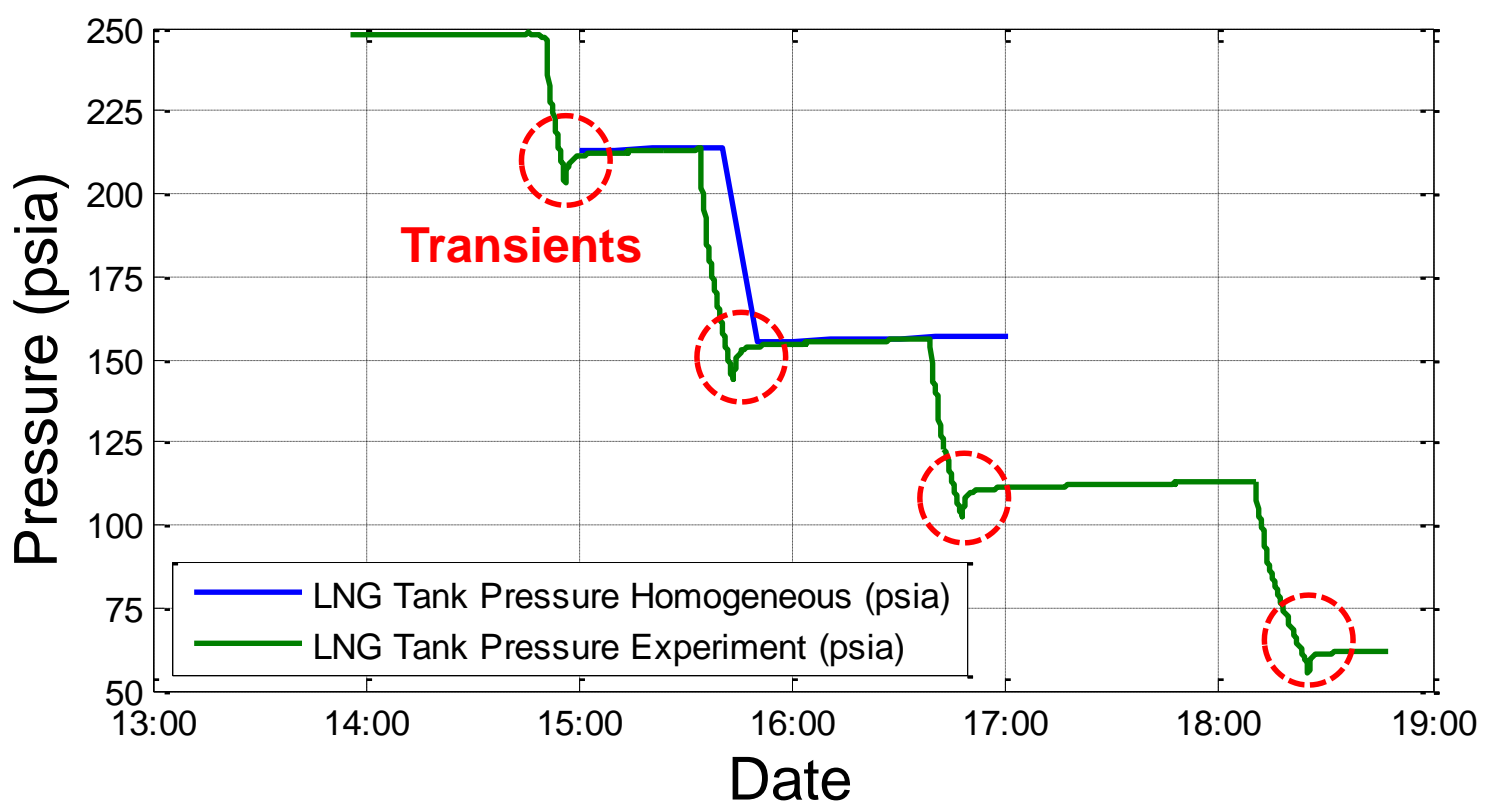

Figure 4.43. Pressure Transient of LNG after Ventings. Experiment 3 with the Tank without an Internal Fuel Pump.

It was believe at the time that the PRV of the tank without an internal fuel pump was not functioning as intended. It was intermittently activated and slowly released vapor when approaching the maximum pressure. For this reason, the tank was vented to atmospheric pressure and the PRV was replaced before starting experiment 4 . Later, it was determined that the behavior of the PRV was normal and likely not malfunctioning. Regardless, it was observed that the venting model error significantly increased for the experiments after the PRV was replaced. An uncharacterized error occurred during installation of the new PRV which affected the manual vents. Another possible reason for the increase in error was the experiments were performed during the winter months. It was probable that some amount of snow was present on the tank, and was not completely removed before the manual vents were executed. In this way, the initial weight conditions of the tank for the simulations may have been affected. Therefore, those measurements were reported but not included in the average performance calculated for the model. The average error of the venting model was calculated with 26 segments as $-0.10 \mathrm{~kg}$ with a 
standard deviation of $0.30 \mathrm{~kg}$. The minimum error of the eight segments with issues was twice the maximum error of the other 26 segments. Additionally, the errors of these eight segments were between 4 and 26 times the standard deviation of the venting model performance.

Table 4.11. Venting Model Results

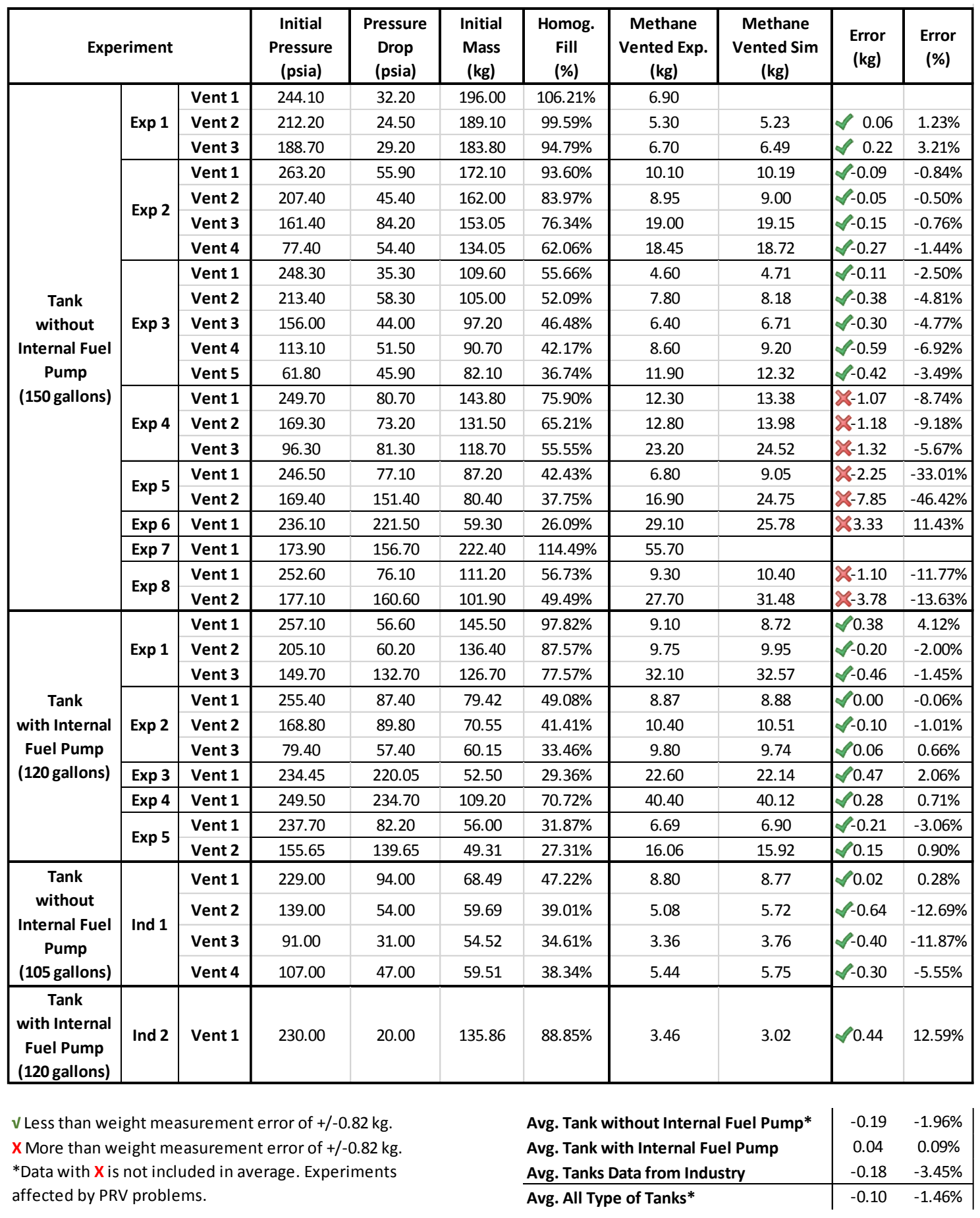


The first venting segment of experiment 1 and experiment 7 with the tank without an internal fuel pump were not simulated since the tank may have been over filled. Initial homogeneous fill levels were calculated as $106.21 \%$ and $114.49 \%$, respectively. Initial fill levels with the tank without an internal fuel pump ranged between $26.09 \%$ and $99.59 \%$, and between $54.62 \%$ and $97.82 \%$ for the tank with an internal fuel pump. Industry performed the vents with fill levels between $34.61 \%$ and $88.85 \%$.

The total mass of methane vented was measured between $3.36 \mathrm{~kg}$ and $55.70 \mathrm{~kg}$ when the pressure was reduced between 20.00 psia and 234.70 psia and the fill levels were between $26.09 \%$ and $99.56 \%$. The maximum error was estimated as $-0.64 \mathrm{~kg}$ which was below the $+/-0.82 \mathrm{~kg}$ weight instrumentation error. The maximum error for the vents where PRV issues occurred was estimated as $-7.85 \mathrm{~kg}$. A comparison between the experimental and simulated masses of methane vented from the tank without an internal fuel pump is shown in Figure 4.44 for the initial three experiments and in Figure 4.45 for the experiments after the PRV was replaced. Figure 4.46 shows a comparison for the tank with an internal fuel pump, and Figure 4.47 shows the experimental data from the industry. The measurement weight error of $+/-0.82 \mathrm{~kg}$ was shown in the figures as an error bar around the experimental values. Additionally, a direct comparison between the experimental and simulated mass of methane vented is shown in Figure 4.48 where good agreement of the model closer to the unit line was observed.

As was expected, the larger the pressure drop in the tank the larger the total mass vented. As well, the higher the fill level in the tank the larger the amount of methane released to drop the pressure. A bubble diagram is shown in Figure 4.49 to help visualize the mixed trends as a function of pressure drop and fill level. Bubble size represents the total mass vented. The experimental values are provided in the middle of each bubble. Simulation results overlap the experimental results using dashed lines. The minimum experimental mass vented was observed as $3.36 \mathrm{~kg}$ for the fill level of $34.61 \%$ and pressure drop of $31.00 \mathrm{psia}$ for one of the industry experiments with the 105 gallon tank without an internal fuel pump. The largest experimental mass vented was $55.70 \mathrm{~kg}$ for the tank without an internal fuel pump for a pressure drop of 156.70 psia and fill level of $114.49 \%$. This overfill corresponded to experiment 7 and was not simulated. Blue bubbles represent the experiments with the tank without an internal fuel pump. Orange bubbles indicate the tank 
with an internal fuel pump, and pink bubbles the data points from the industry. A variance in size of the experimental bubbles with similar conditions of fill level and pressure drop was observed, since the tank capacities were different.

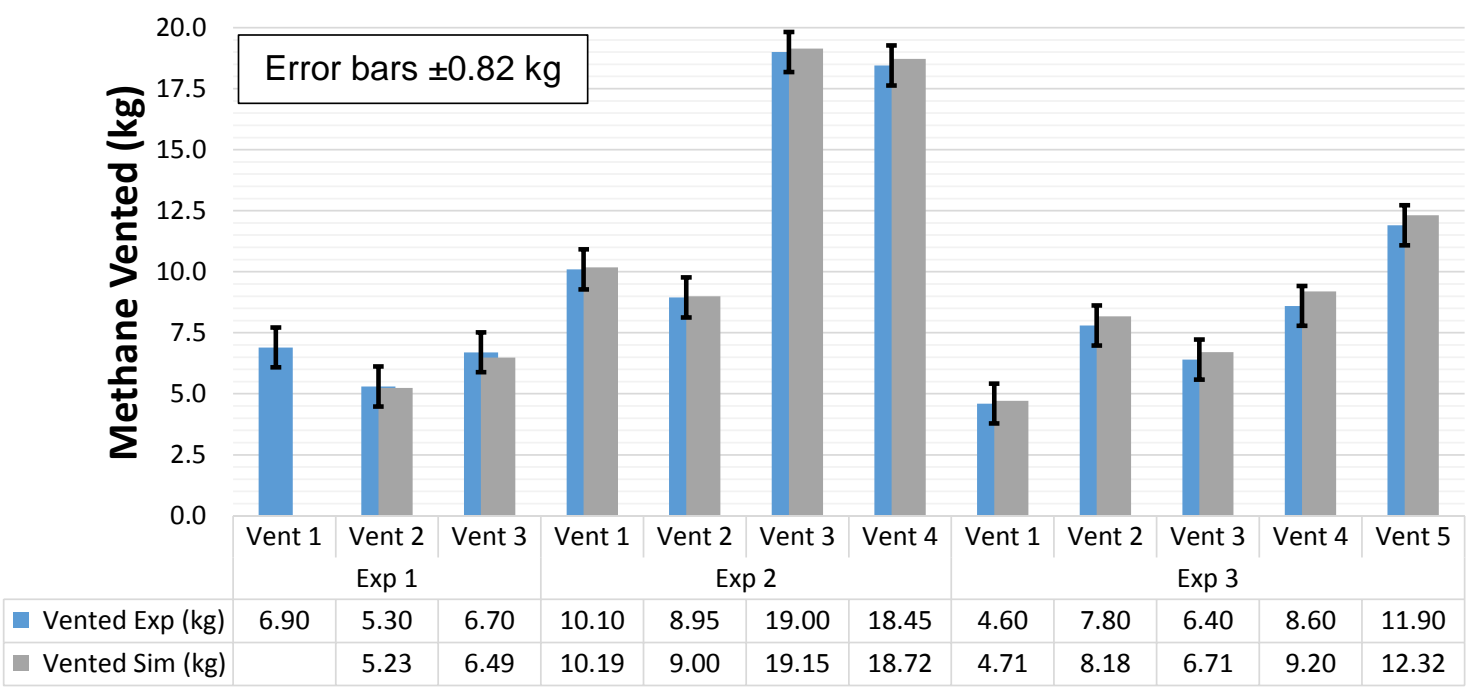

Figure 4.44. Venting Comparison for Tank without Internal Pump (150 gallons) for Experiments 1-3.

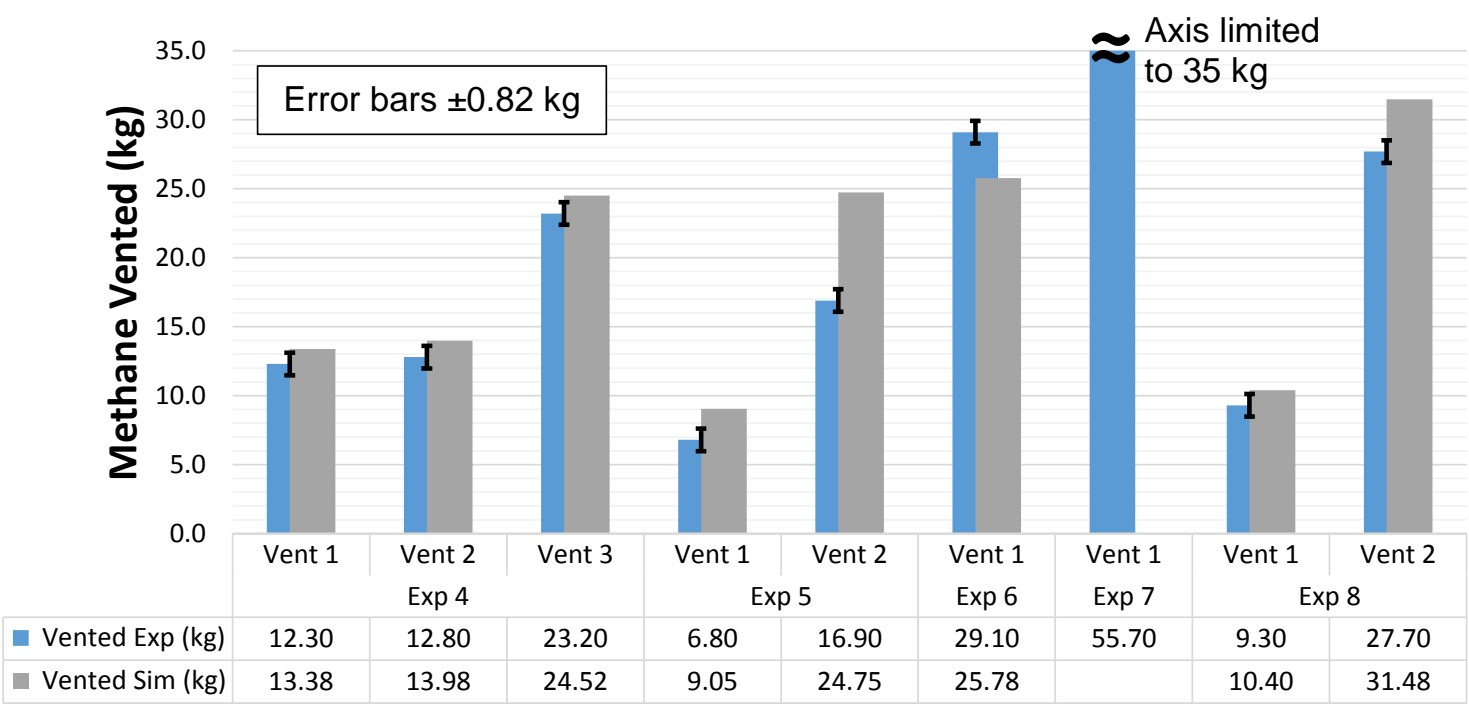

Figure 4.45. Venting Comparison for Tank without Internal Pump (150 gallons). Experiments 4-8 affected by PRV Problems 


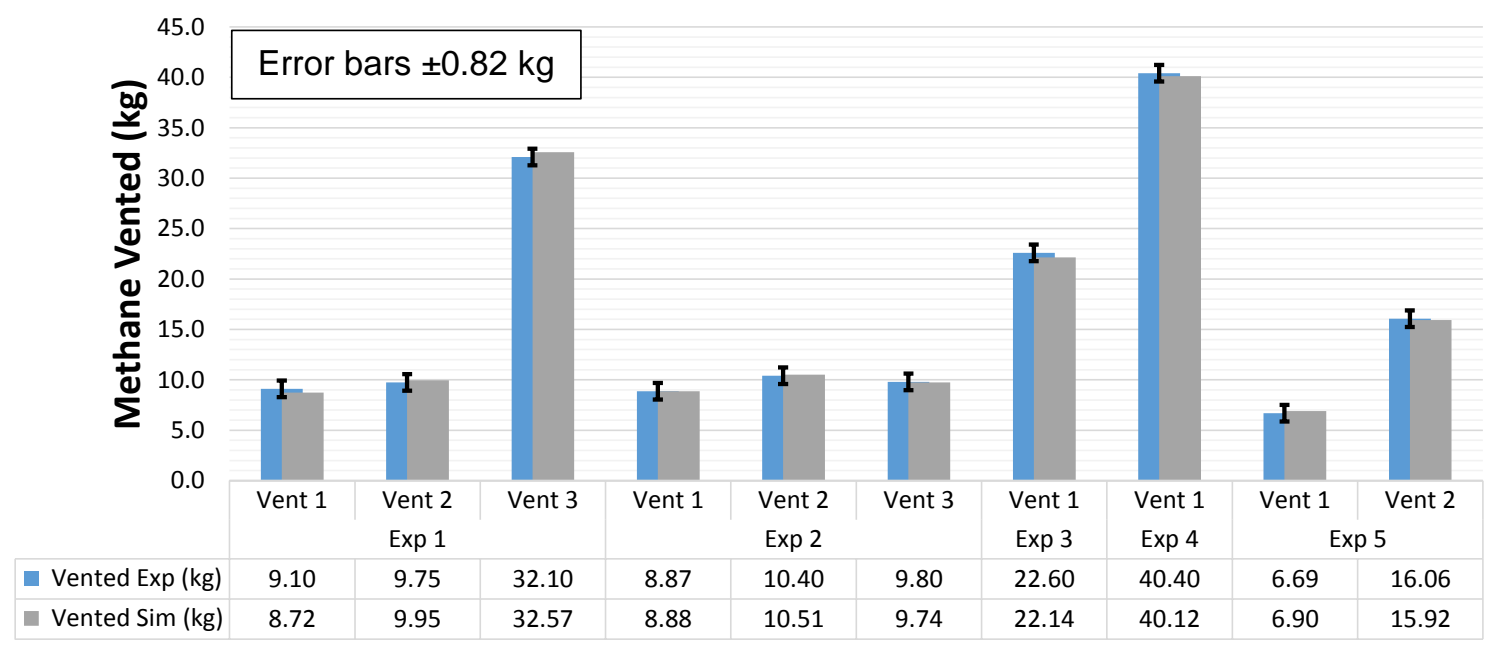

Figure 4.46. Venting Comparison for Tank with Internal Pump (120 gallons).

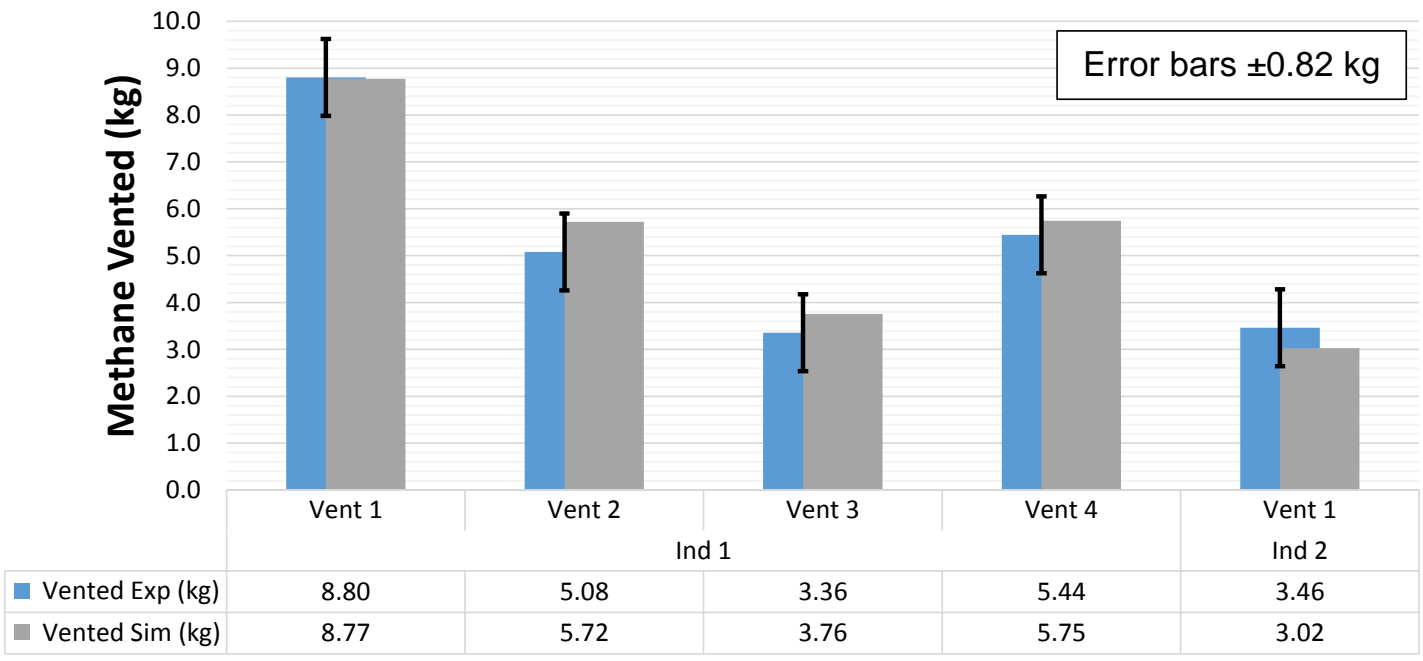

Figure 4.47. Venting Comparison for Data Provided by Industry. 


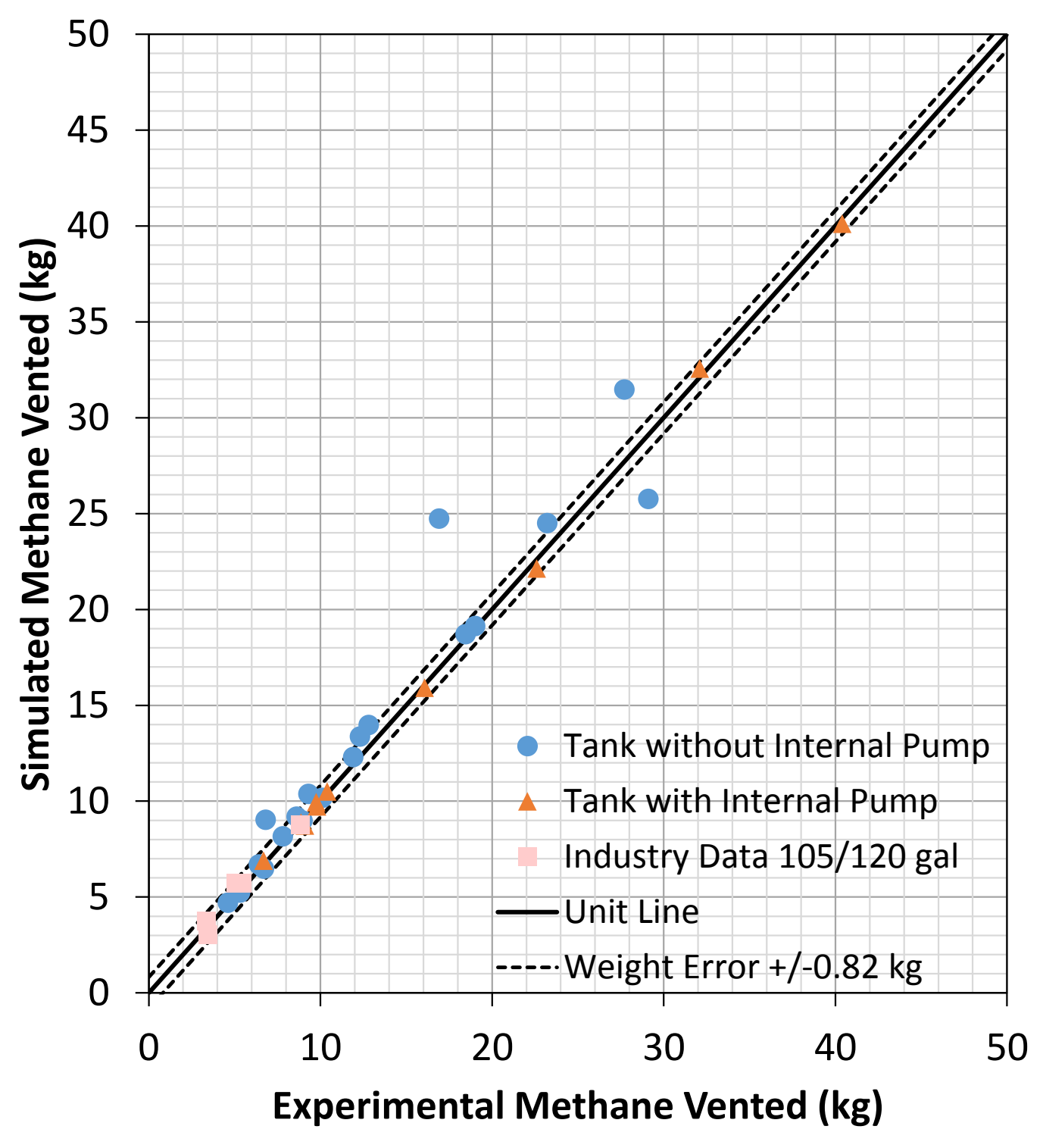

Figure 4.48. Experimental (kg) vs Simulated (kg) LNG Vented. 


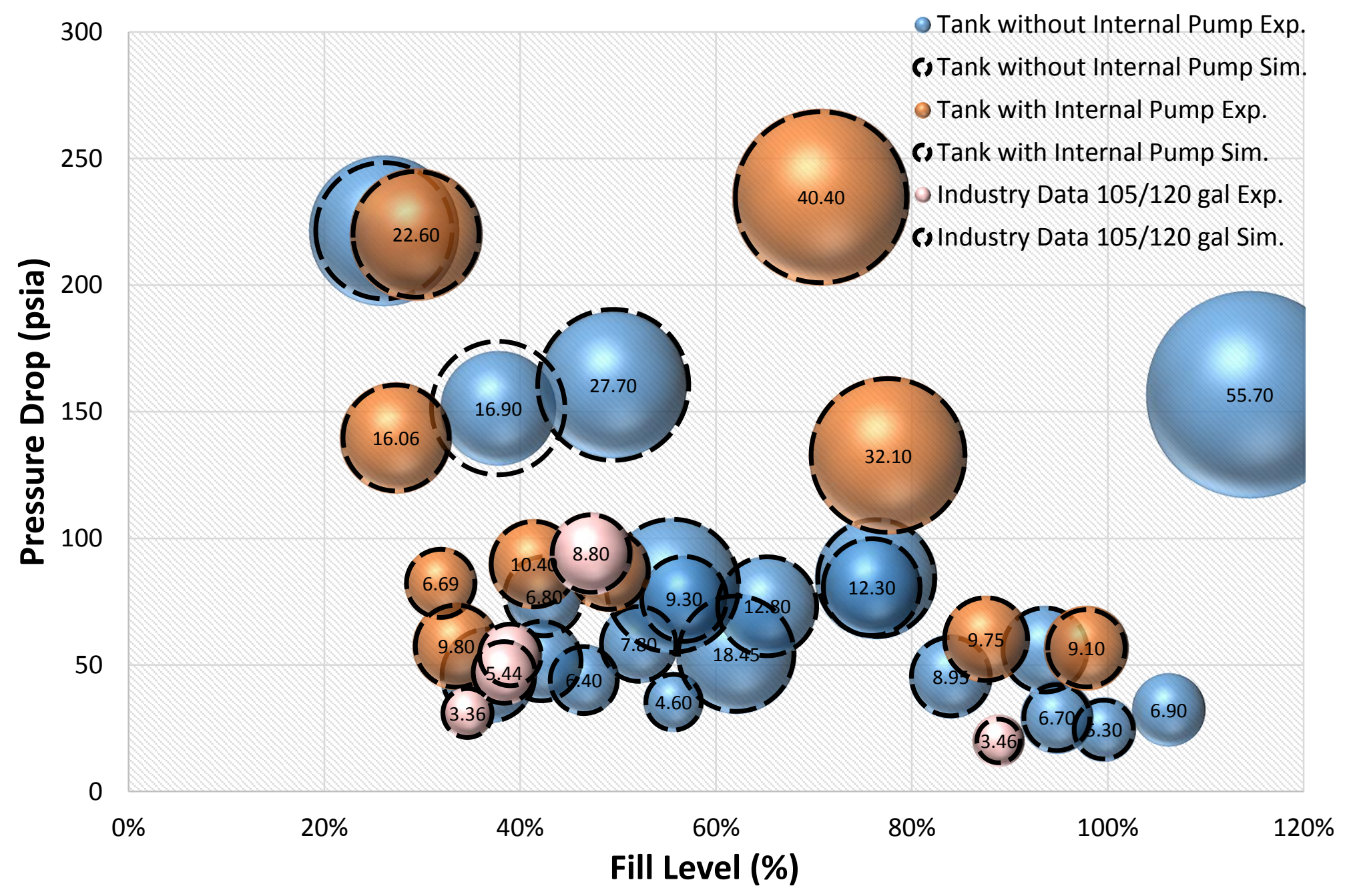

Figure 4.49. Experimental LNG Vented (kg) vs Pressure Drop and Fill Level. 


\subsection{Model Comparison with Fueling Stations with LNG Vehicles Refueling}

The full station model was compared against fourteen time periods from two LNG fueling stations, six from the Station 1 in Nevada and eight from the Station 2 located in Utah. The data set was subdivided for Station 1 each time the station was refueled and for Station 2 each time it was refueled and each time a manual vent was observed. Segments were between 19 and 98 hours in length.

Results from the LNG Fueling Station model using the homogeneous and stratified approaches were compared with the experimental data from the LNG stations. Results of pressure rise and fill level change are shown in the following two sections: Section 4.5.1 with the Station 1, and Section 4.5.2 with Station 2. Section 4.5.3 describes a detailed analysis of the results. Furthermore, detailed figures including the weather data, change of estimated masses, fuel dispensed to vehicles, temperature maps, and heat transfer calculated for selected segments are shown in Appendix C for Station 1 located in Nevada, and in Appendix D for Station 2 in Utah. Four segments were selected showing detailed simulations with the offload pump effect, a fast vapor removal, and two initial fill levels.

The LNG bulk tank dimensions and heat transfer values assumed for the simulations are shown in Table 4.12. Parameters were selected based on manufacturer literature, materials property tables, and assumptions for cryogenic tanks by Chen et al. [14]. Additionally, for confidentially with the LNG tank manufactures and station owners that provided information for this work all values reported that were not in the public documentation were changed. Similarly, sizes and lengths of piping of the stations used in the simulations are not reported. The gross capacity of the tanks were publically specified by the manufactures as 25,252 gallons $(95,5891)$ and 15,520 gallons $(58,7501)$ for Station One and Two, respectively. The relief valve pressure set point was selected as $135 \mathrm{psig}$ for both tanks and the surface absorptivity for white paint of 0.14 was used. The average ambient pressure at the location of the stations are shown in Table 4.13 and are used to convert between psig and psia. Multilayer insulation (MLI) was assumed in the vacuum area with a thermal conductivity of $5 \cdot 10^{-5} \mathrm{~W} /(\mathrm{m} \cdot K)$. The internal layer, external layer, and struts were assumed to be made of stainless steel. The thermal conductivity of the 
internal and external shells were recalculated every time step using the current ambient and internal wall temperatures, respectively. The thermal conductivity through the struts were calculated as the mean thermal conductivity between the ambient and internal wall temperatures. The struts were assumed to support the inner tank from the top, bottom, and sides (cylindrical region). The area ratio was defined as the cross-sectional area of support material divided by the external surface area of the tank designed to statically support the vessel and LNG product in it. The location and distribution of the struts were unknown. Therefore, the struts were assumed as the more often used in stationary tanks with stronger support of the inner tank from the top and bottom sections.

Table 4.12. Dimensions and Heat Transfer Values Used in the Simulations for the LNG Bulk Tanks at the Fueling Stations

\begin{tabular}{|c|c|c|c|c|}
\hline Variable Name & $\begin{array}{c}\text { Tank at } \\
\text { Station } 1 \text { in } \\
\text { Nevada }\end{array}$ & $\begin{array}{c}\text { Tank at } \\
\text { Station } 2 \\
\text { in Utah }\end{array}$ & Units & Reference \\
\hline Tank Volume Capacity & 95,589 & 58,750 & 1 & $\begin{array}{c}\text { Manufacture } \\
\text { Literature }\end{array}$ \\
\hline Relief Valve Pressure & 135 & 135 & psig & $\begin{array}{c}\text { Manufacture } \\
\text { Literature }\end{array}$ \\
\hline Outside Diameter & 2.9972 & 2.8956 & $\mathrm{~m}$ & $\begin{array}{c}\text { Manufacturer } \\
\text { Literature }\end{array}$ \\
\hline Insulation Thickness & 0.0667 & 0.0600 & $\mathrm{~m}$ & $\begin{array}{c}\text { Assumption based } \\
\text { on Chen et al. }\end{array}$ \\
\hline $\begin{array}{l}\text { External Shell Layer } \\
\text { Thickness }\end{array}$ & 0.0206 & 0.0206 & $\mathrm{~m}$ & $\begin{array}{c}\text { Assumption based } \\
\text { on Chen et al. }\end{array}$ \\
\hline $\begin{array}{l}\text { Internal Shell Layer } \\
\text { Thickness }\end{array}$ & 0.0206 & 0.0206 & $\mathrm{~m}$ & $\begin{array}{c}\text { Assumption based } \\
\text { on Chen et al. }\end{array}$ \\
\hline Length/Height of Tank & 20.3357 & 13.3350 & $\mathrm{~m}$ & $\begin{array}{c}\text { Manufacturer } \\
\text { Literature }\end{array}$ \\
\hline Top Area Ratio & $7.303 e-4$ & $7.303 e-4$ & $(-)$ & $\begin{array}{c}\text { Assumption based } \\
\text { on Chen et al. }\end{array}$ \\
\hline Cylindrical Area Ratio & $1.350 \mathrm{e}-5$ & $1.350 \mathrm{e}-5$ & $(-)$ & $\begin{array}{c}\text { Assumption based } \\
\text { on Chen et al. }\end{array}$ \\
\hline Bottom Area Ratio & $7.3030 \mathrm{e}-4$ & $7.303 e-4$ & $(-)$ & $\begin{array}{c}\text { Assumption based } \\
\text { on Chen et al. }\end{array}$ \\
\hline $\begin{array}{l}\text { Insulation Conductivity } \\
\text { (MLI) }\end{array}$ & $5.00 e-5$ & $5.00 e-5$ & $\mathrm{~W} /(\mathrm{m} * \mathrm{~K})$ & $\begin{array}{c}\text { Manufacturer } \\
\text { Literature }\end{array}$ \\
\hline $\begin{array}{l}\text { Surface Absorptivity } \\
\text { (White Paint) }\end{array}$ & 0.14 & 0.14 & $(-)$ & $\begin{array}{c}\text { Material Property } \\
\text { Tables }\end{array}$ \\
\hline
\end{tabular}


Table 4.13. Average Ambient Pressure at Experimental Locations

\begin{tabular}{|c|c|c|}
\hline Location & Elevation & Ambient Pressure \\
\hline Morgantown, West Virginia & $293 \mathrm{~m}(960 \mathrm{ft})$. & $14.4 \mathrm{psi}$ \\
\hline Station 1 in Nevada & $610 \mathrm{~m}(2,001 \mathrm{ft})$. & $13.7 \mathrm{psi}$ \\
\hline Station 2 in Utah & $1302 \mathrm{~m}(4,272 \mathrm{ft})$. & $12.6 \mathrm{psi}$ \\
\hline
\end{tabular}

The stratified approach was formulated for vertical tanks. The LNG bulk tank at Station 2 was a vertical tank, however, at Station 1 in Nevada the bulk tank was horizontal and equivalent vertical tank dimensions were used. The height of the tank was maintained as $2.9972 \mathrm{~m}$ and an equivalent radius of $3.1862 \mathrm{~m}$ was calculated conserving the tank volume.

Both fueling stations recorded storage tank pressure electronically, however, only Station One automatically recorded LNG level and fuel dispensing information. Therefore, data from vehicle refueling events were manually logged in parallel for both stations. LNG level at the bulk tank of Station 2 was only manually observed from the gauge at the beginning and end of the three fueling offloads and at four of the manual ventings.

A summary of the vehicle refueling events observed at both stations is provided in Table 4.14. For Station 1 fuel was dispensed to a total of 685 vehicles. WVU personnel observed $458(67 \%)$ of those refueling vehicles and were able to obtain complete data sets on $365(53.3 \%)$ vehicle refueling events. The remaining $320(46.7 \%)$ vehicle refueling events were approximated using averages of the actual transactions observed. In a similar way, a total of 221 vehicle refueling events were observed at Station 2. Electronic transactions were not available at Station 2, therefore, some of the vehicle refueling events were not observed and were not accounted for. Some of the vehicles using the LNG stations had single tanks and others had two LNG tanks, referred to as driver side tank and passenger side tank. The driver side tanks were typically larger than the passenger side tanks. At Station 1, driver side tanks had a capacity of 120 gallons and passenger side tanks had a capacity of 70 gallons. At Station 2, driver side tanks were of 120 gallons and passenger side tanks were between 60 and 120 gallons. The key parameters collected from each refueling event were vehicle tank level and pressure upon arrival, and vehicle tank pressure after fueling. The stations were not capable of delivering fuel to vehicles with tank pressures exceeding $150 \mathrm{psig}$. The stations were equipped such that vehicle tanks could 
reduce their pressure by venting vapor back to the station before allow the refueling. The fleet summary in Table 4.14 include the minimum, maximum, and average of the vehicle tank pressures upon arrival and after returning vapor to the stations. Arrival and postventing pressures were used to estimate the amount of methane returned to the station bulk tank. The vehicles at Station 1 vented down to between 55 and 155 psig. At Station 2 vehicles always vented down to 130 psig.

Table 4.14. Summary of Fleet Recorded at the LNG Fueling Stations

\begin{tabular}{|c|c|c|c|c|c|}
\hline \multicolumn{3}{|c|}{ Variable Name } & $\begin{array}{c}\text { Tank at } \\
\text { Station } 1 \\
\text { in Nevada }\end{array}$ & $\begin{array}{c}\text { Tank at } \\
\text { Station } 2 \\
\text { in Utah }\end{array}$ & Units \\
\hline \multicolumn{3}{|c|}{ Vehicles Recorded } & $365 / 685$ & $221 /(231-251)$ & $(-)$ \\
\hline \multicolumn{3}{|c|}{ Vehicles with 2 Tanks } & 345 & 205 & $(-)$ \\
\hline \multicolumn{3}{|c|}{ Vehicles with a Single Tank } & 20 & 16 & $(-)$ \\
\hline \multirow{2}{*}{\multicolumn{3}{|c|}{$\begin{array}{l}\text { Driver Tanks Arrived Above } 150 \text { psig } \\
\text { Total Driver Tanks Vented to Station }\end{array}$}} & 142 & 87 & $(-)$ \\
\hline & & & 242 & 119 & $(-)$ \\
\hline \multirow{2}{*}{\multicolumn{3}{|c|}{$\begin{array}{l}\text { Passenger Tanks Arrived Above } 150 \text { psig } \\
\text { Total Passenger Tanks Vented to Station }\end{array}$}} & 145 & 61 & $(-)$ \\
\hline & & & 217 & 104 & $(-)$ \\
\hline \multirow{6}{*}{ 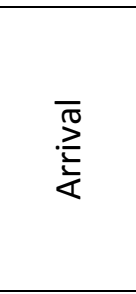 } & \multirow{3}{*}{ Driver Tank } & Min. & 27 & 50 & psig \\
\hline & & Max. & 243 & 250 & psig \\
\hline & & Avg. & 146 & 144 & psig \\
\hline & \multirow{3}{*}{ Passenger Tank } & Min. & 25 & 50 & psig \\
\hline & & Max. & 245 & 230 & psig \\
\hline & & Avg. & 150 & 143 & psig \\
\hline \multirow{6}{*}{ 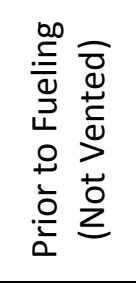 } & \multirow{3}{*}{ Driver Tank } & Min. & 27 & 50 & psig \\
\hline & & Max. & 165 & 145 & psig \\
\hline & & Avg. & 115 & 118 & psig \\
\hline & \multirow{3}{*}{ Passenger Tank } & Min. & 25 & 50 & psig \\
\hline & & Max. & 155 & 130 & psig \\
\hline & & Avg. & 115 & 116 & psig \\
\hline \multirow{6}{*}{ 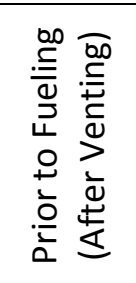 } & \multirow{3}{*}{ Driver Tank } & Min. & 45 & 130 & psig \\
\hline & & Max. & 165 & 130 & psig \\
\hline & & Avg. & 116 & 130 & psig \\
\hline & \multirow{3}{*}{ Passenger Tank } & Min. & 55 & 130 & psig \\
\hline & & Max. & 155 & 130 & psig \\
\hline & & Avg. & 116 & 130 & psig \\
\hline \multirow{6}{*}{ 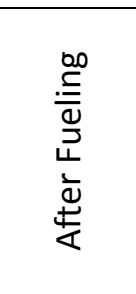 } & \multirow{3}{*}{ Driver Tank } & Min. & 95 & 100 & psig \\
\hline & & Max. & 220 & 180 & psig \\
\hline & & Avg. & 149 & 145 & psig \\
\hline & \multirow{3}{*}{ Passenger Tank } & Min. & 85 & 100 & psig \\
\hline & & Max. & 225 & 180 & psig \\
\hline & & Avg. & 152 & 145 & psig \\
\hline
\end{tabular}


The entire experimental data set for the fueling Station 1 in Nevada is shown in Figure 4.50. Six segments divided by the tanker offloads are observed. The bulk tank pressure stayed between a minimum of 74.8 psia and the maximum PRV pressure of 148.7 psia $(135+13.7 \mathrm{psi})$. The station bulk tank vented twice when the PRV pressure was reached at the end of segment 3 and segment 4 . The vehicles did not use the station during Sundays. A slower pressure rise during Sundays compared to a typical work day was observed.
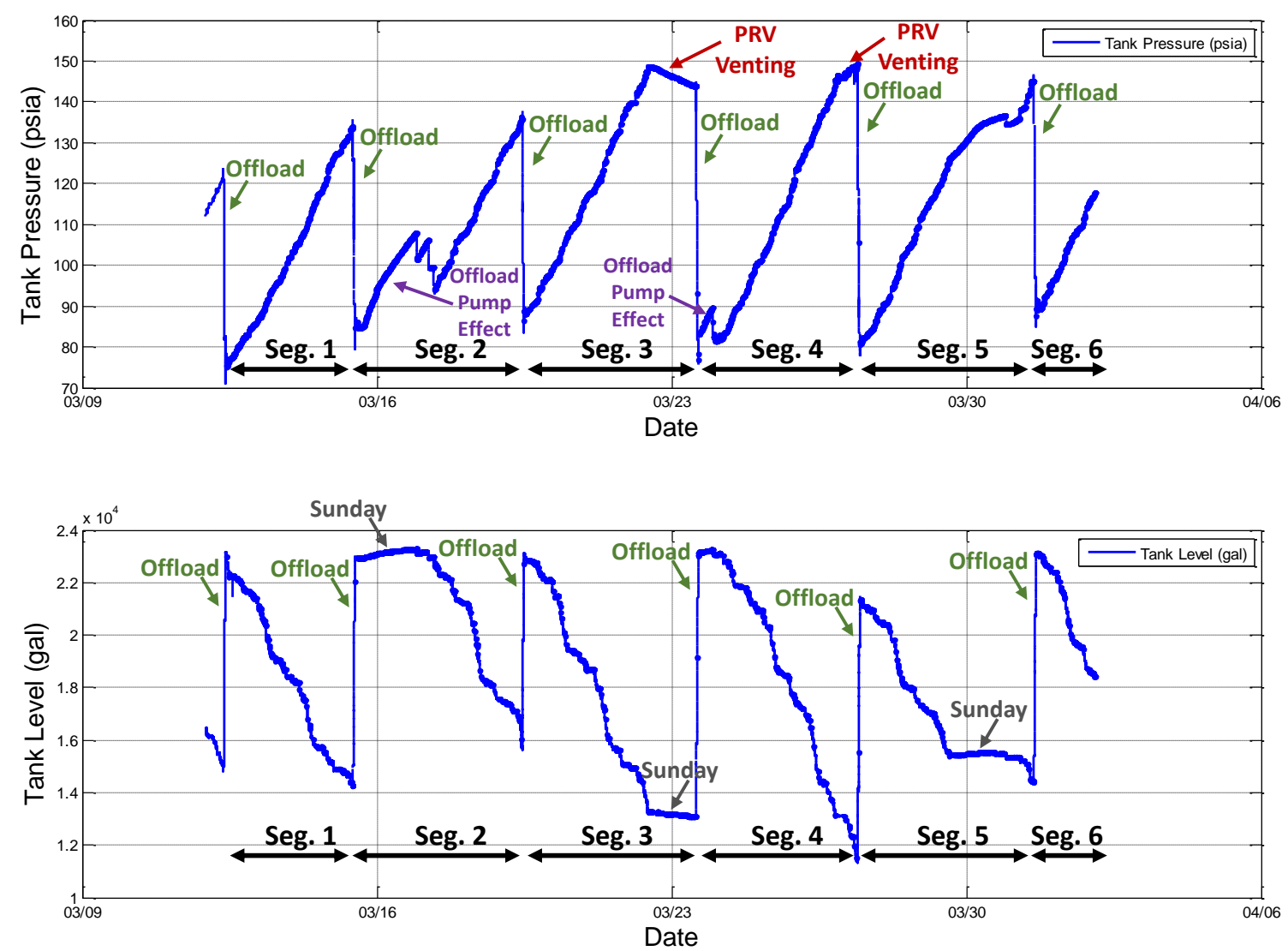

Figure 4.50. Full Experimental Data for Fueling Station 1 in Nevada.

Other continuous signals recorded during the time at Station 1 were the temperature and pressure of the offload pump. Figure 4.51 shows the offload pump pressure compared to the tank pressure. An "offload pump effect" was noted at the beginning of segment 2 and segment 4 where the tank pressure rapidly increased. It was observed that after the tankers delivered LNG into the bulk tank the offload pump maintained the same pressure 
as the bulk tank, making it clear that these were still connected. The offload pump tracked the tank pressure after each tanker offload between 24 hours and 36 hours. At this point the pressure started to slowly decrease diverging from the tank pressure, which indicated a disconnection with the bulk tank. It was observed that the temperature inside the offload pump (therefore in the piping used) increased until reaching ambient temperature. Disconnection occurred always around $50^{\circ} \mathrm{F}(255.93 \mathrm{~K})$.

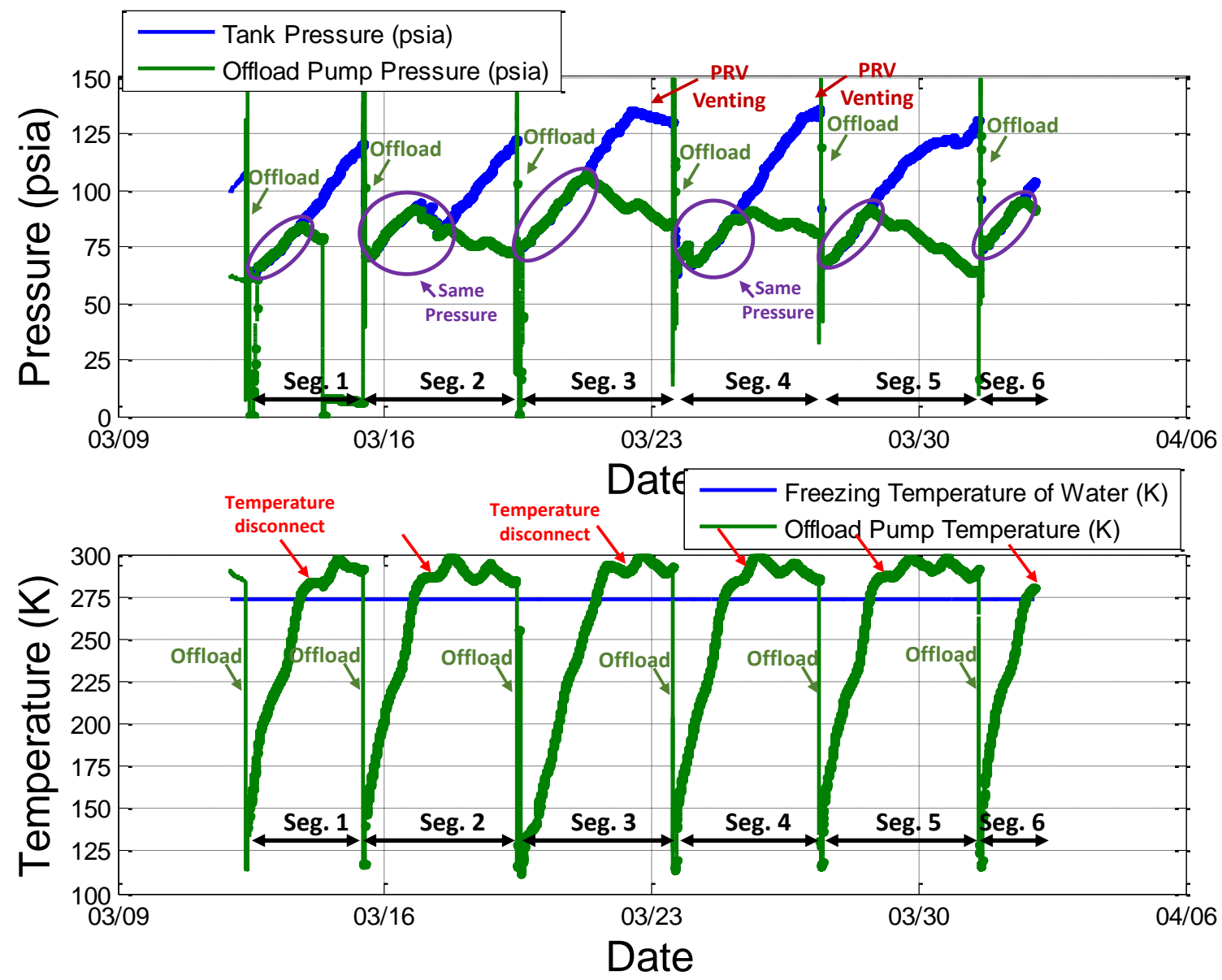

Figure 4.51. Offload Pump Effect at Fueling Station 1 in Nevada.

During the "offload pump effect" it is believe that the residual LNG inside the offload pump piping was expanding into the top of the bulk tank as warmer vapor through a one way check valve. The warm vapor accumulated at the top of the tank may have affected the pressure measurement system. The effect was more notable during the beginning of segment 2 and segment 4 when the station tank was idle and vehicles were not fueling. The station was closed during Sundays and opened early Mondays. LNG bulk tanks determine the liquid level in the tank by measuring the differential pressure between 
the top and bottom of the tank. Pressure in the tank is measured by the vapor pressure in the top of the tank. After vehicles started arriving at the station the "offload pump effect" disappeared. It is believed that the dispensing and recirculation of LNG mixed the cumulated warmer vapor that was at the top of the tank in the entire vapor region. Nevertheless, the warm vapor continued entering the tank from the offload pump piping until the disconnection with the bulk tank.

To compensate for the offload pump behavior an average heat transfer value was calculated and added during the time that the offload pump was connected to the bulk tank. Offload pump piping dimensions and lengths were provided by the station owners and were used in the calculations. The liquid LNG remaining in the pipes was calculated and the total heat necessary to evaporate the liquid to ambient temperature was estimated. Heat transfer by the offload pump effect was estimated for each simulation segment between 11.1 MJ/day and 43.3 MJ/day. As it will be seen in Section 4.5.3 it accounted for an average of $3.1 \%$ of the total heat transfer calculated. The mass of vapor leaking into the tank (total of around $15 \mathrm{~kg}$ ) was neglected since the average mass entering the tank in a time step was very small (around $0.02 \%$ ) compared to the total mass of vapor in the ullage. During the simulations there was not an instant match with the tank pressure recorded when the offload pump effect was presented, since it was believed that a false pressure head happened affecting the top measuring system. However, on average the heat transfer added compensated for the behavior happening and after the effect disappeared a matching of the pressure was observed where the simulation pressure followed the experimental pressure trends.

The entire experimental data for the fueling Station 2 in Utah is shown in Figure 4.52. Eight segments divided by three tanker offloads and four manual ventings were observed. The bulk tank pressure stayed between a minimum of 63.3 psia and a maximum pressure of 109.8 psia. The station bulk tank did not reach the maximum PRV pressure of 147.6 psia $(135+12.6 \mathrm{psi})$, however it was manually vented six times by station operators. The fill level of the bulk tank was not automatically recorded and was observed from the tank gauge only before and after the tanker offloads and manual vents. The initial fill level of segment 1 and the final level of segment 8 were estimated using the information logged 
from the vehicle dispensing records. An "offload pump effect" was not observed in Station 2 and extra heat transfer by this behavior was not included, nevertheless, any information of the offload pump was not provided nor recorded.
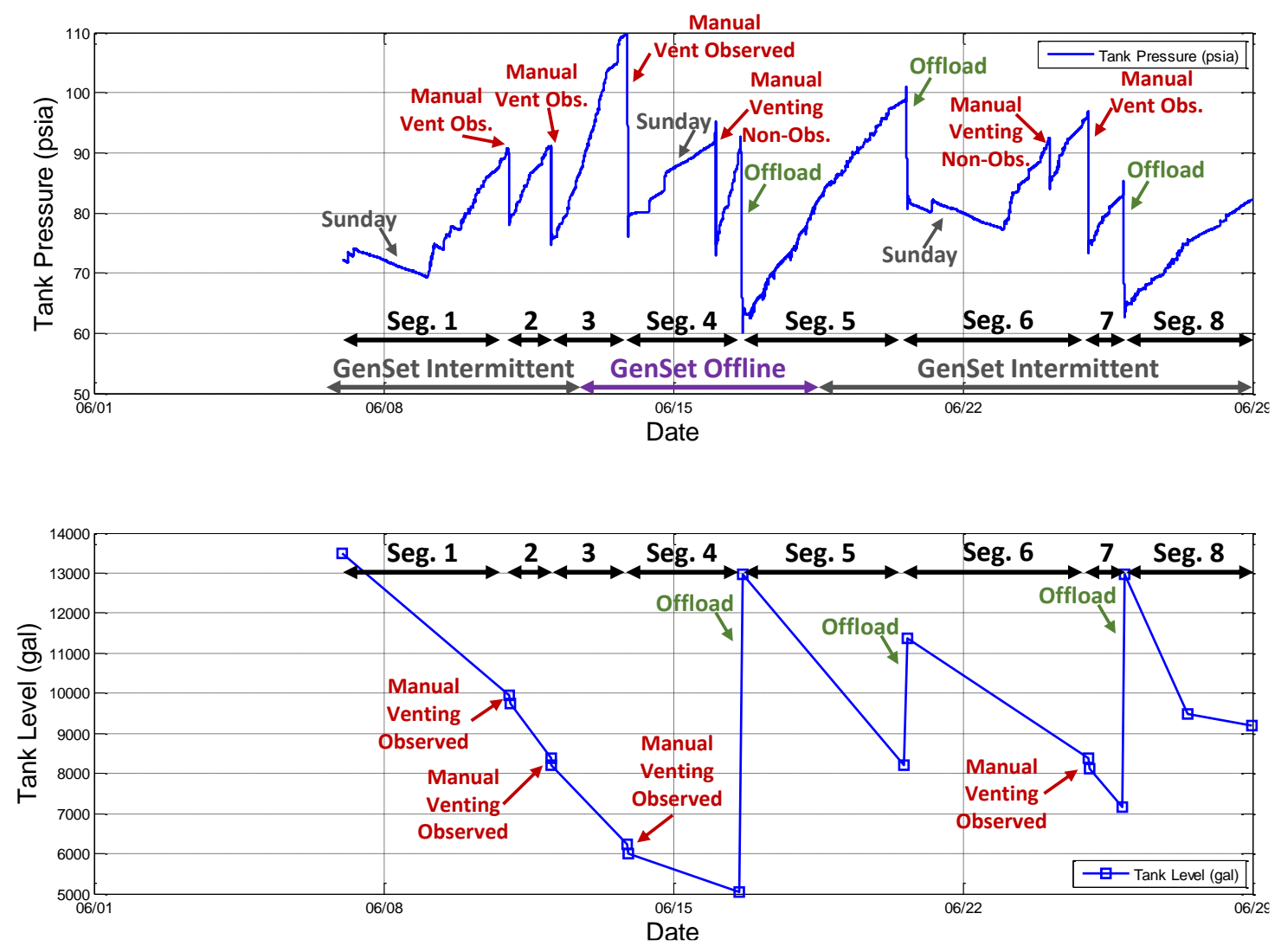

Figure 4.52. Full Experimental Data for Fueling Station 2 in Utah.

The Station 2 employed a natural gas fired turbine for electricity generation to consume excess LNG boil off gas. During the three weeks at the station a series of issues occurred with the electrical generator. Figure 4.52 includes the period of time when the generator was offline and the periods when it was working intermittently. The maximum electrical generator fuel consumption rate was assumed based on turbine specification as $8.70 \mathrm{~kg} / \mathrm{h}$, since this showed a net full load power of $30 \mathrm{~kW}$ and efficiency of $27 \%$. Actual turbine operating demand and fuel consumption which are required to better understand its role in vapor withdraw and station tank performance were not known. However, after observing the pressure profile of the second station a constant load power of $100 \%, 50 \%$, and $25 \%$ were assumed and distributed around the seven segments when the generator was 
partially in use. Respectively linear vapor consumption rates assumed were 8.70, 4.35, and $2.18 \mathrm{~kg} / \mathrm{h}$. Nevertheless, vapor consumption is not necessarily linear with respect to power load. The station was closed on Sundays and did not dispense to vehicles those days. The bulk tank pressure during the beginning of segments 1 and 6 decreased and a constant load of $100 \%$ was assumed for the electrical generator. Fuel was not dispensed during those times. It was believed that a fast removal of vapor from the station tank will dissipate the stratification in the vapor region, which was counter to the assumptions of the stratified thermodynamic approach. Therefore, segment 1 and segment 6 were simulated twice: 1a/6a at the beginning of the segments and $1 b / 6 b$ starting at the end of the decrease in tank pressure. The initial fill levels for the second simulations were estimated using the information logged about the fuel dispensed. As it will be seen in the results in Section 4.5.2 the stratified approach performed poorly when simulations started at the beginning of segments 1 and 6, however a large improvement was observed when simulations were started after the pressure stopped decreasing. The stratified approach assumed that temperature stratification was developing in the vapor and in the liquid region simultaneously, and thermodynamic relations following this assumption were used. In order to be able to simulate a constant fast removal of vapor from the tank a model that assumes development of stratification in the liquid region and not in the vapor region needs to be developed, with appropriate relations between the two regions.

The heat transfer model independently calculated the heat leak through the top and bottom of the tank wall, and the heat leak affecting the vapor and liquid regions. Heat transfer through the vapor and liquid regions were calculated using the temperature profiles which divided the liquid and vapor regions in $\mathrm{N}_{V}$ and $\mathrm{N}_{\mathrm{L}}$ layers respectively. Additionally, the heat transfer model estimated the heat leak associated with vehicle transactions: in the vapor return line, in the cool down of piping between the tank and dispensers (recirculation), and in the cool down of the station dispensers.

Vapor was returned in a bare stainless steel line of lengths greater than $60 \mathrm{ft}$. (18.3 $\mathrm{m})$. It was assumed that vapor started in the return pipe at the saturated temperature and pressure of the vehicle tank and arrived to the bulk tank after traveling through the bare pipe as a super-heated vapor at ambient temperature and bulk tank pressure. For each vehicle that vented vapor back to the station the heat necessary to increase the temperature 
of the vapor was estimated and added into the vapor region of the bulk tank. The amount of mass vented and enthalpy related to dropping the pressure from the vehicle tank was estimated and added into the bulk tank as well.

Recirculation of LNG was used at the stations to maintain the cold temperature of the pipes before dispensing LNG into the vehicles. Station 1 constantly recirculated LNG maintaining their systems always ready for the vehicles. Station 2 only recirculated previous to dispensing LNG to a vehicle. For the simulations it was assumed that both stations constantly recirculated LNG to cool down their pipes. The valve and fixture specifics present in the lines were unknown and equivalent lengths of pipe were used. Lengths were provided by the owners for Station 1 and were visually estimated for Station 2. A resistance network was used to calculate the heat input through the multiple types of pipes found in a station with their equivalent lengths and proper thermal conductivity values. Four types of piping were used: bare, foam insulated, vacuum jacketed (VJP), and MLI piping.

The heat transfer by the fuel dispensers was modeled similarly to the recirculation piping. Fuel dispensers at the stations modeled were cooled only each time that a vehicle was fueled. Heat gained by the station was calculated from the cool down prior a vehicle refueling and the heat transferred to the LNG left in the dispenser after fueling.

The homogeneous approach used the total heat transfer into the thermodynamic model as the sum of all the heat leaks. The stratification approach used the heat leaks estimated for each layer in the vapor and liquid regions. However, the heat leak through the top surface and by vapor return were equally distributed and added into each of the vapor region layers. Similarly, heat leak through the bottom of the tank, by recirculation, and by use of the dispensers were equitably distributed into the liquid region layers. During all the simulations the same amount of 400 layers were used for both regions.

\subsubsection{Results for the Fueling Station 1 in Nevada}

The following figures shows the pressure rise and fill level results for the Fueling Station 1 in Nevada. Results from the LNG Fueling Station model using the homogeneous and stratified approaches were compared with the experimental data from the LNG station. 
Section 4.5.3 describes a detailed analysis of the results. Furthermore, detailed figures including the weather data, change of estimated masses, dispensing, temperature maps, and calculated heat transfer for selected segments are shown in Appendix C. Two segments were selected showing detailed simulations with the offload pump effect, and with a $86.88 \%$ initial fill level.

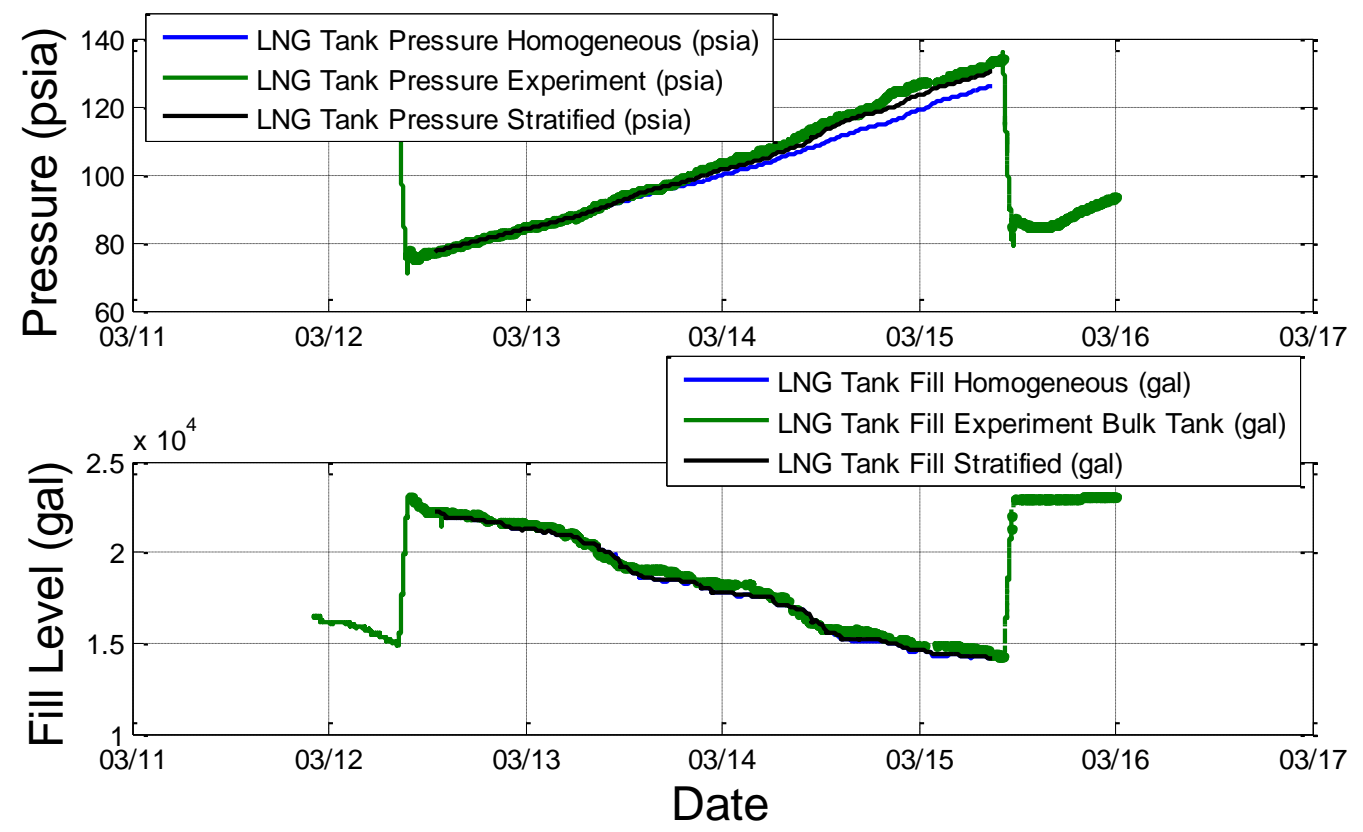

Figure 4.53. Fueling Station 1 in Nevada. Segment 1. Initial Fill Level: 86.88\%.
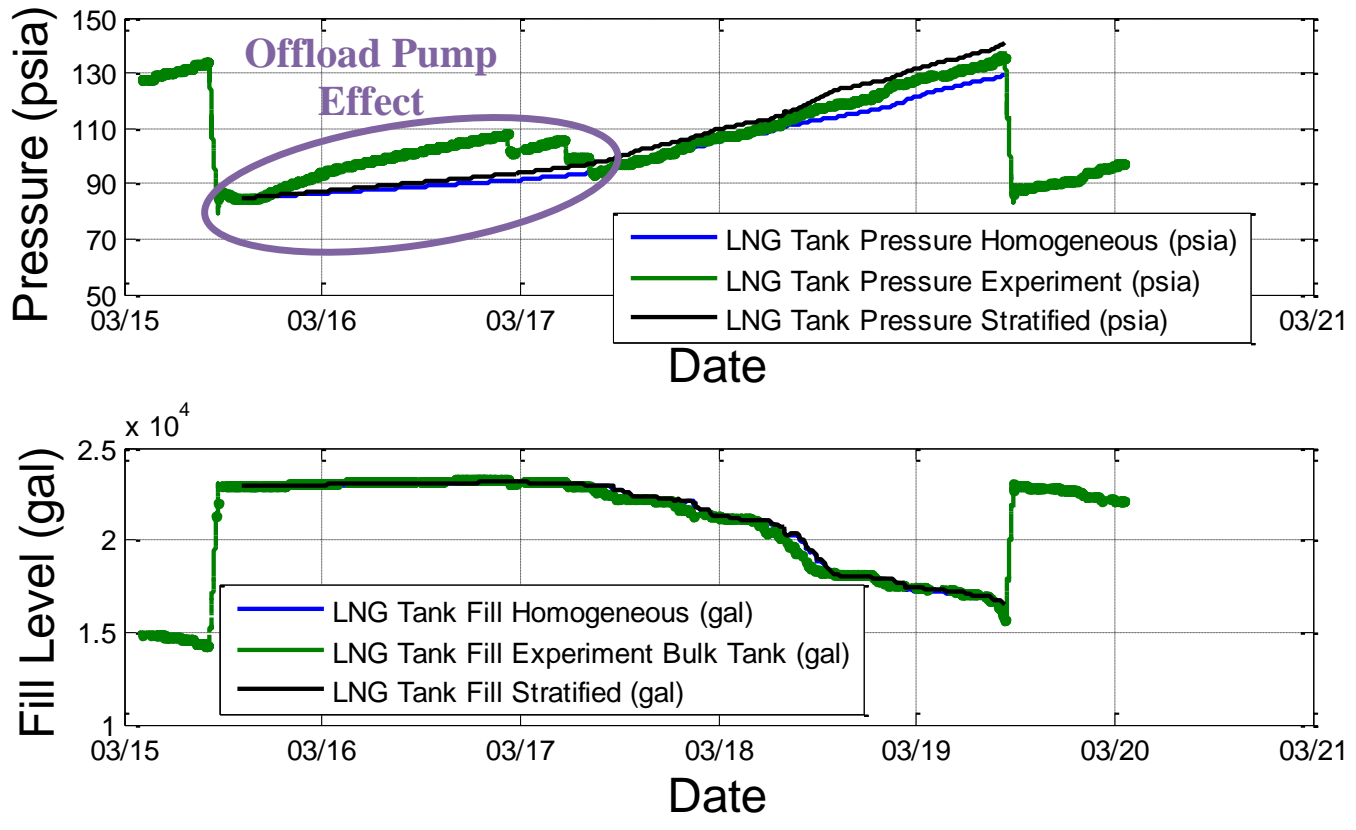

Figure 4.54. Fueling Station 1 in Nevada. Segment 2. Initial Fill Level: 90.85\%. 


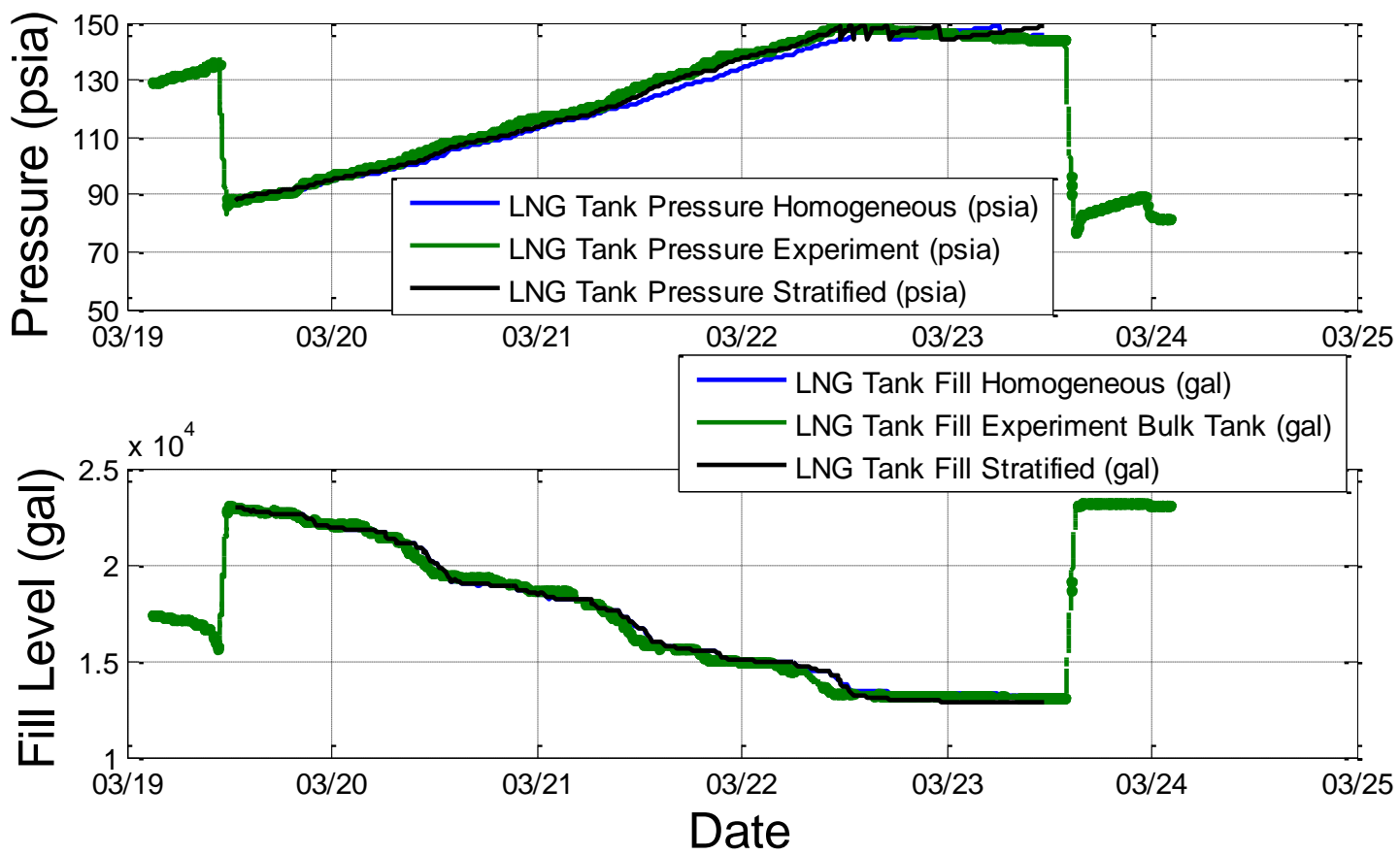

Figure 4.55. Fueling Station 1 in Nevada. Segment 3. Initial Fill Level: 90.95\%.
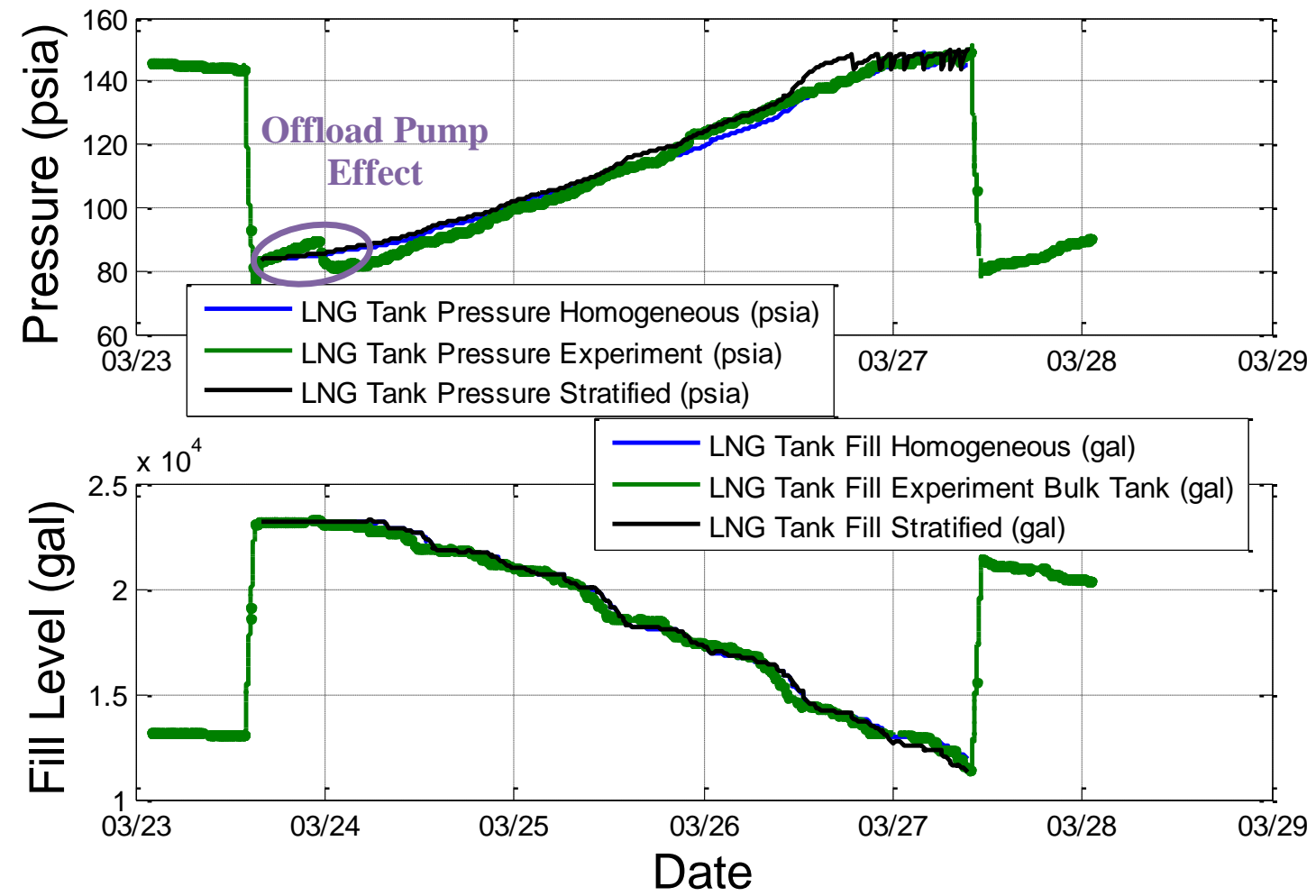

Figure 4.56. Fueling Station 1 in Nevada. Segment 4. Initial Fill Level: 91.70\%. 


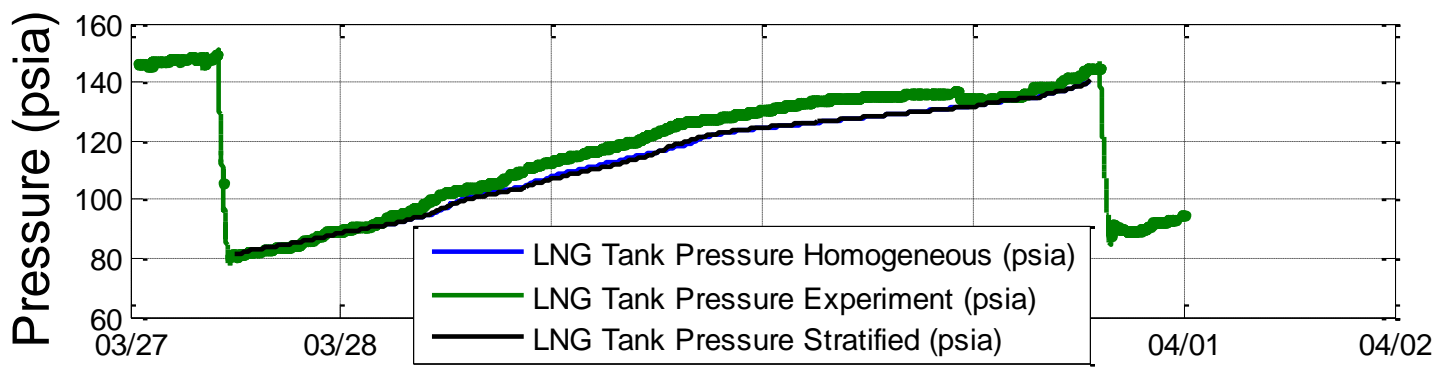

\section{Date}

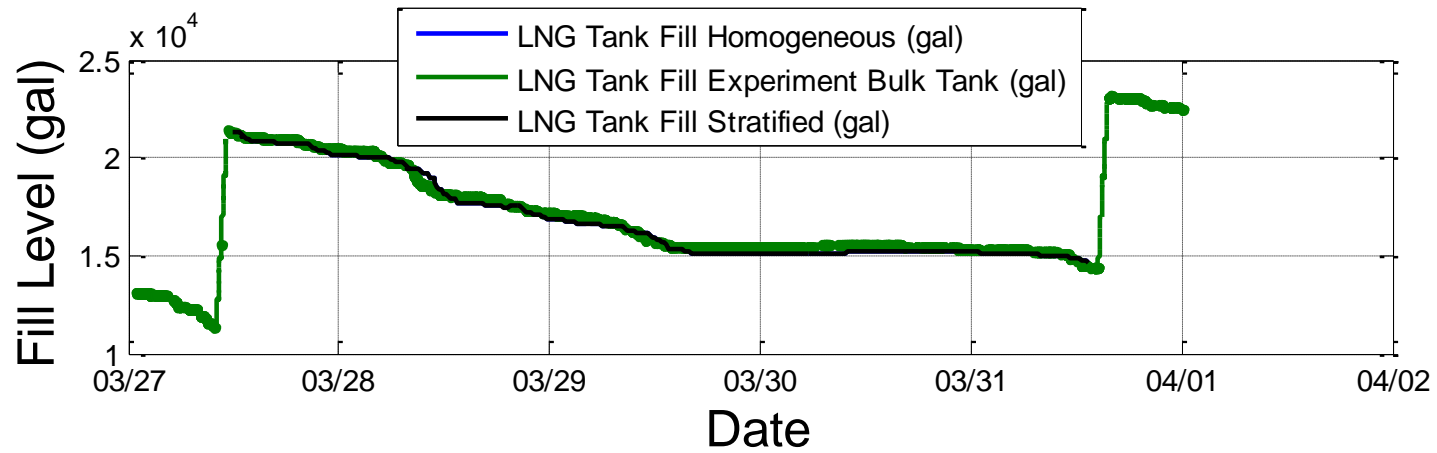

Figure 4.57. Fueling Station 1 in Nevada. Segment 5. Initial Fill Level: 84.51\%.
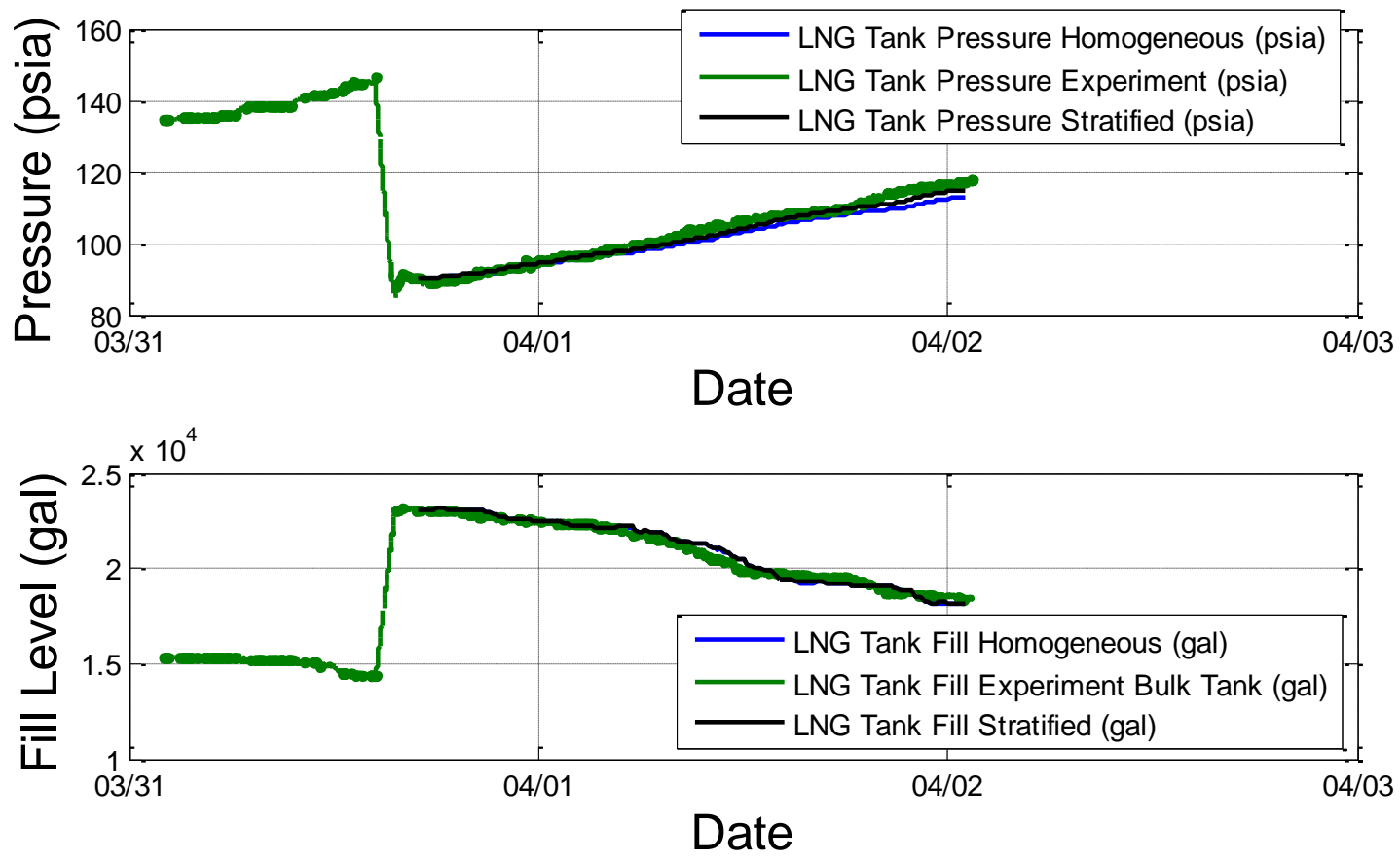

Figure 4.58. Fueling Station 1 in Nevada. Segment 6. Initial Fill Level: 91.54\%. 


\subsubsection{Results for the Fueling Station 2 in Utah}

The following figures shows the pressure rise and fill level change results for the Fueling Station 2 in Utah. Results from the LNG Fueling Station model using the homogeneous and stratified approaches were compared with the experimental data from the LNG station. Section 4.5.3 describes a detailed analysis of the results. Furthermore, detailed figures including the weather data, change of estimated masses, dispensing, temperature maps, and heat transfer calculated for selected segments are shown in Appendix D. Two segments were selected showing detailed simulations with a fast vapor removal, and with a $62.83 \%$ initial fill level.
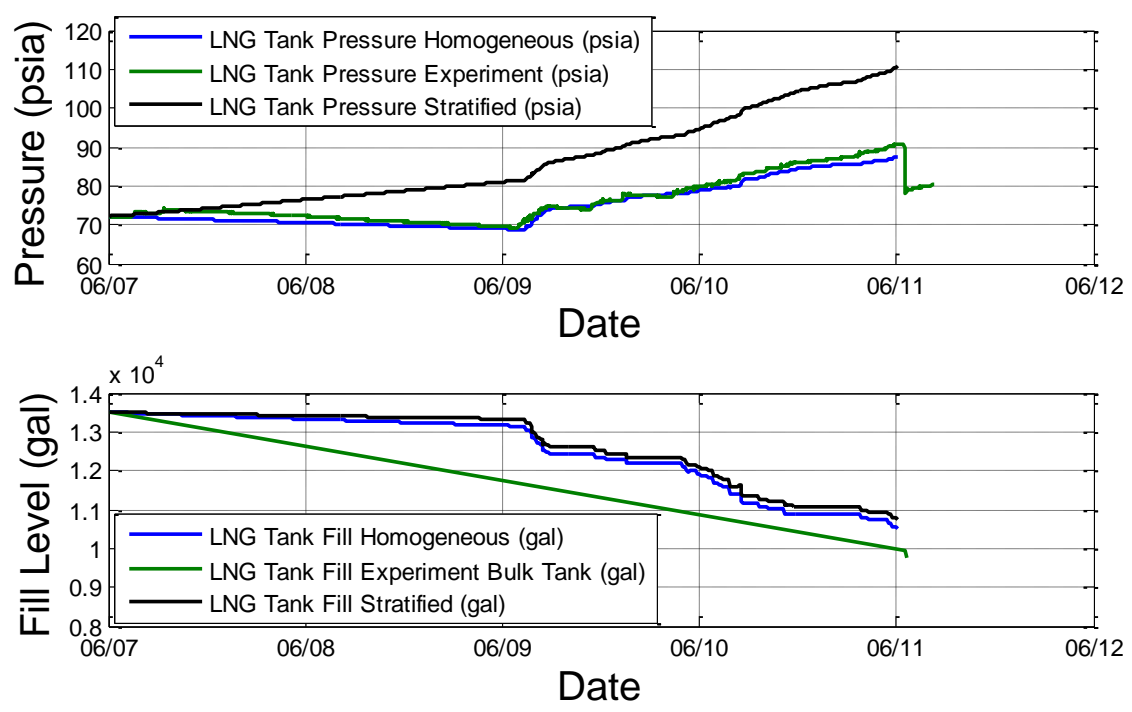

Figure 4.59. Fueling Station 2. Segment 1a. GenSet: On. Initial Fill Level: 86.99\%.

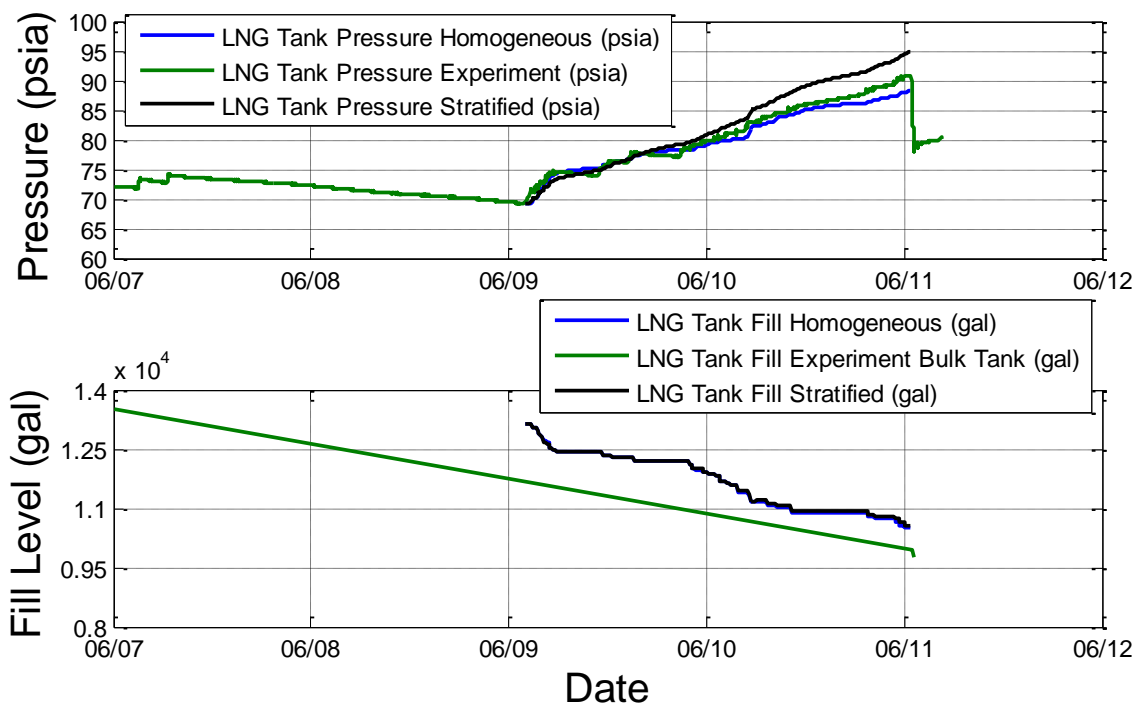

Figure 4.60. Fueling Station. Segment 1b. GenSet: On. Initial Fill Level: 84.73\%. 

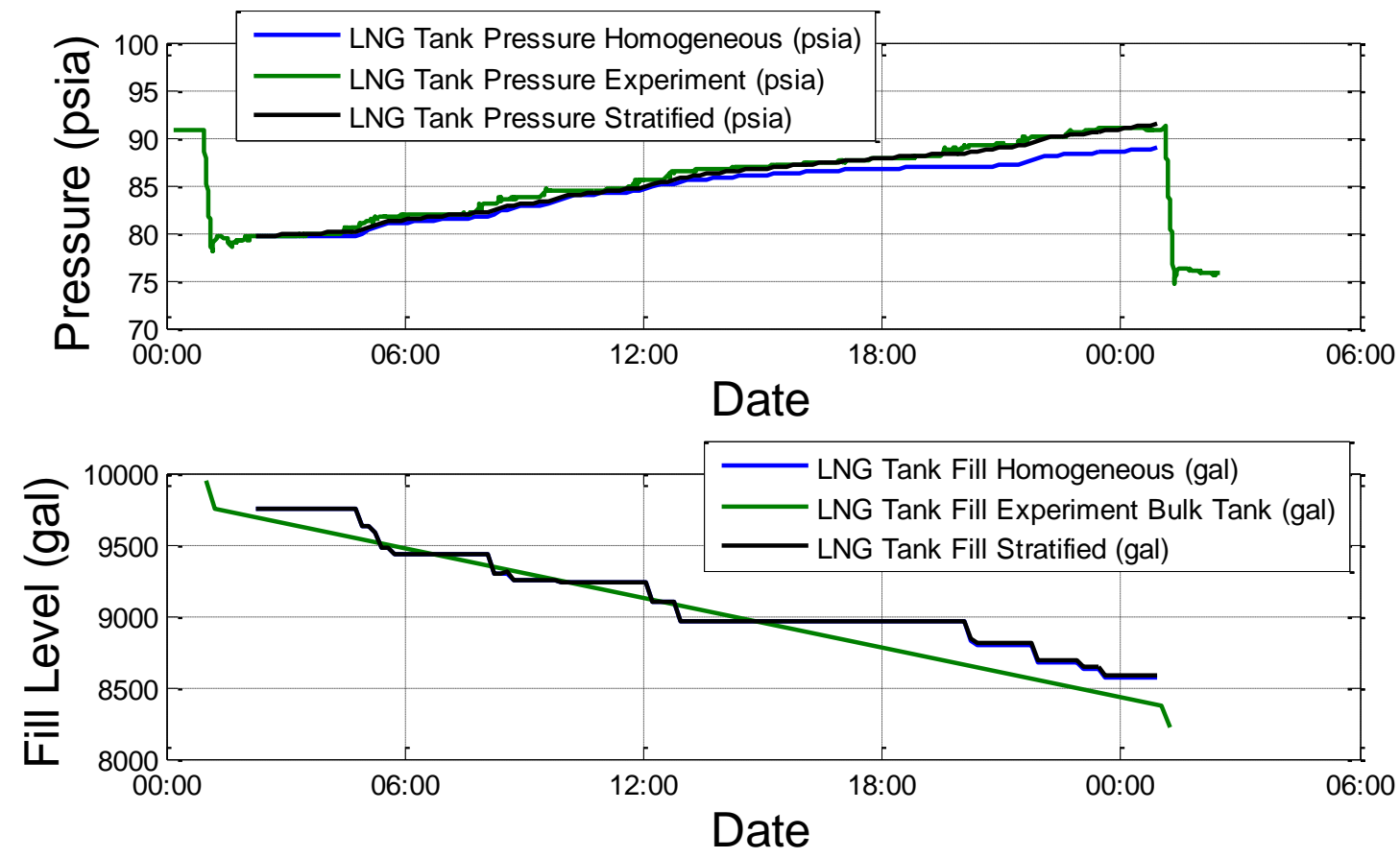

Figure 4.61. Fueling Station 2 in Utah. Segment 2. GenSet: On. Initial Homogeneous Fill Level: $62.83 \%$.
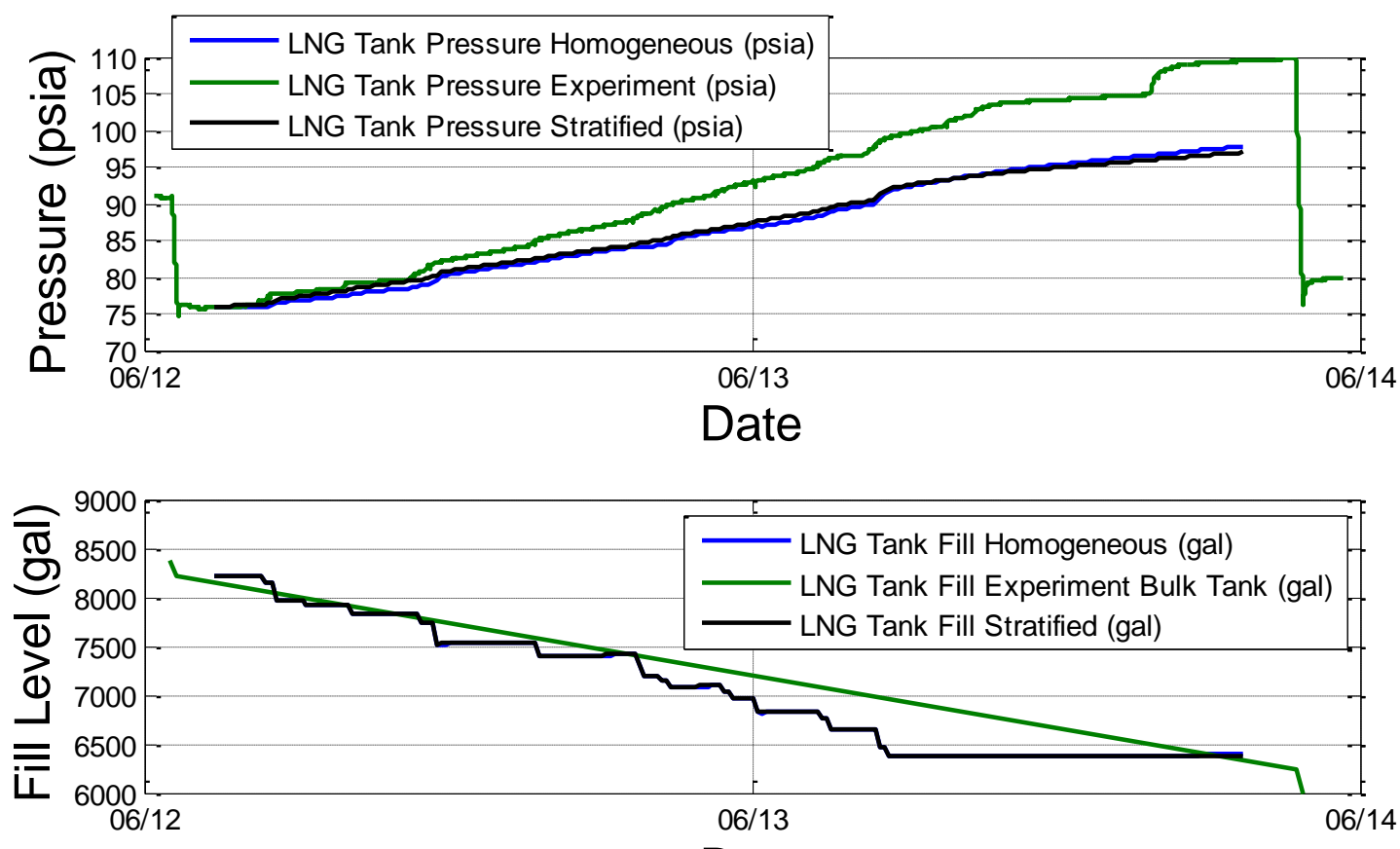

Figure 4.62. Fueling Station 2 in Utah. Segment 3. GenSet: On/Off. Initial Homogeneous Fill Level: 52.96\%. 

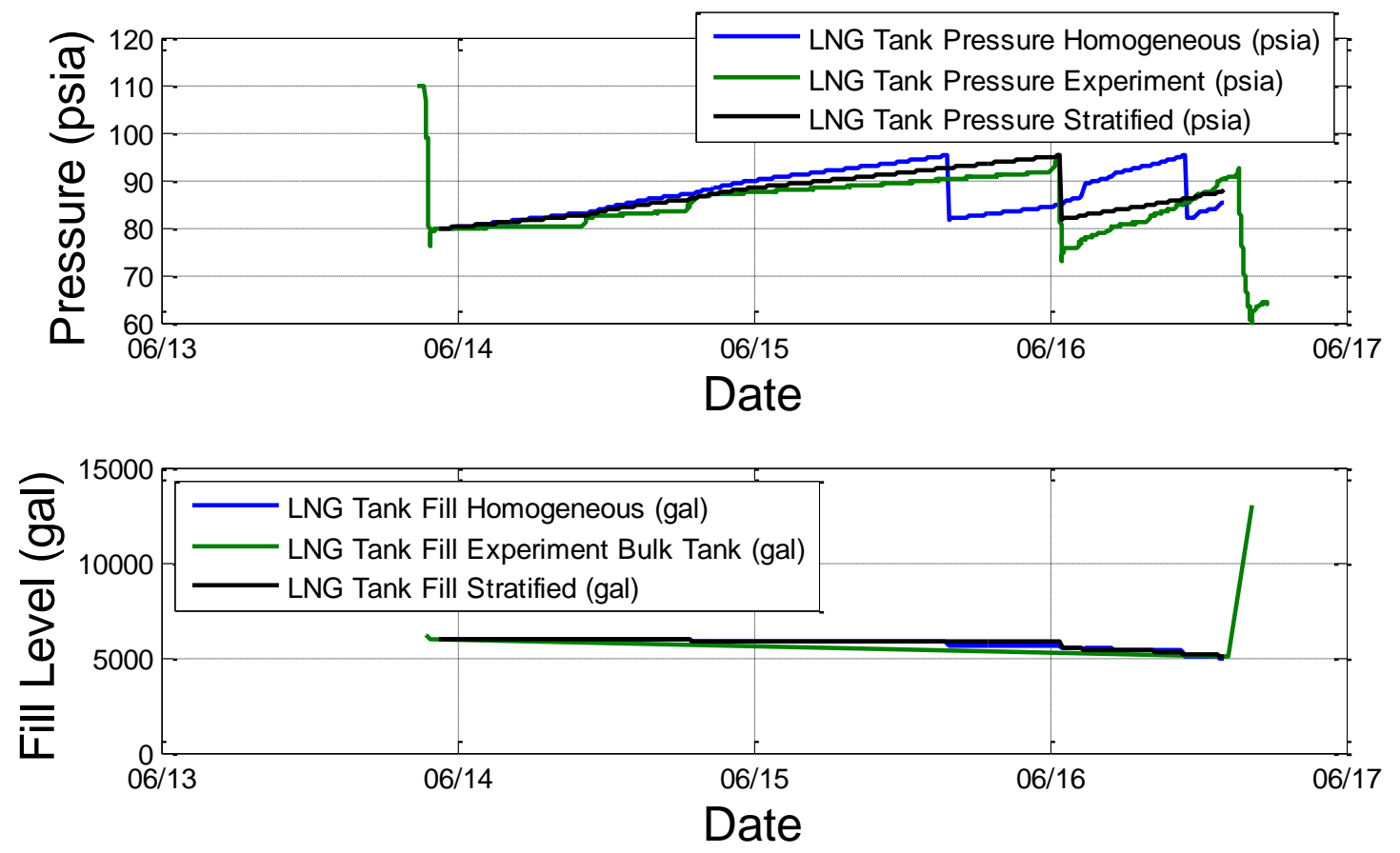

Figure 4.63. Fueling Station 2 in Utah. Segment 4. GenSet: Off. Initial Homogeneous

Fill Level: $38.66 \%$.
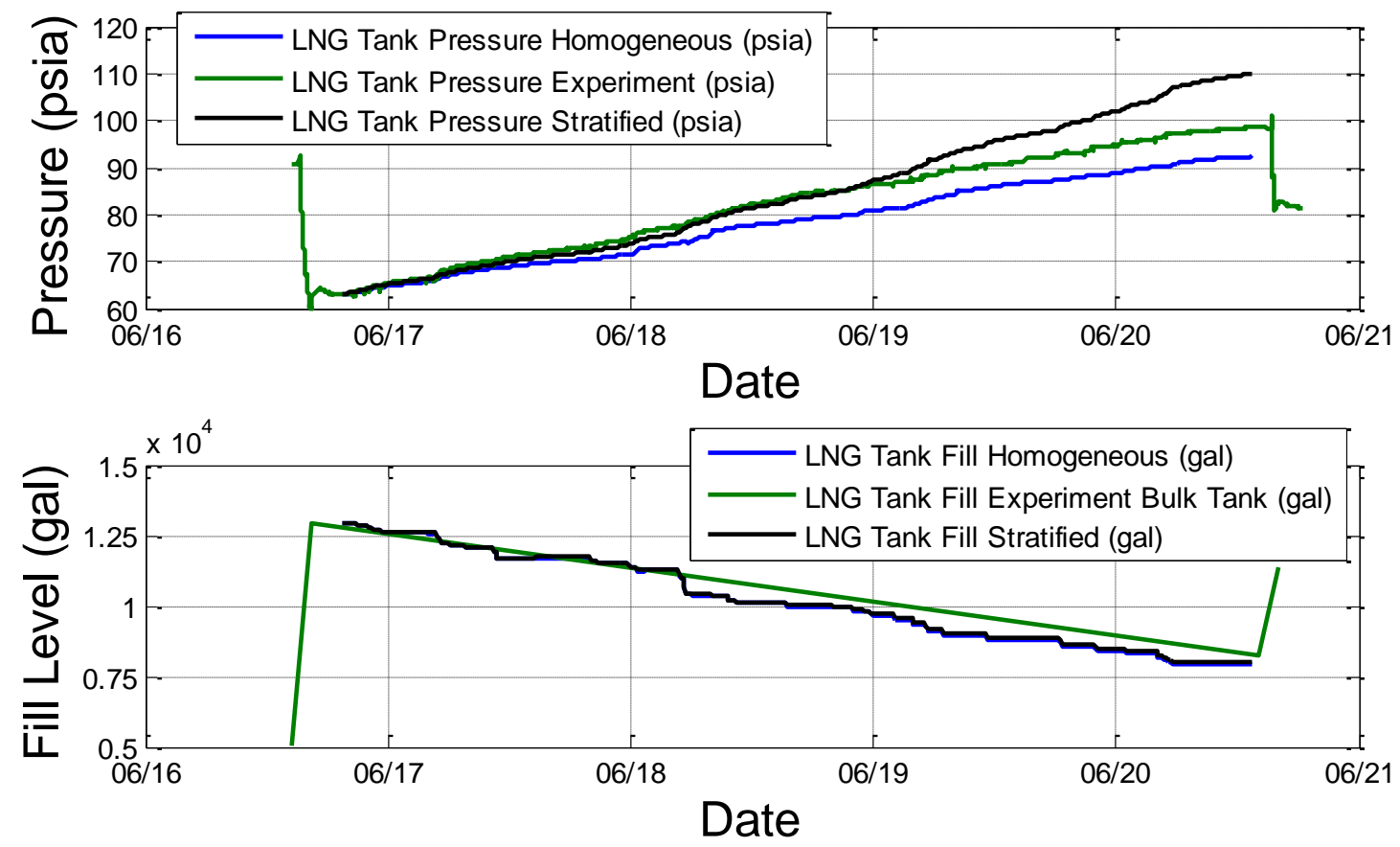

Figure 4.64. Fueling Station 2 in Utah. Segment 5. GenSet: Off/On. Initial Homogeneous Fill Level: $83.50 \%$. 

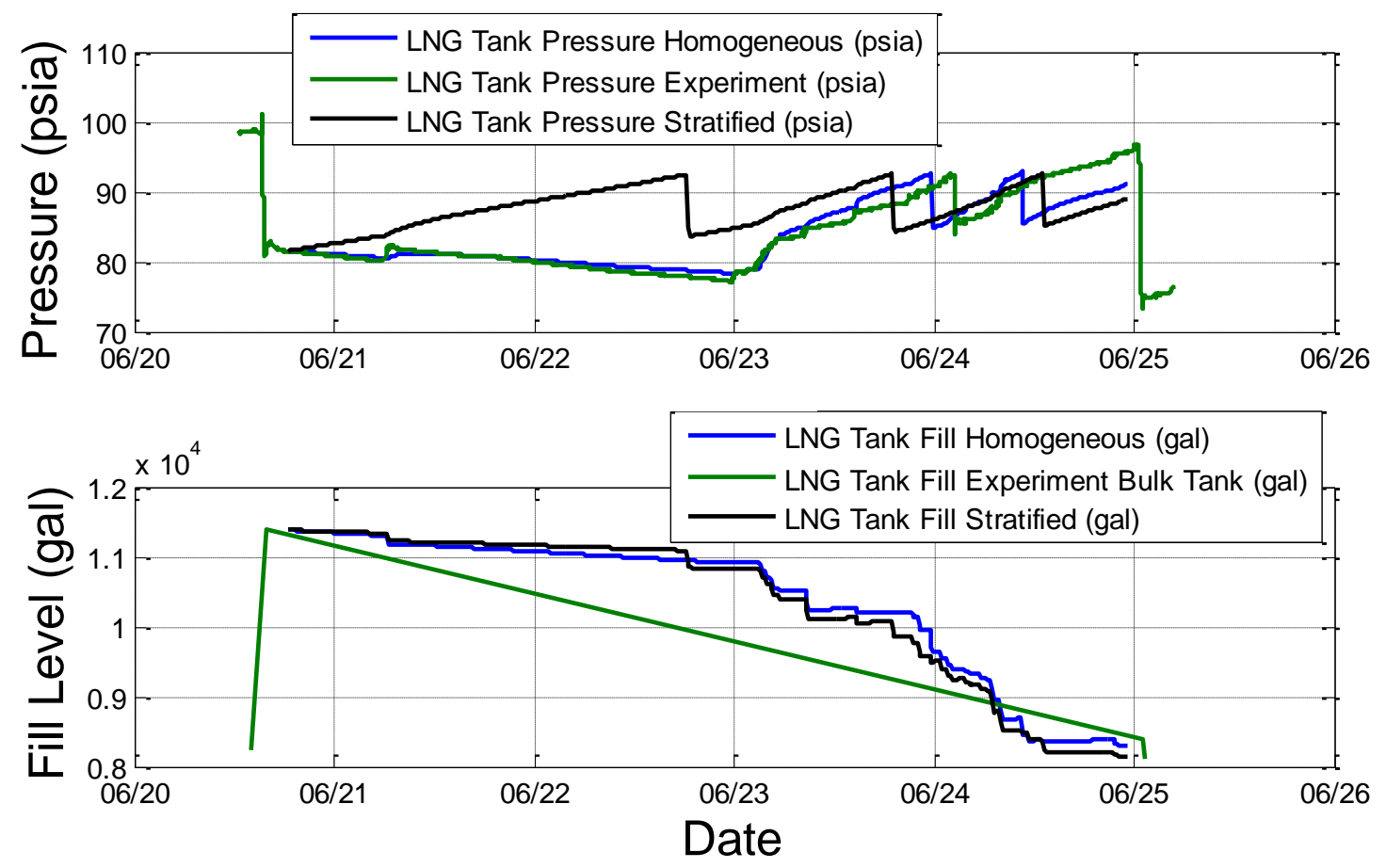

Figure 4.65. Fueling Station 2 in Utah. Segment 6a. GenSet: On. Initial Homogeneous Fill Level: $73.33 \%$.
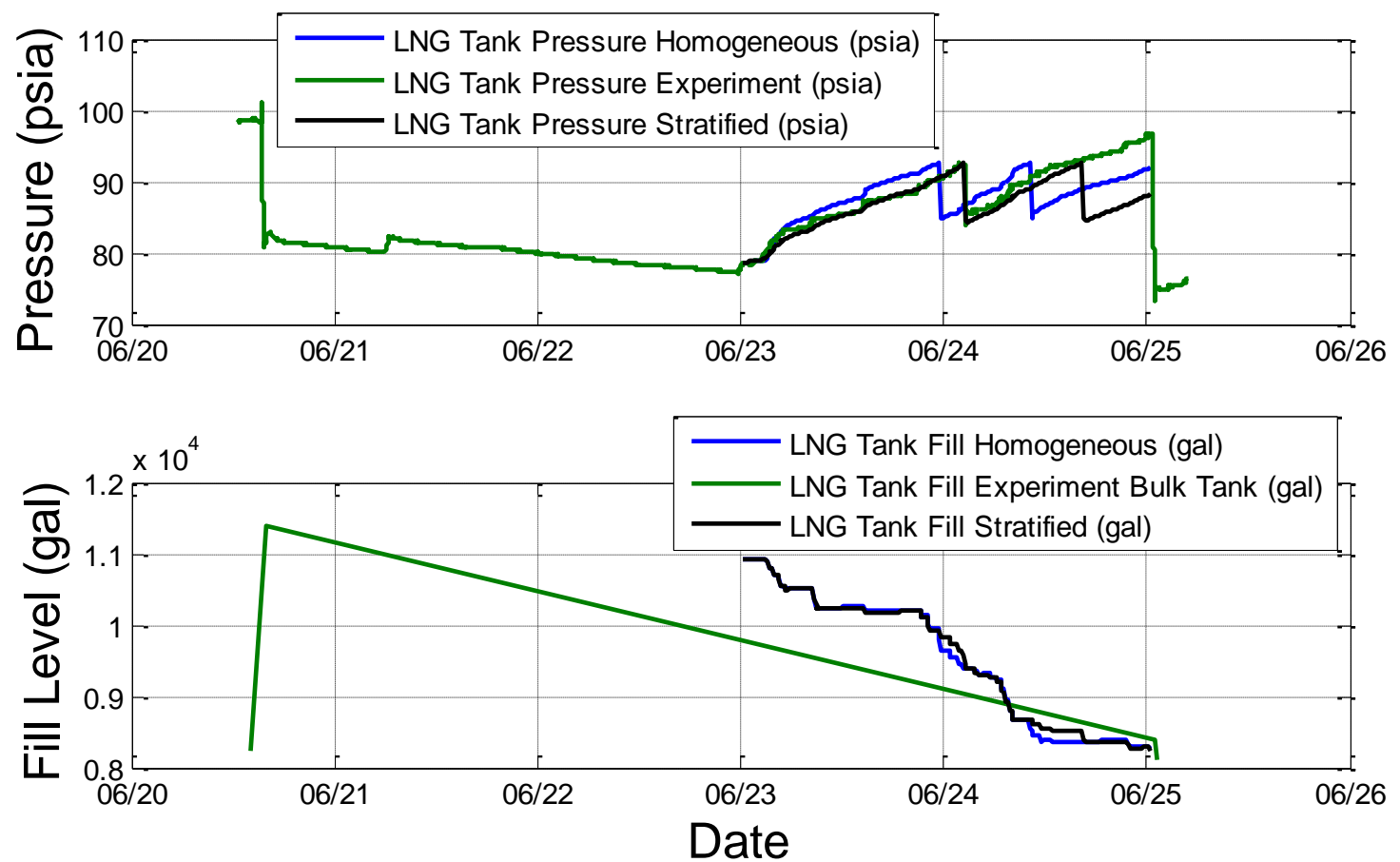

Figure 4.66. Fueling Station 2 in Utah. Segment 6b. GenSet: On. Initial Homogeneous Fill Level: $70.30 \%$. 

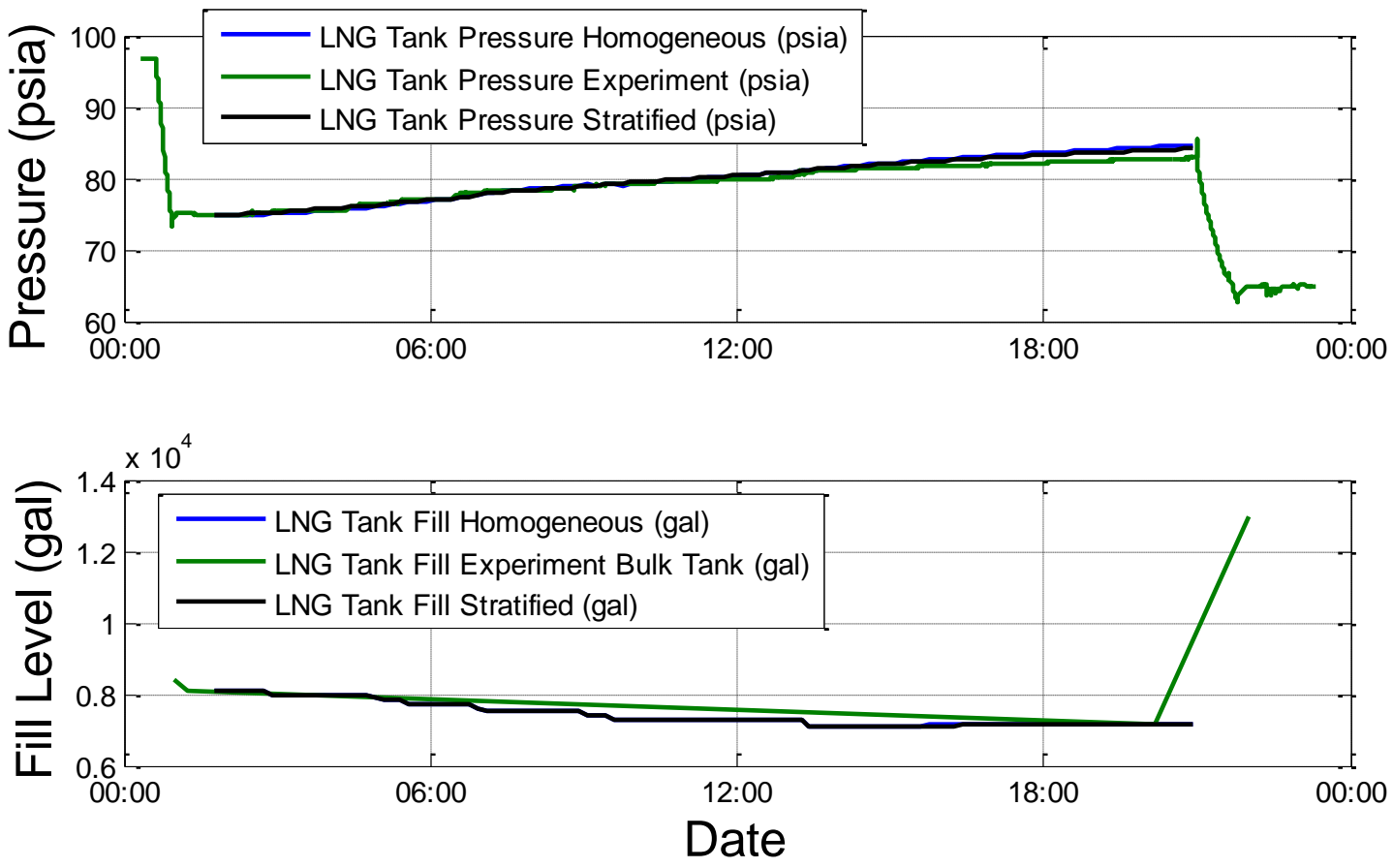

Figure 4.67. Fueling Station 2 in Utah. Segment 7. GenSet: On. Initial Homogeneous Fill Level: $52.25 \%$.
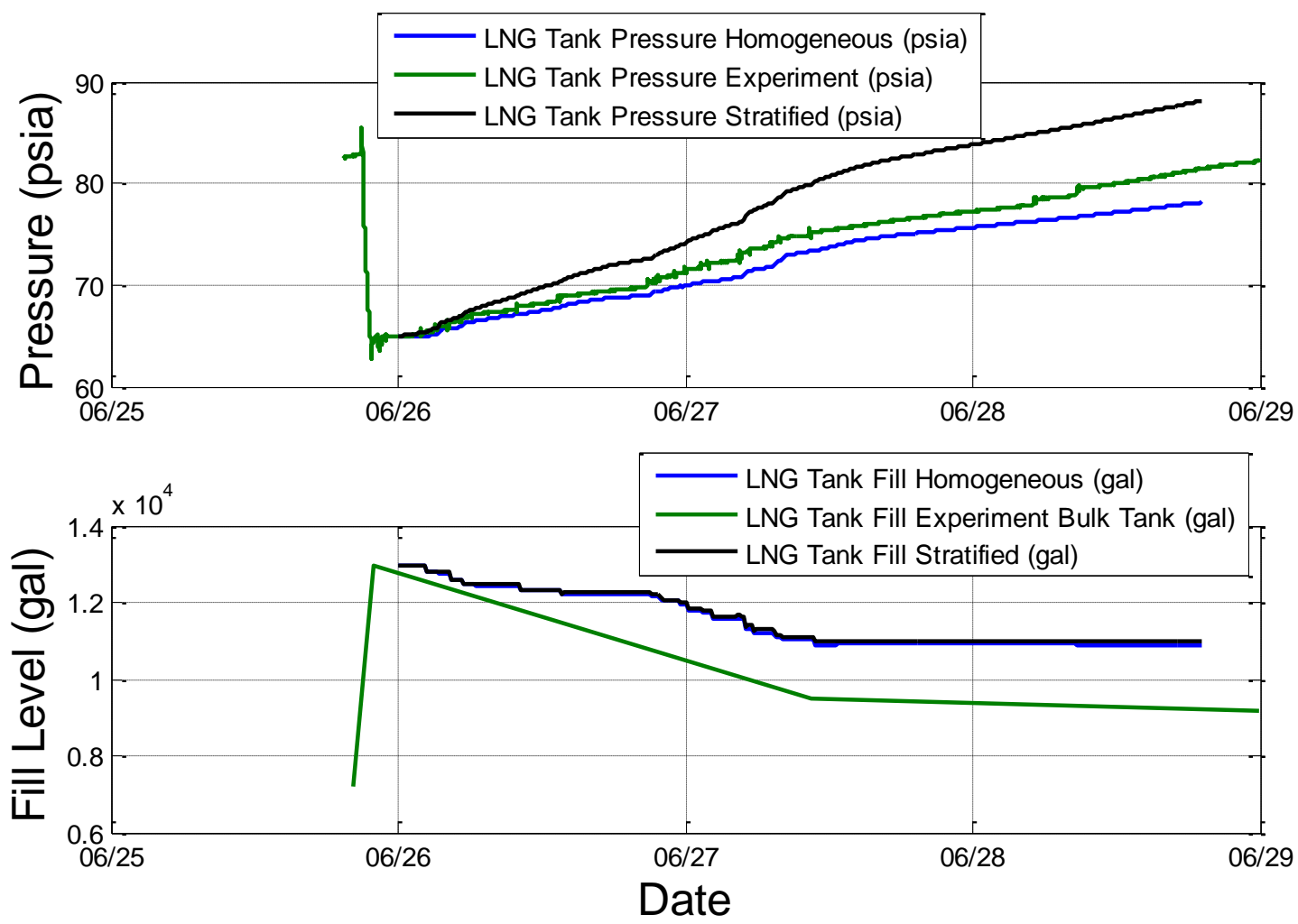

Figure 4.68. Fueling Station 2 in Utah. Segment 8. GenSet: On. Initial Homogeneous Fill Level: $83.57 \%$. 


\subsubsection{Analysis of Audits and Simulations of Fueling Stations with LNG Vehicles Refueling}

A summary of the audits from the LNG fueling stations compared to the homogenous and stratified simulations is shown in Table 4.15. The pressure rise $(d P)$ was measured from the beginning of the simulation until the end, or until venting started. The corresponding time was used $(d t)$. The rate of pressure rise with respect to time $(d P / d t)$ was calculated using both stations results with an average error of -0.36 psia/day $(1.13 \%)$ using the stratified approach and an average error of -1.67 psia/day (-10.43\%) using the homogeneous approach. Both approaches presented cases of over prediction and under prediction. The stratified approach had an error in $d P / d t$ between $-8.00 \mathrm{psia} /$ day $(-39.03 \%)$ and $2.75 \mathrm{psia} /$ day $(28.23 \%)$. The homogeneous approach had an error in $d P / d t$ between $-7.49 \mathrm{psia} /$ day $(-36.55 \%)$ and $2.15 \mathrm{psia} /$ day $(17.38 \%)$.

For Station 1 , the $d P / d t$ had an average error of -0.44 psia/day $(-1.85 \%)$ using the stratified approach and an average error of -1.92 psia/day (-10.61\%) using the homogeneous approach. For Station 2, the average error in $d P / d t$ was $-0.30 \mathrm{psia} /$ day (3.37\%) using the stratified approach and an average error of -1.49 psia/day (-10.30\%) using the homogeneous approach. Even though the average errors of Station 2 were smaller that for Station 1, it is believe that Station 1 simulations were more accurate and within closer agreement since more precise information was available from the owners of the station. Additionally, the maximum errors with Station 1 were smaller than with Station 2. The error in $d P / d t$ using the stratified approach was between -1.84 psia/day (-8.97\%) and $1.19 \mathrm{psia} / \mathrm{day}(8.94 \%)$ for Station 1 versus $-8.00 \mathrm{psia} / \mathrm{day}(-39.03 \%)$ and $2.75 \mathrm{psia} / \mathrm{day}$ (28.23\%) of Station 2. Similarly, the error in $d P / d t$ using the homogeneous approach was between $-3.35 \mathrm{psia} /$ day $(-16.34 \%)$ and $-1.13 \mathrm{psia} /$ day $(-7.23 \%)$ for Station 1 versus -7.49 psia/day $(-36.55 \%)$ and 2.15 psia/day $(17.38 \%)$ of Station 2. Note that the results from segments $1 \mathrm{a}$ and $6 \mathrm{a}$ were not included in the average results since the behavior of the Station 2 during those segments went against the assumptions of the stratified thermodynamic approach developed. 
Analysis of trends between simulated segments and between the stations results were not performed since a common base of comparison was not possible. Although the trends analyzed for the hold time experiments performed with the LNG vehicle tanks where all the simulations started at 20 psia and only the initial fill level and ambient conditions changed. A comparison using the number of vehicles fueled at the stations was attempted, however, it was not further pursued since each segment had a different distribution of vehicles arriving at the stations with different amounts of fuel dispensed and vapor returned. Therefore, clear trends were not observed and analysis was not reported.

It was observed that pressure rise in LNG fueling stations was strongly dominated by the heat transfer resulting from dispensing fuel to vehicles. Figure 4.69 shows as an example the heat transfer estimated for the segment 1 in the LNG fueling Station 1 in Nevada. It was observed in the overall results that typically the heat transfer associated with the transactions (sum of the vapor return from vehicle tanks when fueled, the recirculation, and the dispensers cool down) was around 10 times larger than the heat leak through the walls of the LNG tank. On the other hand, for idle LNG tanks without extra heat leak sources the pressure rise was dominated by the heat transfer through the walls of the tank, as was shown in the results of the hold time of LNG vehicle tanks.

In the results of Station 1 for segment 2 and segment 4 the "offload pump effect" was observed. During the simulations there was not an instant match with the tank pressure recorded when the offload pump effect was observed. However, on average the heat transfer added compensated for the behavior happening and after the effect disappeared a matching of the pressure was observed where the simulation pressure followed the experimental pressure trends. The PRV venting was observed at the end of segment 3 and segment 4 where the results of $d P / d t$ were calculated before the ventings started.

The simulation that best represented Station 2 was believe to be for segment 4 when the electrical generator was off during the entire time. An assumption of the fuel consumption by the generator was not necessary. It is believe that all vehicles fueled were recorded during this segment. The error in $d P / d t$ was -0.39 psia/day (-5.08\%) using the stratified approach and $1.20 \mathrm{psia} /$ day $(15.52 \%)$ using the homogeneous approach. 
Segment 3 and segment 4 from Station 2 had the electrical generator partially off. In segment 3 the generator was initially on and was turned off for the last $60 \%$ of the segment. During the initial time the generator was simulated as on and a deviation from the experimental pressure was observed. When the generator was off the experimental pressure rise trend had a similar trend to the simulations. In segment 4 the generator was off and it stayed off until 50\% of segment 5, when it was repaired and started running again. During the first half of segment 5 the experimental and simulated pressure rises had a good agreement. A deviation from the experimental pressure was observed for the last half of the segment when the generator was simulated as on.

The segments 1 and 6 of Station 2 were simulated twice: $1 \mathrm{a} / 6 \mathrm{a}$ at the beginning of the segments and $1 \mathrm{~b} / 6 \mathrm{~b}$ starting at the end of the decrease in tank pressure. The initial fill levels for the second simulations were estimated using the information recorded about the vehicles refueled. From the results the stratified approach did not performed well when simulations started at the beginning of the segments, however a large improvement was observed when started after the pressure stopped decreasing. It was believed that the fast removal of vapor from the station tank using the $100 \%$ fuel load of the electrical generator was breaking up the stratification in the vapor region which went against the assumptions of the stratified thermodynamic approach developed. The homogenous approach simulations performed well and were able to track the pressure of the bulk tank with the fast removal of vapor. 
Table 4.15. Summary of Audit Stations Compared with Homogenous and Stratified Simulations.

\begin{tabular}{|c|c|c|c|c|c|c|c|c|c|c|c|c|c|c|c|c|c|c|c|}
\hline \multicolumn{2}{|c|}{ Segment } & \multirow{2}{*}{\begin{tabular}{|l|} 
Start Dates \\
$3 / 12 / 2014$ \\
\end{tabular}} & \multirow{2}{*}{$\begin{array}{c}\text { GenSet } \\
\text { N/A }\end{array}$} & \multirow{2}{*}{\begin{tabular}{|c}
$\begin{array}{c}\text { Avg. } \\
\text { Ambient } \\
\text { Temp. (' }{ }^{\circ} \text { K) }\end{array}$ \\
290.02 \\
\end{tabular}} & \multirow{2}{*}{$\begin{array}{c}\begin{array}{c}\text { Avg. Solar } \\
\text { Loading } \\
\left(\mathrm{W} / \mathrm{m}^{\wedge} \mathbf{2}\right)\end{array} \\
482.77 \\
\end{array}$} & \multirow{2}{*}{\begin{tabular}{|c|}
$\begin{array}{c}\text { Initial } \\
\text { Mass (kg) }\end{array}$ \\
32381.68 \\
\end{tabular}} & \multirow{2}{*}{\begin{tabular}{|c|}
$\begin{array}{c}\text { Homog. } \\
\text { Fill } \\
(\%)\end{array}$ \\
$86.88 \%$ \\
\end{tabular}} & \multirow{2}{*}{\begin{tabular}{|c|}
$\begin{array}{c}\text { Initial } \\
\text { Pressure } \\
\text { (psia) }\end{array}$ \\
77.31 \\
\end{tabular}} & \multirow{2}{*}{$\begin{array}{c}\begin{array}{c}\text { Press. } \\
\text { Rise Exp. } \\
\text { (psia) }\end{array} \\
55.96\end{array}$} & \multirow{2}{*}{\begin{tabular}{|c}
$\begin{array}{c}\text { Press. Rise } \\
\text { Homog. } \\
\text { (psia) }\end{array}$ \\
48.78
\end{tabular}} & \multirow{2}{*}{\begin{tabular}{|c|}
$\begin{array}{c}\text { Press. } \\
\text { Rise Strat. } \\
\text { (psia) }\end{array}$ \\
52.96 \\
\end{tabular}} & \multirow{2}{*}{$\begin{array}{c}\begin{array}{c}\text { Time } \\
\text { (days) }\end{array} \\
2.83 \\
\end{array}$} & \multirow{2}{*}{\begin{tabular}{|c|}
$\begin{array}{c}\mathrm{dP} / \mathrm{dt} \\
\text { Exp. } \\
\text { (psia/day) }\end{array}$ \\
19.75 \\
\end{tabular}} & \multirow{2}{*}{\begin{tabular}{|c|}
$\begin{array}{c}\mathrm{dP} / \mathrm{dt} \\
\text { Homog. } \\
\text { (psia/day) }\end{array}$ \\
17.22 \\
\end{tabular}} & \multirow{2}{*}{\begin{tabular}{|c|}
$\begin{array}{c}\mathrm{dP} / \mathrm{dt} \\
\text { Strat. } \\
\text { (psia/day) }\end{array}$ \\
18.69
\end{tabular}} & \multirow{2}{*}{\begin{tabular}{|c|}
$\begin{array}{c}\text { Error dP/dt } \\
\text { Homog. } \\
\text { (psia/day) }\end{array}$ \\
-2.54
\end{tabular}} & \multirow{2}{*}{\begin{tabular}{|c|}
$\begin{array}{c}\text { Error dP/dt } \\
\text { Homog. } \\
(\%)\end{array}$ \\
$-12.84 \%$ \\
\end{tabular}} & \multirow{2}{*}{$\begin{array}{c}\text { Error dP/dt } \\
\text { Strat. } \\
\text { (psia/day) }\end{array}$} & \multirow{2}{*}{\begin{tabular}{|c}
$\begin{array}{c}\text { Error dP/dt } \\
\text { Strat. } \\
(\%)\end{array}$ \\
$-5.37 \%$
\end{tabular}} \\
\hline \multirow{6}{*}{$\begin{array}{l}\text { Audit 1 } \\
\text { Station } \\
\text { in } \\
\text { Nevada }\end{array}$} & Seg 1 & & & & & & & & & & & & & & & & & & \\
\hline & Seg 2 & \begin{tabular}{|l|}
$3 / 15 / 2014$ \\
\end{tabular} & N/A & 290.79 & 497.98 & 33090.64 & $90.85 \%$ & 84.56 & 51.53 & 44.75 & 56.13 & 3.85 & 13.37 & 11.61 & 14.56 & -1.76 & $-13.15 \%$ & 1.19 & $8.94 \%$ \\
\hline & Seg 3 & \begin{tabular}{|l|}
$3 / 19 / 2014$ \\
\end{tabular} & N/A & 290.39 & 498.30 & 33005.87 & $90.95 \%$ & 88.24 & 59.17 & 4.81 & 57.90 & 2.89 & 20.48 & 8.97 & 20.04 & -1.51 & $-7.37 \%$ & -0.44 & $2.14 \%$ \\
\hline & Seg 4 & \begin{tabular}{|l|}
$3 / 23 / 2014$ \\
\end{tabular} & N/A & 293.53 & 518.65 & 33433.93 & $91.70 \%$ & 83.37 & 50.79 & 47.37 & 52.24 & 2.78 & 18.24 & 17.01 & 18.76 & -1.23 & $-6.73 \%$ & 0.52 & $2.87 \%$ \\
\hline & Seg 5 & \begin{tabular}{|l|}
$3 / 27 / 2014$ \\
\end{tabular} & N/A & 291.15 & 467.80 & 30938.94 & $84.51 \%$ & 81.40 & 63.45 & 58.87 & 59.38 & 4.07 & 15.59 & 14.47 & 14.59 & -1.13 & $-7.23 \%$ & -1.00 & $-6.42 \%$ \\
\hline & Seg 6 & \begin{tabular}{|l|}
$3 / 31 / 2014$ \\
\end{tabular} & N/A & 287.65 & 613.94 & 33155.26 & $91.54 \%$ & 90.10 & 27.32 & 22.85 & 24.86 & 1.33 & 20.49 & 17.14 & 18.65 & -3.35 & $-16.34 \%$ & -1.84 & $-8.97 \%$ \\
\hline \multirow{10}{*}{$\begin{array}{c}\text { Audit } 2 \\
\text { Station } \\
\text { in } \\
\text { Utah }\end{array}$} & Seg 1a & $6 / 7 / 2014$ & $\mathrm{ON}$ & 5.68 & 486.90 & 19747.67 & $86.99 \%$ & 72.14 & 19.62 & .34 & 38.58 & 4.00 & 4.91 & 3.84 & 9.64 & -1.07 & $-21.83 \%$ & 4.74 & $96.59 \%$ \\
\hline & Seg $1 b$ & 6/9/2014 & $\mathrm{ON}$ & 97.44 & 497.04 & 19307.53 & $84.73 \%$ & 69.26 & 22.65 & 18.97 & 25.67 & 1.95 & 11.61 & 9.72 & 13.15 & -1.89 & $-16.27 \%$ & 1.54 & $13.31 \%$ \\
\hline & Seg 2 & \begin{tabular}{|l|}
$6 / 11 / 2014$ \\
\end{tabular} & ON & 295.20 & 497.04 & 14293.65 & $62.83 \%$ & 79.61 & 12.30 & 9.28 & 11.77 & \begin{tabular}{|l|}
0.94 \\
\end{tabular} & 13.02 & 9.82 & 12.46 & -3.20 & $-24.58 \%$ & -0.56 & $-4.31 \%$ \\
\hline & Seg 3 & $6 / 12 / 2014$ & ON/OFF & 298.61 & 507.62 & 12167.80 & $52.96 \%$ & 75.85 & 34.71 & 22.02 & 21.16 & 1.69 & 20.49 & 13.00 & 12.49 & -7.49 & $-36.55 \%$ & -8.00 & $-39.03 \%$ \\
\hline & Seg 4 & 6/13/2014 & OFF & 290.66 & 511.69 & \begin{tabular}{|l|}
8992.71 \\
\end{tabular} & $38.66 \%$ & 79.70 & 16.14 & 18.65 & 15.32 & 2.08 & 7.75 & 8.95 & 7.35 & 1.20 & $15.52 \%$ & -0.39 & $-5.08 \%$ \\
\hline & Seg 5 & \begin{tabular}{|l|}
$6 / 16 / 2014$ \\
\end{tabular} & OFF/ON & 286.82 & 482.99 & 19162.68 & $83.50 \%$ & 63.15 & 36.54 & 29.21 & 46.85 & 3.75 & 9.74 & 7.79 & 12.49 & -1.95 & $-20.06 \%$ & 2.75 & $28.23 \%$ \\
\hline & Seg $6 a$ & $6 / 18 / 2014$ & ON & 297.17 & 506.45 & 16569.13 & $73.33 \%$ & 81.51 & -3.64 & -2.74 & 10.96 & 1.99 & -1.83 & -1.38 & 5.52 & 0.46 & $-24.83 \%$ & 7.35 & $-400.99 \%$ \\
\hline & Seg $6 b$ & $6 / 23 / 2014$ & ON & 296.91 & 497.04 & 15948.69 & $70.30 \%$ & 78.60 & 11.94 & 14.01 & 11.96 & 0.97 & 12.37 & 14.52 & 12.39 & 2.15 & $17.38 \%$ & 0.02 & $0.17 \%$ \\
\hline & Seg 7 & 6/25/2014 & ON & 300.14 & 434.81 & 12020.45 & $52.25 \%$ & 74.81 & 9.14 & 9.79 & 9.30 & 0.80 & 11.45 & 12.26 & 11.65 & 0.81 & $7.10 \%$ & 0.20 & $1.78 \%$ \\
\hline & Seg 8 & 6/26/2014 & ON & 294.04 & 502.70 & \begin{tabular}{|l|}
19140.51 \\
\end{tabular} & $83.57 \%$ & 64.91 & 17.61 & 13.22 & 23.23 & 2.80 & 6.29 & 4.72 & 8.30 & -1.57 & $-24.95 \%$ & 2.01 & $31.90 \%$ \\
\hline
\end{tabular}

*Audit 2 Segments 1 a and 6a not included in average.

\begin{tabular}{l|cc|cc|} 
Avg. Audit 1 & -1.92 & $-10.61 \%$ & -0.44 & $-1.85 \%$ \\
\hline Avg. Audt & -1.49 & $-10.30 \%$ & -0.30 & $3.37 \%$ \\
\hline
\end{tabular}

\begin{tabular}{r|rr|rr|} 
Avg. Audit 2* & -1.49 & $-10.30 \%$ & -0.30 & $3.37 \%$ \\
\hline Both Stations* & -1.67 & $-10.43 \%$ & -0.36 & $1.13 \%$
\end{tabular}




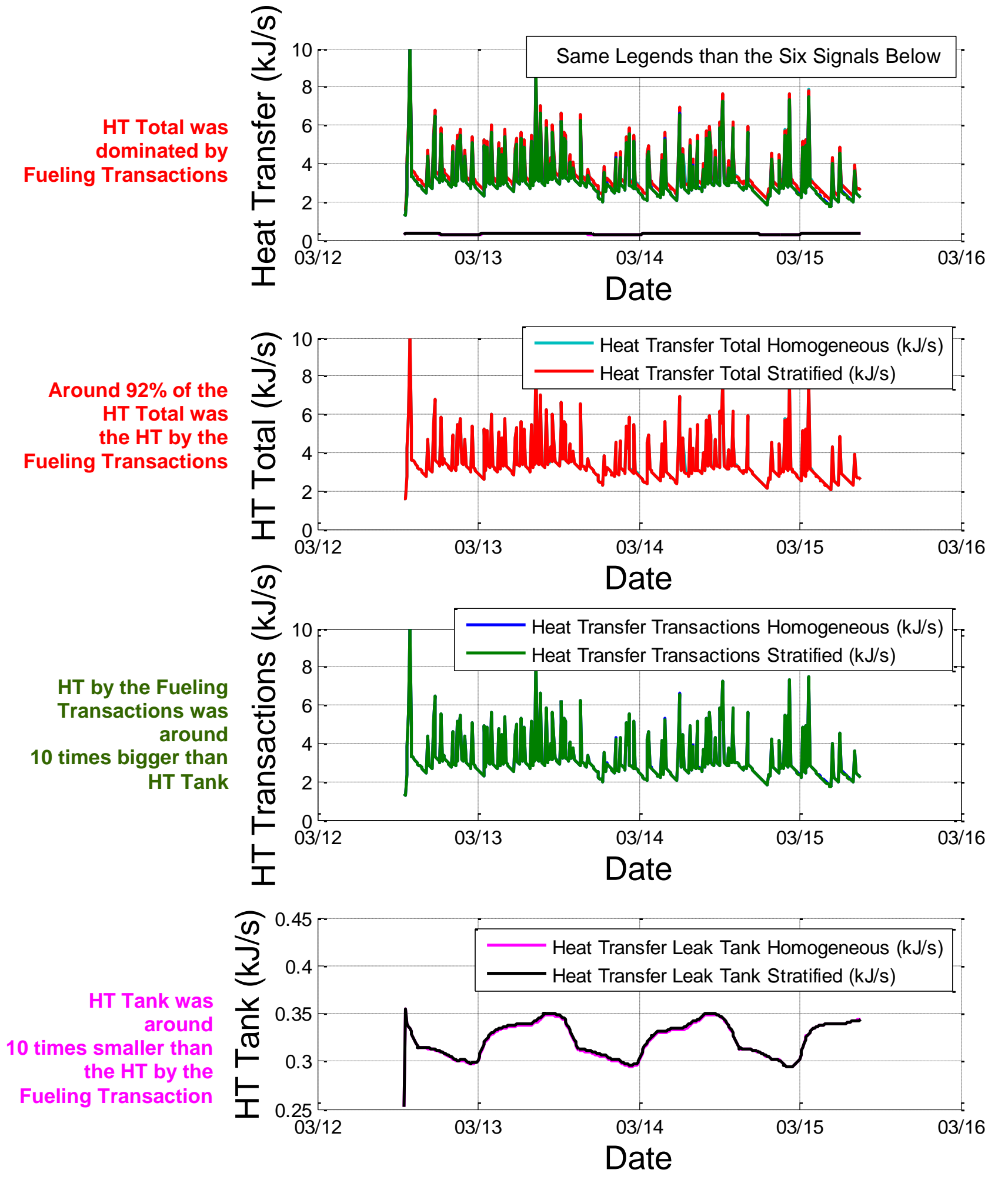

Figure 4.69. Fueling Station 1 in Nevada. Segment 1. Comparison of Heat Transfer Magnitudes Estimated. 
It was observed that the error in the pressure rise increased when vehicle data was not recorded and not included in the simulations. Figure 4.70 shows as an example the results for segment 3 during the audit at Station 2 in Utah. After analyzing the experimental pressure rise of the tank, it was believe that six vehicles transaction were not recorded strongly affecting the simulations. Blue dash lines were added on the figure at the times that the transactions should have occurred. In this particular simulation a total heat transfer peak was estimated up to $10 \mathrm{~kJ} / \mathrm{s}$ for each time that a vehicle arrived, when the average total heat transfer maintained around $2 \mathrm{~kJ} / \mathrm{s}$. Since vehicles arrived at the station far apart from each other a higher heat transfer rate occurred due to the necessary cool down of the dispenser from higher temperatures. When vehicles arrived grouped the cool down cost was lower. The final difference of experimental pressure $(d P)$ had an error around 12 psia compared to the simulations. It was believe that each of the six vehicles not recorded should have accounted for around 2 psia increase in the overall pressure of the bulk tank, highly improving the simulations results. Instead, a cumulative deviation was observed each time a vehicle was not included. The $d P / d t$ obtained for this segment had an underestimation of $8.00 \mathrm{psia} / \mathrm{day}(39.03 \%)$ using the stratified approach and underestimation of 7.49 psia/day $(36.55 \%)$ using the homogeneous approach.

During the three weeks period of each audit the Station 2 refueled approximately a third of vehicle less as Station 1. Station 2 had 221 vehicles refueled and it was believe that between 10 and 30 vehicles in total were not accounted for. Between 0 and 6 vehicles transactions were missed per each segment. Station 1 observed 685 vehicles where the values of 320 vehicles were approximated. Additionally, it was noticed that the pipping lengths observed at Station 2 were around $20 \%$ shorter than at Station 1. In this way, the maximum error in Station 1 was smaller since even though some vehicle transactions were approximated some respective energy transferred into the bulk tank was accounted instead of completely omitted. At, Station 2 some vehicle transactions were completely omitted and the maximum error in $d P / d t$ was 4.3 times higher with the stratified approach and 2.2 times higher with the homogenous approach than the maximum errors of Station 1. 

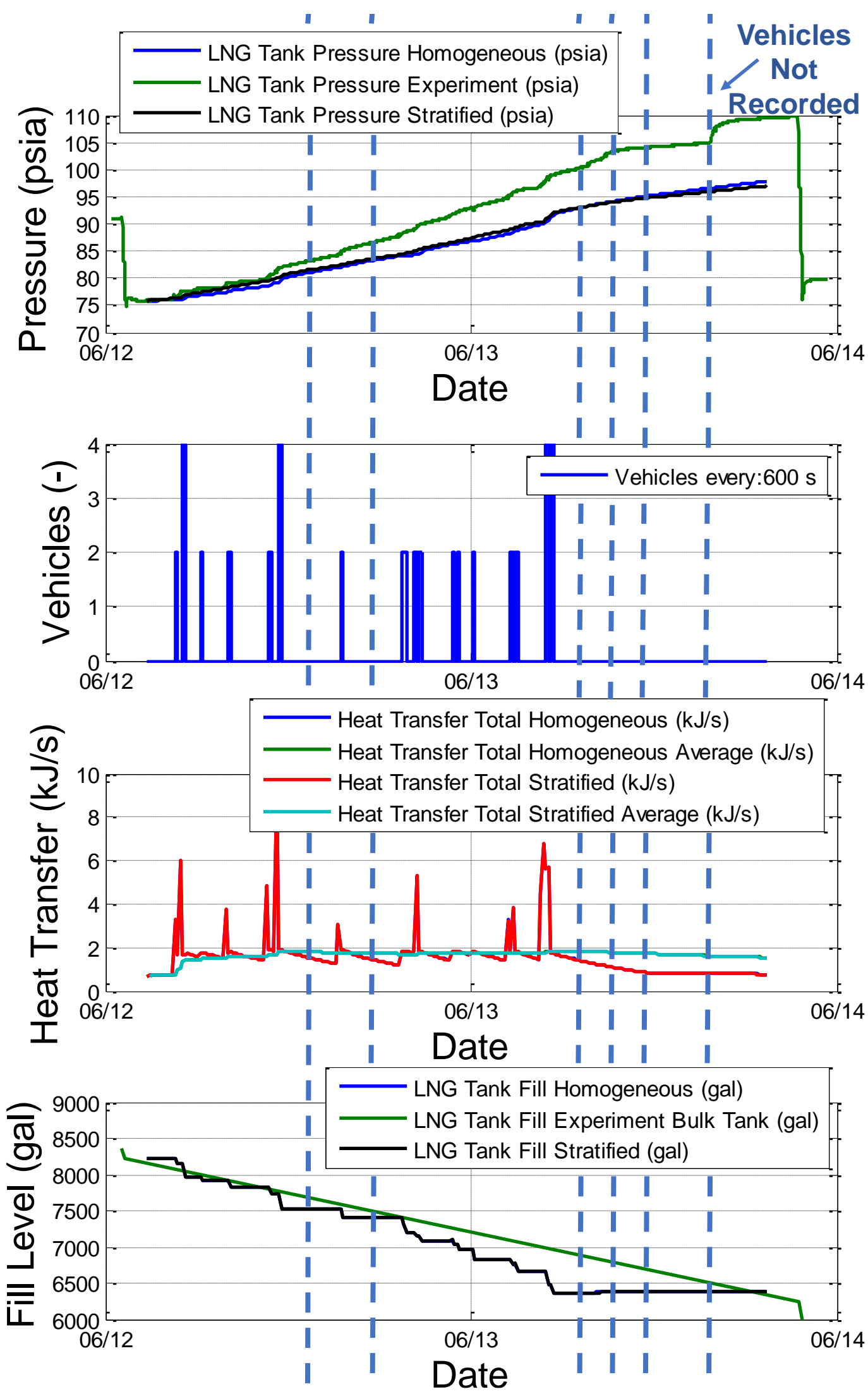

Figure 4.70. Fueling Station 2 in Utah. Segment 3. Showing Vehicles Not Recorded. 
A summary of manual and PRV vents is shown in Table 4.16. Two vents were slow releases by the PRV during Audit 1 and four out of the six were manual vents observed by WVU personnel during Audit 2. The total methane vented was estimated using the difference of fill level measured and the information provided about the LNG dispensed into the vehicles. The first PRV vent happened at the end of segment 3 and no vehicles were refueled during that time. According to the fill level data, approximately 204 gallons were estimated to have vented and a pressure drop of 4.78 psia was recorded. The second PRV venting was observed at the end of segment 4 and 1506 gallons of LNG was dispensed into vehicles. The fill level vented was estimated as 305 gallons and the pressure in the tank increased 4.15 psia since vehicle were refueled during that time. Therefore a total of 509 gallons of LNG were vented by the two PRV events during the time at Audit 1. During Audit 2, each manual vent observed dropped the fill level between 150 gallons and 282 gallons for a total 863 gallons. Corresponding pressure drops were between 6.58 and 30.06 psia. The two manual vents not observed at Audit 2 were not estimated since information of some vehicles refueling transactions during the time was believed to not be recorded. In addition, the correct fuel consumption of the electrical generator was not known. It was observed that Station 2 was differently managed and it does not represent the desired behavior of LNG fueling stations. However, it is clear that the performing of manual vents in bulk tanks generate significant methane emissions to the environment. Nevertheless, Station 1 did not have a large enough fleet which made it an under-utilized LNG fueling station prone to PRV vents. It was observed that slow releases by PRVs generate as much emissions as manual vents. The total methane vented by the two stations was equal to approximately 1372 gallons of LNG. 
Table 4.16. Manual and PRV Ventings during the LNG Fueling Stations Audited

\begin{tabular}{|c|c|c|c|c|c|c|c|}
\hline \multicolumn{2}{|c|}{ Ventings } & Observed & $\begin{array}{c}\text { Initial Pressure } \\
\text { (psia) }\end{array}$ & $\begin{array}{c}\text { Pressure } \\
\text { Drop (psia) }\end{array}$ & $\begin{array}{l}\text { Initial Fill } \\
\text { Level (gal) }\end{array}$ & \begin{tabular}{|c|} 
LNG Dispensed \\
(gal)
\end{tabular} & $\begin{array}{c}\text { Fill Level } \\
\text { Vented (gal) }\end{array}$ \\
\hline \multirow{2}{*}{$\begin{array}{l}\text { Audit } 1 \\
\text { Station } \\
\text { in } \\
\text { Nevada }\end{array}$} & $\begin{array}{c}\text { Seg } 3 \text { PRV } \\
\text { Vent } \\
\end{array}$ & YES & 148.63 & 4.78 & 13279 & 0 & 204 \\
\hline & $\begin{array}{c}\text { Seg } 4 \text { PRV } \\
\text { Vent }\end{array}$ & YES & 145.65 & -4.15 & 13163 & 1506 & 305 \\
\hline \multirow{6}{*}{$\begin{array}{c}\text { Audit } 2 \\
\text { Station } \\
\text { in } \\
\text { Utah }\end{array}$} & Vent 1 & YES & 90.83 & 11.80 & 9940 & 0 & 190 \\
\hline & Vent 2 & YES & 90.77 & 15.09 & 8370 & 0 & 150 \\
\hline & Vent 3 & YES & 109.80 & 30.06 & 6241 & 0 & 241 \\
\hline & Vent 4 & NO & 92.51 & 16.94 & & & \\
\hline & Vent 5 & NO & 92.46 & 6.58 & & & \\
\hline & Vent 6 & YES & 96.83 & 21.99 & 8391 & 0 & 282 \\
\hline & & & & & & Total Station 1 & 509 \\
\hline & & & & & & Total Station 2 & 863 \\
\hline & & & & & & otal Both Station & 1372 \\
\hline
\end{tabular}

The performance between the homogeneous and stratified approach simulations for the LNG fueling stations is compared in Figure 4.71. The error in $d P / d t$ of each segment was plotted with bars. The axis was limited to \pm 4 psia/day removing the high error of segments 1a, 3, and 6a of Station 2. It was observed that for LNG fueling stations the stratified approach presented in general better results than the homogenous approach. However, the homogenous approach was in general able to predict the trends in pressure rise in fueling stations but not as accurately as the stratified approach. For the simulations of Station 1 in Nevada: the homogeneous approach under-predicted the $d P / d t$ between 0.44 and $3.35 \mathrm{psia} / \mathrm{day}$, and the stratified approach under-predicted by $1.06 \mathrm{psia} / \mathrm{day}$ and over-predicted by $1.19 \mathrm{psia} /$ day. In the case of Station 2 in Utah: the homogenous approach under-predicted by $3.35 \mathrm{psia} /$ day and over-predicted by $2.15 \mathrm{psia} /$ day, and the stratified approach under-predicted by $0.39 \mathrm{psia} /$ day and over-predicted by $2.75 \mathrm{psia} /$ day. 


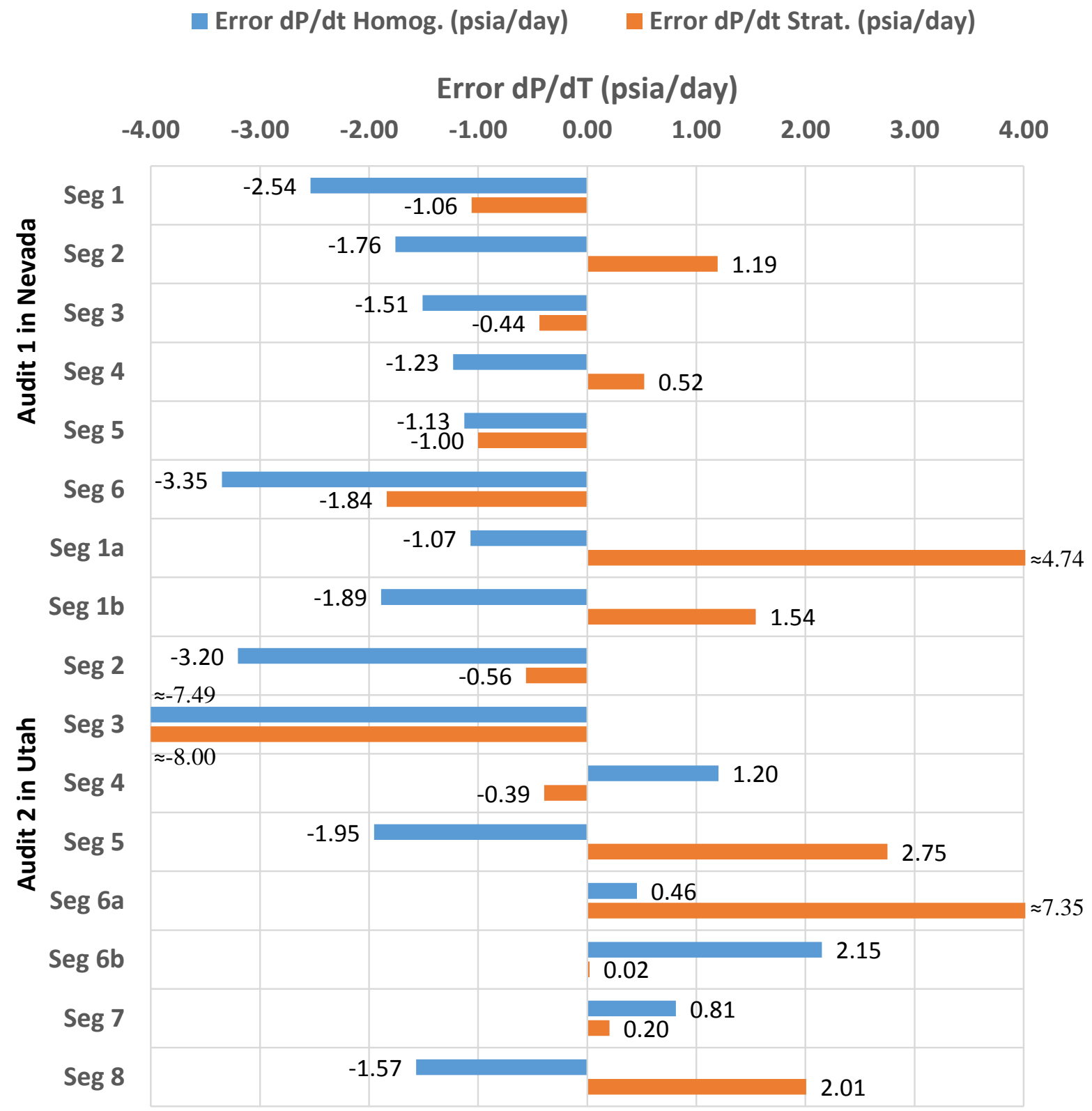

Figure 4.71. Error in the LNG Fueling Stations Simulated dP/dt (psia/day).

The computational time of the entire LNG Station Model with vehicles dispensing was measured with an average of $1.1 \mathrm{~min} /$ (day simulated) using the homogeneous approach and $45.9 \mathrm{~min} /($ day simulated) using the stratified approach. Same computational performance was achieved when vehicles were not dispensed. A time step of 600 seconds was used for a total of 144 global iterations per day. A sensitivity of time step was not included since it was assumed that a vehicle was completely fueled during a time step, 
typically vehicles are completely fueled in around 10 minutes (600 seconds). The stratified approach performed more intermedium iterations during the initial time steps calculating the stratification thickness increase. For example, a simulation of a fueling station dispensing fuel to vehicles during three days took 3.3 minutes ( 0.06 hours) using the homogeneous approach and 137.7 minutes (2.30 hours) using the stratified approach. A simulation of the hold time of a LNG vehicle tank lasting 30 days took 33 minutes $(0.55$ hours) using the homogeneous approach and 1377 minutes (23.0 hours) using the stratified approach. The stratified approach required on average 41.7 times more computational time than the homogenous approach. The stratified approach solved a model with turbulent boundary layer relations when the homogeneous approach solved a model of a control volume using an energy balance and mass balance relations. A computer with Windows 7, $8 \mathrm{~GB}$ of memory RAM, and a quad-core processor of $3.20 \mathrm{GHz}$ was used with MATLAB 2013a installed.

\subsection{Uncertainty and Sensitivity Analysis of the LNG Fueling Station Model}

An uncertainty analysis was performed based on the sensitivity of the more influential parameters in the LNG fueling station model. Table 4.17 shows the uncertainty of the model using the sensitivity in the measurement error of the top five influential parameters. Table 4.18 shows the uncertainty of the model with assumptions applied to the fleet behavior at the station. Segment 1 of fueling Station 1 in Nevada was selected as a baseline. The tables show the errors in the rate of pressure rise with respect to time $(d P / d t)$ in psia/day compared to the experimental value and compared to the baseline simulation. The homogenous approach was used in the thermodynamics of the LNG tank for all the uncertainty analysis performed.

Sensitivity of the variables was performed assuming their respective measurement errors. The ambient temperature was altered by $\pm 5 \mathrm{~K}$ based on the uncertainty of the NOAA weather stations after including artificial heating sources as vehicles and heat-absorbing surfaces such as asphalt $[80,81]$. The uncertainty of the station pressure transducer was rated as \pm 1.885 psia therefore was rounded for a sensitivity of \pm 2 psia. The measurement 
error of the fill level of the stations was not provided. However, it was found that LNG bulk tanks determine the liquid level using a hydrostatic gauge with uncertainty of $\pm 0.9 \%$ [83], therefore the fill level uncertainty was rounded to a sensitivity of $\pm 1 \%$. The complete piping length (recirculation, vapor return, and dispenser piping) was varied by $\pm 10 \%$ since it could be estimated by visual inspection. The pipes were used with the same diameters and insulation types including vacuum jacketed, foam insulated, and bare metal. Similarly, a sensitivity of $\pm 10 \%$ was used in the heat transfer of the offload pump since estimation included the use of the length in the offload pump piping system. In addition, a case neglecting the heat transfer into the bulk tank by the offload pump was included.

Table 4.17. Uncertainty of the LNG Fueling Stations Model by Sensitivity of Variables with Measurement Errors

\begin{tabular}{|c|c|c|c|c|c|c|}
\hline \multirow{2}{*}{$\begin{array}{c}\text { Audit 1 } \\
\text { Segment 1: } \\
\text { Measurement Errors }\end{array}$} & \multirow{2}{*}{$\begin{array}{l}\text { Pressure } \\
\text { Rise } \\
\text { (psia) }\end{array}$} & \multirow{2}{*}{$\begin{array}{c}\mathrm{dP} / \mathrm{dt} \\
\text { (psia/day) }\end{array}$} & \multicolumn{2}{|c|}{$\begin{array}{l}\text { Compared to } \\
\text { Experimental }\end{array}$} & \multicolumn{2}{|c|}{$\begin{array}{c}\text { Compared to Original } \\
\text { Simulation }\end{array}$} \\
\hline & & & $\begin{array}{l}\text { Error dP/dt } \\
\text { (psia/day) }\end{array}$ & $\begin{array}{c}\text { Error dP/dt } \\
(\%)\end{array}$ & $\begin{array}{l}\text { Error dP/dt } \\
\text { (psia/day) }\end{array}$ & $\begin{array}{c}\text { Error } \mathrm{dP} / \mathrm{dt} \\
(\%)\end{array}$ \\
\hline Experimental & 55.96 & 19.75 & 0.00 & $0.00 \%$ & 2.54 & $14.73 \%$ \\
\hline Original & 48.78 & 17.22 & -2.54 & $-12.84 \%$ & 0.00 & $0.00 \%$ \\
\hline Amb. Temp.: $+5^{\circ} \mathrm{K}$ & 50.61 & 17.86 & -1.89 & $-9.57 \%$ & 0.64 & $3.75 \%$ \\
\hline Amb. Temp.: $-5^{\circ} \mathrm{K}$ & 47.14 & 16.64 & -3.11 & $-15.76 \%$ & -0.58 & $-3.36 \%$ \\
\hline Init. Pressure: +2 psia & 49.26 & 17.39 & -2.37 & $-11.98 \%$ & 0.17 & $0.98 \%$ \\
\hline Init. Pressure: -2 psia & 48.43 & 17.09 & -2.66 & $-13.46 \%$ & -0.12 & $-0.71 \%$ \\
\hline Init. Fill Level: $+\mathbf{1} \%$ & 48.23 & 17.02 & -2.73 & $-13.83 \%$ & -0.20 & $-1.14 \%$ \\
\hline Init. Fill Level: -1\% & 49.34 & 17.41 & -2.34 & $-11.84 \%$ & 0.20 & $1.14 \%$ \\
\hline Piping Length: $+\mathbf{1 0} \%$ & 52.31 & 18.46 & -1.29 & $-6.53 \%$ & 1.25 & $7.24 \%$ \\
\hline Piping Length: -10\% & 45.42 & 16.03 & -3.72 & $-18.84 \%$ & -1.19 & $-6.88 \%$ \\
\hline Offload Pump HT: 0 kJ/s & 47.76 & 16.86 & -2.89 & $-14.65 \%$ & -0.36 & $-2.08 \%$ \\
\hline Offload Pump HT: +10\% & 48.87 & 17.25 & -2.50 & $-12.67 \%$ & 0.03 & $0.19 \%$ \\
\hline Offload Pump HT: -10\% & 48.69 & 17.18 & -2.57 & $-13.00 \%$ & -0.03 & $-0.19 \%$ \\
\hline $\begin{array}{c}\text { Combined: } \\
\text { Amb. Temp.: }+5^{\circ} \mathrm{K} \\
\text { Piping Length: }+10 \%\end{array}$ & 54.26 & 19.15 & -0.60 & $-3.04 \%$ & 1.93 & $11.24 \%$ \\
\hline $\begin{array}{c}\text { Combined: } \\
\text { Amb. Temp.: }-5^{\circ} \mathrm{K} \\
\text { Piping Length: }-10 \%\end{array}$ & 43.92 & 15.50 & -4.25 & $-21.52 \%$ & -1.72 & $-9.97 \%$ \\
\hline
\end{tabular}

From Table 4.17 it was observed that the ambient temperature and piping length influenced the model the greatest, each with a change of more than $\pm 3 \%$ in the $d P / d t$. 
Uncertainty using the ambient temperature bounded the $d P / d t$ between +0.64 psia/day $(3.75 \%)$ and -0.58 psia/day $(-3.36 \%)$. The piping length had the biggest uncertainty in the model bounding the $d P / d t$ between $+1.25 \mathrm{psia} / \mathrm{day}(7.24 \%)$ and $-1.19 \mathrm{psia} / \mathrm{day}(-6.88 \%)$. Each of the other three variables used had an uncertainty in the model of less than $\pm 2 \%$ for $d P / d t$. A combined sensitivity utilizing the change in ambient temperature and piping length was performed bounding the uncertainty of the model between $+1.93 \mathrm{psia} / \mathrm{day}$ (11.24\%) and -1.72 psia/day (-9.97\%).

Furthermore, the uncertainty of the model was calculated using the sensitivity of the fleet assumptions for the unknown vehicles which used the station. Results are shown in Table 4.18. A total of 685 vehicles were refueled during the three weeks at Station 1 in Nevada. WVU personnel observed 67\% (458) of those refueling vehicles and were able to obtain complete data sets on 53.3\% (365) of the vehicle refueling events. The remaining $46.7 \%$ (320) vehicle refueling events were approximated using averages of the actual transactions observed. For segment 1 a total of 105 vehicles were refueled at the station and a complete data set was recorded for 39\% (41) of the vehicles. A sensitivity in the remaining $61 \%$ (64) vehicles was applied for the tanks arrival pressure and for the pressure after vapor was returned to the LNG bulk tank. The standard deviation $(\sigma)$ in arrival pressure was calculated for the known vehicle tanks as \pm 24.85 psia and \pm 13.67 psia for the pressure after venting back to the station. In order to have around a $10 \%$ variation a fourth of the standard deviation $(\sigma / 4)$ was used for the sensitivity analysis which accounted for a $9.87 \%$ of change in the average values. The sensitivities were rounded to \pm 6.5 psia in the arrival pressure and \pm 3.5 psia for the pressure after venting back to the station. A case where vehicles arrived with higher pressure and vented to a lower pressure was simulated. The opposite case was simulated as well when vehicles arrived with lower pressure and stopped venting back to the station at higher pressure. Additionally, a case keeping the average arrival pressure in the vehicles the same and assuming that vapor was not returned to the station tank was included.

The uncertainty from Table 4.18 using the sensitivity in the fleet assumptions bounded the $d P / d t$ between +1.57 psia/day $(9.14 \%)$ and $-1.51 \mathrm{psia} /$ day $(-8.78 \%)$. The assumptions in the behavior of the fleet had an important role in the pressure rise of a LNG 
bulk tank. Moreover, the number of vehicles using a station can determine if a station is under-utilize which determined the necessity to handle excess of BOG and this will be addressed in Chapter 5. The baseline simulation estimated a total $624 \mathrm{~kg}$ of methane vapor returned to the station. The simulation with the vehicles at a higher arrival pressure and venting to lower pressure estimated $127.9 \mathrm{~kg}$ of additional methane vapor returned increasing the $d P / d t$ by $1.57 \mathrm{psia} /$ day $(9.14 \%)$. The other case estimated a reduction in $128.9 \mathrm{~kg}$ of methane vapor reducing the $d P / d t$ by $1.51 \mathrm{psia} / \mathrm{day}(8.78 \%)$. The case assuming that the unknown vehicles were not returning vapor to the station had a reduction of $450.5 \mathrm{~kg}$ in vapor return for a reduction in $d P / d t$ of $5.19 \mathrm{psia} / \mathrm{day}(30.14 \%)$. The mass of vapor returned into a LNG bulk tank and the enthalpy that this added into the system was an important source of pressure rise in a fueling station. It should be studied in detail by future researches in this field.

Table 4.18. Uncertainty of the LNG Fueling Stations Model by Sensitivity of the Fleet Assumptions

\begin{tabular}{|c|c|c|c|c|c|c|}
\hline \multirow{2}{*}{$\begin{array}{c}\text { Audit 1 } \\
\text { Segment 1: } \\
\text { Fleet Assumptions }\end{array}$} & \multirow{2}{*}{$\begin{array}{l}\text { Pressure } \\
\text { Rise } \\
\text { (psia) }\end{array}$} & \multirow{2}{*}{$\begin{array}{c}\mathrm{dP} / \mathrm{dt} \\
\text { (psia/day) }\end{array}$} & \multicolumn{2}{|c|}{$\begin{array}{l}\text { Compared to } \\
\text { Experimental }\end{array}$} & \multicolumn{2}{|c|}{$\begin{array}{c}\text { Compared to Original } \\
\text { Simulation }\end{array}$} \\
\hline & & & $\begin{array}{l}\text { Error dP/dt } \\
\text { (psia/day) }\end{array}$ & $\begin{array}{c}\text { Error dP/dt } \\
(\%)\end{array}$ & $\begin{array}{l}\text { Error dP/dt } \\
\text { (psia/day) }\end{array}$ & $\begin{array}{c}\text { Error dP/dt } \\
(\%)\end{array}$ \\
\hline Experimental & 55.96 & 19.75 & 0.00 & $0.00 \%$ & 2.54 & $14.73 \%$ \\
\hline Original & 48.78 & 17.22 & -2.54 & $-12.84 \%$ & 0.00 & $0.00 \%$ \\
\hline $\begin{array}{l}\text { Unknow Vehicles: } \\
\text { Arrival Pressure: }+6.5 \text { psia, } \\
\text { Vapor Returned: }-3.5 \text { psia }\end{array}$ & 53.24 & 18.79 & -0.96 & $-4.87 \%$ & 1.57 & $9.14 \%$ \\
\hline $\begin{array}{l}\text { Unknow Vehicles: } \\
\text { Arrival Pressure: }-6.5 \text { psia, } \\
\text { Vapor Returned: }+3.5 \text { psia }\end{array}$ & 44.50 & 15.70 & -4.05 & $-20.49 \%$ & -1.51 & $-8.78 \%$ \\
\hline $\begin{array}{l}\text { Unknow Vehicles: } \\
\text { Arrival Pressure: } \pm 0 \text { psia, } \\
\text { No Vapor Returned }\end{array}$ & 34.08 & 12.03 & -7.72 & $-39.10 \%$ & -5.19 & $-30.14 \%$ \\
\hline
\end{tabular}




\section{- CHAPTER 5 -}

\section{Applications and Predictions Using the LNG Fueling STATION MODEL}

This chapter shows some of the applications and predictions that can be performed using the LNG fueling station model. Projection of population of LNG vehicles and fueling stations in year 2035 are described. A representative LNG station is defined and BOG is calculated as a function of expected vehicle fleet and station demographics and refueling activity.

\subsection{LNG Vehicle Population and Stations BOG in 2035}

The projection of LNG vehicles and LNG fueling stations in 2035 were developed by Ronald Mongold and was described in detail in his master thesis [84]. Mongold used the following sources of data to develop the heavy-duty natural gas vehicle scenarios:

- U.S. Energy Information Administration (EIA).

- National Petroleum Council (NPC)

- Americas Commercial Transportation (ACT) Research Co.

- American Clean Skies Foundation (ACSF)

Mongold's scenarios were a combination of estimates for vehicle populations, including Compressed Natural Gas (CNG) vehicles and LNG vehicles. The heavy-duty natural gas vehicle population data was further processed to develop a low, medium, and high penetration scenarios. The low penetration scenario was developed by averaging the data reported by EIA and NPC (most conservative two estimates). The medium penetration scenario was developed by averaging the data reported by all four sources. The high penetration scenario was developed by averaging the data reported by ACT and ACFS (most optimistic two estimates). Therefore, Mongold's medium scenario was selected as the more representative scenario. The projection of LNG vehicles from Mongold's medium scenario was used in this dissertation to estimate the BOG from LNG bulk tanks. 
Nevertheless, as shown in Section 5.3 the use of other scenarios will change the threshold of percentage of utilization when estimating the BOG in a fueling station. However, the trend in BOG with respect to percentage of utilization in a fueling station is conserved.

The medium projection scenario of heavy-duty LNG vehicle population for the United States in 2035 by Mongold [84] is shown in Table 5.1. A total of 444,590 LNG vehicles were projected. Two classification of heavy-duty over the road (OTR) tractors were included, short hauls (less or equal than $320 \mathrm{hp}$ ) and long hauls (more than $320 \mathrm{hp}$ ). Short hauls $(\leq 320 \mathrm{hp})$ were vehicles with a 9L spark ignited stoichiometric engine using a LNG tank without an internal fuel pump, and were expected to travel 50,000 miles per year. A population of 154,640 (34.8\%) vehicles was estimated with a fuel consumption of $88.36 \mathrm{~kg}$ of LNG per work day per vehicle. Long hauls (> $320 \mathrm{hp}$ ) were expected to travel 100,000 miles per year and used a 12L spark ignited stoichiometric engine with a LNG tank without an internal fuel pump and a 15L dual fuel compression ignition engine with diesel pilot injection with a tank with an internal fuel pump. A population of 96,650 (21.7\%) vehicles was estimated for the vehicles with a 12L engine with a tank without an internal fuel pump. Fuel consumption was estimated as $162.66 \mathrm{~kg}$ of LNG per work day per vehicle. The vehicles with a 15L engine with tank with an internal fuel pump were estimated to consume $154.23 \mathrm{~kg}$ of LNG per work day per vehicle, with a population of 193,300 (43.5\%) vehicles. The vehicles were assumed to work six days per week.

Table 5.1. Medium Projection of Heavy-Duty LNG Vehicle Population for the United States in 2035 [84]

\begin{tabular}{|c|c|c|c|c|}
\hline LNG Engine Technology & $\begin{array}{l}\text { Population } \\
\text { (vehicles) }\end{array}$ & $\begin{array}{c}\text { Population } \\
\text { (\%) }\end{array}$ & $\begin{array}{c}\text { Annual Fuel } \\
\text { Consumption per } \\
\text { Vehicle } \\
\text { (kg/(year*vehicle)) }\end{array}$ & $\begin{array}{c}\text { Work Day Fuel } \\
\text { Consumption per } \\
\text { Vehicle } \\
\text { (kg/(work_day*vehicle)) }\end{array}$ \\
\hline 9L Engine Tank without Fuel Pump ${ }^{A}$ & 154,640 & $34.8 \%$ & 27,680 & 88.36 \\
\hline 12L Engine Tank without Fuel Pump ${ }^{B}$ & 96,650 & $21.7 \%$ & 50,954 & 162.66 \\
\hline 15L Engine Tank with Fuel Pump ${ }^{B}$ & 193,300 & $43.5 \%$ & 48,314 & 154.23 \\
\hline Total LNG Vehicles & 444,590 & $100 \%$ & & \\
\hline
\end{tabular}

\footnotetext{
${ }^{A}$ Traveles 50,000 miles per year

${ }^{B}$ Traveles 100,000 miles per year
} 
The number of stations in 2035 was based on the assumption that natural gas stations would refuel 80 OTR tractors per station per day. The projected number of stations correlated to the number of predicted vehicles was 5558 LNG stations in the United States.

Mongold reported that BOG emissions from LNG bulk tanks are not known nationally. However, concluded that in a fully utilized station no BOG will occur and gave two numerical examples. The first example stated that one station dispensed 3,000 gallons per day and no emissions would occur. This station served fewer vehicles than 80 , the value reported as an assumption for a fully utilized station. The second example stated that for a severely underutilized station that distributed about 1,500 gallons per day, about $5 \%$ of the total fuel would be vented to the atmosphere. Mongold estimated that few underutilized stations are anticipated to exist in year 2035 [84].

As shown in Section 5.3, Mongold examples were accurate and were validated using the LNG Fueling Station model. Example one was confirmed estimating that if a station dispensed less than 2,861 gallons per day BOG will occur. The second example was validated where a station that dispensed 1,500 gallons per day will vent. The percentage of total fuel vented was estimated as $7.36 \%$ instead of 5\% reported by Mongold.

\subsection{Characteristics of the Representative LNG Station Used}

Based on data available from audited LNG stations and the projection of LNG vehicle population developed by Mongold [84], a representative station was defined to estimate future LNG station emissions. However, LNG stations are complex dynamically dependent systems, station design (dimensions), management processes, and/or fleet behavior drastically affect its emissions and pressure rise rate. The following representative station and utilization demographics were used in the model to evaluate the effect of station utilization on BOG emission rate.

The following sections represent the baseline scenario at the specific representative 2035 station. 


\subsubsection{Vehicles and Fleet Behavior}

Table 5.2 describes the characteristics for the vehicles used in the scenarios. Three engine sizes were used with two types of vehicle technology. Two engine sizes used the vehicle technology where the LNG tank does not have an internal fuel pump. The engine sizes were of $9 \mathrm{~L}$ and of $12 \mathrm{~L}$. The other size of engine was of $15 \mathrm{~L}$ with a tank with an internal fuel pump.

The vehicles with a 9L engine were equipped with one LNG tank of 120 gallon capacity. The arrival pressure assumed at the station was of $130 \mathrm{psig}$ with a fill level of $30 \%$, these vehicles refueled every work day with $88.36 \mathrm{~kg}$ (61.42 gal) of LNG as reported by Mongold [84]. The vehicles with 12L and 15L engine were equipped with two LNG tanks, one of 120 gallons and one of 70 gallon capacity. Both LNG tanks in the vehicles with a $12 \mathrm{~L}$ engine were assumed to arrive with a pressure of $130 \mathrm{psig}$ and $50 \%$ fill level, a total of $162.66 \mathrm{~kg}$ (113.06 gal) of LNG was dispensed into each vehicle per work day. The vehicles with a 15L engine with tank with an internal fuel pump were assumed to vent back to the station bulk tank. Both LNG tanks in the vehicles with a 15L engine were assumed to arrive with a pressure of $170 \mathrm{psig}$ and 50\% fill level, each tank vented down to $120 \mathrm{psig}$, and a total of $154.23 \mathrm{~kg}$ (10.7.20 gal) of LNG per work day was dispensed into each vehicle. All LNG tanks in the vehicles were assumed to leave the station with a $90 \%$ fill level. The density of liquid methane at 70 psig was used where the weight of 1 gallon was calculated equal to $1.44 \mathrm{~kg}$.

Table 5.2. Vehicle Characteristics for the Representative Station

\begin{tabular}{l|ccc}
\hline \multicolumn{1}{c|}{ Type of Vehicles } & $\begin{array}{c}\text { 9L Engine } \\
\text { Tank without } \\
\text { Fuel Pump }\end{array}$ & $\begin{array}{c}\text { 12L Engine } \\
\text { Tank without } \\
\text { Fuel Pump }\end{array}$ & $\begin{array}{c}\text { 15L Engine } \\
\text { Tank with } \\
\text { Fuel Pump }\end{array}$ \\
\hline Vehicles Tanks & 1: $120 \mathrm{gal}$ & $\begin{array}{c}\text { 2: } 120 \mathrm{gal}, \\
70 \mathrm{gal}\end{array}$ & $\begin{array}{c}2: 120 \mathrm{gal}, \\
70 \mathrm{gal}\end{array}$ \\
Arrival Pressure & $130 \mathrm{psig}$ & $130 \mathrm{psig}$ & $170 \mathrm{psig}$ \\
Arrival Level & $30 \%$ & $50 \%$ & $50 \%$ \\
Pressure after Venting & $\mathrm{N} / \mathrm{A}$ & $\mathrm{N} / \mathrm{A}$ & $120 \mathrm{psig}$ \\
Final Level after & $90 \%$ & $90 \%$ & $90 \%$ \\
Dispensing & $88.36 \mathrm{~kg}$ & $162.66 \mathrm{~kg}$ & $154.23 \mathrm{~kg}$ \\
Fuel Dispensed & $(61.42 \mathrm{gal})$ & $(113.06 \mathrm{gal})$ & $(107.20 \mathrm{gal})$ \\
\hline
\end{tabular}


The number of vehicles refueled were from 5 up to 120 per day. The distribution of vehicle technology of Mongold [84] was conserved as 34.8\% of 9L engine vehicles, $21.7 \%$ of $12 \mathrm{~L}$ engine vehicles, and $43.5 \%$ of $15 \mathrm{~L}$ engine vehicles. In some cases the number of each vehicle technology was rounded to the closer value to keep the integrity of vehicles in the simulations.

The total number of vehicles arriving at the station for refueling was assumed to be evenly spaced during each day. It was assumed that initially the group of $15 \mathrm{~L}$ engine vehicles arrived and vented back to the station, followed by the group of 9L engine vehicles, and ended with the group of $12 \mathrm{~L}$ engine vehicles. The group of vehicles with a 9L engine and $12 \mathrm{~L}$ engine did not vent back to the station. This sequence was repeated each day of the simulations until the total mass in the LNG bulk tank was reduced by the entire tanker offload. A different order of vehicle type arrivals was not explorer. This order affects the stopping point during the last day simulated changing the total BOG estimated in a fueling station. However, the trend in BOG with respect to percentage of utilization in a fueling station is conserved.

\subsubsection{Station Tank}

One vertical station LNG tank of 25,000 gallons (94,635 1) was selected for all the scenarios simulations. Table 5.3 shows a summary of the tank characteristics. The initial fill level of $90 \%$ was used. The initial pressure was assumed as 70 psig with a maximum PRV pressure of 140 psig. The PRV was assumed to drop the pressure 1 psig when activated. The total mass of vapor methane vented was tracked to calculate the BOG during the simulations.

Table 5.3. Station Bulk Tank Parameters

\begin{tabular}{l|cc}
\hline \multicolumn{1}{c|}{ Variable Name } & Value & Units \\
\hline Tank Orientation & Vertical & $(-)$ \\
Tank Volume Capacity & 25,000 & gal \\
& $(94,635)$ & $(\mathrm{I})$ \\
Initial Tank Pressure & 70 & psig \\
Relief Valve Pressure & 140 & psig \\
PRV Drop Pressure & 1 & psig \\
Initial Fill Level & 90 & $\%$ \\
Initial Total Tank Mass & 32,458 & $\mathrm{~kg}$ \\
\hline
\end{tabular}


Table 5.4 shows a summary of the tank dimensions and heat transfer values which were assumed closer to the ones in a typical bulk tank of the capacity selected. The height of the LNG bulk tank was $20.32 \mathrm{~m}$ and the outside diameter was $3.00 \mathrm{~m}$. The tank was assumed to be painted with white paint of 0.14 surface absorptivity. Multilayer insulation (MLI) was assumed in the vacuum area with a thermal conductivity of 5 . $10^{-5} \mathrm{~W} /(\mathrm{m} \cdot \mathrm{K})$. The internal layer, external layer, and struts were assumed to be made of stainless steel. The struts were assumed to support the inner tank from the top, bottom, and sides (cylindrical region). The area ratio was assumed with stronger support of the bulk tank from the top and bottom sections.

Table 5.4. Station Bulk Tank Dimensions and Heat Transfer Values Used

\begin{tabular}{l|cc}
\hline \multicolumn{1}{c|}{ Variable Name } & Value & Units \\
\hline Outside Diameter & 3.00 & $\mathrm{~m}$ \\
\hline Insulation Thickness & 0.0667 & $\mathrm{~m}$ \\
External Shell Layer Thickness & 0.0206 & $\mathrm{~m}$ \\
Internal Shell Layer Thickness & 0.0206 & $\mathrm{~m}$ \\
\hline Length/Height of Tank & 20.32 & $\mathrm{~m}$ \\
\hline Top Area Ratio & $7.303 \mathrm{e}-4$ & $(-)$ \\
Cylindrical Area Ratio & $1.350 \mathrm{e}-5$ & $(-)$ \\
Bottom Area Ratio & $7.303 \mathrm{e}-4$ & $(-)$ \\
\hline Insulation Conductivity (MLI) & $5.00 \mathrm{e}-5$ & $\mathrm{~W} /\left(\mathrm{m}^{*} \mathrm{~K}\right)$ \\
\hline Surface Absorptivity (White Paint) & 0.14 & $(-)$ \\
\hline
\end{tabular}

\subsubsection{Station Piping}

The station piping for each section of the piping system was modeled as an equivalent length of piping distributed (by percentage), in order to allow the station to be easily scaled. The station piping dimensions are shown in Table 5.5. All pipes were assumed to be made of schedule 10 stainless steel pipe. The nominal diameters of the pipes was between 1 and 2.5 inches. The piping system consisted of three main sections. The first section was the recirculation/dispenser supply piping assumed with an equivalent length of $90 \mathrm{~m}$. Three types of insulations were used in the pipes of this section: vacuum jacketed (VJP), rigid foam, and bare pipe. The second section was the dispenser piping with an equivalent length of $5 \mathrm{~m}$ assumed. The dispenser piping used VJP as insulation and 
bare pipes. The third section was the vapor return piping assumed with an equivalent length of $30 \mathrm{~m}$ of bare pipes.

Table 5.5. Station Piping Dimensions

\begin{tabular}{|c|c|c|c|}
\hline $\begin{array}{c}\text { Nominal } \\
\text { Diameter (in) }\end{array}$ & $\begin{array}{c}\text { Type of } \\
\text { Insulation }\end{array}$ & $\begin{array}{c}\text { Composition } \\
(\%)\end{array}$ & $\begin{array}{l}\text { Length } \\
\text { (m) }\end{array}$ \\
\hline \multicolumn{4}{|c|}{$\begin{array}{l}\text { Recirculation/Dispenser Supply Piping } \\
\text { (Equivalent Length: } 90 \text { meters) }\end{array}$} \\
\hline 2.5 & Vacuum Jacketed & $65 \%$ & 48.75 \\
\hline 2.0 & Vacuum Jacketed & $15 \%$ & 11.25 \\
\hline 2.0 & Rigid Foam & $10 \%$ & 7.50 \\
\hline 1.5 & Rigid Foam & $9 \%$ & 6.75 \\
\hline 1.0 & Bare & $1 \%$ & 0.75 \\
\hline \multicolumn{4}{|c|}{$\begin{array}{c}\text { Dispenser Piping } \\
\text { (Equivalent Length: } 5 \text { meters) }\end{array}$} \\
\hline 1.5 & Vacuum Jacketed & $25 \%$ & 1.25 \\
\hline 1.0 & Bare & $75 \%$ & 3.75 \\
\hline \multicolumn{4}{|c|}{$\begin{array}{c}\text { Vapor Return Piping } \\
\text { (Equivalent Length: } 30 \text { meters) }\end{array}$} \\
\hline 1.0 & Bare & $100 \%$ & 30.00 \\
\hline
\end{tabular}

\subsubsection{Weather Conditions}

The model accounted for varying ambient conditions. Table 5.6 shows the assumed representative conditions. The ambient pressure at the location of the station was assumed as 14.7 psi and was used to convert between psig and psia. The ambient temperature was represented as a sinusoidal wave with the peak temperature at $3 \mathrm{pm}$ and the low at $3 \mathrm{am}$. An average ambient temperature of $298 \mathrm{~K}$ was assumed oscillating around $\pm 10 \mathrm{~K}$. The solar loading assumed raised from 0 to the peak at noon and back to zero during a twelve hour window. The direct solar loading was assumed with a peak of $900 \mathrm{~W} / \mathrm{m}^{2}$ and the diffuse solar loading with a peak of $90 \mathrm{~W} / \mathrm{m}^{2}$. Figure 5.1 shows an illustration of the ambient temperature and solar loading used in the simulations. 
Table 5.6. Solar Loading and Ambient Conditions

\begin{tabular}{l|cc}
\hline \multicolumn{1}{c|}{ Variable Name } & Value & Units \\
\hline Ambient Pressure & 14.7 & $\mathrm{psi}$ \\
Ambient Temperature & $298 \pm 10$ & $\mathrm{~K}$ \\
Peak Direct Solar Loading & 900 & $\mathrm{~W} / \mathrm{m}^{2}$ \\
Peak Diffuse Solar Loading & 90 & $\mathrm{~W} / \mathrm{m}^{2}$ \\
\hline
\end{tabular}
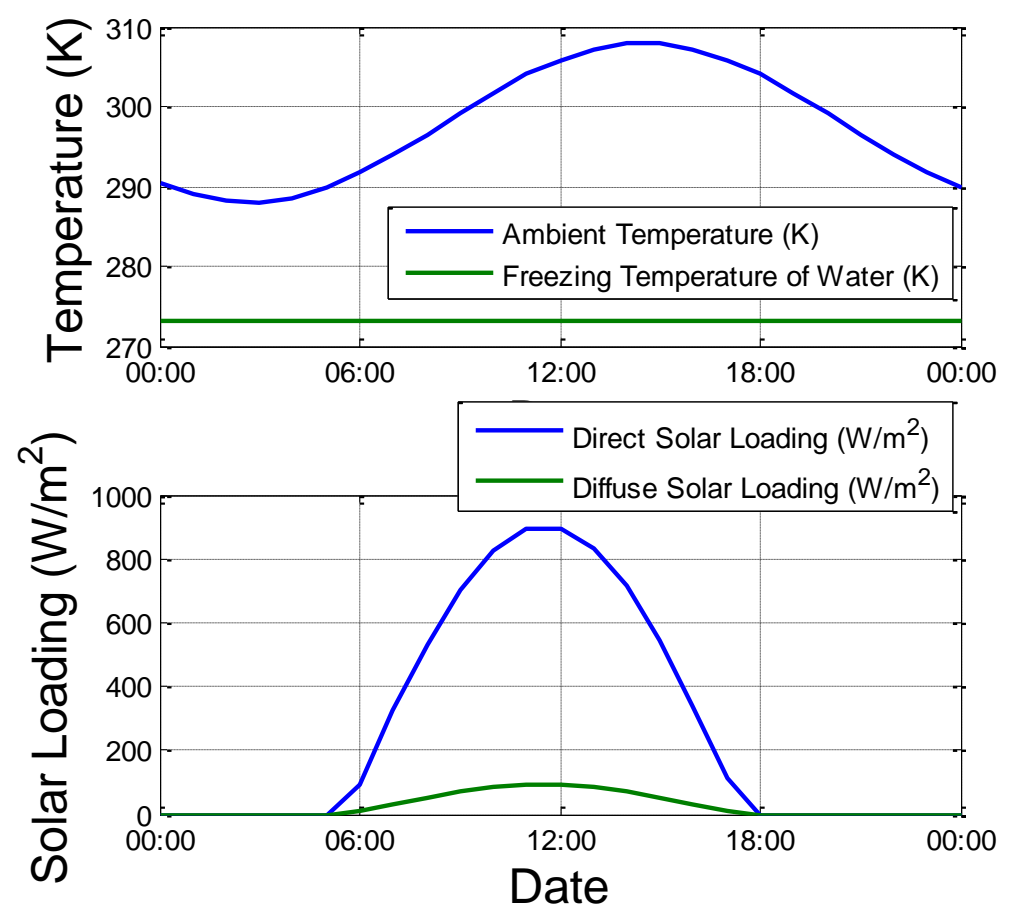

Figure 5.1. Solar Loading and Ambient Temperature used in the Simulations.

\subsubsection{Utilization}

The percentage of utilization of a LNG fueling station was defined as the total fuel dispensed into vehicles in a day divided by the tanker offload:

$$
\% \text { Utilization }=\frac{\# \text { Vehicles } * \text { Fuel Delivered per Vehicle }(\mathrm{kg})}{\text { Tanker Offload }(\mathrm{kg})}
$$

A typical LNG tanker that offloads to a station have two standard capacities carrying 10,000 gallons or 13,000 gallons of LNG. Normally tankers will not deliver partial 
loads. The definition of $100 \%$ utilization was then the maximum number of vehicles that can be filled from this quantity of LNG in a day. In this way $100 \%$ utilization always has the same meaning when referring to a specific amount of LNG. The 25,000 gallons station tank selected had a capacity of 22,500 gallons (because of $10 \%$ ullage volume) of LNG. An offload of 13,000 gallons of LNG was assumed taking the bulk tank from 38\% to $\sim 90 \%$ fill level.

The percentages of utilization were used as inputs into the model to calculate the percentage of fuel lost due to BOG venting. The percentage of fuel lost to BOG was defined as the total LNG vented divided by the tanker offload:

$$
\% \text { Fuel Lost to BOG }=\frac{\text { Fuel Vented }(\mathrm{kg})}{\text { Tanker Offload }(\mathrm{kg})}
$$

where the tanker offload was converted from gallons into kilograms using the density of the liquid methane at the initial pressure of the bulk tank simulation.

\subsection{Simulation of BOG from a LNG Fueling Station Tank with Vehicles Refueling}

The BOG was calculated as a function of number of vehicles refueling for the typical LNG station described in Section 5.2. The LNG Fueling Station model was used with the homogenous thermodynamic approach. All of the simulation used a time step of 600 seconds (10 minutes). A summary of the results of the simulations is shown in Table 5.7. The total LNG vented in the fueling station as a function of percentage of utilization was plotted in Figure 5.2. From the simulations it was observed that if a station had less than a $22.00 \%$ station utilization, BOG would occur. The threshold for the station simulated was calculated as 2,860.64 gal (4,115.69 kg) of LNG dispensed per day where 31 vehicles were refueled per day. If the percentage of utilization was equal to or higher than $22.00 \%$ the fuel vented was zero. The fuel vented increased as a function of the percentage of utilization with an exponential trend when less than the threshold calculated. The minimum amount of vehicles refueled was 5 vehicles per day with a total of $450.30 \mathrm{gal}(647.86 \mathrm{~kg})$ of LNG dispensed per work day in which case the total mass of vapor methane vented was 
estimated as 3,250.06 gal $(4,675.95 \mathrm{~kg})$. The station vented beginning on day 8.96 and continuing until day 22.83 , for a total of 13.87 days venting. This was equal to a fueling station utilization of $3.46 \%$ with a total of $25.00 \%$ of the methane vented as BOG. The use of other scenarios will change the threshold of utilization at which BOG occurs. However, the trend in BOG with respect to percentage of utilization in a fueling station is conserved.

Table 5.7. Simulation of LNG Vented in a Fueling Station.

\begin{tabular}{|c|c|c|c|c|c|c|c|c|c|c|c|}
\hline \multirow{3}{*}{$\begin{array}{c}\text { Total } \\
\text { Vehicles } \\
\text { Fueled per } \\
\text { Day }\end{array}$} & \multicolumn{3}{|c|}{ Vehicle Distribution } & \multirow{3}{*}{$\begin{array}{c}\text { LNG } \\
\text { Dispensed } \\
\text { in a Work } \\
\text { Day (gal) }\end{array}$} & \multirow{3}{*}{$\begin{array}{c}\text { LNG } \\
\text { Dispensed } \\
\text { in a Work } \\
\text { Day (kg) }\end{array}$} & \multirow{3}{*}{$\begin{array}{c}\text { LNG } \\
\text { Fueling } \\
\text { Station } \\
\text { Utilization } \\
\text { (\%) }\end{array}$} & \multirow[b]{3}{*}{$\begin{array}{c}\text { First } \\
\text { Venting } \\
\text { (days) }\end{array}$} & \multirow{3}{*}{$\begin{array}{l}\text { Total } \\
\text { LNG } \\
\text { Vented } \\
\text { (gal) }\end{array}$} & \multirow{3}{*}{$\begin{array}{l}\text { Total } \\
\text { LNG } \\
\text { Vented } \\
\text { (kg) }\end{array}$} & \multirow{3}{*}{$\begin{array}{c}\text { Time } \\
\text { Needed to } \\
\text { Consume an } \\
\text { Offload } \\
\text { (days) }\end{array}$} & \multirow{3}{*}{$\begin{array}{c}\text { Total } \\
\text { LNG } \\
\text { Vented } \\
(\%)\end{array}$} \\
\hline & $34.8 \%$ & $21.7 \%$ & $43.5 \%$ & & & & & & & & \\
\hline & $\begin{array}{c}\text { 9L Engine } \\
\text { Tank without } \\
\text { Fuel Pump }\end{array}$ & $\begin{array}{l}\text { 12L Engine } \\
\text { Tank without } \\
\text { Fuel Pump }\end{array}$ & $\begin{array}{l}\text { 15L Engine } \\
\text { Tank with } \\
\text { Fuel Pump }\end{array}$ & & & & & & & & \\
\hline 5 & 2 & 1 & 2 & 450.30 & 647.86 & $3.46 \%$ & 8.96 & 3250.06 & 4675.95 & 22.83 & $25.00 \%$ \\
\hline 9 & 3 & 2 & 4 & 839.18 & 1207.36 & $6.46 \%$ & 7.38 & 2148.69 & 3091.38 & 15.25 & $16.53 \%$ \\
\hline 15 & 5 & 3 & 7 & 1396.68 & 2009.45 & $10.74 \%$ & 6.13 & 1055.38 & 1518.40 & 9.83 & $8.12 \%$ \\
\hline 20 & 7 & 4 & 9 & 1846.98 & 2657.31 & $14.21 \%$ & 5.51 & 624.04 & 897.82 & 7.92 & $4.80 \%$ \\
\hline 25 & 9 & 5 & 11 & 2297.28 & 3305.17 & $17.67 \%$ & 5.23 & 202.15 & 290.84 & 5.78 & $1.56 \%$ \\
\hline 28 & 10 & 6 & 12 & 2578.96 & 3710.43 & $19.84 \%$ & 5.10 & 37.52 & 53.98 & 5.17 & $0.29 \%$ \\
\hline 30 & 10 & 7 & 13 & 2799.23 & 4027.33 & $21.53 \%$ & 4.82 & 16.06 & 23.11 & 4.83 & $0.12 \%$ \\
\hline 31 & 11 & 7 & 13 & 2860.64 & 4115.69 & $22.00 \%$ & N/A & 0.00 & 0.00 & 4.74 & $0.00 \%$ \\
\hline 40 & 14 & 9 & 17 & 3699.83 & 5323.05 & $28.46 \%$ & N/A & 0.00 & 0.00 & 3.63 & $0.00 \%$ \\
\hline 60 & 21 & 13 & 26 & 5546.81 & 7980.35 & $42.67 \%$ & N/A & 0.00 & 0.00 & 2.38 & $0.00 \%$ \\
\hline 80 & 28 & 17 & 35 & 7393.80 & 10637.66 & $56.88 \%$ & N/A & 0.00 & 0.00 & 1.86 & $0.00 \%$ \\
\hline 120 & 42 & 26 & 52 & 11093.62 & 15960.71 & $85.34 \%$ & $\mathrm{~N} / \mathrm{A}$ & 0.00 & 0.00 & 1.20 & $0.00 \%$ \\
\hline
\end{tabular}

$100 \%$ Utilization $=13,000$ gallons of LNG 13,000 gallons@70 psig=18,703.47 kg

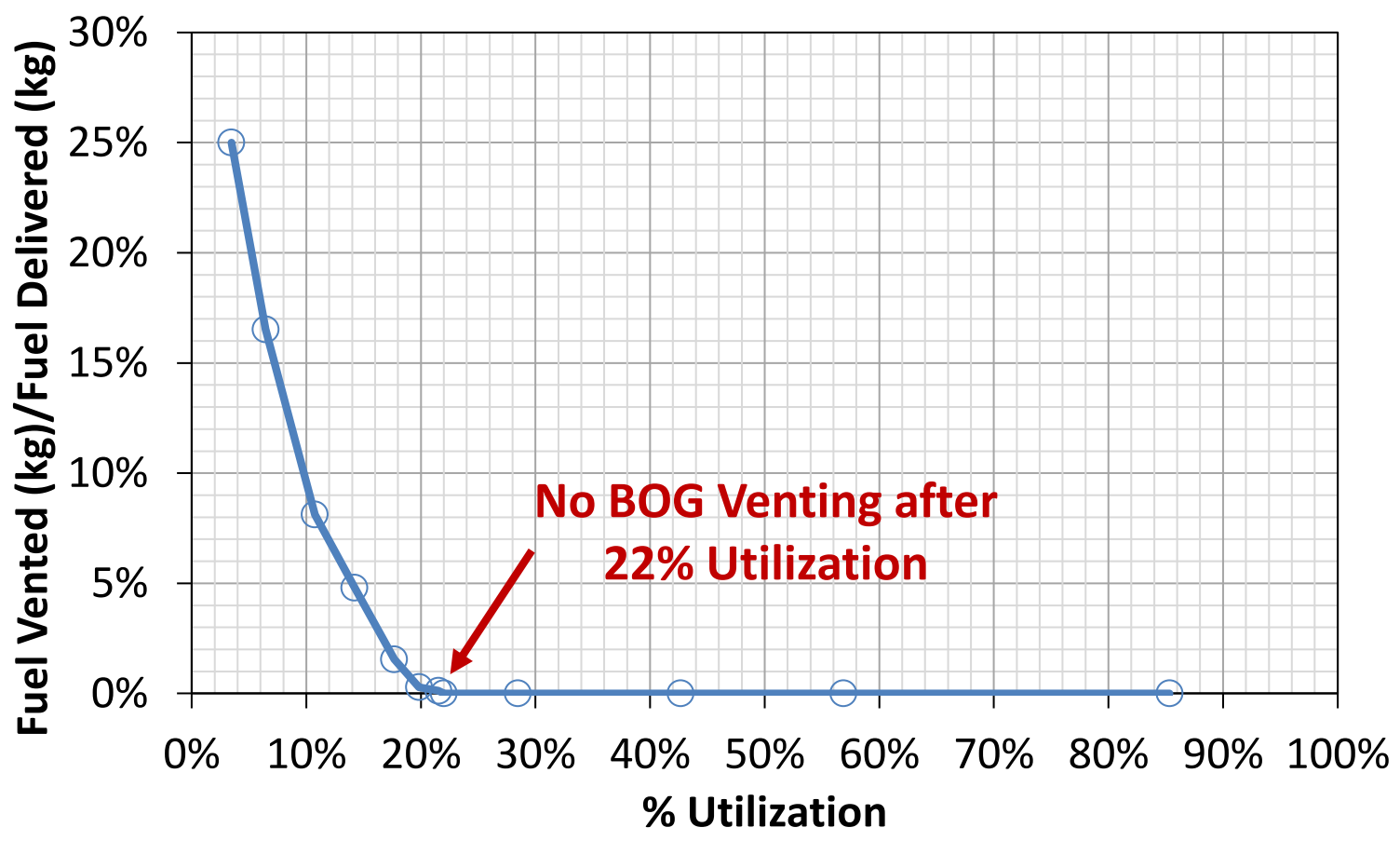

Figure 5.2. Total LNG Vented in a Fueling Station by \%Utilization. 


\section{- CHAPTER 6 - \\ CONCLUSIONS \& RECOMMENDATIONS}

A comprehensive thermodynamics and emissions model of liquefied natural gas tanks and fueling stations was developed in MATLAB/Simulink to calculate methane emitted from tanks.

Numerous researchers have approached several topics related to LNG and boil of gas, however, not many comprehensive analytic and dynamic thermodynamic models of BOG from LNG fueling stations have been developed. An extended and detailed model like the one developed in this work was not found in the literature.

The main contributions of this dissertation were the development of a thermodynamic LNG tank model using a homogeneous and a stratified approach, the modeling of the principal components involved in LNG fueling stations, and the integration of all in one comprehensive thermodynamic and emissions model, which is not currently available in the literature. Additionally, the model allowed the simulation of different future scenarios as a function of fueling station activity. Furthermore, the work developed could be adapted to develop a comprehensive model for LNG vehicle fuel tanks or used with other cryogenic liquids such as hydrogen.

The model was compared with experimental data acquired from vehicle tanks with an internal fuel pump and without an internal fuel pump, and with LNG fueling stations in the United States. The complete LNG Fueling Station Model achieved an average error of $-0.36 \mathrm{psia} /$ day $(1.13 \%)$ in the rate of pressure change with respect to time using the stratified approach and an average error of -1.67 psia/day (-10.43\%) using the homogeneous approach. For fueling stations both approaches presented cases of over prediction and under prediction. The stratified approach had an error in $d P / d t$ between $8.00 \mathrm{psia} /$ day (-39.03\%) and $2.75 \mathrm{psia} /$ day (28.23\%). The homogeneous approach had an error in $d P / d t$ between -7.49 psia/day (-36.55\%) and 2.15 psia/day (17.38\%). Validation of the hold time of vehicle tanks achieved an average error of -1.01 psia/day (-2.64\%) using the stratified approach and 14.56 psia/day (204.25\%) using the homogeneous approach. For vehicle tanks the homogenous approaches always over predicted and the stratified 
approach presented cases of over prediction and of under prediction. The stratified approach had an error in $d P / d t$ between -6.31 psia/day (-44.90\%) and $4.13 \mathrm{psia} / \mathrm{day}$ (21.40\%). The homogeneous approach had an error in $d P / d t$ between $2.35 \mathrm{psia} /$ day (12.16\%) and $39.48 \mathrm{psia} / \mathrm{day}(883.96 \%)$. Additionally, an average error of $-0.10 \mathrm{~kg}$ ($1.46 \%$ ) was achieved in the total LNG mass emitted by boil off for the Venting Model when using LNG vehicle tanks between 105 and 150 gallons. The error in mass vented was between $-0.64 \mathrm{~kg}(-12.69 \%)$ and $0.47 \mathrm{~kg}(2.06 \%)$. Nevertheless, these error can likely be partially reduced by using additional model validation data and more precise values for the LNG tanks and stations dimensions.

It was verified by the experimental data that thermal stratification inside the tanks plays an important role in pressure rise and hold time of LNG tanks. It was observed that oscillating a LNG tank caused the tank pressure to decrease lending support to the existence of stratified liquid and vapor regions with superheated vapor. However, the type of oscillations applied were not believe to be mixing the LNG back to saturated conditions, and no significant effect was observed in the overall experiments.

The stratification model provided outstanding results comparted to the homogeneous model for hold time of tanks when tanks were sitting idle for several days without any disturbance, where the main source of heat into the tank was through the wall insulation. Due the nature of the homogeneous model, a higher heat leak into the tank was estimated affecting the pressure rise. It was observed that a higher heat transfer rate into the tank was calculated when the fill level of the tank was decreasing and the homogeneous approach was used. Due to stratification the vapor in the ullage had a higher temperature than the saturated temperature. Nevertheless, the homogenous approach presented better performance than the stratified approach when the fill level exceeded approximately $85 \%$.

For bulk tanks at fueling stations additional sources of heat were estimated to affect the liquid and vapor inside the LNG tank. It was observed that pressure rise in LNG fueling stations was strongly dominated by the heat addition associated with vehicle refueling activity. From the overall results it was observed that typically the energy transfer associated with the transactions (sum of vapor return, recirculation, and dispenser cool down) was approximately 10 times larger than the heat leak through the walls of the LNG 
tank. On the other hand, for idle LNG stations the pressure rise was dominated by the heat transfer through the walls of the tank.

Even though the average errors of Station 2 were smaller than for Station 1, it is believe that Station 1 simulations were more accurate and in closer agreement with experimental data since more precise information was available from the owners of the station. Additionally, the maximum errors with Station 1 were around four times smaller than with Station 2. The simulation that best represented Station 2 was believe to be for segment 4 when the electrical generator was off during the entire segment. Assumption of fuel consumption by the generator was not necessary. It is believe that all vehicle refueling activity was recorded during this segment.

During the simulations there was not a match with the tank pressure recorded when the "offload pump effect" was observed. However, the pressure was matched after the "offload pump effect" disappeared. The simulations included the energy into the tank estimated by this behavior. After this match, the simulation pressure continued following the experimental pressure trends.

It was believed that a fast removal of vapor from the station tank will dissipate the stratification in the vapor region, which was not accounted for in the assumptions of the stratified thermodynamic approach. The stratified approach assumed a stratification developed in the vapor and in the liquid region simultaneously, and thermodynamic relations following this assumption between both regions were used. In order to be able to simulate a constant fast removal of vapor from the tank a model that will assume stratification in the liquid region and not in the vapor region needs to be developed, with appropriate relations between the two regions.

It was observed that the error in the pressure rise increased when direct vehicle data were not recorded and not included in the simulations. Correct information of the vehicle refueling transactions and arrival times at the stations are necessary in order to have a more accurate modeling of the bulk tank pressure.

A total of 509 gallons of LNG was vented by the two PRV events during the time at Audit 1, 204 gallons and 305 gallons respectively. During Audit 2, each manual vent observed dropped the fill level between 150 gallons to 282 gallons for a total 863 gallons. It was observed that Station 2 was differently managed and it does not represent the desired 
behavior of LNG fueling stations. However, it is clear that the performing of manual vents in bulk tanks generate significant methane emissions to the environment. Nevertheless, Station 1 did not have a large enough fleet which made it an under-utilized LNG fueling station prone to PRV vents. It was observed that slow releases by PRVs generate as high emissions as manual vents. The total methane vented by the two stations was approximately 1372 gallons of LNG.

Behavior of the fleet utilizing a station have an important role in the pressure rise of a LNG bulk tank. The number of vehicles using a station can determine if a station is under-utilize which determined the necessity to handle excess of boil off gases. The mass of vapor returned into a LNG bulk tank and the enthalpy that this added into the system was an important source of pressure rise in a fueling station. It should be studied in detail by future researches in this field.

The BOG was calculated as a function of vehicle dispensed using a representative LNG station and a representative fleet. The LNG Fueling Station model was used with the homogenous thermodynamic approach. All of the simulation used a time step of 600 seconds (10 minutes). From the simulations it was observed that if a station had less than a $22.0 \%$ station utilization, BOG would occur. The threshold for the station used was calculated as 2,861 gal $(4,116 \mathrm{~kg})$ of LNG dispensed per day where 31 vehicles were dispended per day. If the percentage of utilization was equal or higher than $22.0 \%$ the fuel vented was zero. If the percentage of utilization was less than the threshold the fuel vented increased with an exponential trend. The use of other scenarios will change the threshold of percentage of utilization when estimating the BOG in a fueling station. However, the trend in BOG respect to percentage of utilization in a fueling station is conserved.

For LNG fueling stations the stratified approach generally produced better results than the homogenous approach. However, the homogenous approach was in general able to predict the trends in pressure rise in fueling stations but not as accurately as the stratified approach.

The computational time of the entire LNG Station Model with vehicles dispensing was measured with an average of $1.1 \mathrm{~min} /$ (day simulated) using the homogeneous approach and $45.9 \mathrm{~min} /$ (day simulated) using the stratified approach. The same computational performance was achieved when vehicles were not refueled. A time step of 600 seconds 
was used for a total of 144 global iterations per day. The stratified approach required in average 41.7 times more computational time than the homogenous approach. The stratified approach solved a model with turbulent boundary layer relations when the homogeneous approach solved a model of a control volume using an energy balance and mass balance relations. A computer with Windows 7, 8 GB of memory RAM, and a quad-core processor of $3.20 \mathrm{GHz}$ was used with MATLAB 2013a installed.

For future research in this field two linked pathways are recommended to be studied in more detail: the pressure rise estimation and the methane emission prediction. To improve the pressure rise estimation a deeper analysis could be done in the sources of heat into the LNG station tanks pertained to dispensing fuel to vehicles. Since the refueling of vehicles dominated the pressure rise in a station tank. More study of the heat leak through the walls of the LNG tank is not recommended, however, this is very important for idle tanks. The sources of heat by vehicle refueling include the cooling of the station piping during fueling, the amount of vapor methane and enthalpy returned from vehicles tanks before refueling, and heat gained in the LNG dispenser system. As well, full access to LNG fueling stations can help to discover other possible heat sources of importance. For nonidle LNG tanks, a weighted average between the homogeneous and stratified predictions could be analyzed to improve the pressure rise estimation. An entropy balance could be applied to verify the numerical prediction of the model, where the change of entropy in a closed system is not negative. To improve the methane emissions prediction in fueling stations a venting model which includes hysteresis in PRV valves can be developed. For both pathways a more accurate recording of fuel dispensed and characteristics of vehicles using the stations is needed. Failure to include vehicles utilizing the station can create compounding errors in the simulations. Additionally, a stratified model assuming a horizontal cylindrical tank can be attempted and compared to the vertical model developed. Another recommendation is to validate the model developed with respect to other cryogenic fluids. Nevertheless, to acquire more data of pressure rise and methane venting from fueling stations and LNG vehicle tanks is recommended to continue improving the understanding of this field of LNG systems. 


\section{REFERENCES}

[1] M. Dickens, J. Neff, and D. Grisby, "APTA 2012 Public Transportation Fact Book," American Public Transportation Association, Washington, DC, 2012.

[2] N. Chase, "Energy Use and Trends in the U.S. Heavy-Duty Vehicle Sector," U.S. Energy Information Administration, Washington, DC, 2012.

[3] W. Liss, "Demand Outlook: A Golden Age of Natural Gas," Chemical Engineering Progress, vol. 108, pp. 35-40, 2012.

[4] J. T. Jensen, "The Development of a Global LNG Market," Oxford Institute for Energy Studies, 2004.

[5] Chart Industries, "The LNG Value Chain," March, 2014.

[6] Clean Energy, "LNG Tech 101: Overview of Cooling, Storage and Fleet Fueling," NorthStar Inc. and IMW Industries, 2014.

[7] C. Emmer, "A Short Primer on Cryogenic Tanks," presented at the Society of Naval Architects and Marine Engineers Great Lakes and Great Rivers Section, 2012.

[8] TOKYO GAS Co. (May, 2013). LNG Technologies - Chapter3 - In-Ground LNG Storage Tanks. Available: http://www.tokyo-gas.co.jp/lngtech/ug-tank/index.html

[9] Clean Energy. (May, 2013). LNG Production and Storage. Clean Energy California LNG Plant. Available: http://www.cleanenergyfuels.com/company/california_lng_plant.html

[10] Chart Ferox. (May, 2013). LNG Tanks and Cylinders. Available: http://www.chartferox.com/LNG/Tanks_and_Cylinders.aspx

[11] J. Fesmire, S. Augustynowicz, and S. Rouanet, "Aerogel Beads as Cryogenic Thermal Insulation System," in AIP Conference Proceedings, 2002, p. 1541.

[12] F. White, Heat Transfer. Reading, MA: Addison Wesley Publishing, 1984.

[13] M. Liggett, "Space-Based $\mathrm{LH}_{2}$ Propellant Storage System: Subscale Ground Testing Results," Cryogenics, vol. 33, pp. 438-442, 1993.

[14] Q.-S. Chen, J. Wegrzyn, and V. Prasad, "Analysis of Temperature and Pressure Changes in Liquefied Natural Gas (LNG) Cryogenic Tanks," Cryogenics, vol. 44, pp. 701-709, 2004.

[15] V. Getmanets, L. Goncharenko, R. Mikhalchenko, N. Pershin, G. Zhun, and H. Stears, "The Single Component Superinsulation," Cryogenics, vol. 39, pp. 10371038, 1999.

[16] Chart Ferox. (May, 2013). LNG Vehicle Systems. Available: http://www.chartferox.com/LNG/Vehicle_Systems/Vehicle_Systems.aspx

[17] E. J. Pleban, "Analytical Heat Transfer Investigation of Insulated Liquid Methane Wing Tanks for Supersonic Cruise Aircraft," Final Report for National Aeronautics and Space Administration (NASA), 1970.

[18] N. Chatterjee and J. Geist, "Effects of Stratification on Boil-Off Rates in LNG Tanks," Pipeline and Gas Journal, vol. 199, 1972.

[19] R. Edwards, J. Larivé, V. Mahieu, and P. Rouveirolles, "Well-to-Wheels Analysis of Future Automotive Fuels and Powertrains in the European Context," Joint Research Centre (JRC) Scientific and Technical Reports, 2011.

[20] M. M. Foss, "Introduction to LNG: An Overview on Liquefied Natural Gas (LNG), Its Properties, Organization of the LNG Industry and Safety Considerations," 
Energy Economics Research at the Bureau Economic Geology, The University of Texas, 2012.

[21] W. Qiang, L. Yanzhong, Z. Zhe, and J. Anjun, "Developing Advantages of LNG in Automobile Industry," Natural Gas Industry, vol. 22, pp. 93-95, 2002.

[22] TIAX, "U.S. and Canadian Natural Gas Vehicle Market Analysis: Liquefied Natural Gas Infrastructure," Final Report for America's Natural Gas Alliance (ANGA), 2011.

[23] N. Siu, J. Herring, L. Cadwallader, W. Reece, and J. Byers, "Qualitative Risk Assessment for an LNG Refueling Station and Review of Relevant Safety Issues," Idaho National Engineering Lab., Idaho Falls, ID, United States,1998.

[24] J. W. Moon, Y. P. Lee, Y. Jin, E. S. Hong, and H. M. Chang, "Cryogenic Refrigeration Cycle for Re-Liquefaction of LNG Boil-Off Gas," in International Cryocooler Conference, Cryostar. The Cryostar Magazine, 2007, pp. 629-635.

[25] D. Andress, The Phillips Optimized Cascade LNG Process: A Quarter-of-aCentury of Improvements: American Institute of Chemical Engineers, 1996.

[26] D. L. Andress and R. J. Watkins, "Beauty of Simplicity: Phillips Optimized Cascade LNG Liquefaction Process," Advances in Cryogenic Engineering, Vols. 49A and B, vol. 710, pp. 91-98, 2004.

[27] P. Nekså, E. Brendeng, M. Drescher, and B. Norberg, "Development and Analysis of a Natural Gas Reliquefaction Plant for Small Gas Carriers," Journal of Natural Gas Science and Engineering, vol. 2, pp. 143-149, 2010.

[28] J. Wegrzyn and M. Gurevich, "Liquefied Natural Gas for Trucks and Buses," SAE Technical Paper 2000-01-2210, 2000.

[29] R. Chandler, M. Gifford, and B. Carpenter, "Resource Guide for Heavy-Duty LNG Vehicles, Infrastructure, and Support Operations," Final Report for Brookhaven National Laboratory, 2002.

[30] W.-L. Litzke and J. Wegrzyn, "Natural Gas as a Future Fuel for Heavy-Duty Vehicles," SAE Technical Paper 2001-01-2067, 2001.

[31] K. Chandler, P. Norton, and N. Clark, "Waste Management's LNG Truck Fleet: Final Results," US Department of Energy, 2001.

[32] J. Wegrzyn, "Processing, Transportation and Storage of LNG," in Natural Gas Vehicle Technology Forum, Albany, NY, 2003.

[33] M. M. Barash and D. Rangnow, "Designing and Implementing Information Management Systems for LNG Receiving Terminals," Resources2 Energy, 2007.

[34] Y. Shin and Y. P. Lee, "Design of a Boil-Off Natural Gas Reliquefaction Control System for LNG Carriers," Applied Energy, vol. 86, pp. 37-44, 2009.

[35] H. T. Liu and L. X. You, "Characteristics and Applications of the Cold Heat Exergy of Liquefied Natural Gas," Energy Conversion and Management, vol. 40, pp. 15151525, Sep 1999.

[36] W. Qiang, Y. Z. Li, and C. Xi, "Exergy Analysis of Liquefied Natural Gas Cold Energy Recovering Cycles," International Journal of Energy Research, vol. 29, pp. 65-78, Jan 2005.

[37] M. Chaker, C. B. Meher-Homji, P. Pillai, D. Bhattacharya, and D. Messersmith, "Application of Boil Off Gas Compressors in LNG Plants," in The American Society of Mechanical Engineers (ASME) Turbo Expo 2014: Turbine Technical Conference and Exposition, 2014. 
[38] C. A. Powars, "Best Practices to Avoid LNG Fueling Station Venting Losses," Brookhaven National Laboratory, San Jose, CA, 2010.

[39] M. Murphy, H. Ketola, and P. Raj, "Clean Air Program: Summary Assessment of the Safety, Health, Environmental and System Risks of Alternative Fuel. Final Report," Department of Transportation, Cambridge, MA, United States. John A. Volpe National Transportation Systems Center, 1995.

[40] J. A. Alderman, "Introduction to LNG Safety," Process Safety Progress, vol. 24, pp. 144-151, 2005.

[41] P. Cleaver, M. Johnson, and B. Ho, "A Summary of some Experimental Data on LNG Safety," Journal of Hazardous Materials, vol. 140, pp. 429-438, Feb 202007.

[42] Cryogenic Fuels Inc., "Liquid Methane Fuel Characterization and Safety Assessment Report," Final Report for Booz-Allen \& Hamilton, 1991.

[43] A. Luketa-Hanlin, "A Review of Large-Scale LNG Spills: Experiments and Modeling," Journal of Hazardous Materials, vol. 132, pp. 119-140, 2006.

[44] P. Murray, "LNG Tank Design, Life Expectancy, and LNG Safety Aspects," in Natural Gas Vehicle Technology Forum (NGVTF) 2014 Meeting, Upton, NY, 2014.

[45] G. G. Dimopoulos and C. A. Frangopoulos, "A Dynamic Model for Liquefied Natural Gas Evaporation During Marine Transportation," International Journal of Thermodynamics, vol. 11, pp. 123-131, 2008.

[46] R. Sedlaczek, "Boil-Off in Large-And Small-Scale LNG Chains," M.S. Petroleum Engineering, Department of Petroleum Engineering and Applied Geophysics, Norwegian University of Science and Technology, Trondheim, 2008.

[47] E. Adom, S. Z. Islam, and X. Ji, "Modelling of Boil-Off Gas in LNG Tanks: A Case Study," International Journal of Engineering and Technology, vol. 2, pp. 292-296, 2010.

[48] R. Ahluwalia and J. Peng, "Dynamics of Cryogenic Hydrogen Storage in Insulated Pressure Vessels for Automotive Applications," International Journal of Hydrogen Energy, vol. 33, pp. 4622-4633, 2008.

[49] G. Grayson, A. Lopez, F. Chandler, L. Hastings, and S. Tucker, "Cryogenic Tank Modeling for the Saturn AS-203 Experiment," presented at the $42^{\text {nd }}$ AIAA/ASME/SAE/ASEE Joint Propulsion Conference and Exhibit, Sacramento, CA, 2006.

[50] S. H. Ho and M. M. Rahman, "Three-Dimensional Analysis for Liquid Hydrogen in a Cryogenic Storage Tank with Heat Pipe-Pump System," Cryogenics, vol. 48, pp. 31-41, 2008.

[51] C. Panzarella, D. Plachta, and M. Kassemi, "Pressure Control of Large Cryogenic Tanks in Microgravity," Cryogenics, vol. 44, pp. 475-483, 2004.

[52] S. Barsi and M. Kassemi, "Numerical and Experimental Comparisons of the SelfPressurization Behavior of an $\mathrm{LH}_{2}$ Tank in Normal Gravity," Cryogenics, vol. 48, pp. 122-129, 2008.

[53] J. J. Ren, J. Y. Shi, P. Liu, M. S. Bi, and K. Jia, "Simulation on Thermal Stratification and De-Stratification in Liquefied Gas Tanks," International Journal of Hydrogen Energy, vol. 38, pp. 4017-4023, 2013.

[54] G. Grayson, A. Lopez, F. Chandler, L. Hastings, A. Hedayat, and J. Brethour, "CFD Modeling of Helium Pressurant Effects on Cryogenic Tank Pressure Rise Rates in 
Normal Gravity," presented at the $43^{\text {rd }}$ AIAA/ASME/SAE/ASEE Joint Propulsion Conference and Exhibit, Cincinnati, OH, 2007.

[55] M. Ratner, G. Fumitaka, D. Kirk, and P. Schallhorn, "Modeling of Upper Stage Cryogenic Propellant Stratification in a Rotating, Reduced Gravity Environment," in Thermal and Fluids Analysis Workshop (TFAWs), 2005, pp. 8-12.

[56] T. Jagannathan, S. Mohanan, and R. Nagarajan, "Mechanistic Modeling of Destratification in Cryogenic Storage Tanks using Ultrasonics," Ultrasonics, vol. 54, pp. 76-83, 2014.

[57] S. Roh, G. Son, G. Song, and J. Bae, "Numerical Study of Transient Natural Convection in a Pressurized LNG Storage Tank," Applied Thermal Engineering, vol. 52, pp. 209-220, 2013.

[58] S. Roh and G. Son, "Numerical Study of Natural Convection in a Liquefied Natural Gas Tank," Journal of Mechanical Science and Technology, vol. 26, pp. 31333140, 2012.

[59] M. Seo and S. Jeong, "Analysis of Self-Pressurization Phenomenon of Cryogenic Fluid Storage Tank with Thermal Diffusion Model," Cryogenics, vol. 50, pp. 549$555,2010$.

[60] X. Li, G. Xie, and R. Wang, "Experimental and Numerical Investigations of Fluid Flow and Heat Transfer in a Cryogenic Tank at Loss of Vacuum," Heat and Mass Transfer, vol. 46, pp. 395-404, 2010.

[61] C. Ludwig and M. Dreyer, "Analyses of Cryogenic Propellant Tank Pressurization based upon Experiments and Numerical Simulations," presented at the $5^{\text {th }}$ European Conference for Aeronautics and Space Sciences (EUCASS), Munich, Germany, 2013.

[62] C. Ludwig and M. Dreyer, "Investigations on Thermodynamic Phenomena of the Active-Pressurization Process of a Cryogenic Propellant Tank," Cryogenics, vol. 63, pp. 1-16, 2014.

[63] D. H. Riemer, "Cryogenic Tank Stratification a Simpler Approach," in Advances in Cryogenic Engineering. vol. 31, ed: Springer US, 1986, pp. 957-962.

[64] R. Arnett and D. Millhiser, "A Theoretical Model for Predicting Thermal Stratification and Self Pressurization of a Fluid Container," Proceedings of the Conference on Propellant Tank Pressurization and Stratification, vol. 2, 1965.

[65] R. Arnett and R. Voth, " A Computer Program for the Calculation of Thermal Stratification and Self-Pressurization in a Liquid Hydrogen Tank," National Bureau of Standards, Boulder, CO, 1972.

[66] S. Gursu, S. Sherif, T. Veziroglu, and J. Sheffield, "Analysis and Optimization of Thermal Stratification and Self-Pressurization Effects in Liquid Hydrogen Storage Systems-Part 1: Model Development," Journal of Energy Resources Technology, vol. 115, pp. 221-227, 1993.

[67] S. Gursu, S. Sherif, T. Veziroglu, and J. Sheffield, "Analysis and Optimization of Thermal Stratification and Self-Pressurization Effects in Liquid Hydrogen Storage Systems_-Part 2: Model Results and Conclusions," Journal of Energy Resources Technology, vol. 115, pp. 228-231, 1993.

[68] R. F. Lacovic, F. C. Yeh, S. V. J. Szabo, R. J. Brun, A. J. Stofan, and J. A. Berns, "Management of Cryogenic Propellants in a Full-Scale Orbiting Space Vehicle," National Aeronautics and Space Administration (NASA), Washington, DC, 1968. 
[69] J. C. Aydelott and C. M. Spuckler, "Effect of Size on Normal-Gravity SelfPressurization of Spherical Liquid Hydrogen Tankage," National Aeronautics and Space Administration (NASA), Washington, DC, 1969.

[70] E. Eckert and T. W. Jackson, "Analysis of Turbulent Free-Convection Boundary Layer on Flat Plate," National Advisory Committee for Aeronautics (NACA), Washington, DC, 1950.

[71] J. T. Hailer, "LNG Station Analysis for the Prediction of Pressure Rise and Vented Emissions," M.S. Mechanical Engineering, Department of Mechanical and Aerospace Engineering, West Virginia University, Morgantown, WV, 2015.

[72] ASTM International, "D3956-12 Standard Specification for Methane Thermophysical Property Tables," National Institute of Standards and Technology (NIST), Gaithersburg, MD, 2012.

[73] B. Younglove and J. F. Ely, Thermophysical Properties of Fluids: II. Methane, Ethane, Propane, Isobutane, and Normal Butane: American Chemical Society and the American Institute of Physics for the National Bureau of Standards, 1987.

[74] R. F. Barron, G. Nellis, and J. M. Pfotenhauer, Cryogenic Heat Transfer: CRC Press, 1999.

[75] E. Eckert and R. Drake, Heat and Mass Transfer. New York, NY: McGraw-Hill, 1959.

[76] M. Jacob, Heat Transfer Vol. 1: Wiley, New York, 1949.

[77] A. Schmidt, J. Purcell, W. Wilson, and R. Smith, "An Experimental Study Concerning the Pressurization and Stratification of Liquid Hydrogen," in Advances in Cryogenic Engineering, ed: Springer, 1960, pp. 487-497.

[78] M. Ursan, "What is Boil-Off?," presented at the United Nations Economic Commission for Europe (UNECE) Task Force on Liquefied Natural Gas Vehicles, Brussels, Belgium, 2011.

[79] NOAA, "Requirements and Standards for NWS Climate Observations," ed: National Oceanic and Atmospheric Administration (NOAA) and National Weather Services (NWS), 2014.

[80] A. Watts, "Is the US Surface Temperature Record Reliable?," The Heartland Institute, Chicago, IL, 2009.

[81] S. Fall, A. Watts, J. Nielsen-Gammon, E. Jones, D. Niyogi, J. R. Christy, and R. A. Pielke, "Analysis of the Impacts of Station Exposure on the US Historical Climatology Network Temperatures and Temperature Trends," Journal of Geophysical Research: Atmospheres, vol. 116, 2011.

[82] N. N. Greenwood and A. Earnshaw, Chemistry of the Elements: Elsevier, 1997.

[83] R. F. Barron, Cryogenic Systems: Clarendon Press, 1985.

[84] R. A. Mongold, "Scenario-Based Estimation Model for Methane Emissions in the Heavy-Duty Transportation Sector," M.S. Mechanical Engineering, Department of Mechanical and Aerospace Engineering, West Virginia University, Morgantown, WV, 2015. 


\section{APPENDIX A:}

\section{RESULTS OF EXPERIMENTAL HOLD TIME FOR LNG VEHICLE TANKS Without InTERNAL FUEL PUMP}

\section{A.1. LNG Vehicle Tank with High Initial Fill Level: 89.03\%}
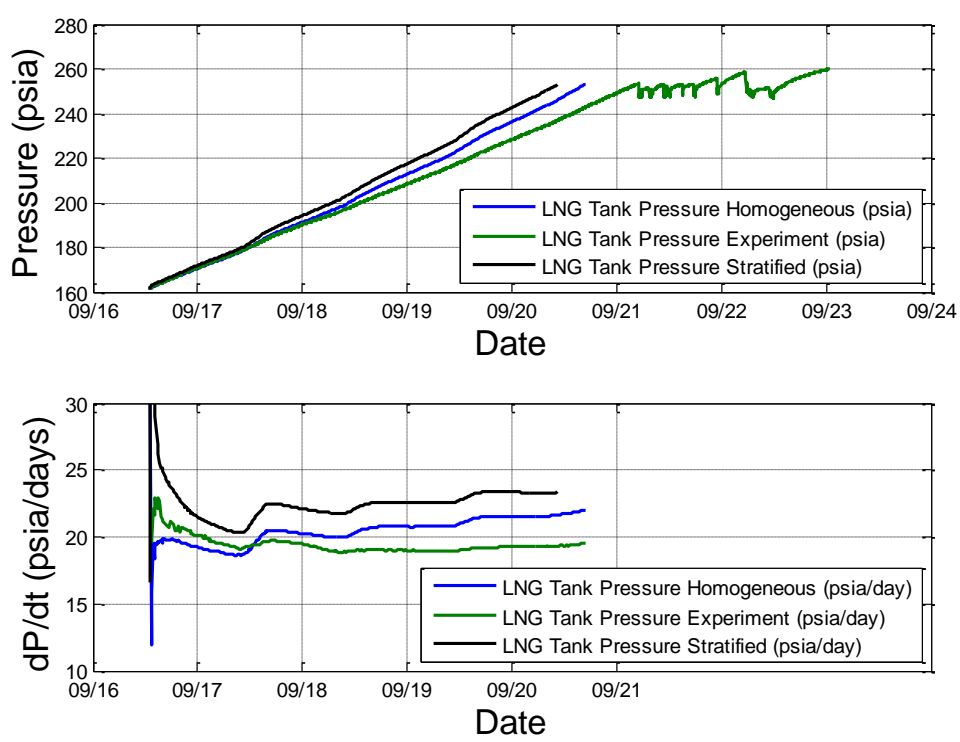

Figure A.1. Hold Time Experiment 2 with LNG Vehicle Tank without Internal Fuel

Pump. Simulated Pressure and dP/dt. Initial Homogeneous Fill Level: 89.03\%
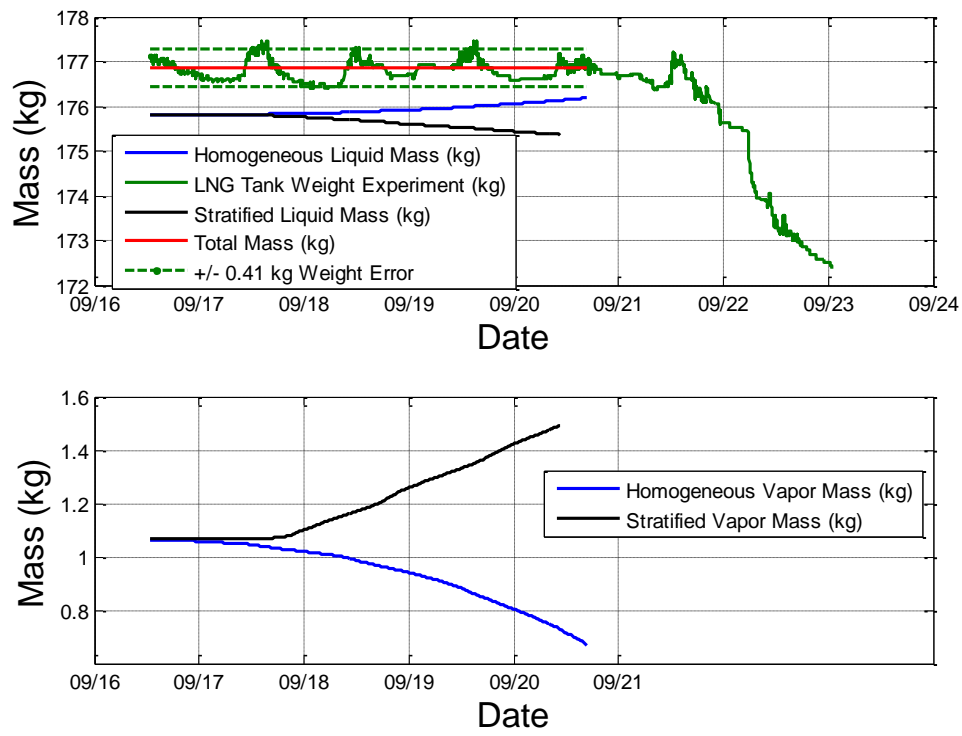

Figure A.2. Hold Time Experiment 2 with LNG Vehicle Tank without Internal Fuel Pump. LNG and Vapor Mass Comparison. 

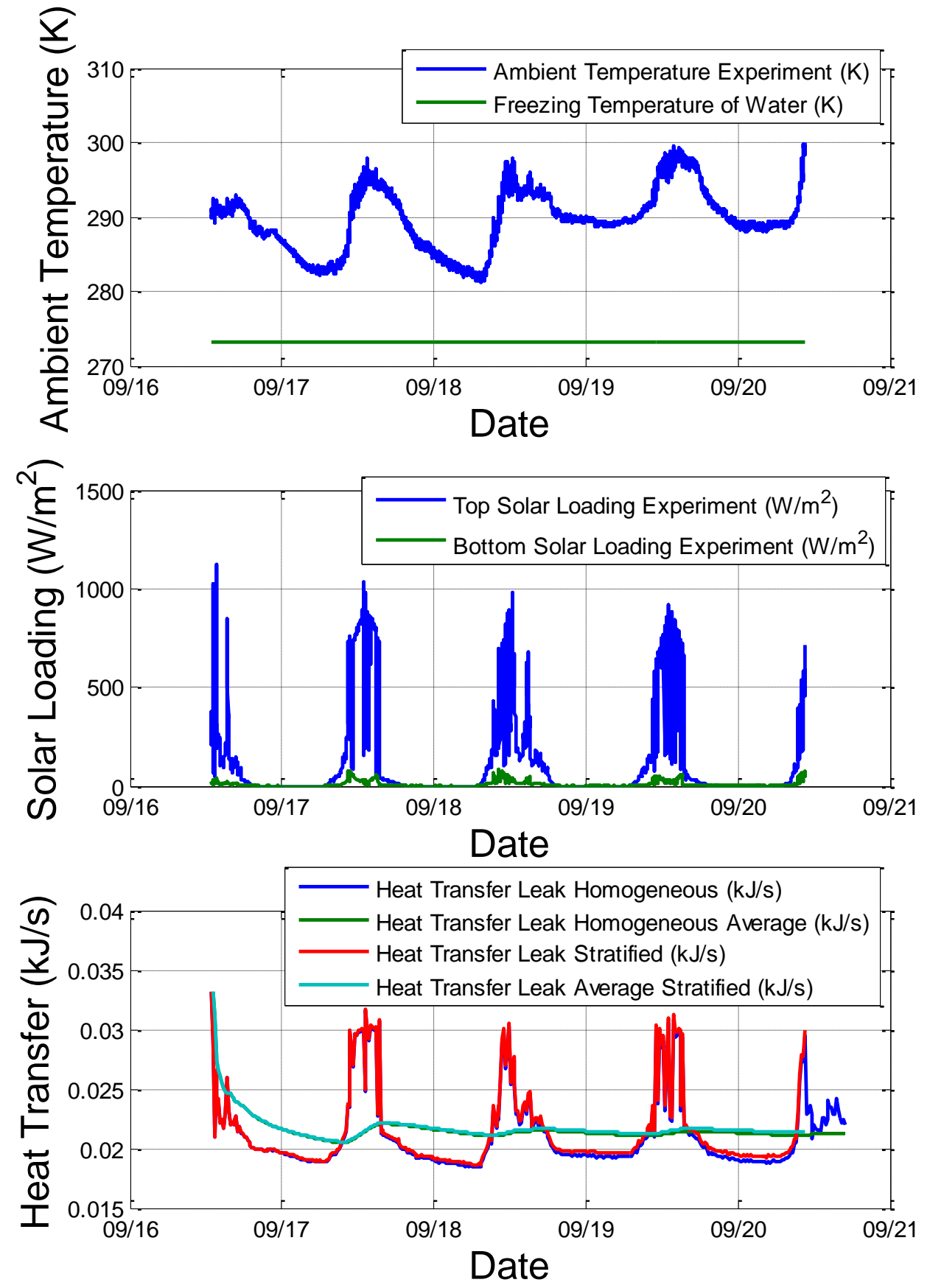

Figure A.3. Hold Time Experiment 2 with LNG Vehicle Tank without Internal Fuel Pump. Total Heat Transfer Leak Simulated and Weather Data. Average Ambient Temperature: $289.63 \mathrm{~K}$ 

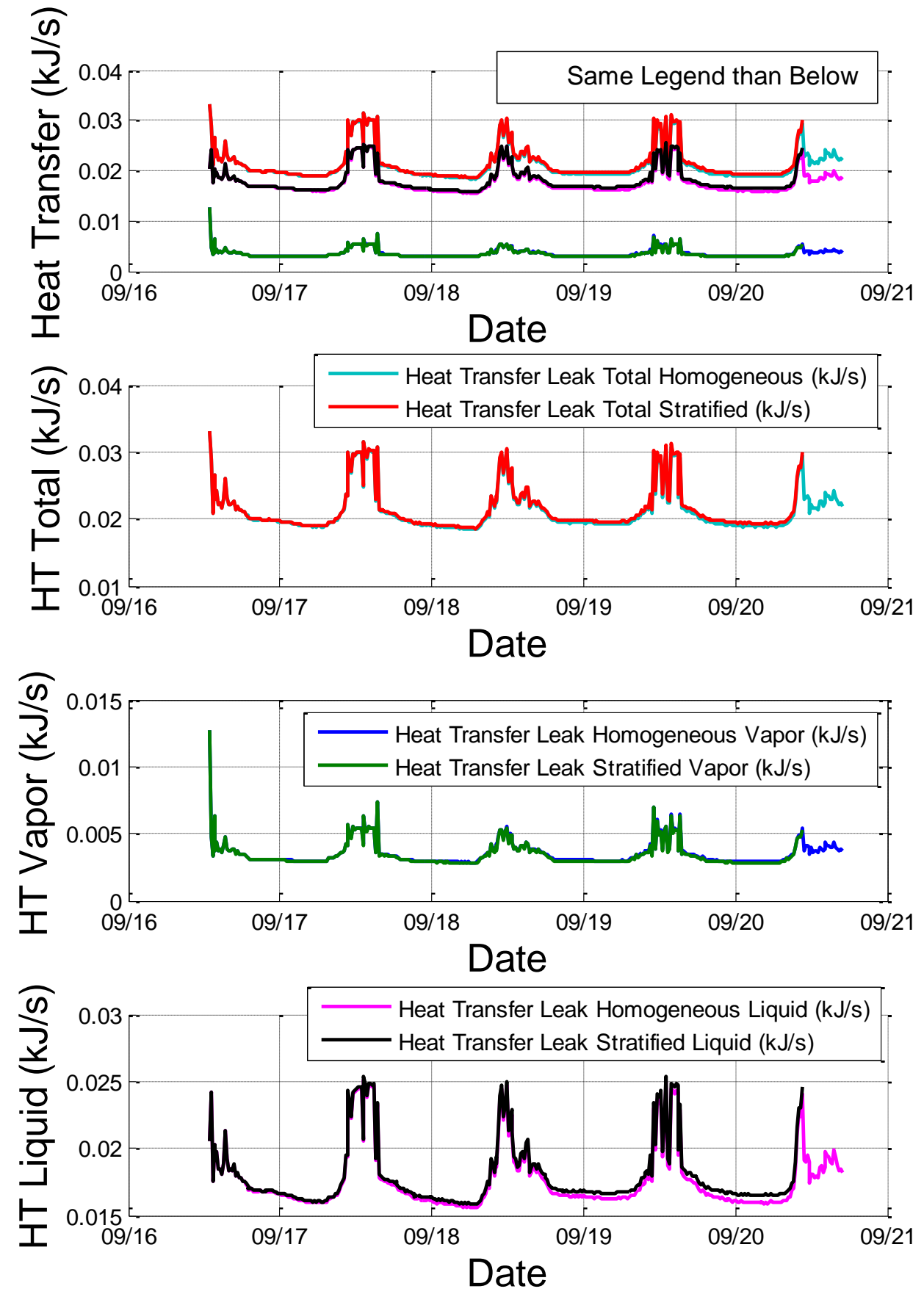

Figure A.4. Hold Time Experiment 2 with LNG Vehicle Tank without Internal Fuel Pump. Total Heat Transfer Leak Used for the Vapor and Liquid Regions. 

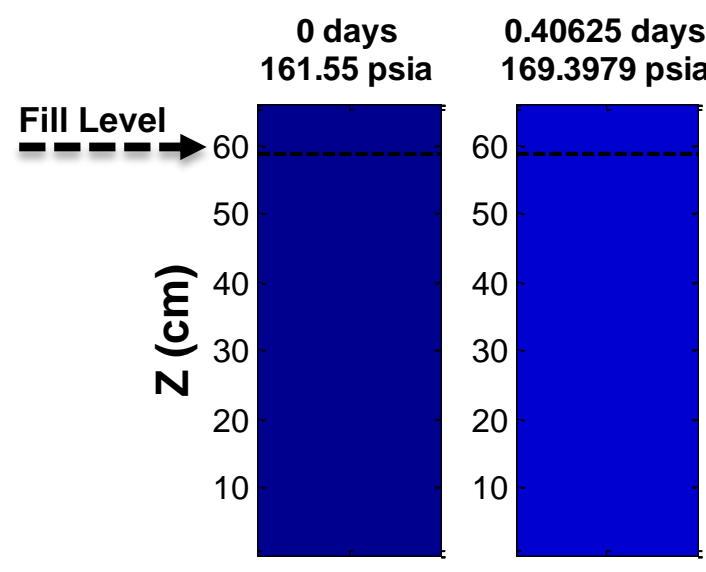

1.0313 days

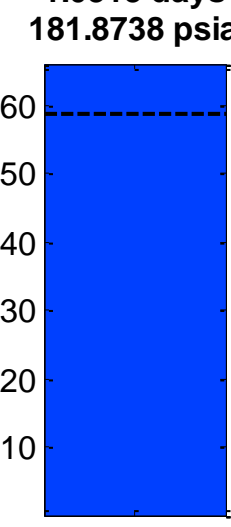

2.0729 days

204.2325 psia

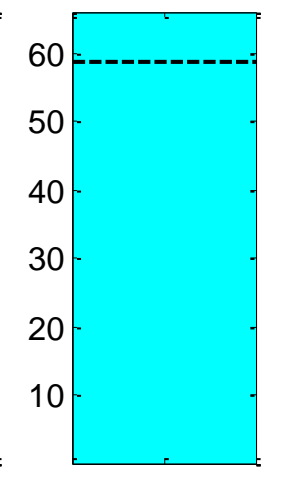

2.8958 days 221.9063 psia

3.3125 days

3.7292 days

4.1458 days Temp.
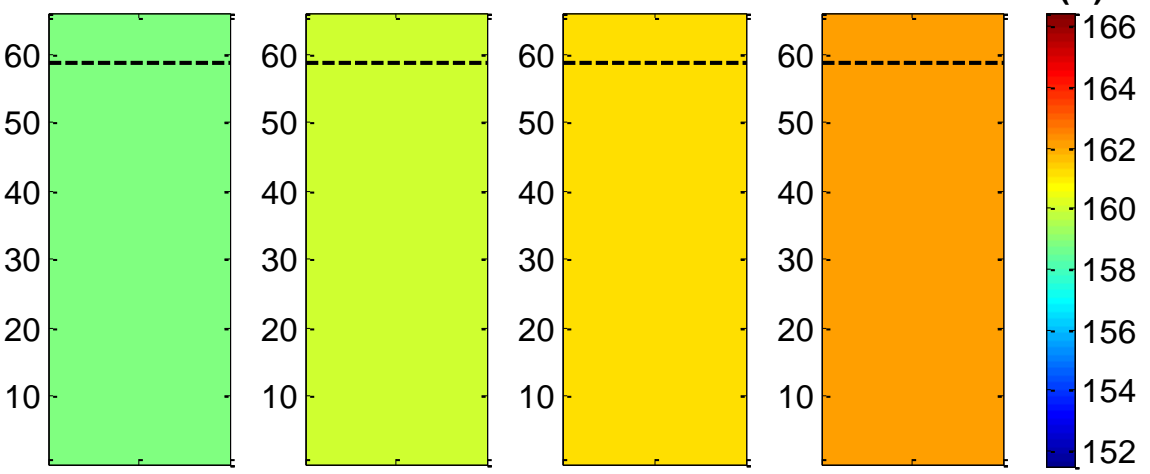

a. Homogeneous Approach.
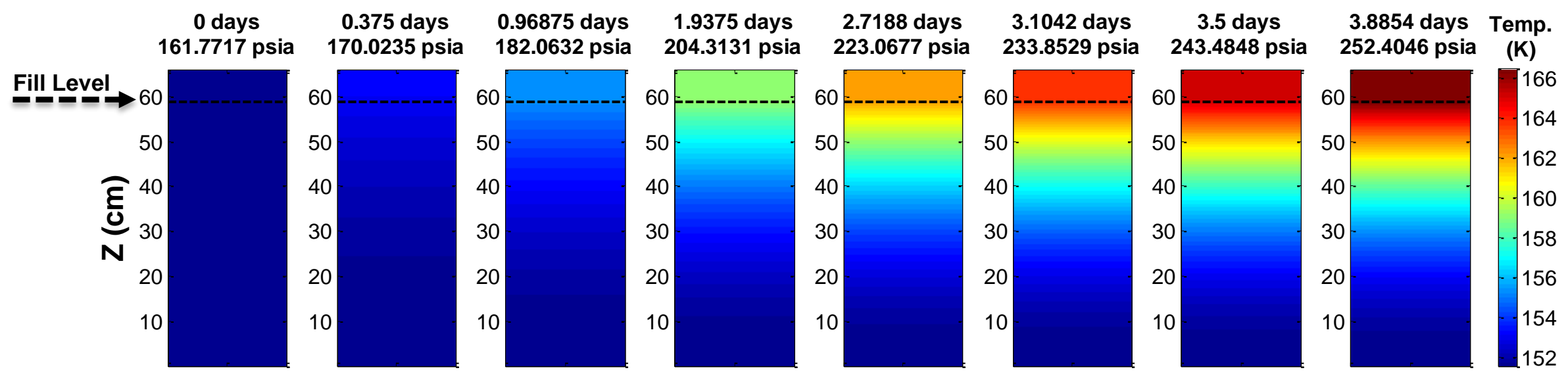

b. Stratified Approach.

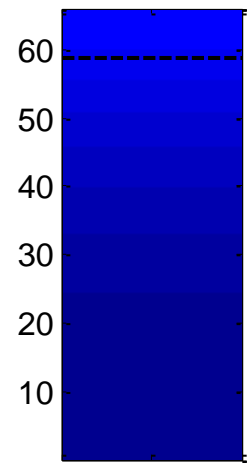

Figure A.5. Hold Time Experiment 2 with LNG Vehicle Tank without Internal Fuel Pump. Initial Homogeneous Fill Level: 89.03\%.

Temperature Map Comparisons. 


\section{A.2. LNG Vehicle Tank with Low Initial Fill Level: $10.81 \%$}
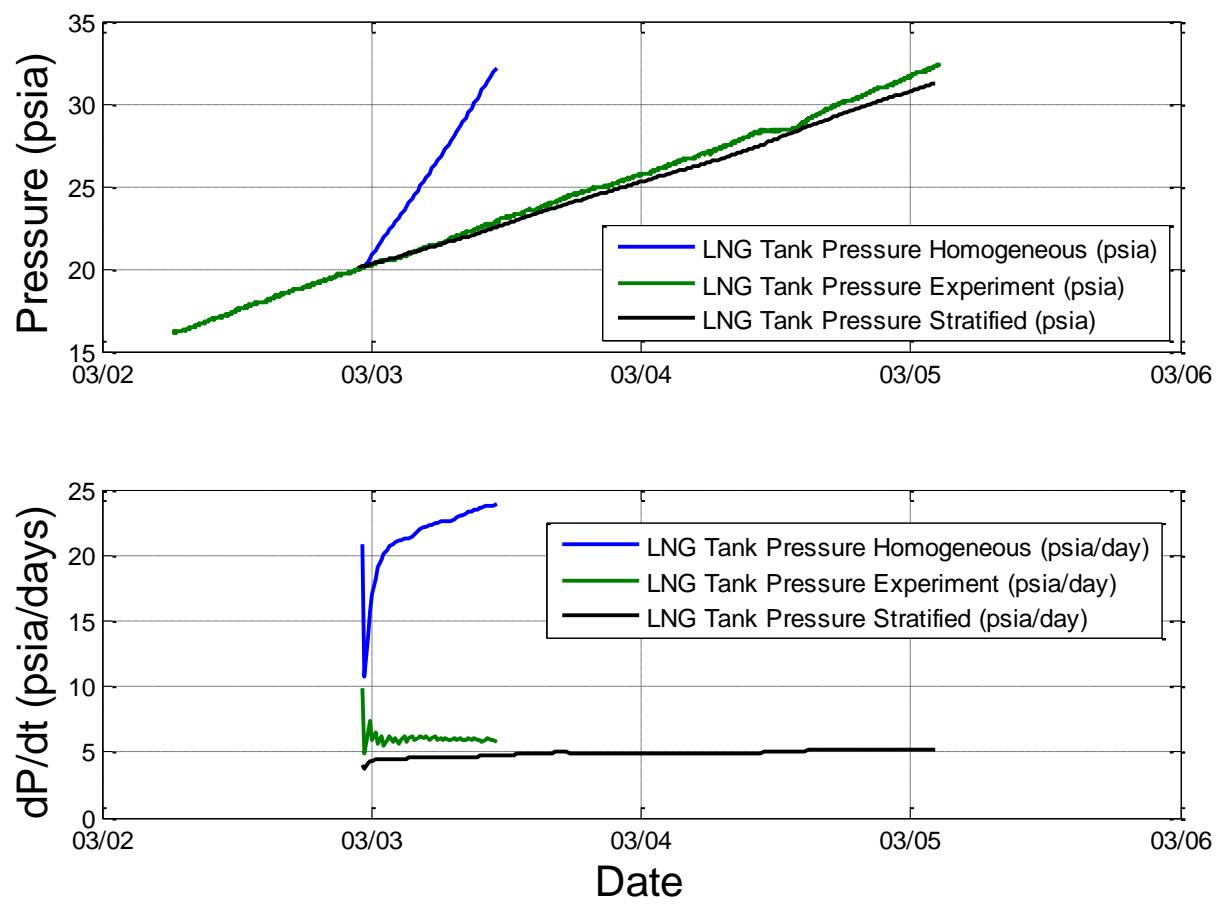

Figure A.6. Hold Time Experiment 8 with LNG Vehicle Tank without Internal Fuel

Pump. Simulated Pressure and dP/dt. Initial Homogeneous Fill Level: 10.81\%

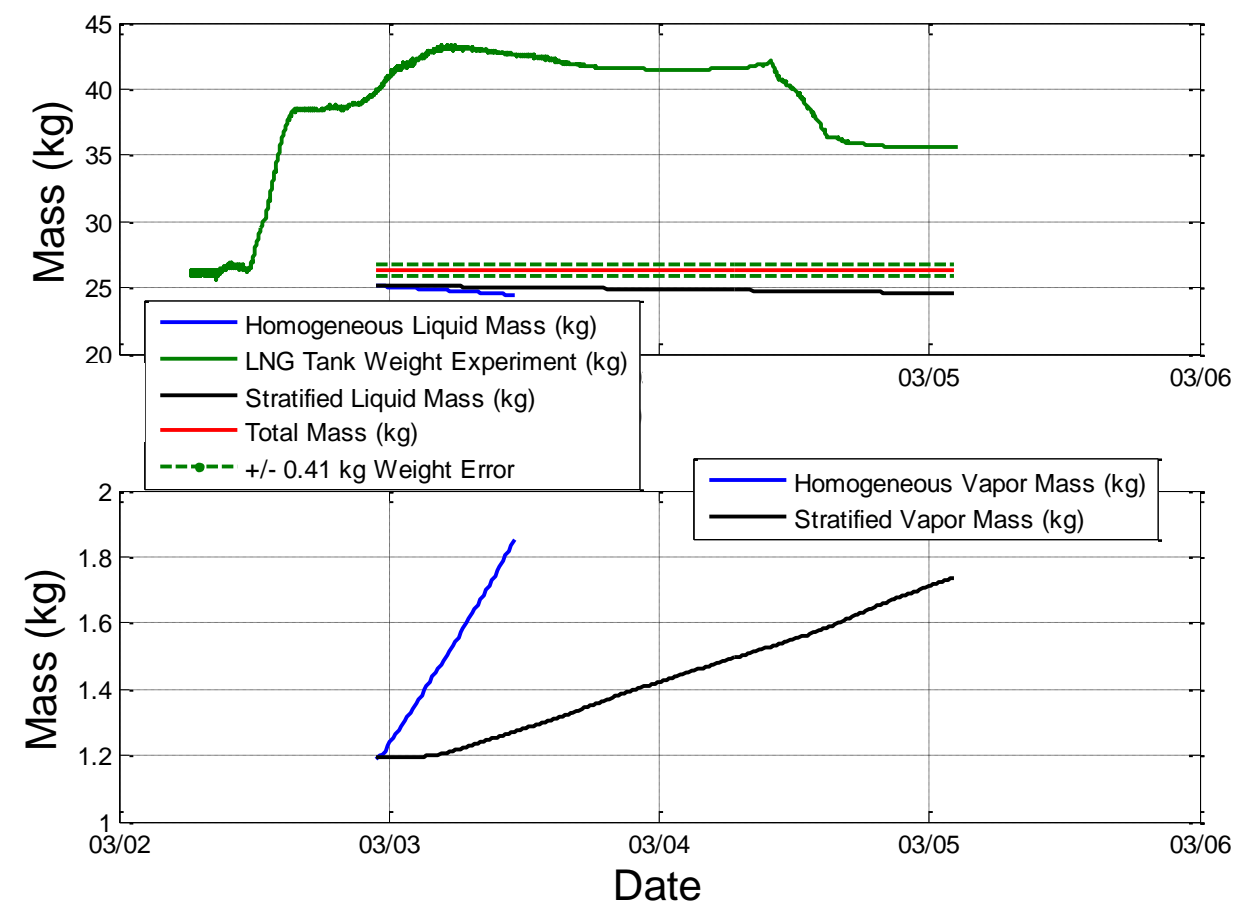

Figure A.7. Hold Time Experiment 8 with LNG Vehicle Tank without Internal Fuel Pump. LNG and Vapor Mass Comparison. 

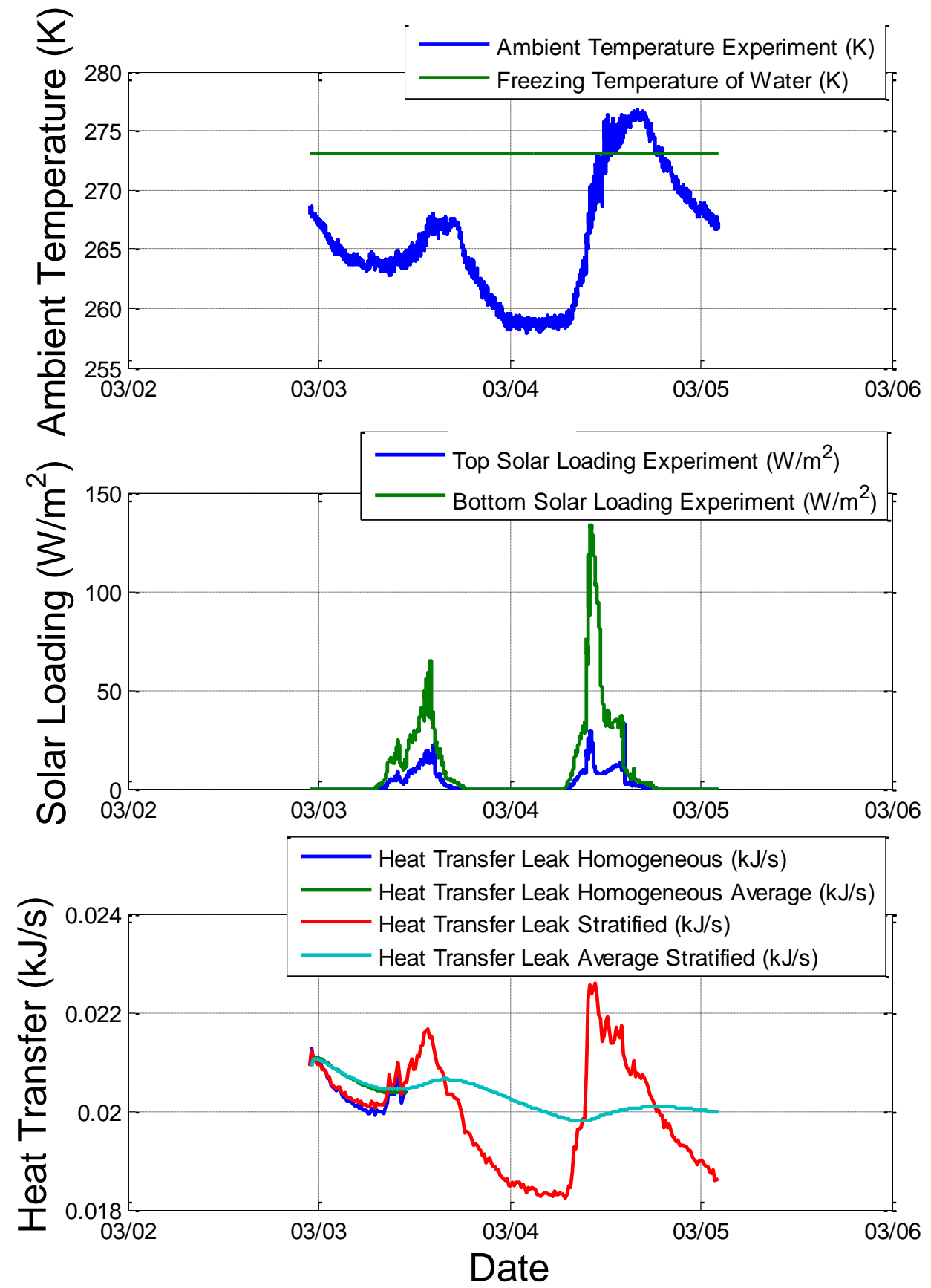

Figure A.8. Hold Time Experiment 8 with LNG Vehicle Tank without Internal Fuel Pump. Total Heat Transfer Leak Simulated and Weather Data. Average Ambient Temperature: $264.69 \mathrm{~K}$ 

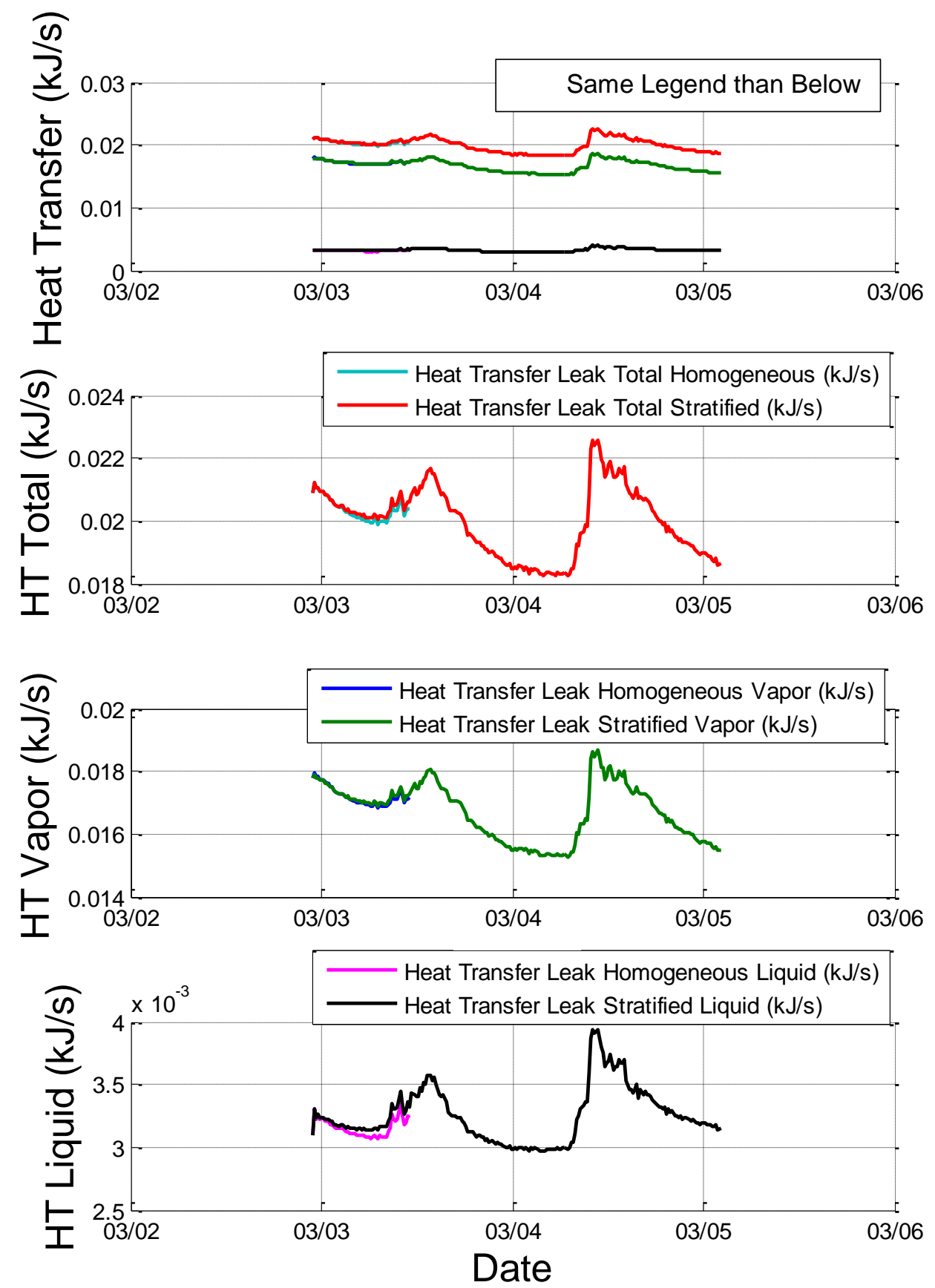

Figure A.9. Hold Time Experiment 8 with LNG Vehicle Tank without Internal Fuel Pump. Total Heat Transfer Leak Used for the Vapor and Liquid Regions. 

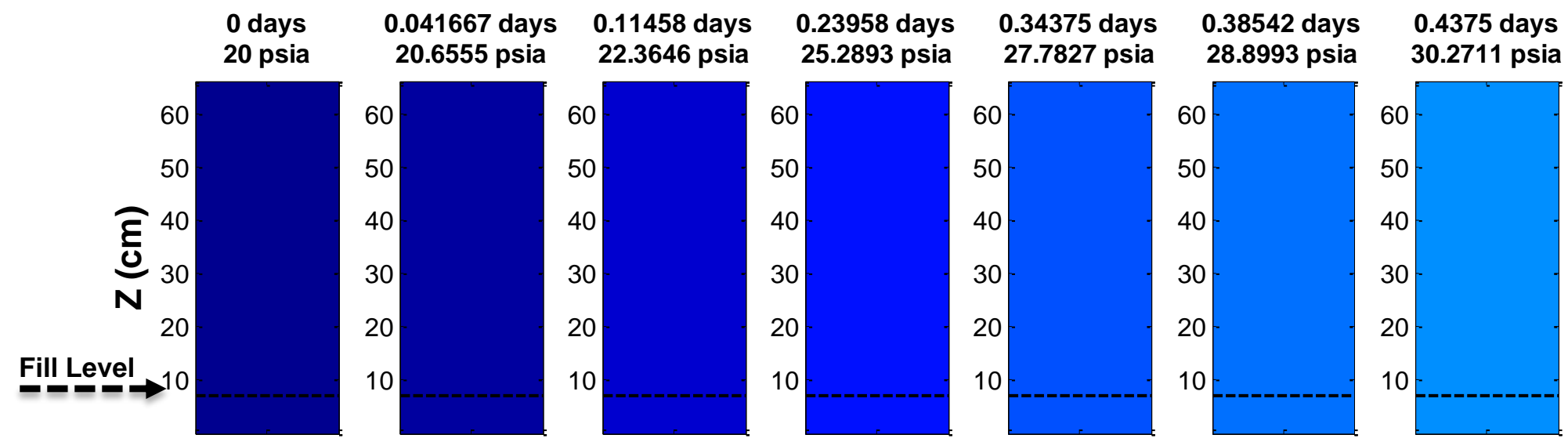

0.48958 days Temp.

31.6325 psia (K)

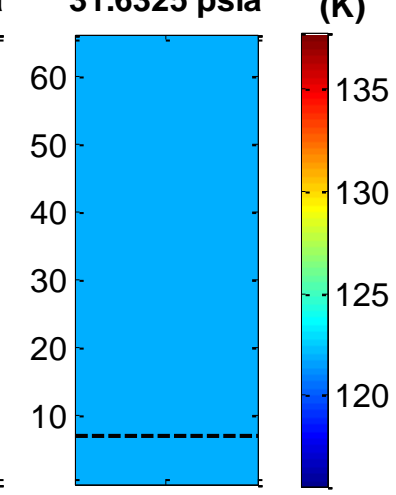

a. Homogeneous Approach.
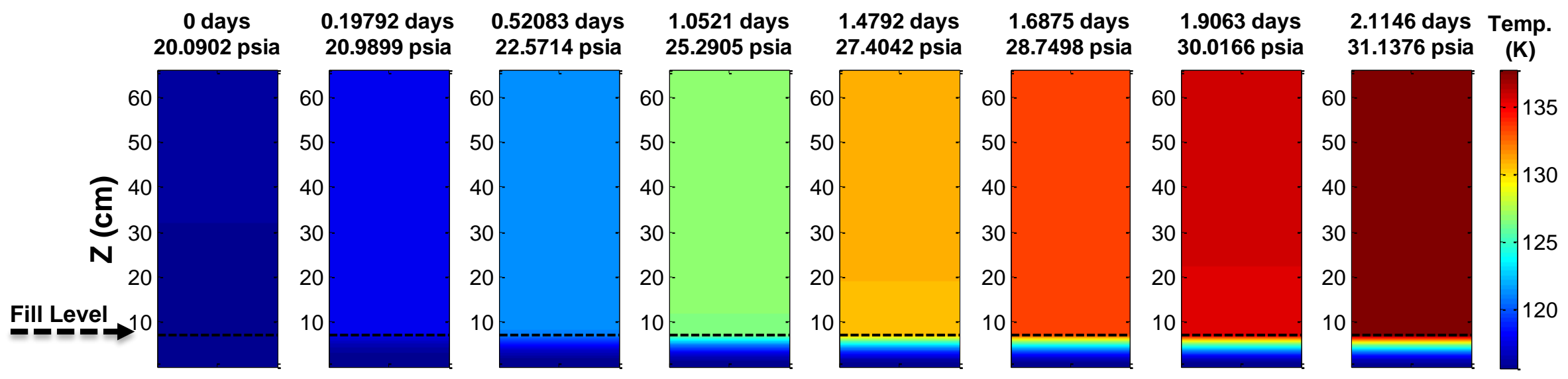

b. Stratified Approach.

Figure A.10. Hold Time Experiment 8 with LNG Vehicle Tank without Internal Fuel Pump. Initial Homogeneous Fill Level: 10.81\%.

Temperature Map Comparisons. 


\section{APPENDIX B:}

\section{RESULTS OF EXPERIMENTAL HOLD TIME FOR LNG VEHICLE TANKS With INTERnAL Fuel PUMP}

\section{B.1. LNG Vehicle Tank with Middle Initial Fill Level: $48.77 \%$}
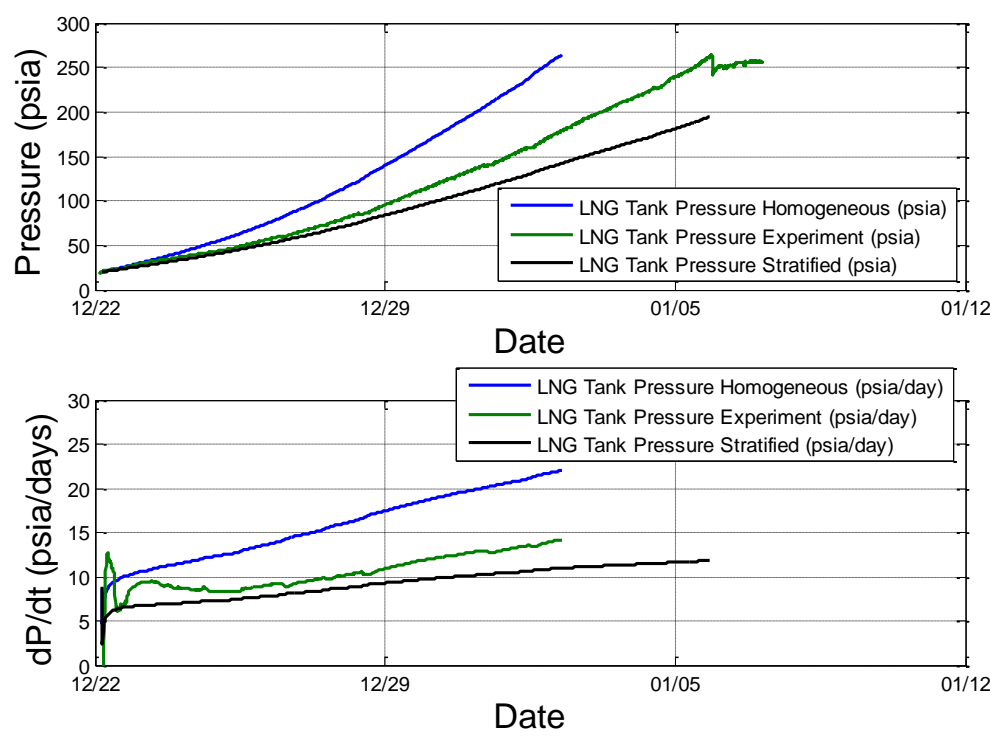

Figure B.1. Hold Time Experiment 2 with LNG Vehicle Tank with Internal Fuel Pump. Simulated Pressure and dP/dt. Initial Homogeneous Fill Level: 48.77\%
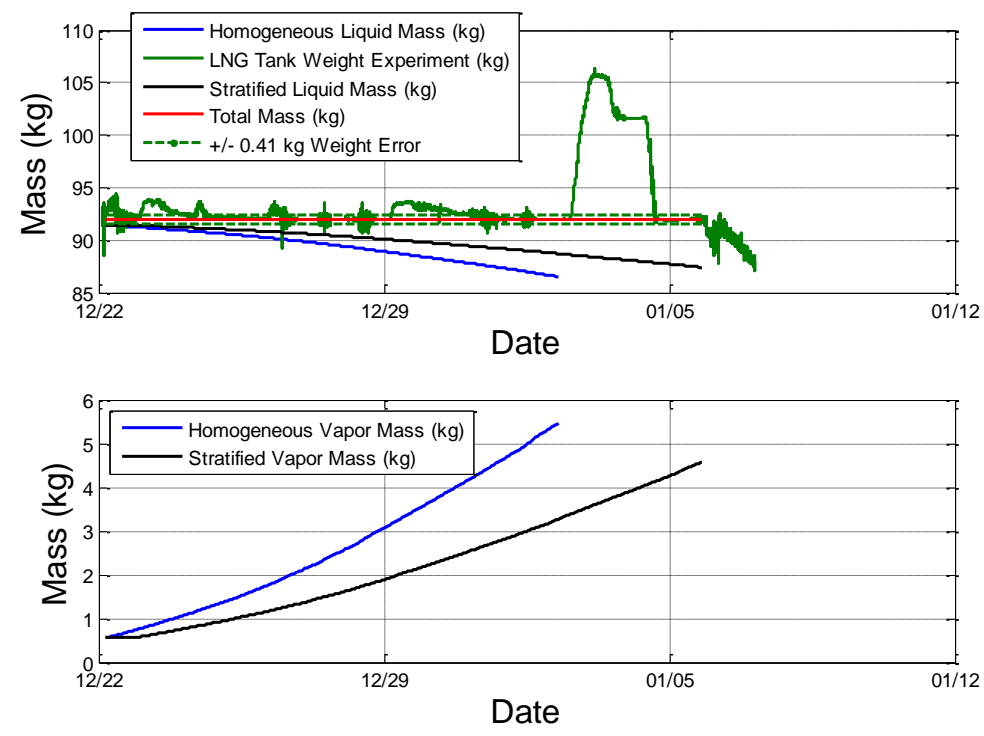

Figure B.2. Hold Time Experiment 2 with LNG Vehicle Tank with Internal Fuel Pump. LNG and Vapor Mass Comparison. 

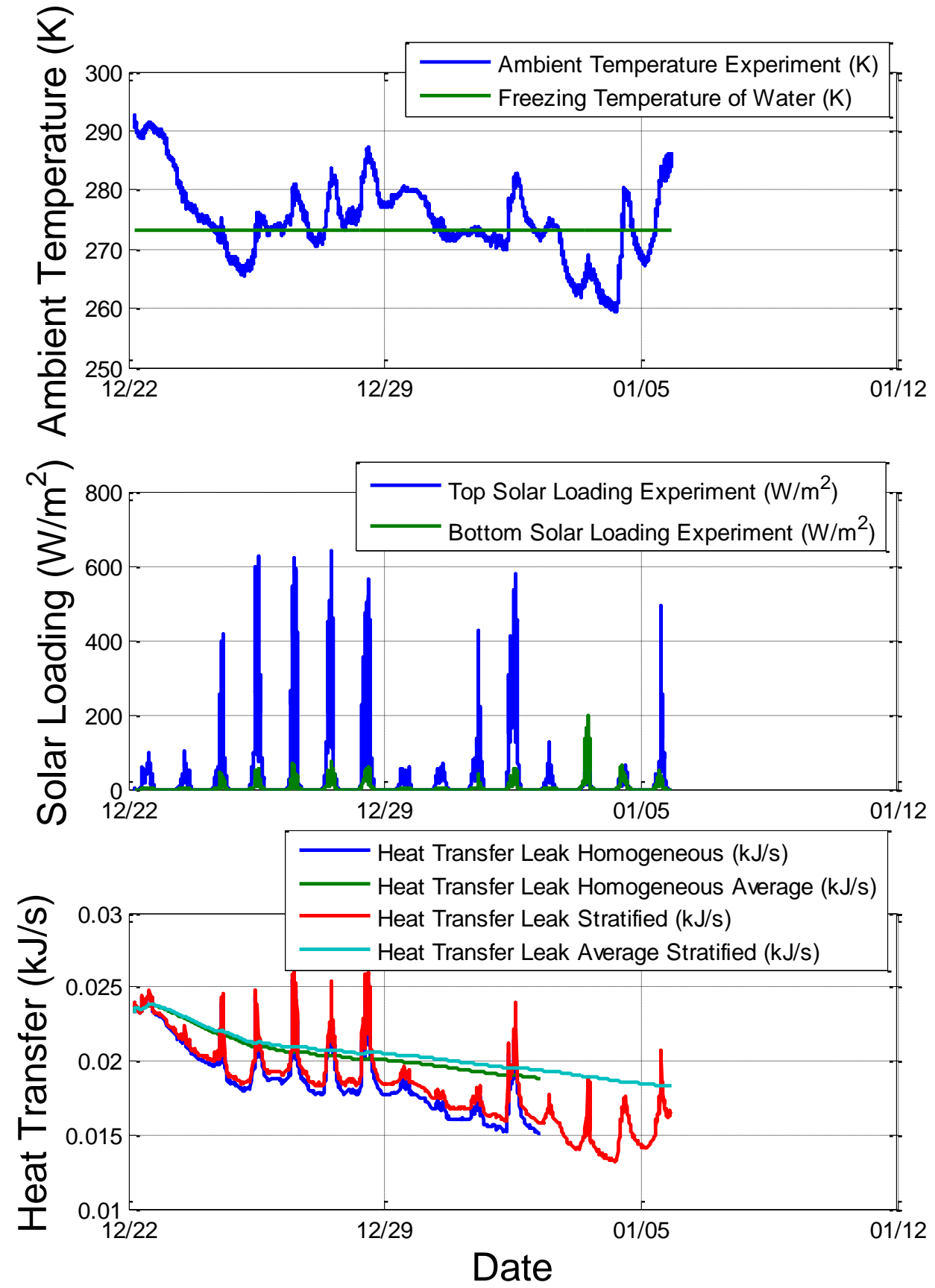

Figure B.3. Hold Time Experiment 2 with LNG Vehicle Tank with Internal Fuel Pump. Total Heat Transfer Leak Simulated and Weather Data. Average Ambient Temperature: $276.54 \mathrm{~K}$ 

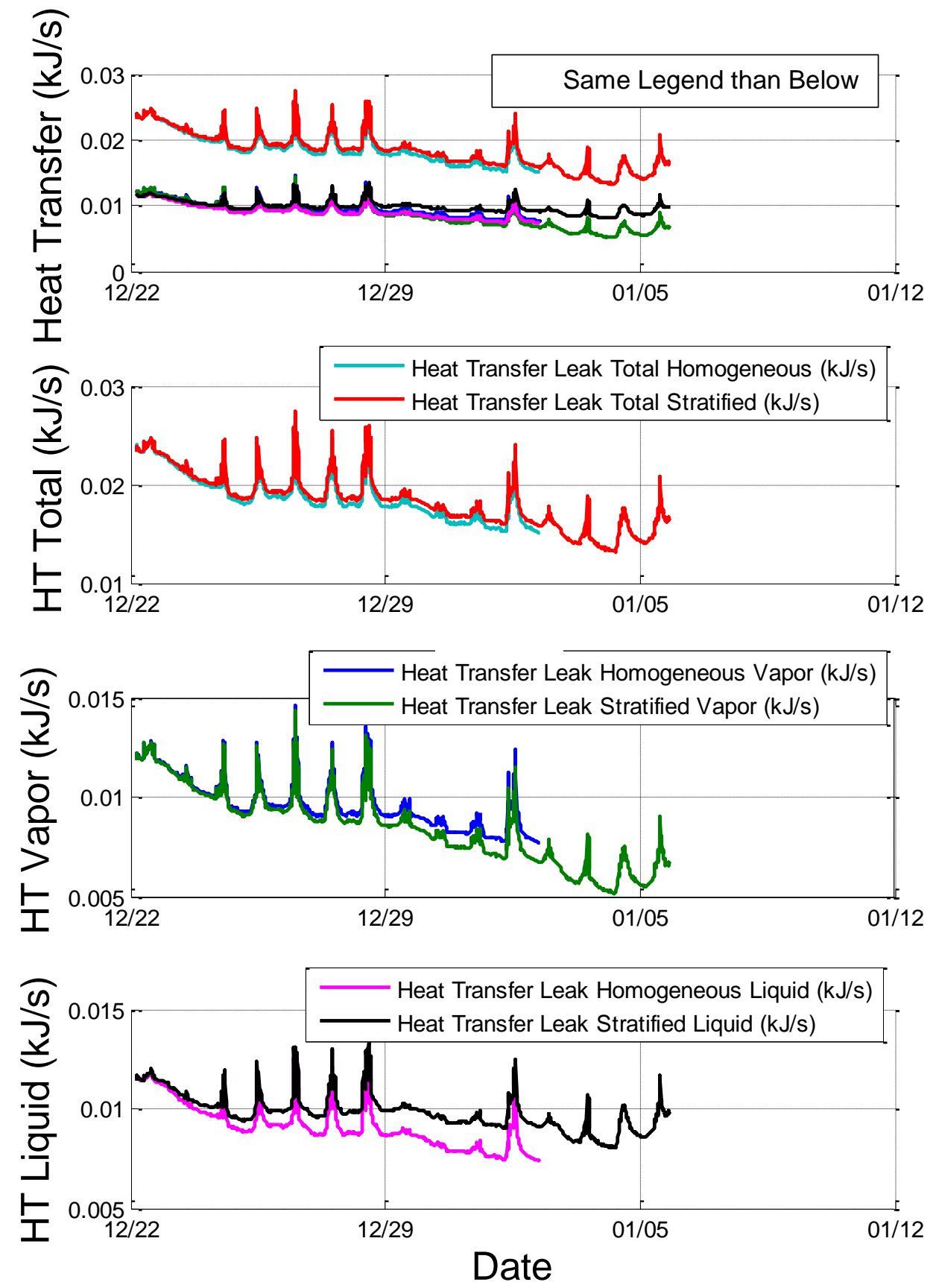

Figure B.4. Hold Time Experiment 2 with LNG Vehicle Tank with Internal Fuel Pump. Total Heat Transfer Leak Used for the Vapor and Liquid Regions. 

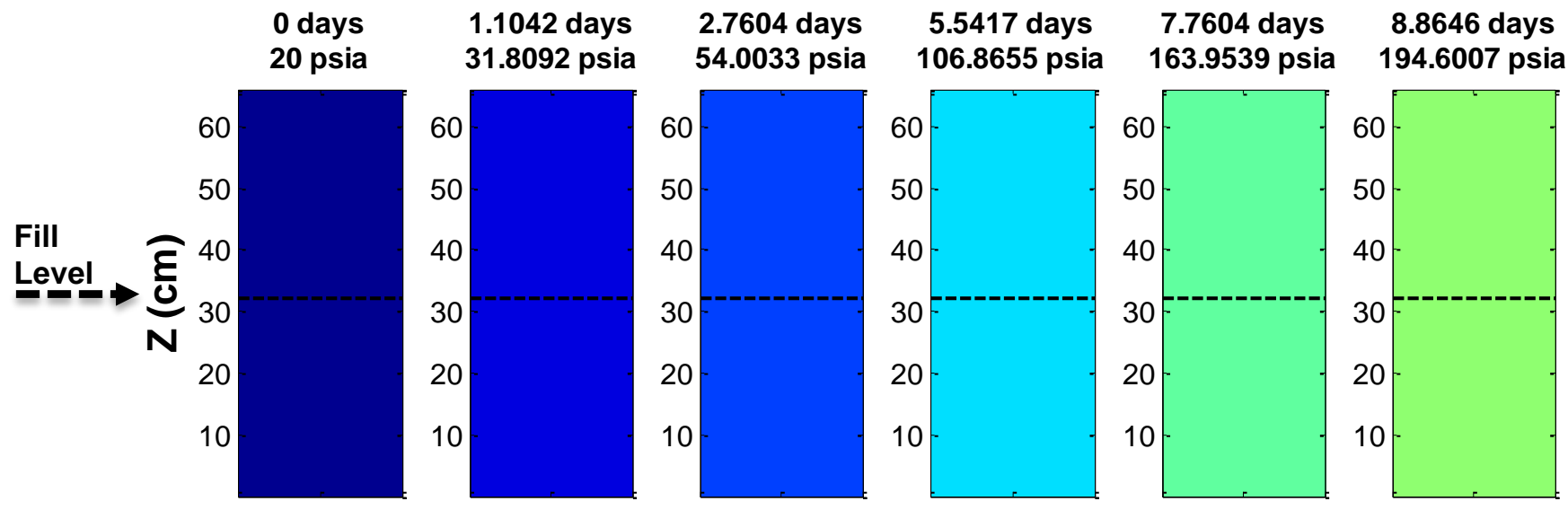

9.9792 days

11.0833 days Temp. 227.1391 psia 263.3651 psia (K)

a. Homogeneous Approach.
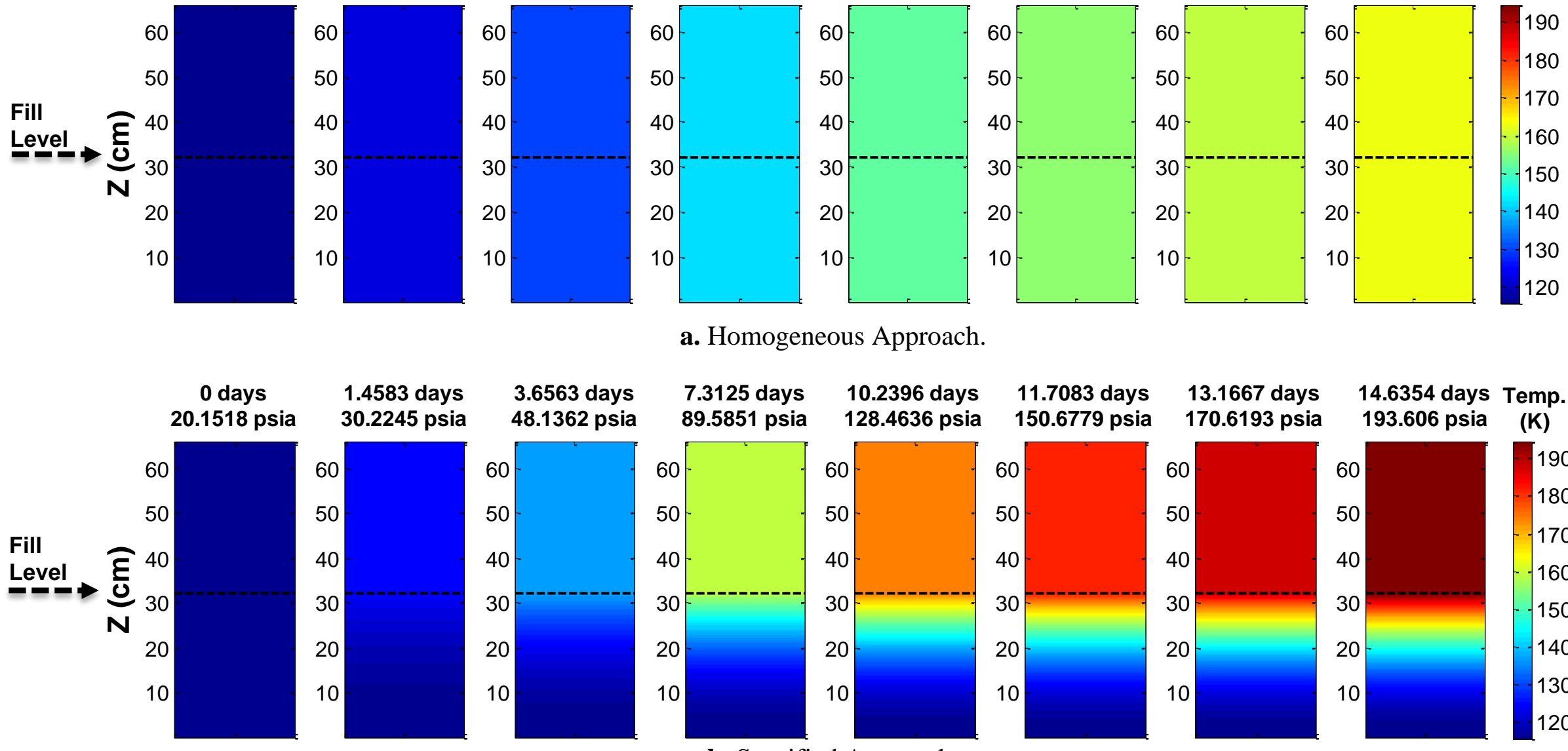

b. Stratified Approach.

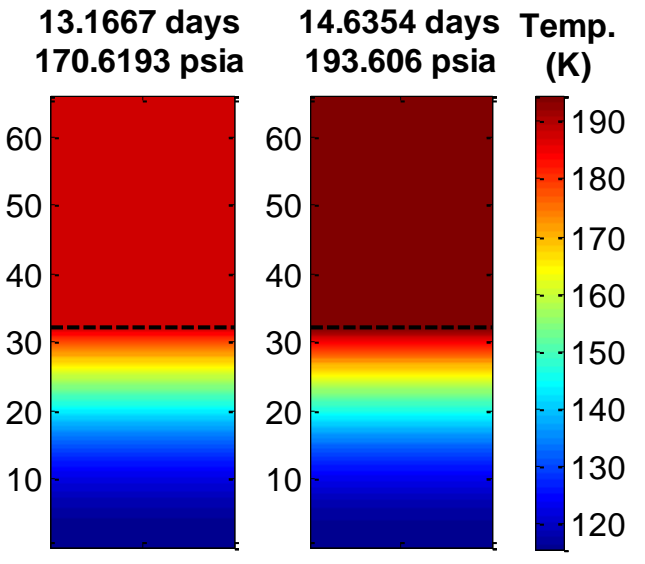

Figure B.5. Hold Time Experiment 2 with LNG Vehicle Tank with Internal Fuel Pump. Initial Homogeneous Fill Level: 48.77\%.

Temperature Map Comparisons. 


\section{APPENDIX C: \\ ReSults OF LNG Fueling Station 1 IN NEVADA WITH \\ VEHICLES REFUELING}

\section{C.1. LNG Fueling Station 1 - Segment 1 with $86.88 \%$ Initial Fill Level}
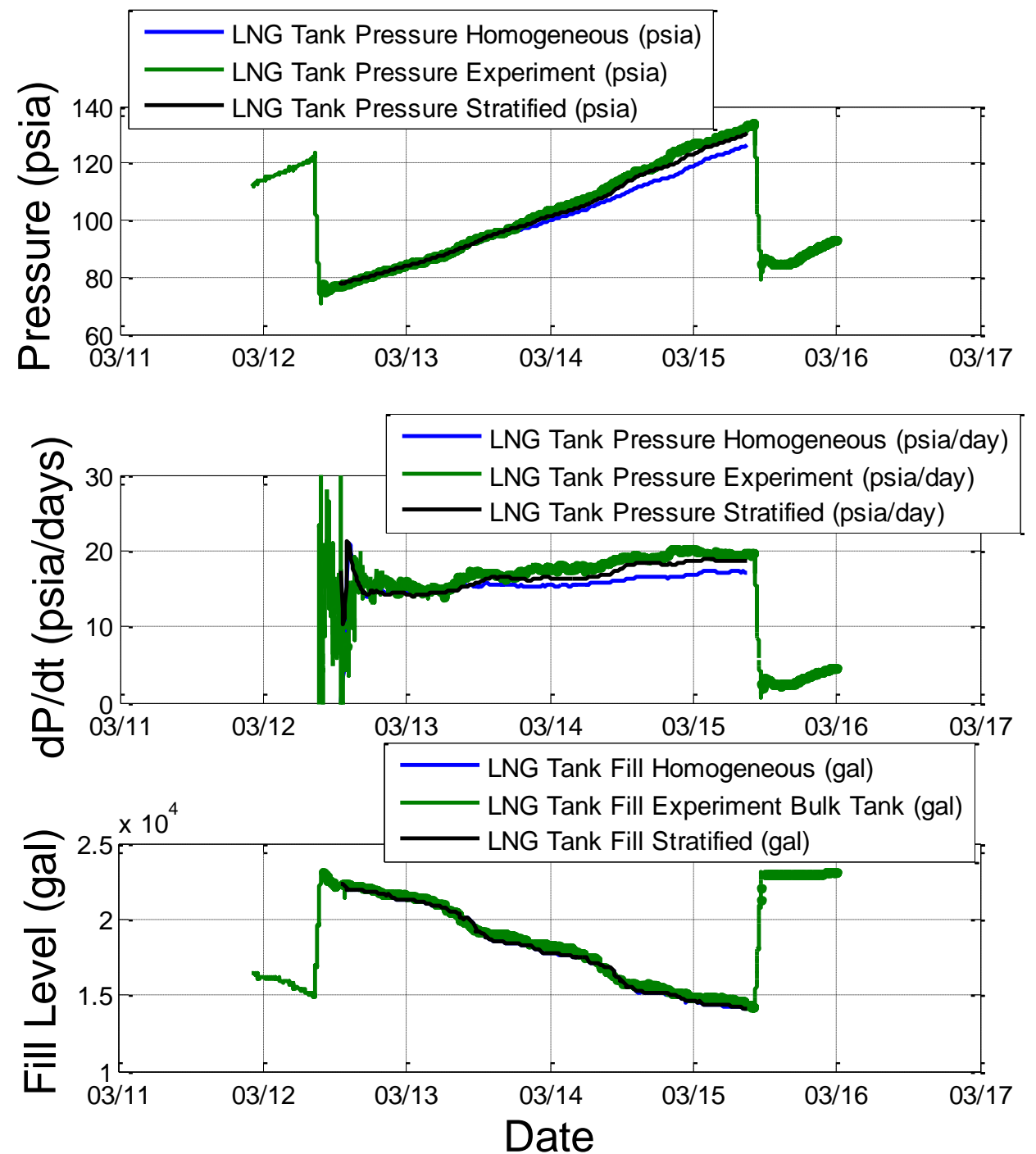

Figure C.1. Fueling Station 1 in Nevada. Segment 1. Simulated Pressure, dP/dt, and Fill Level. Initial Homogeneous Fill Level: 86.88\% 

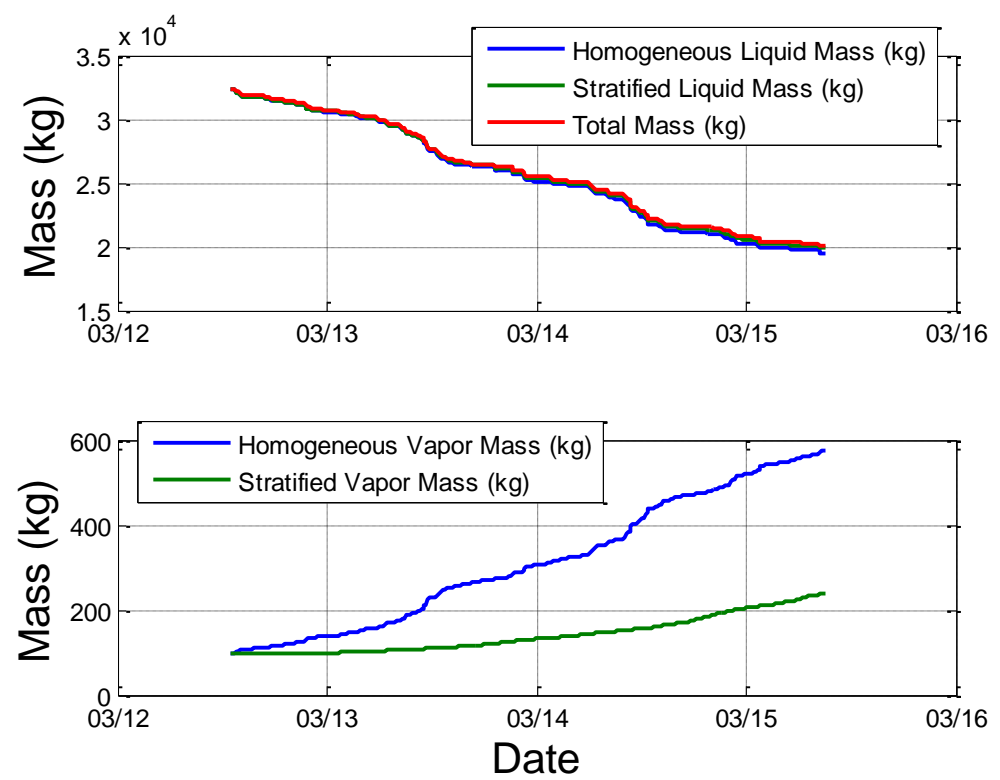

Figure C.2. Fueling Station 1 in Nevada. Segment 1. LNG and Vapor Mass Comparison.
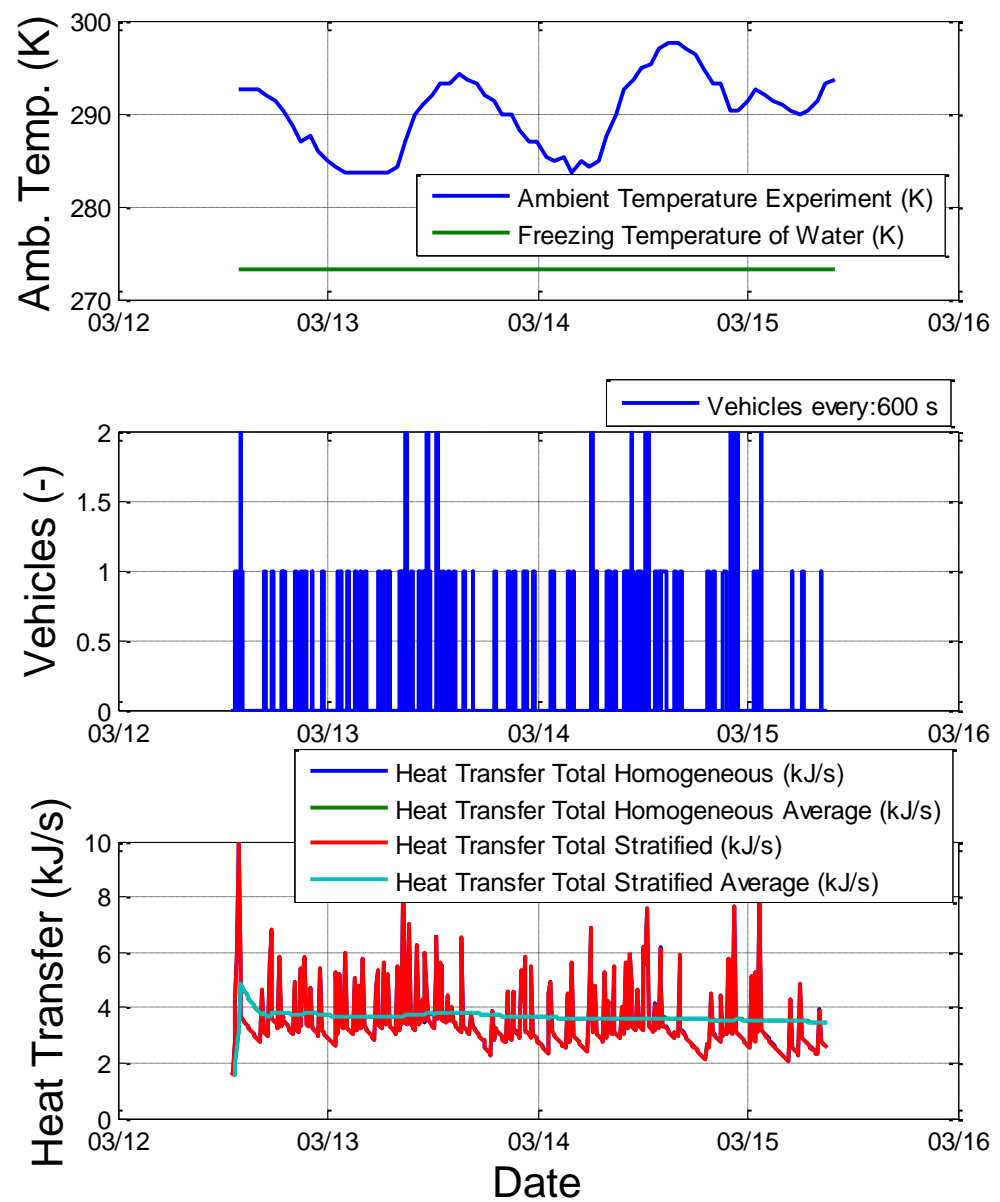

Figure C.3. Fueling Station 1 in Nevada. Segment 1. Total Heat Transfer Simulated, Weather Data, and Vehicles Refueled. 

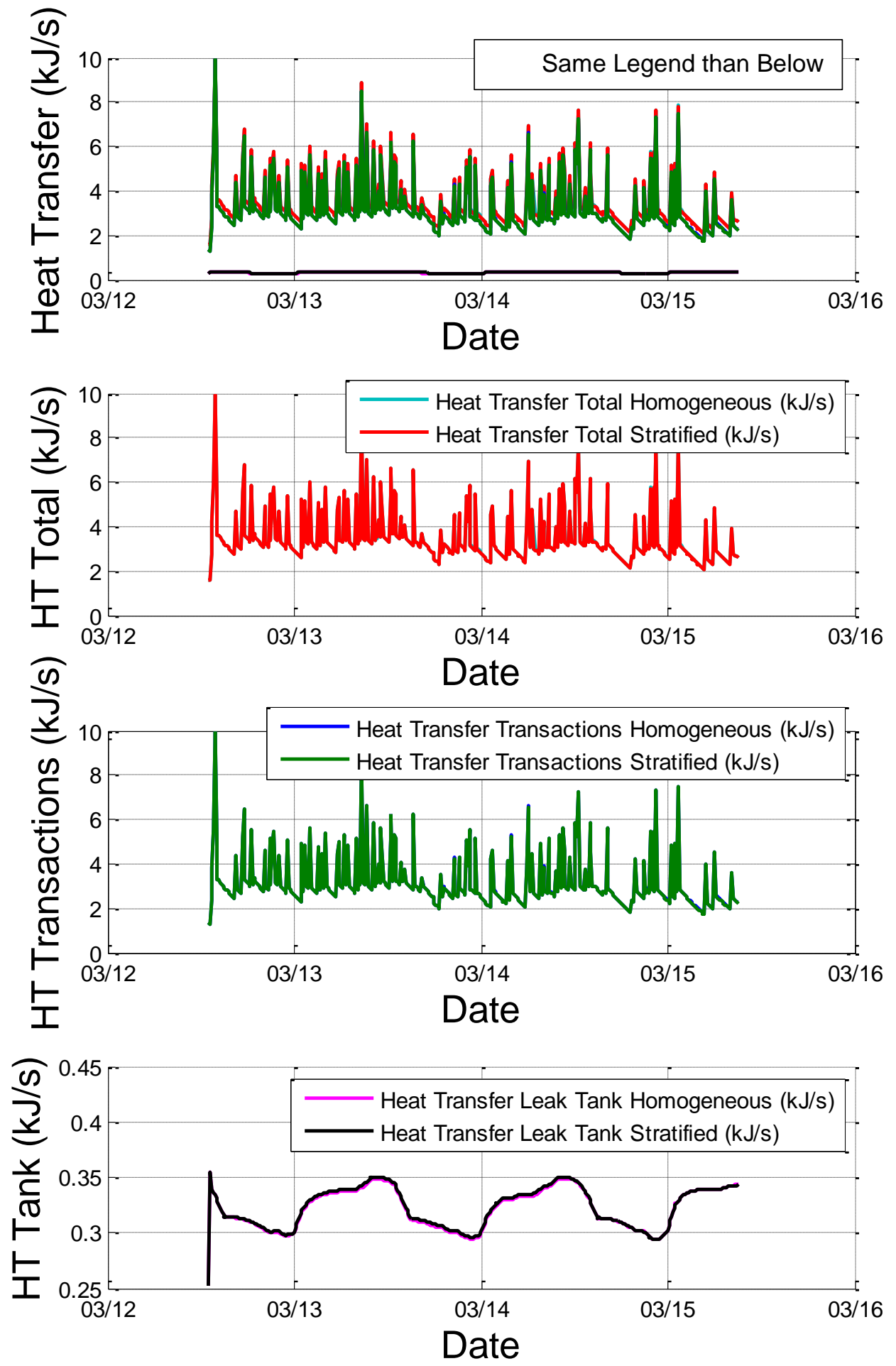

Figure C.4. Fueling Station 1 in Nevada. Segment 1. Total Heat Transfer, Heat Transfer by the Vehicle Transactions, and Heat Leak into the Tank through Walls. 

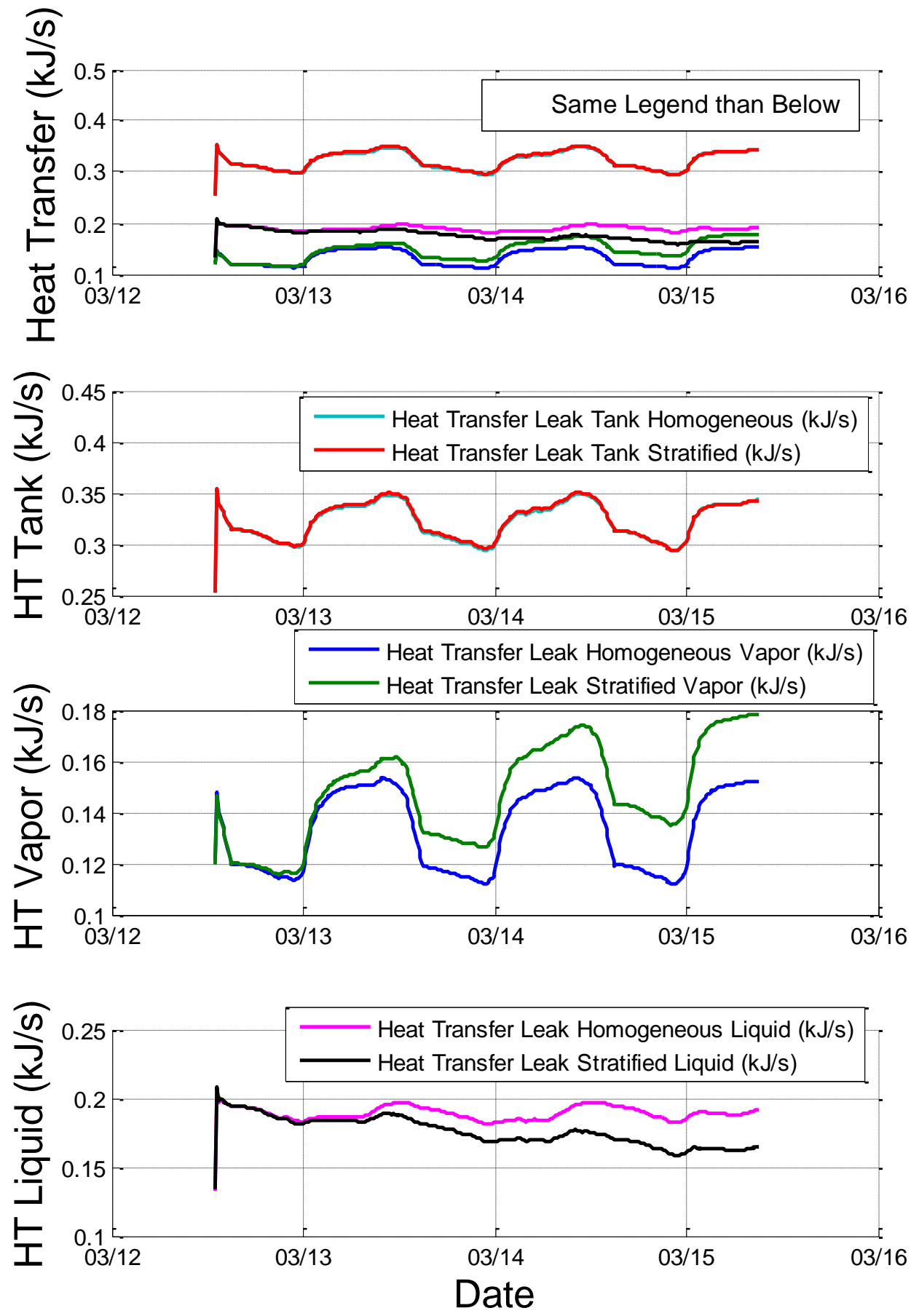

Figure C.5. Fueling Station 1 in Nevada. Segment 1. Heat Transfer Tank Leak into the Vapor and Liquid Regions. 

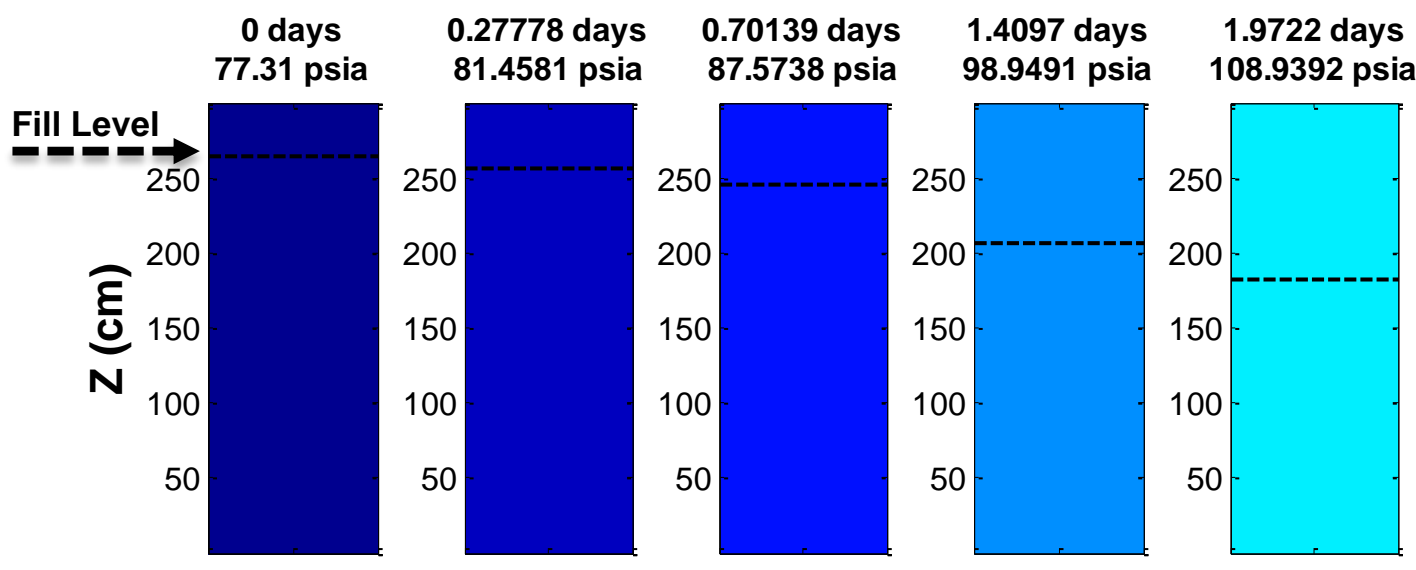

2.2569 days

2.5347 days

2.8194 days Temp.
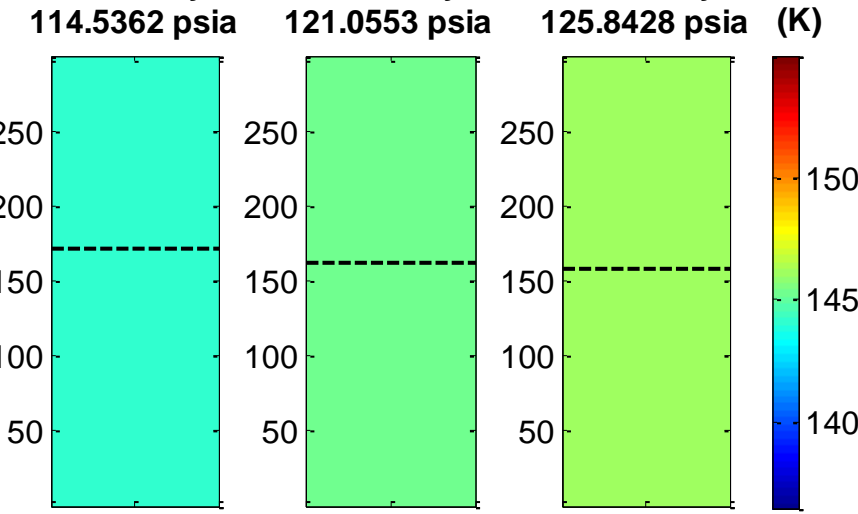

a. Homogeneous Approach.
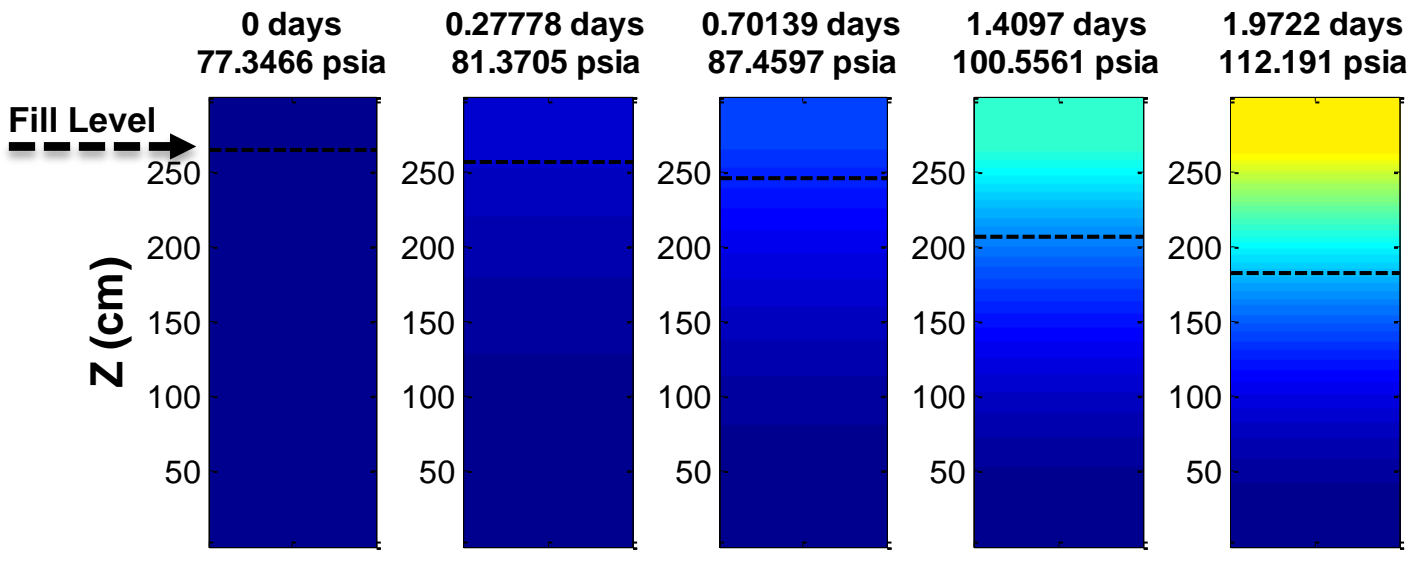

2.2569 days

2.5347 days

2.8194 days Temp. 118.4386 psia $\quad 125.2255$ psia 130.064 psia (K)

b. Stratified Approach.
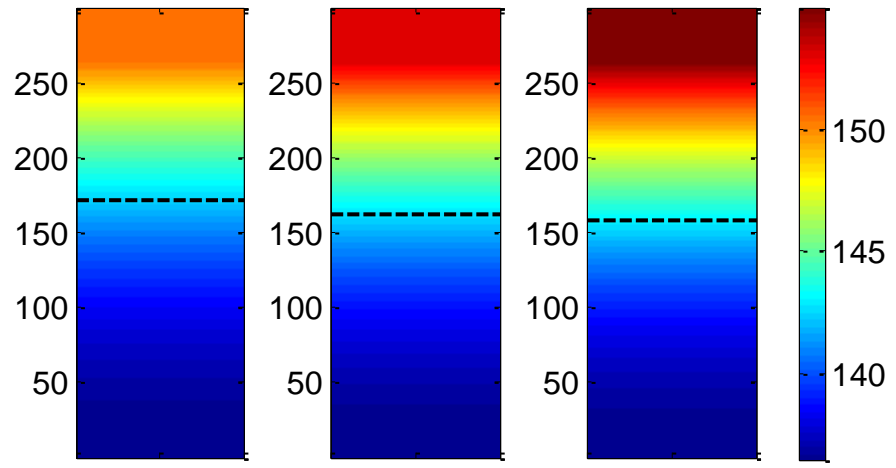

Figure C.6. Fueling Station 1 in Nevada. Segment 1. Initial Homogeneous Fill Level: 86.88\%. Temperature Map Comparisons. 


\section{C.2. LNG Fueling Station 1 - Segment 2 with Offload Pump Effect}
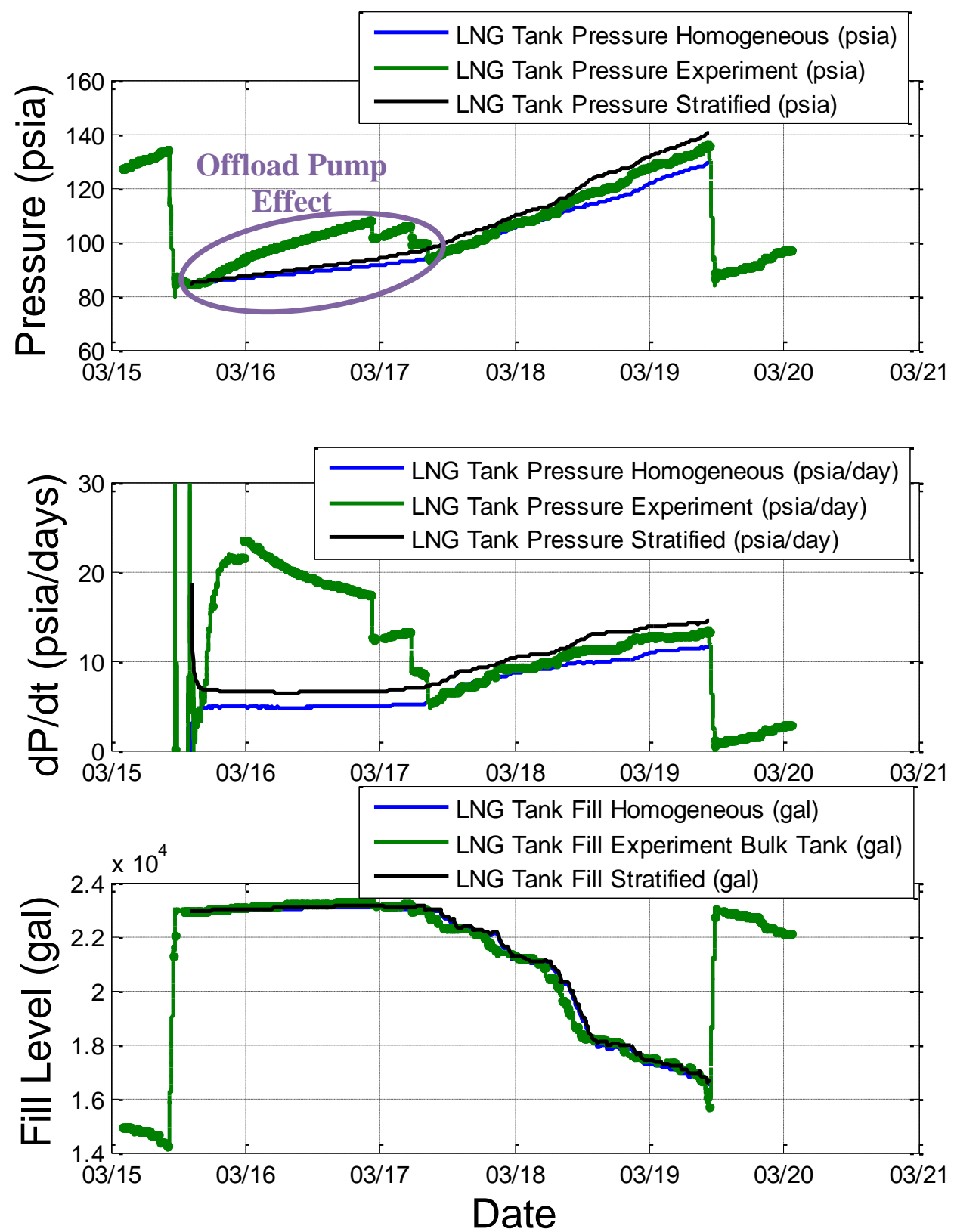

Figure C.7. Fueling Station 1 in Nevada. Segment 2. Simulated Pressure, dP/dt, and Fill Level. Initial Homogeneous Fill Level: 90.85\% 

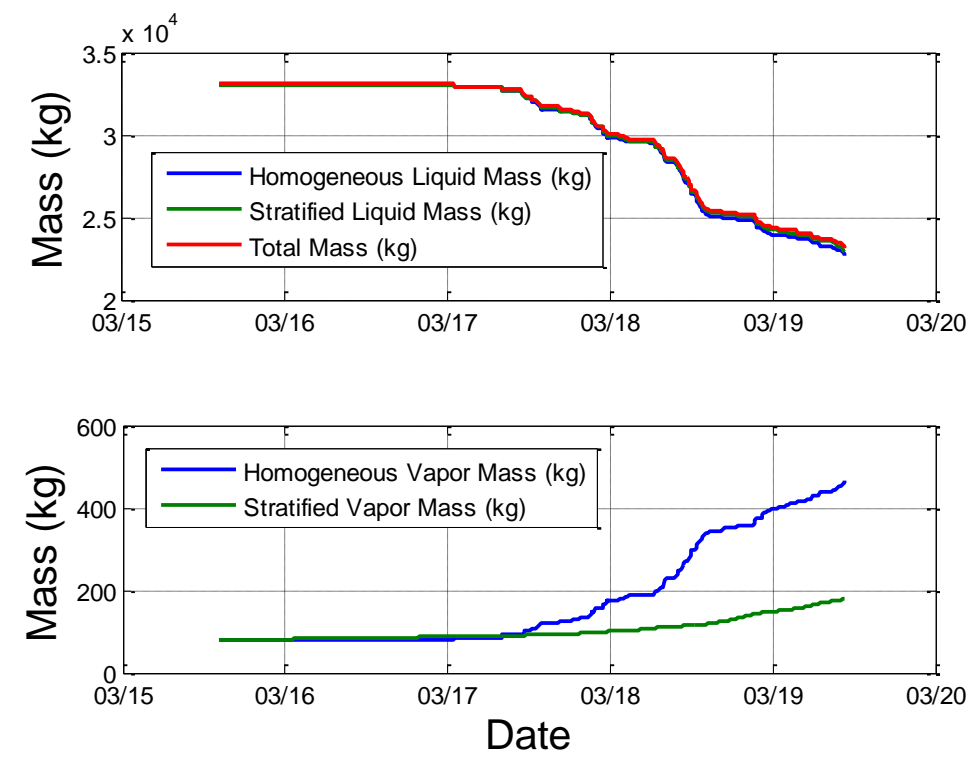

Figure C.8. Fueling Station 1 in Nevada. Segment 2. LNG and Vapor Mass Comparison.
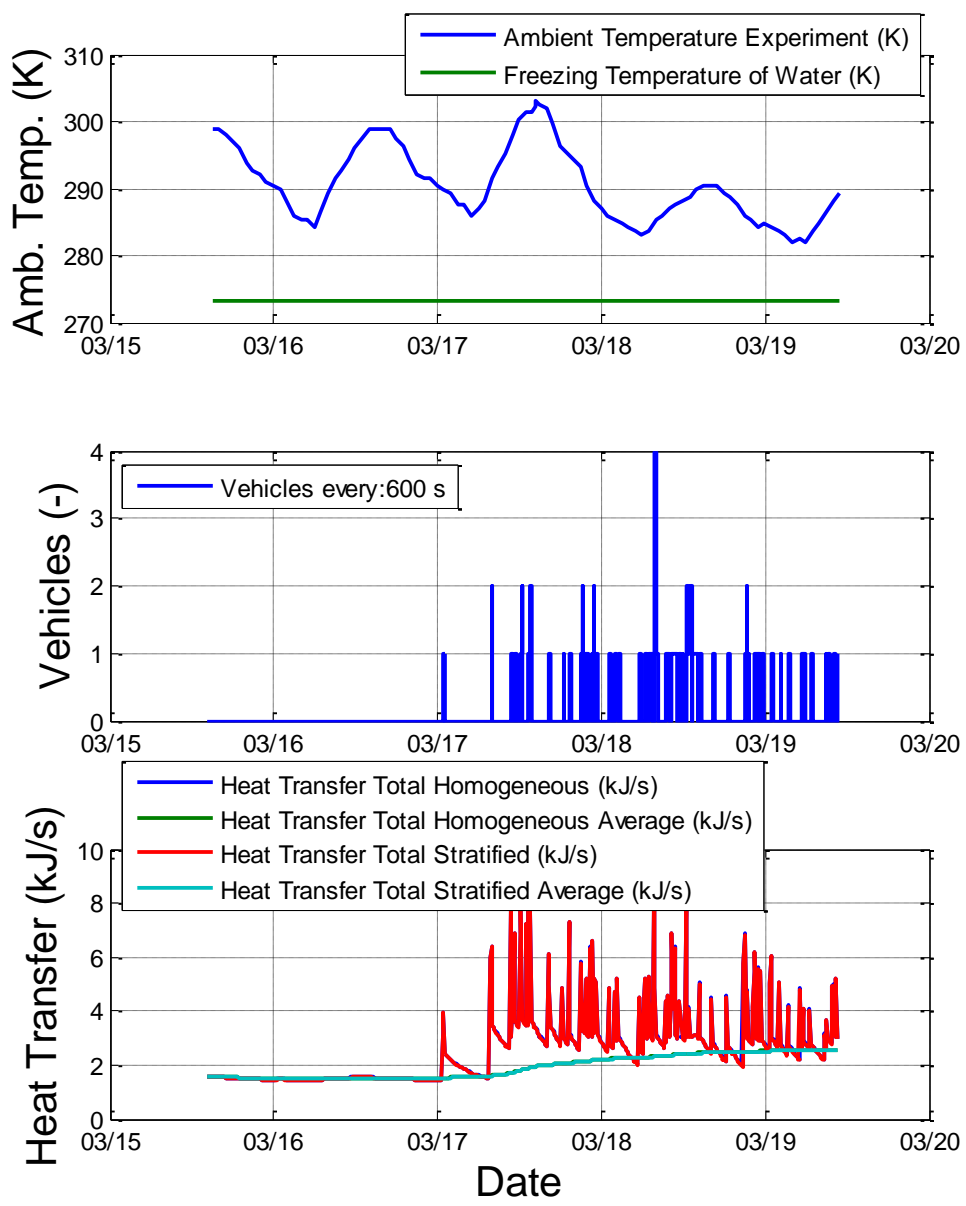

Figure C.9. Fueling Station 1 in Nevada. Segment 2. Total Heat Transfer Simulated, Weather Data, and Vehicles Refueled. 

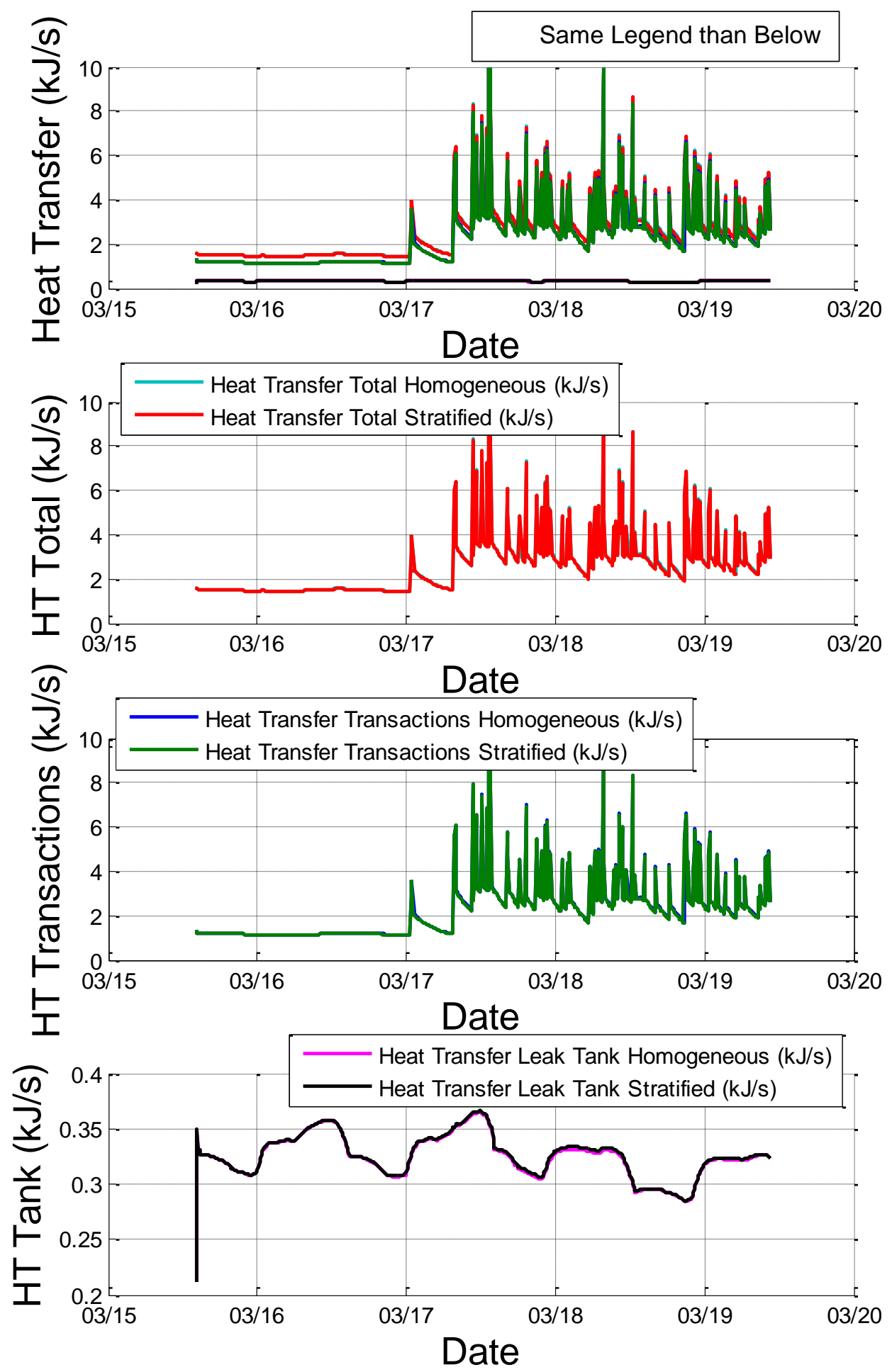

Figure C.10. Fueling Station 1 in Nevada. Segment 2. Total Heat Transfer, Heat Transfer by the Vehicle Transactions, and Heat Leak into the Tank through Walls. 

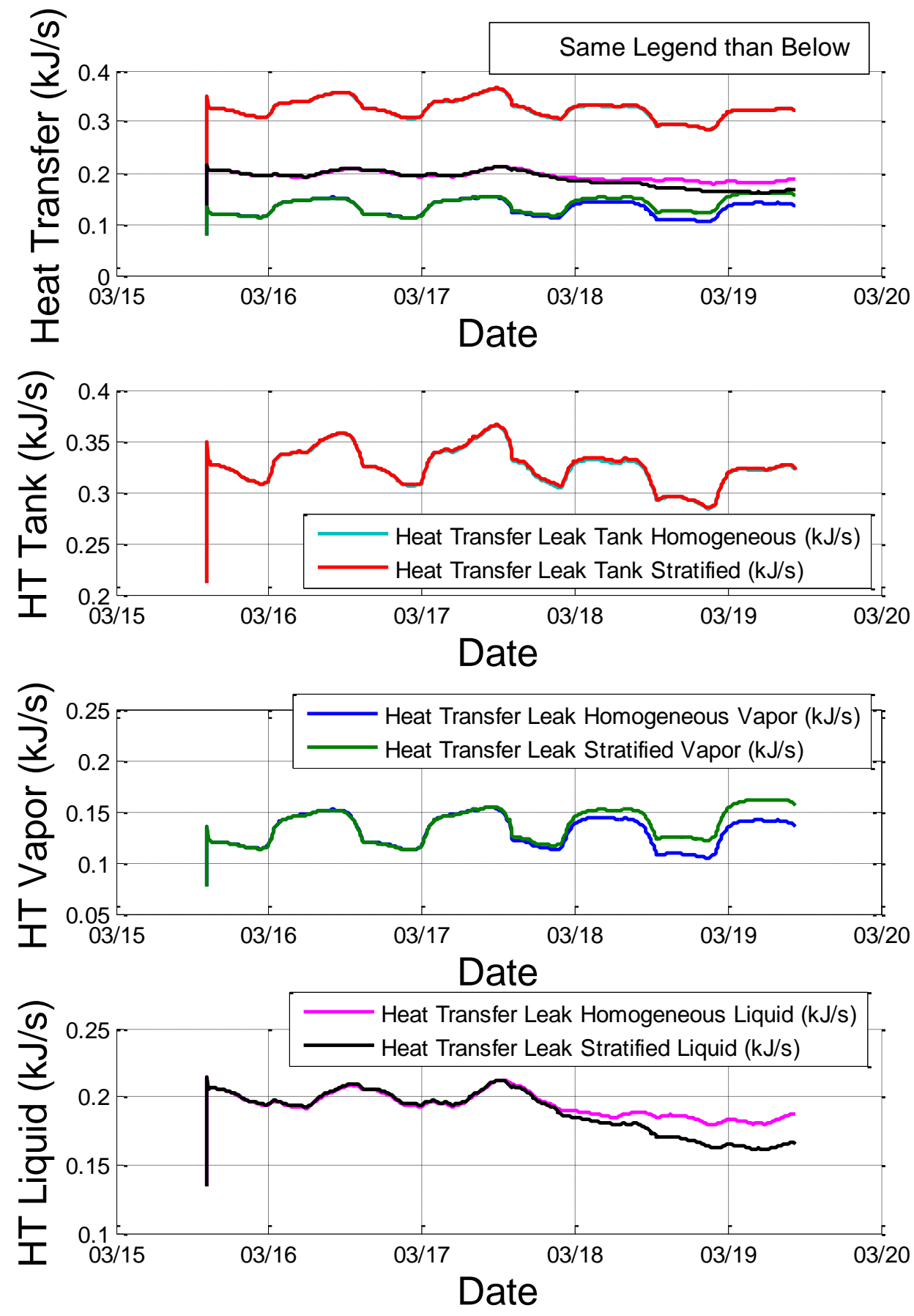

Figure C.11. Fueling Station 1 in Nevada. Segment 2. Heat Transfer Tank Leak into the Vapor and Liquid Regions. 

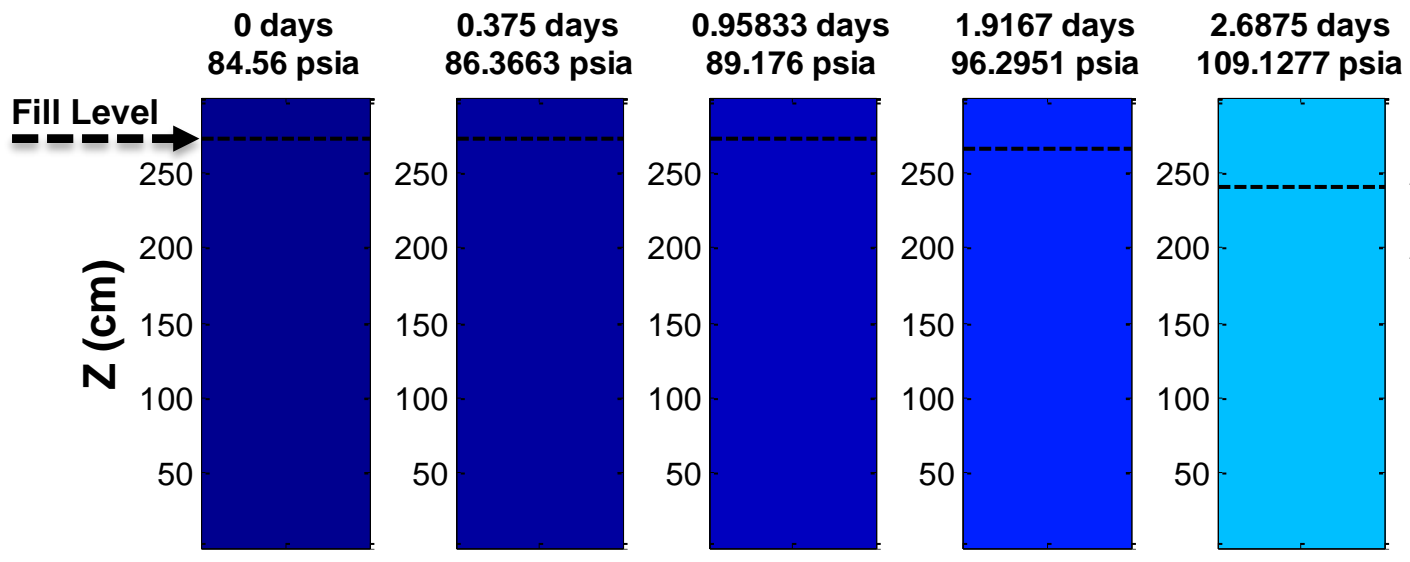

3.0694 days

3.4583 days

3.8403 days Temp.
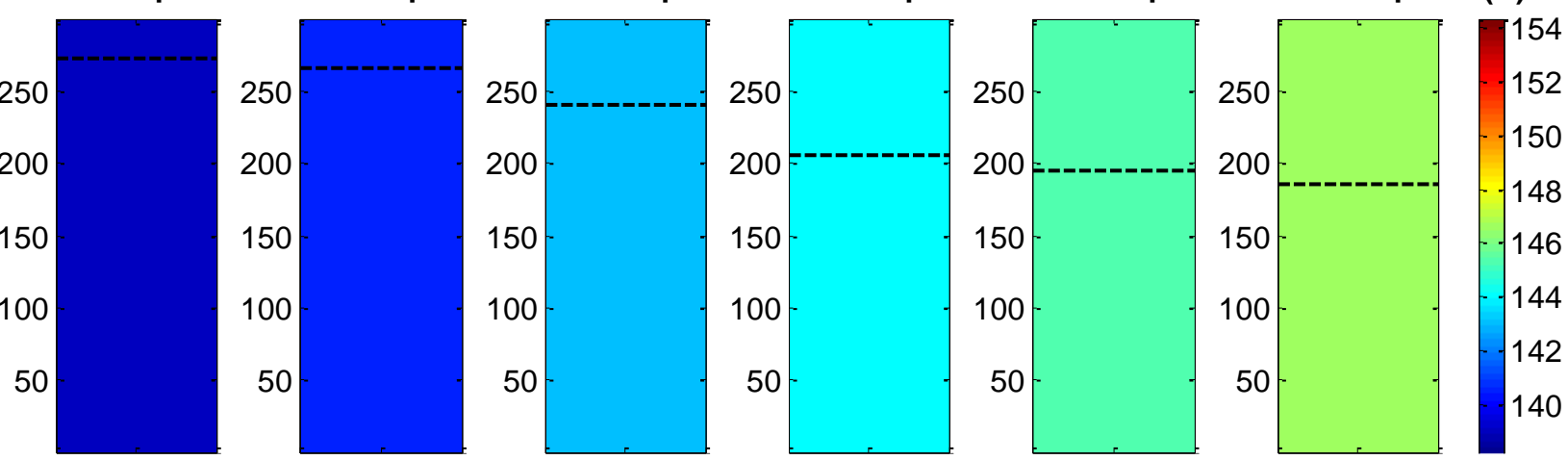

a. Homogeneous Approach.
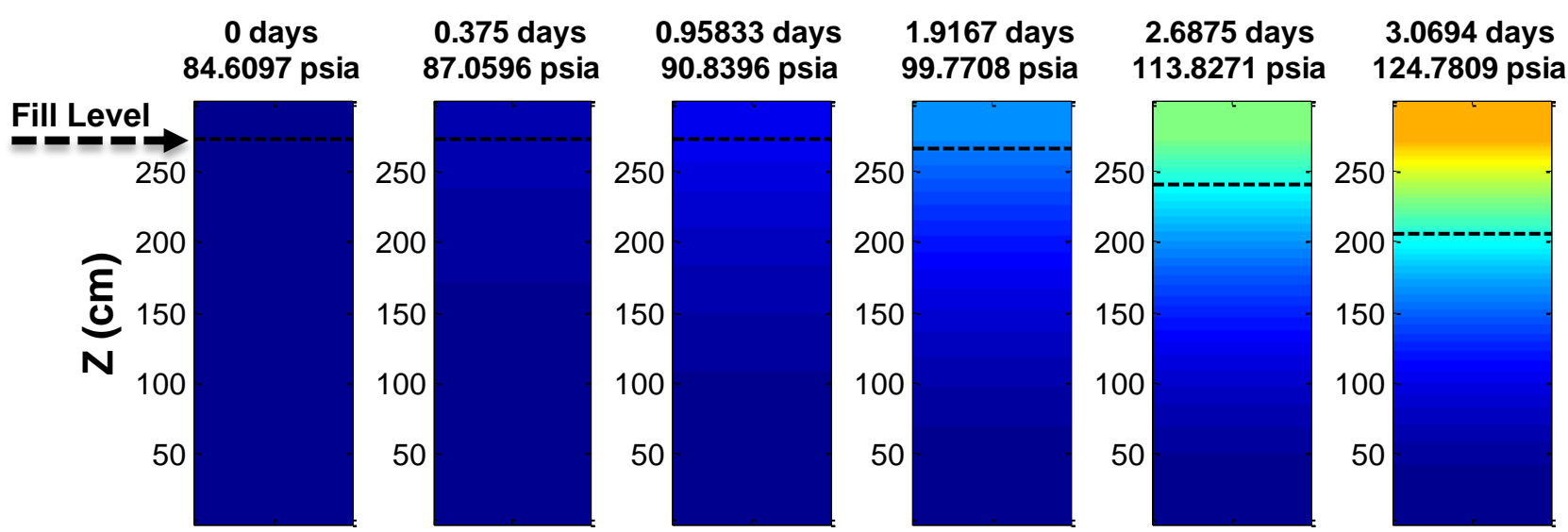

3.4583 days

3.8403 days Temp. 99.7708 psia
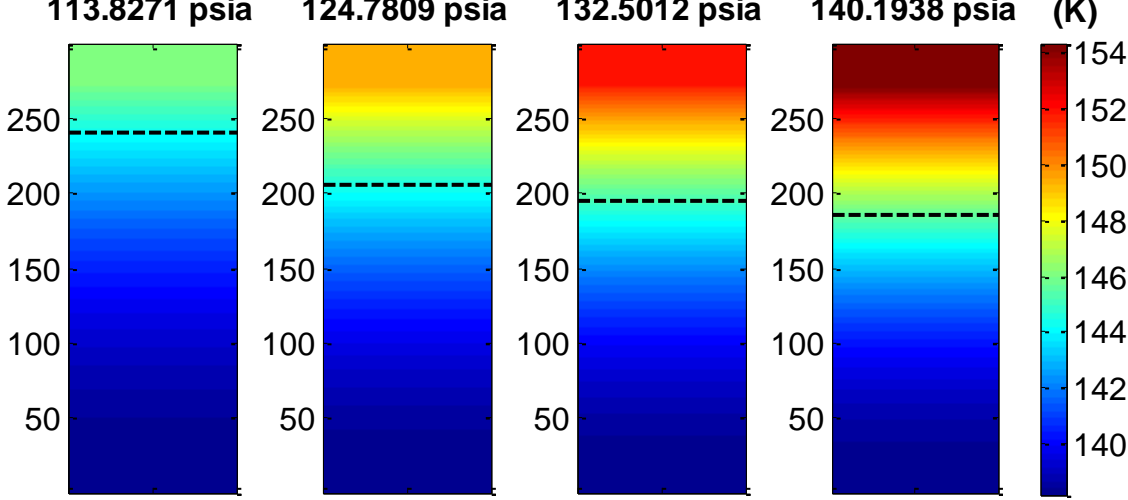

b. Stratified Approach.

Figure C.12. Fueling Station 1 in Nevada. Segment 2. Initial Homogeneous Fill Level: 90.85\%. Temperature Map Comparisons. 


\section{APPENDIX D:}

\section{RESULTS OF LNG FUELING STATION 2 IN UTAH WITH VEHICLES REFUELING}

\section{D.1. LNG Fueling Station 2 - Segment 1a with Vapor Removed Fast}
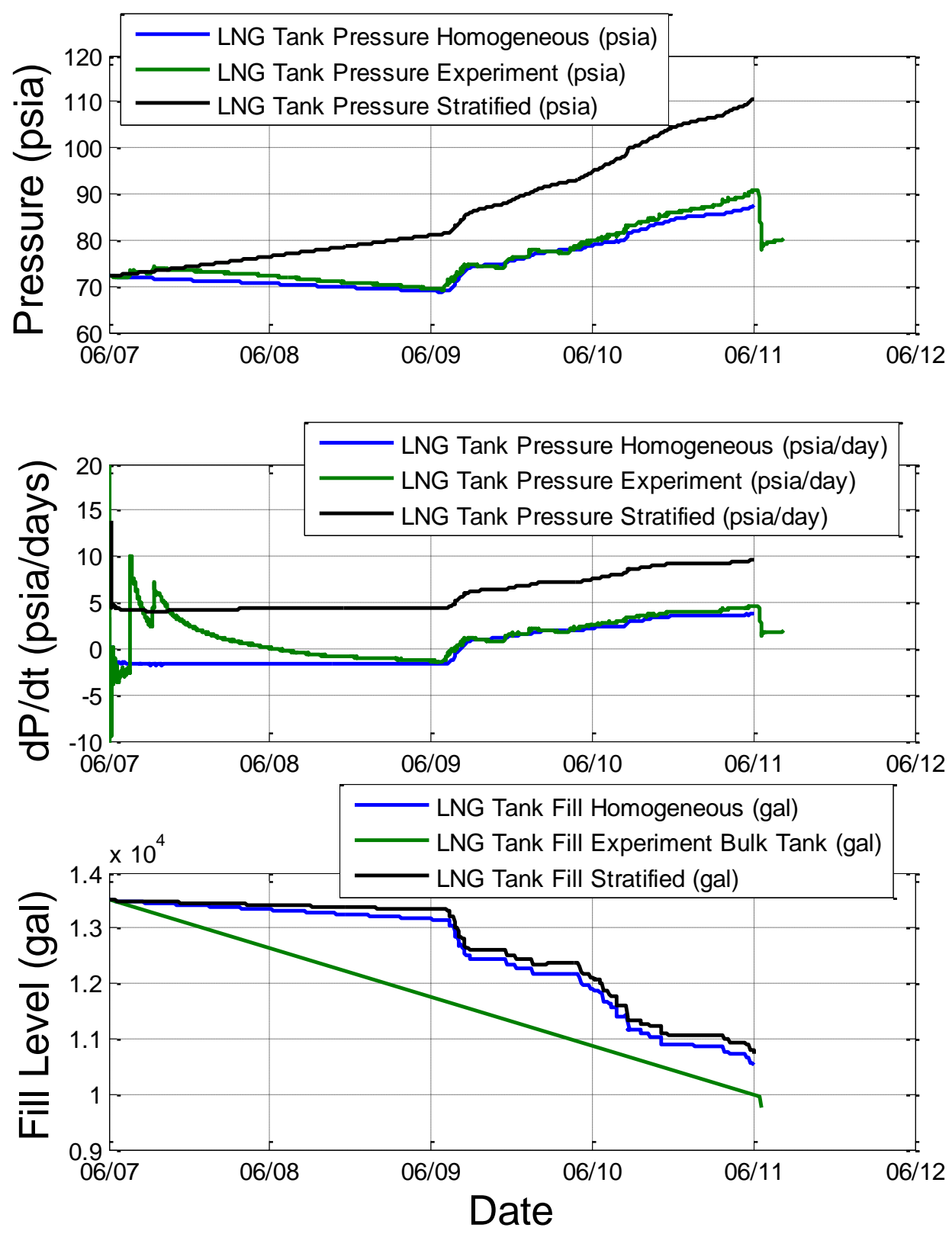

Figure D.1. Fueling Station 2 in Utah. Segment 1a. GenSet: On. Simulated Pressure, dP/dt, and Fill Level. Initial Homogeneous Fill Level: 86.99\% 

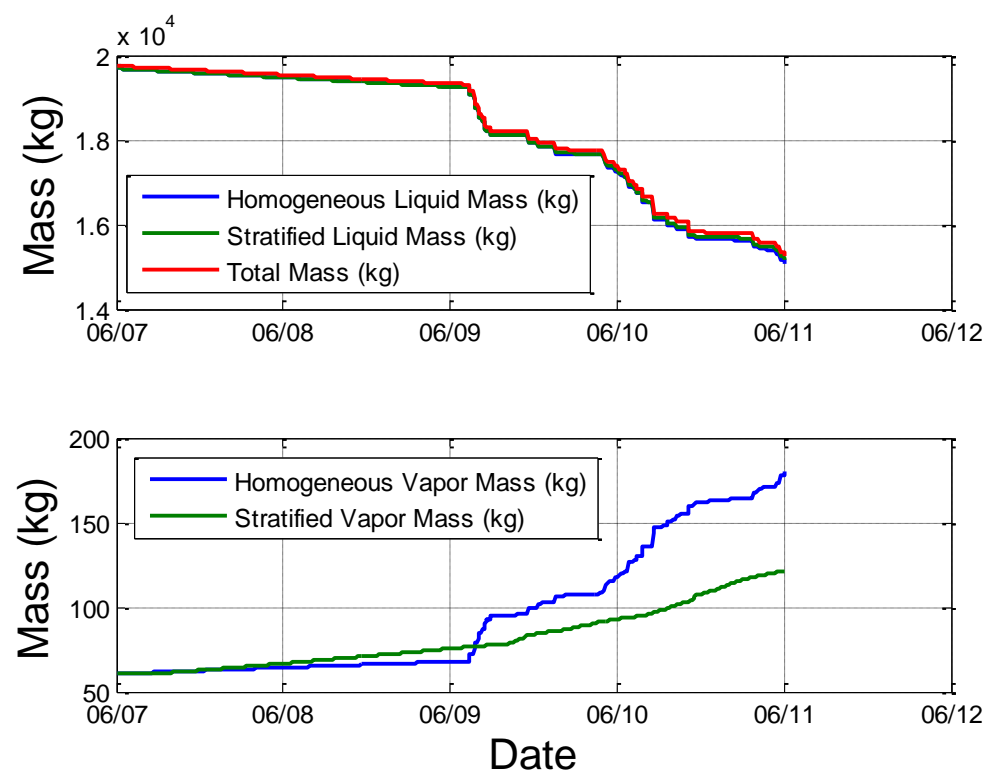

Figure D.2. Fueling Station 2 in Utah. Segment 1a. GenSet: On. LNG and Vapor Mass Comparison.
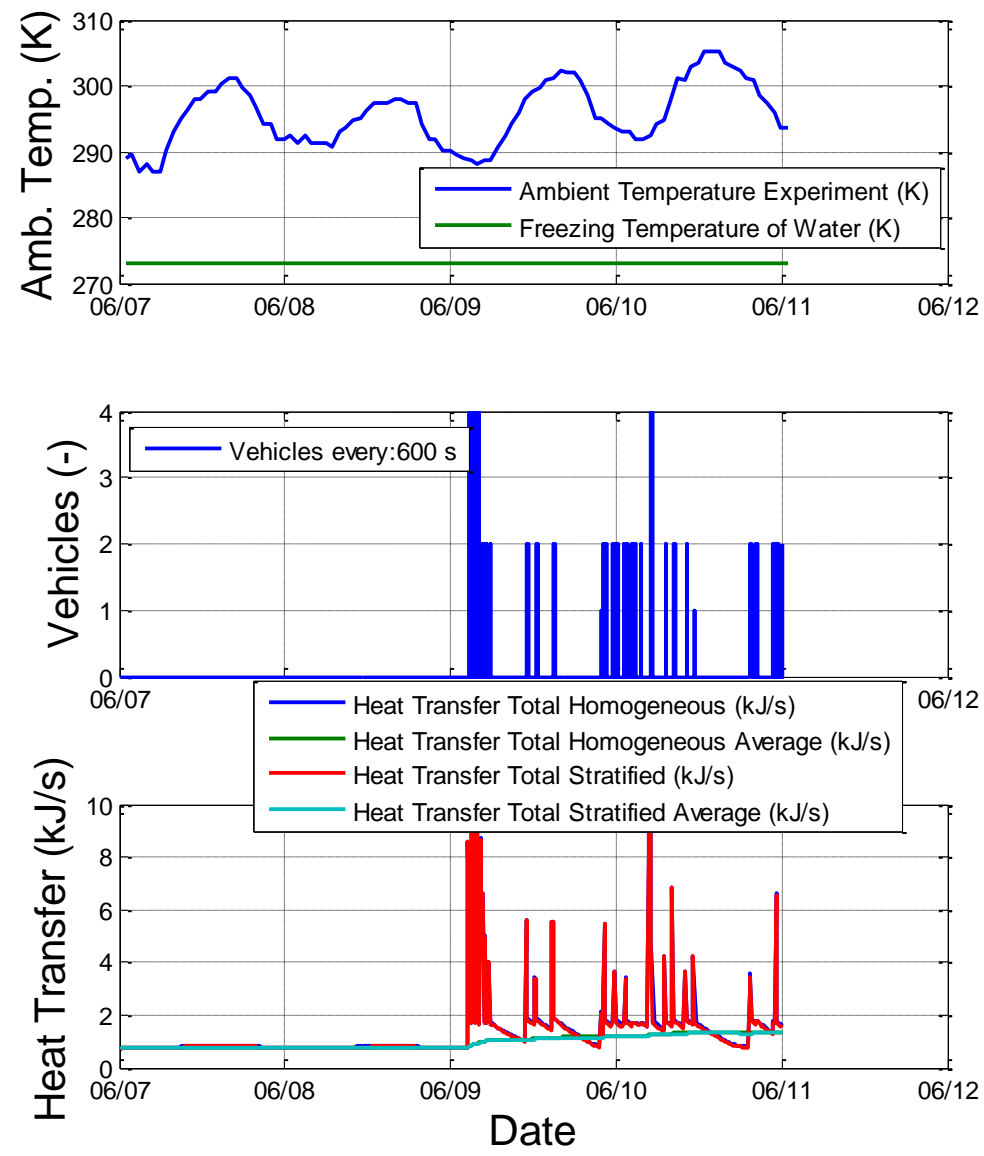

Figure D.3. Fueling Station 2 in Utah. Segment 1a. GenSet: On. Total Heat Transfer Simulated, Weather Data, and Vehicles Refueled. 

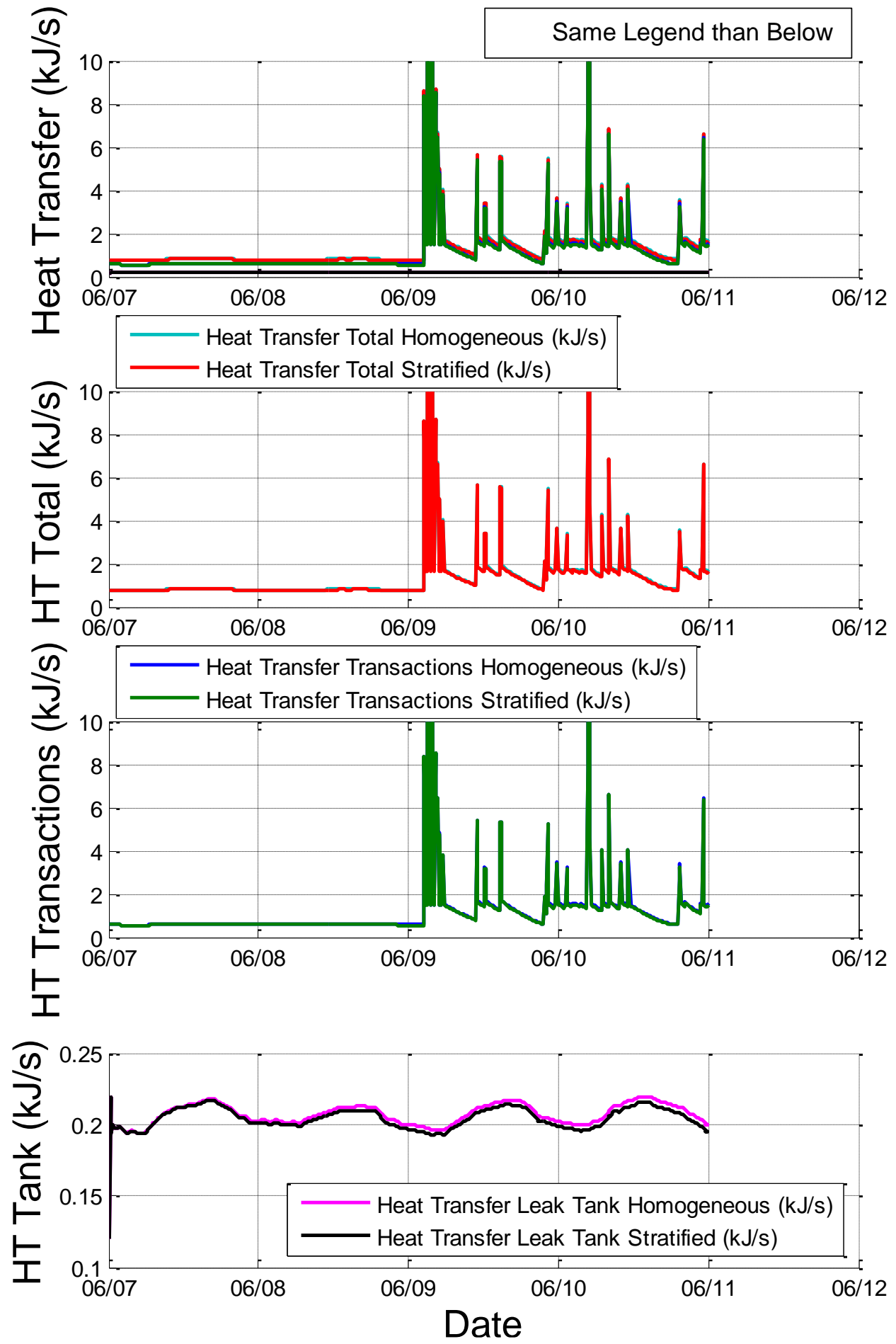

Figure D.4. Fueling Station 2 in Utah. Segment 1a. GenSet: On. Total Heat Transfer, Heat Transfer by the Vehicle Transactions, and Heat Leak into the Tank through Walls. 

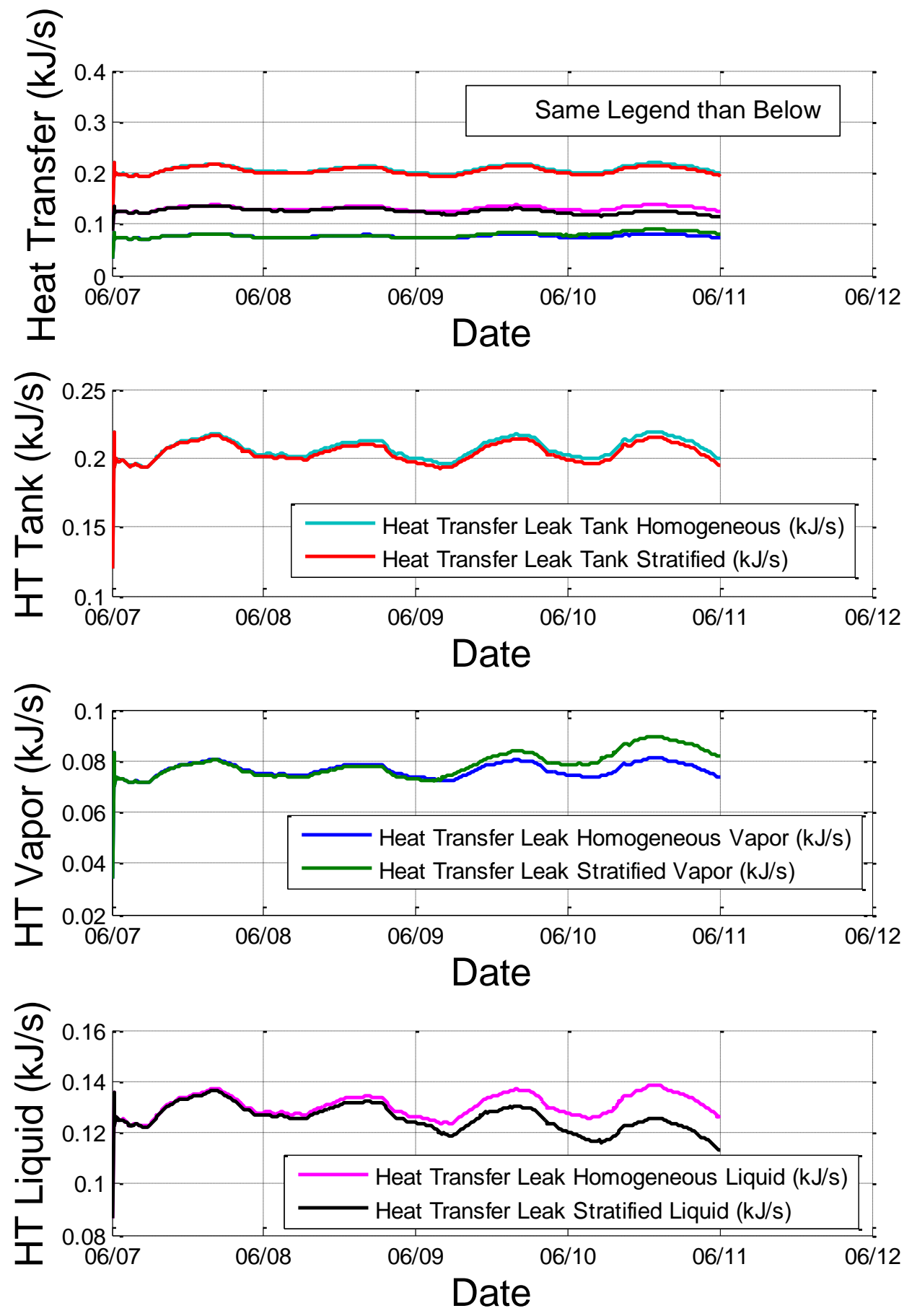

Figure D.5. Fueling Station 2 in Utah. Segment 1a. GenSet: On. Heat Transfer Tank Leak into the Vapor and Liquid Regions. 

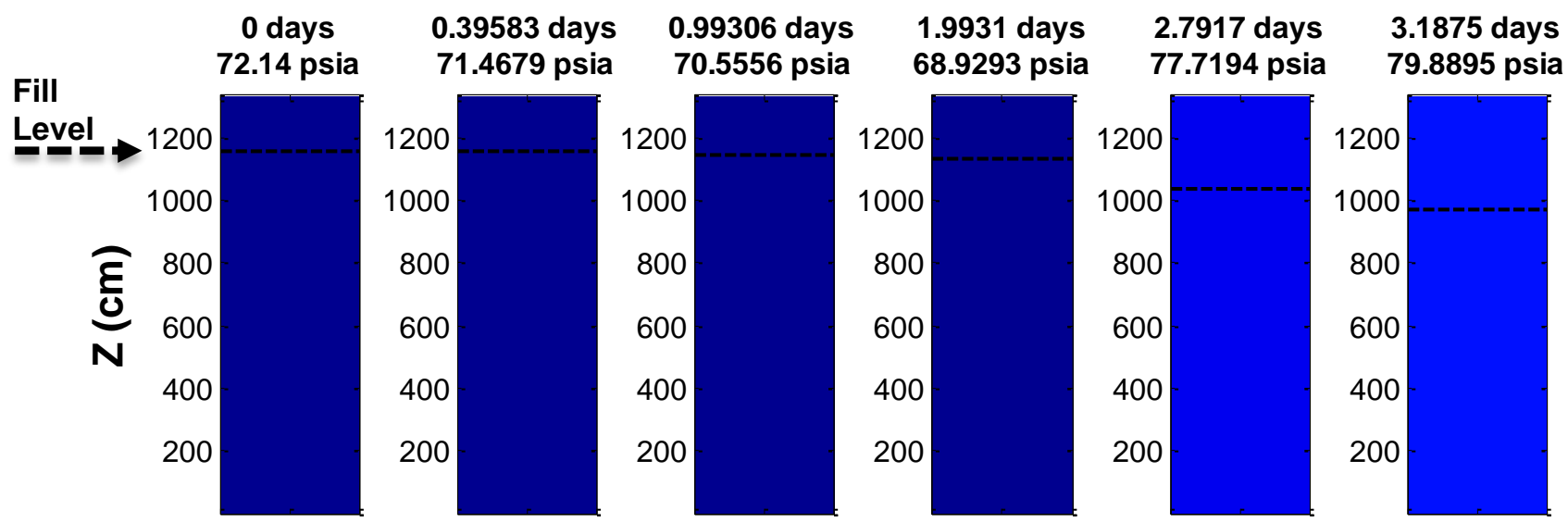

3.5903 days

3.9861 days Temp.
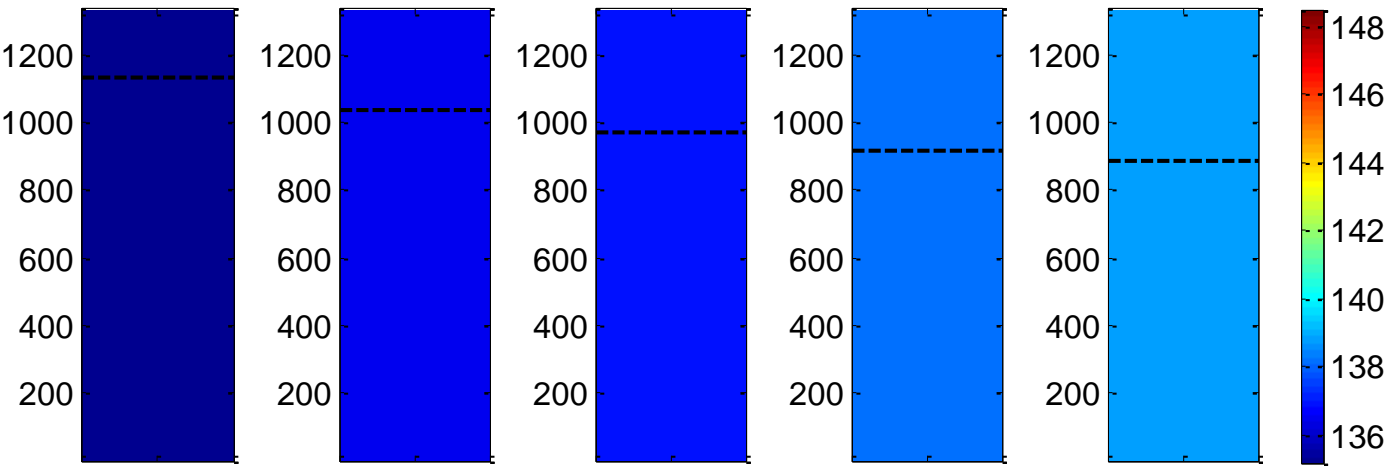

a. Homogeneous Approach.
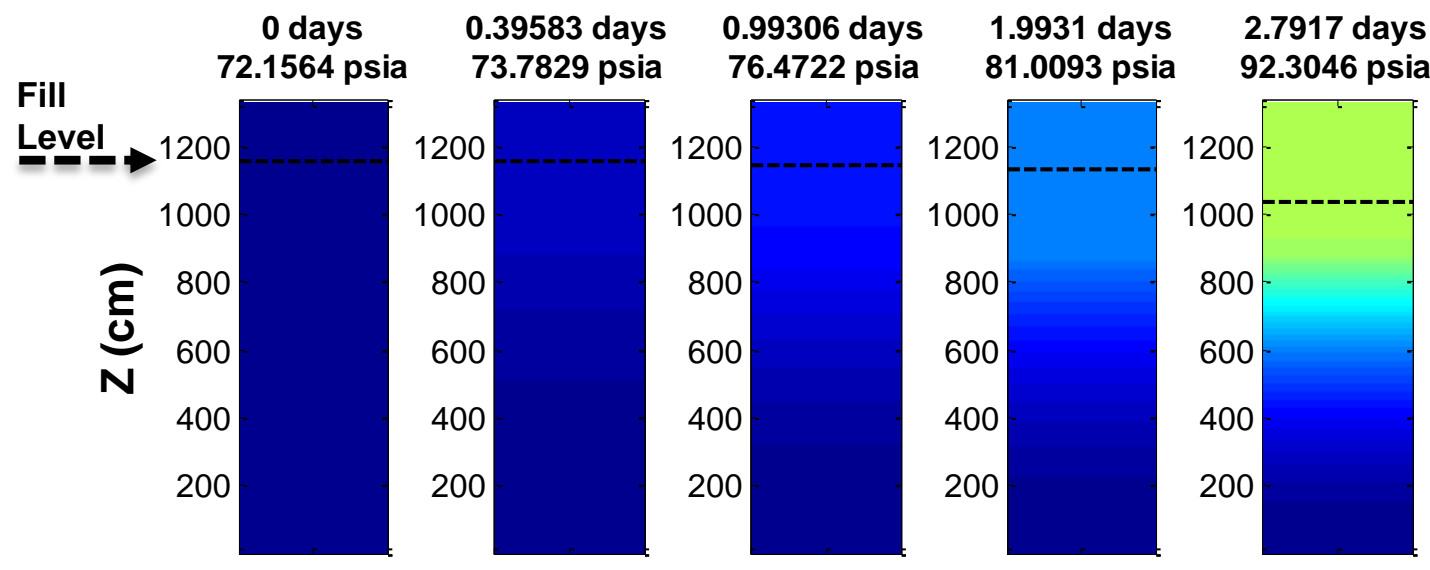

\subsection{5 days 98.0296 psia}

3.5903 days

3.9861 days Temp.
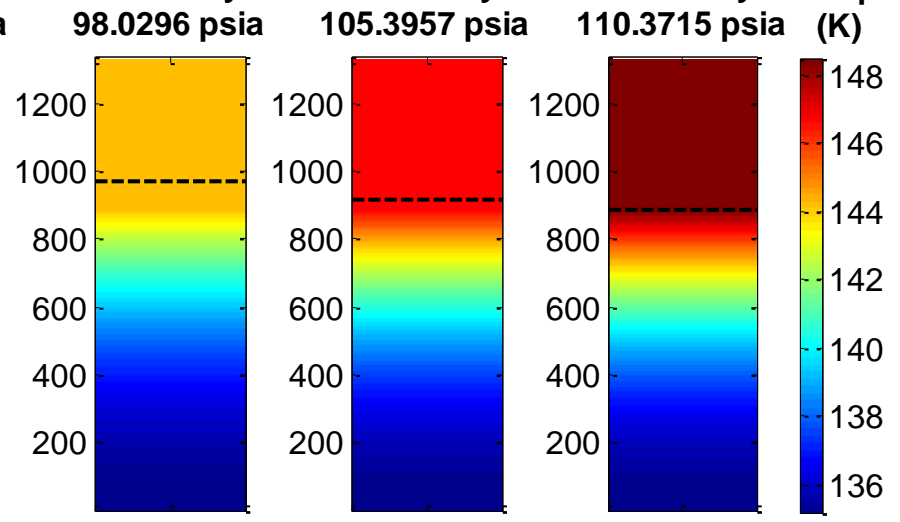

b. Stratified Approach.

Figure D.6. Fueling Station 2 in Utah. Segment 1a. GenSet: On. Initial Homogeneous Fill Level: 86.99\%. Temperature Map Comparisons. 


\section{D.2. LNG Fueling Station 2 - Segment 2 with 62.83\% Initial Fill Level}
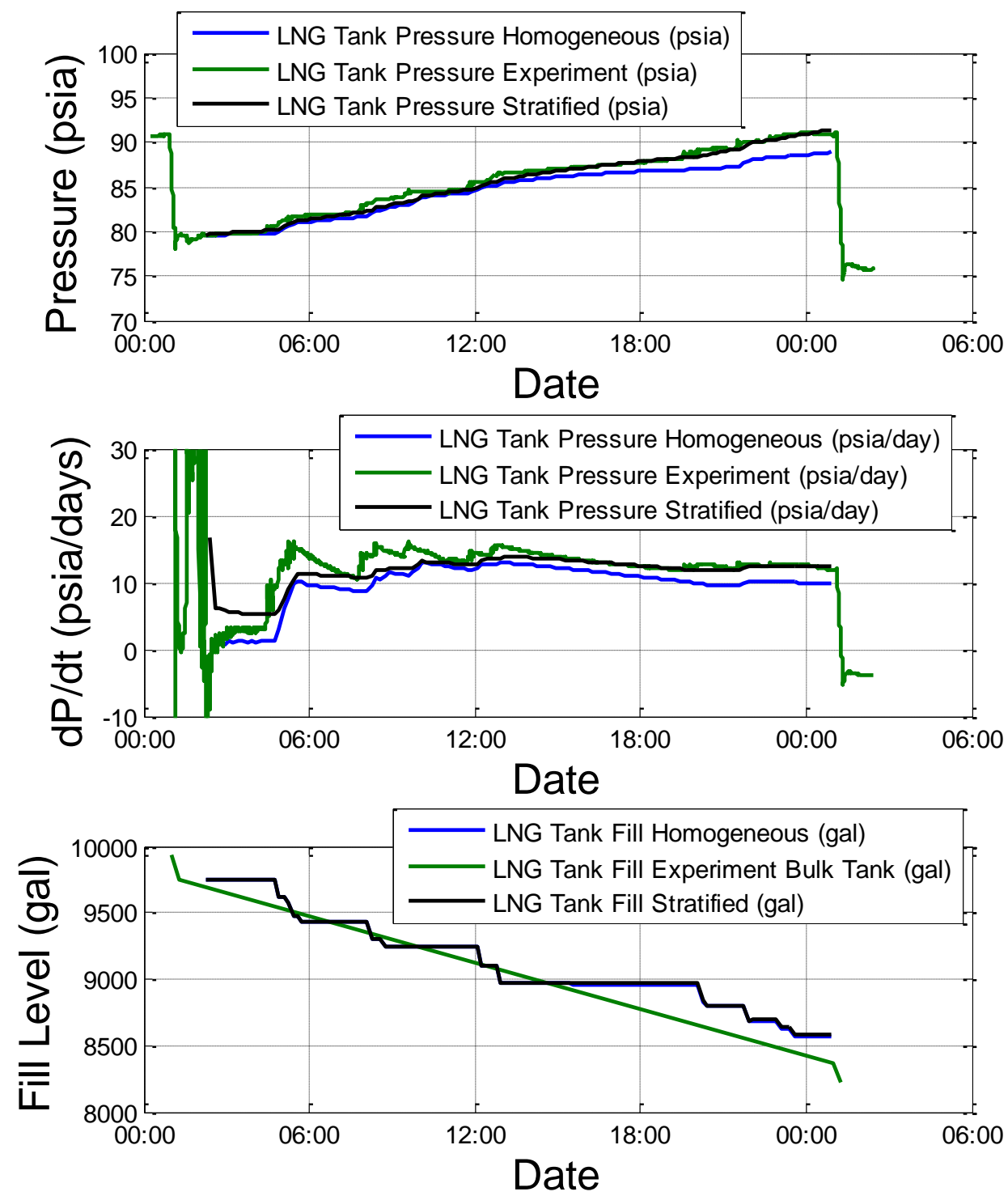

Figure D.7. Fueling Station 2 in Utah. Segment 2. GenSet: On. Simulated Pressure, dP/dt, and Fill Level. Initial Homogeneous Fill Level: 62.83\% 

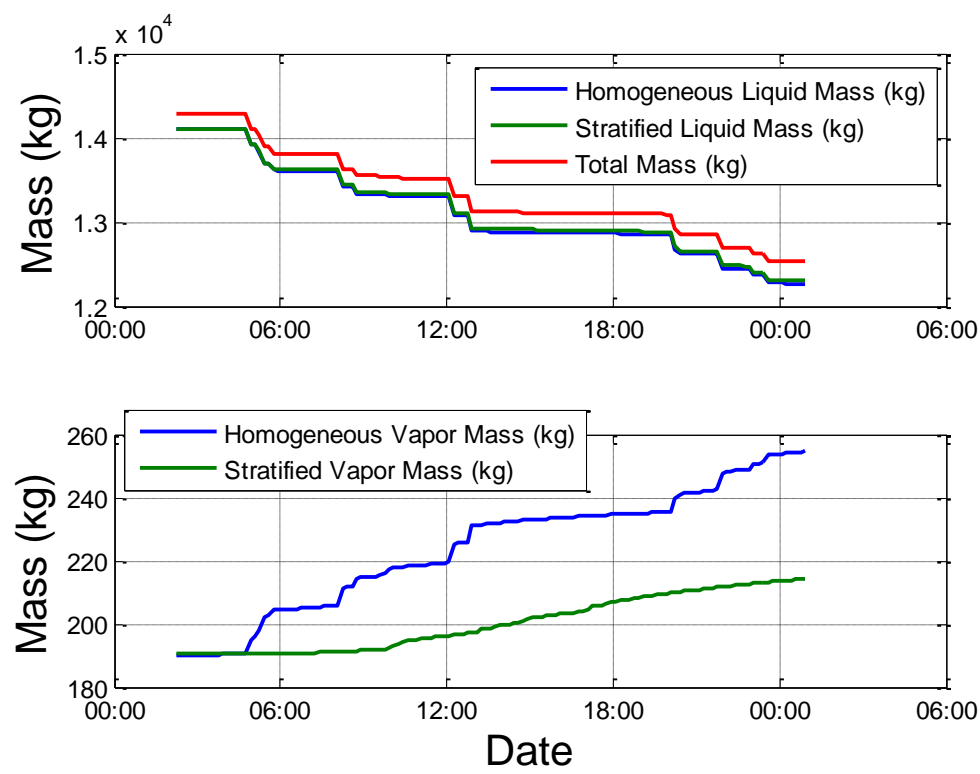

Figure D.8. Fueling Station 2 in Utah. Segment 2. GenSet: On. LNG and Vapor Mass Comparison.
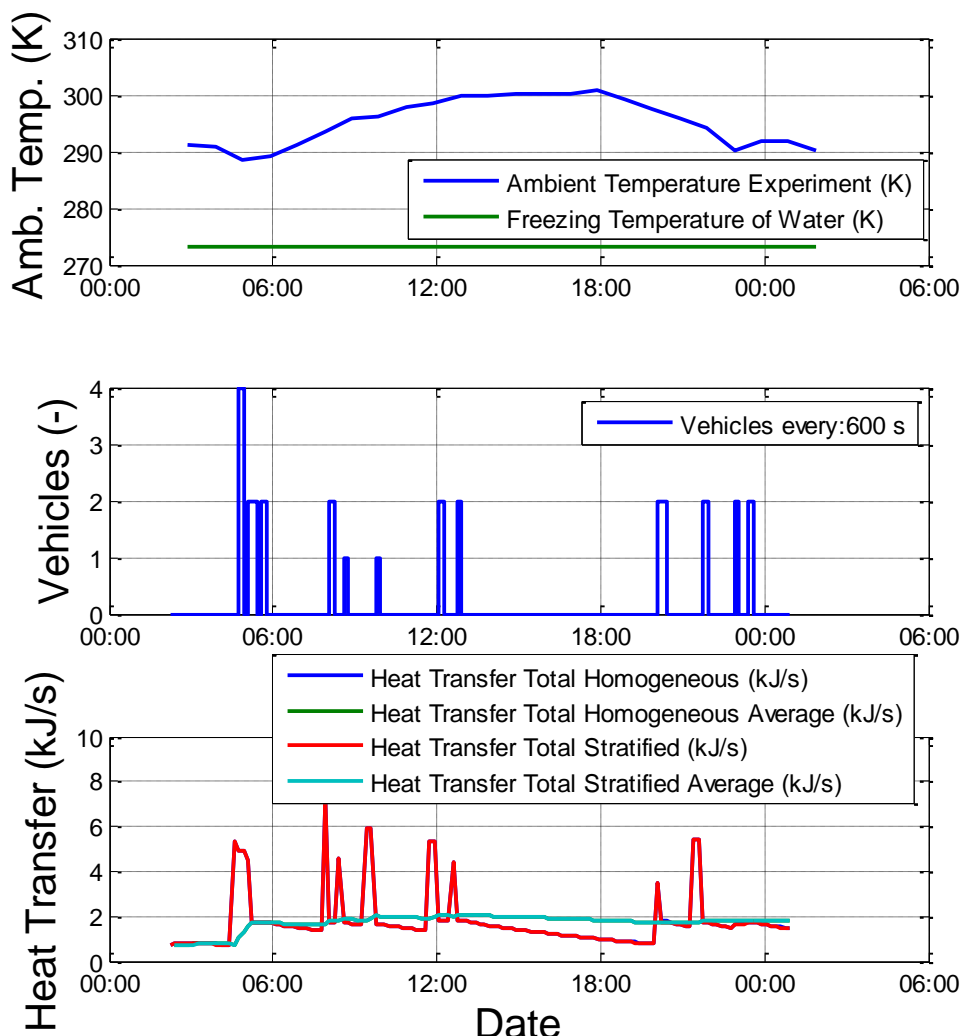

Figure D.9. Fueling Station 2 in Utah. Segment 2. GenSet: On. Total Heat Transfer Simulated, Weather Data, and Vehicles Refueled. 

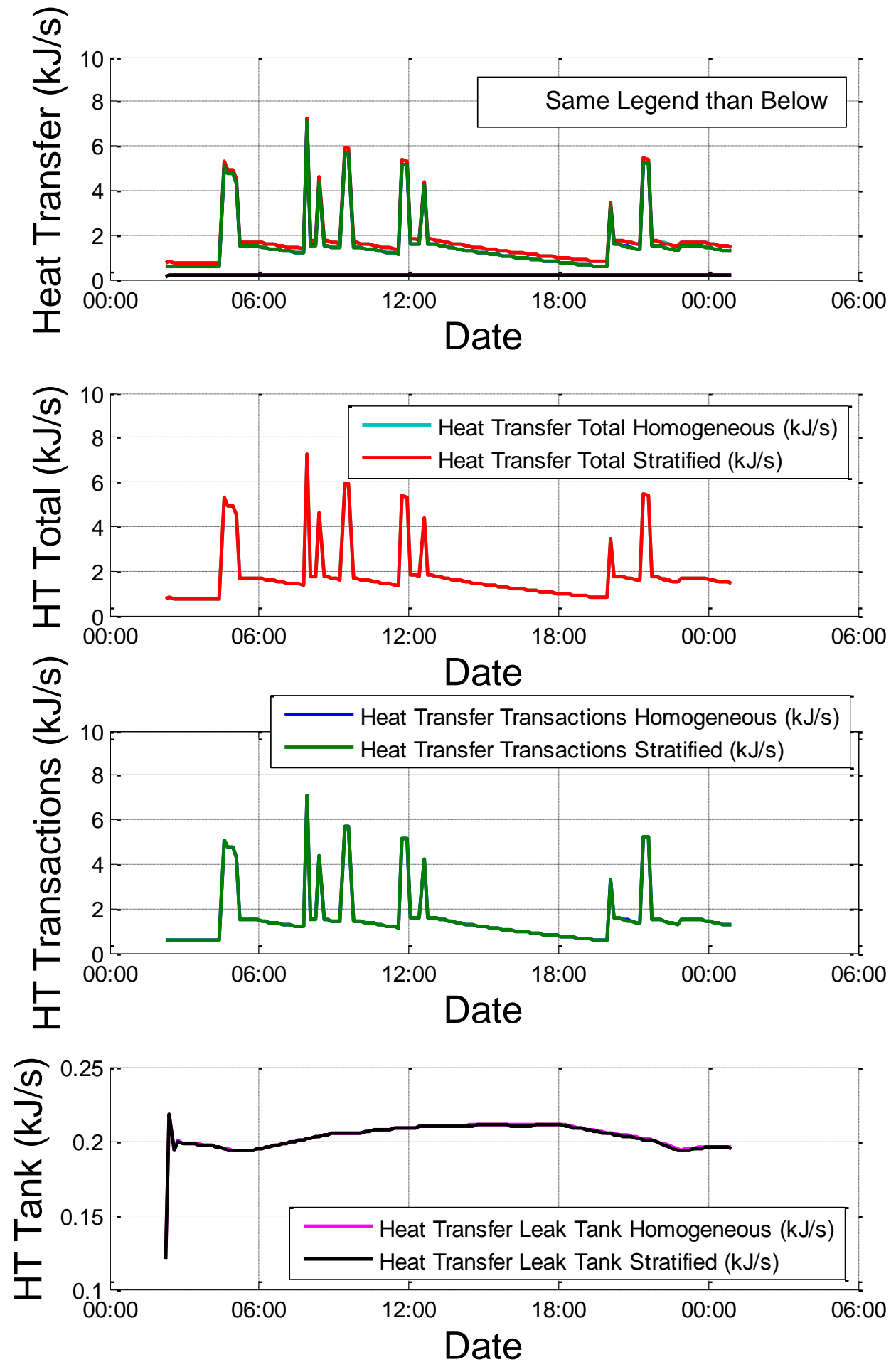

Figure D.10. Fueling Station 2 in Utah. Segment 2. GenSet: On. Total Heat Transfer, Heat Transfer by the Vehicle Transactions, and Heat Leak into the Tank through Walls. 

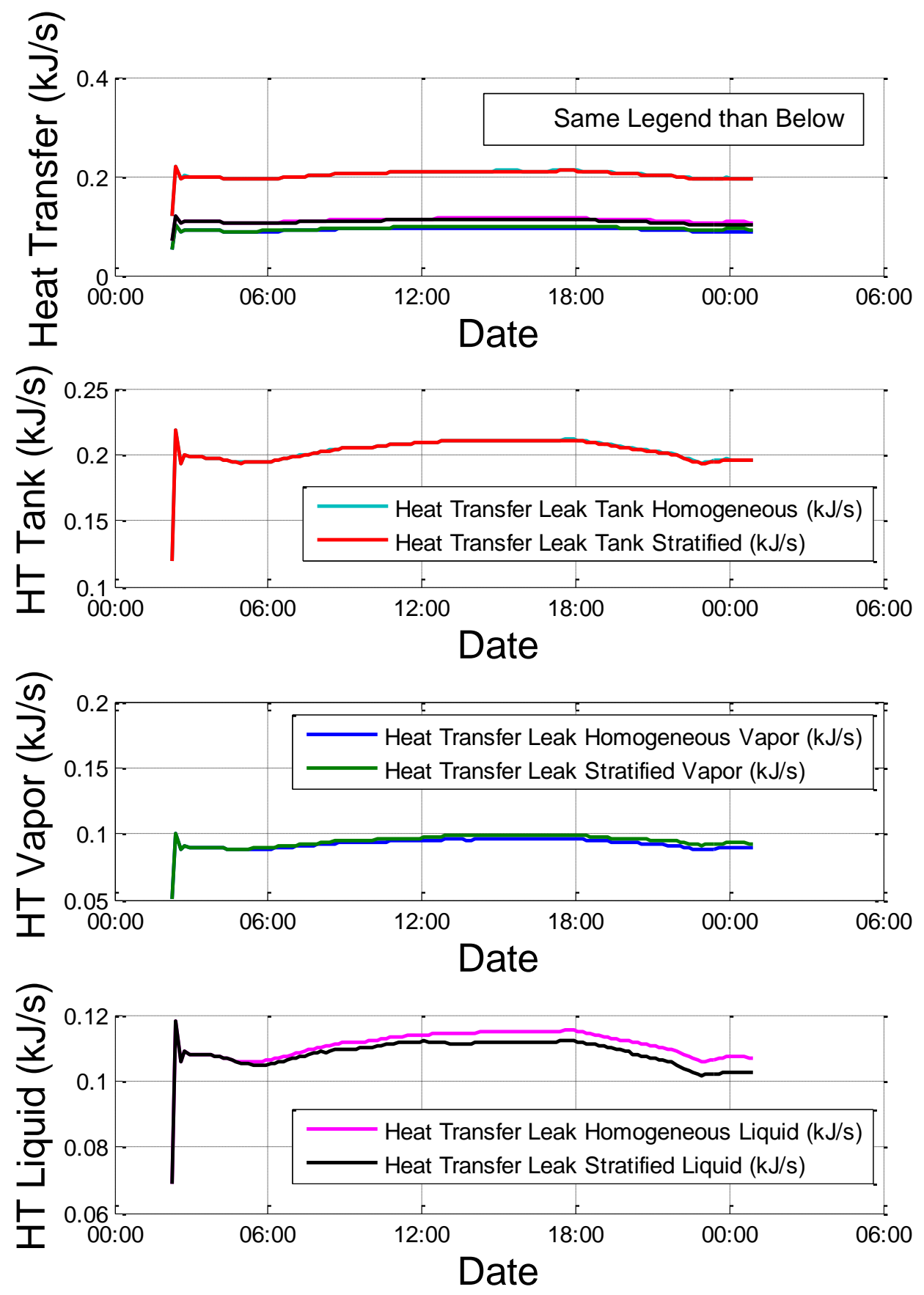

Figure D.11. Fueling Station 2 in Utah. Segment 2. GenSet: On. Heat Transfer Tank Leak into the Vapor and Liquid Regions. 

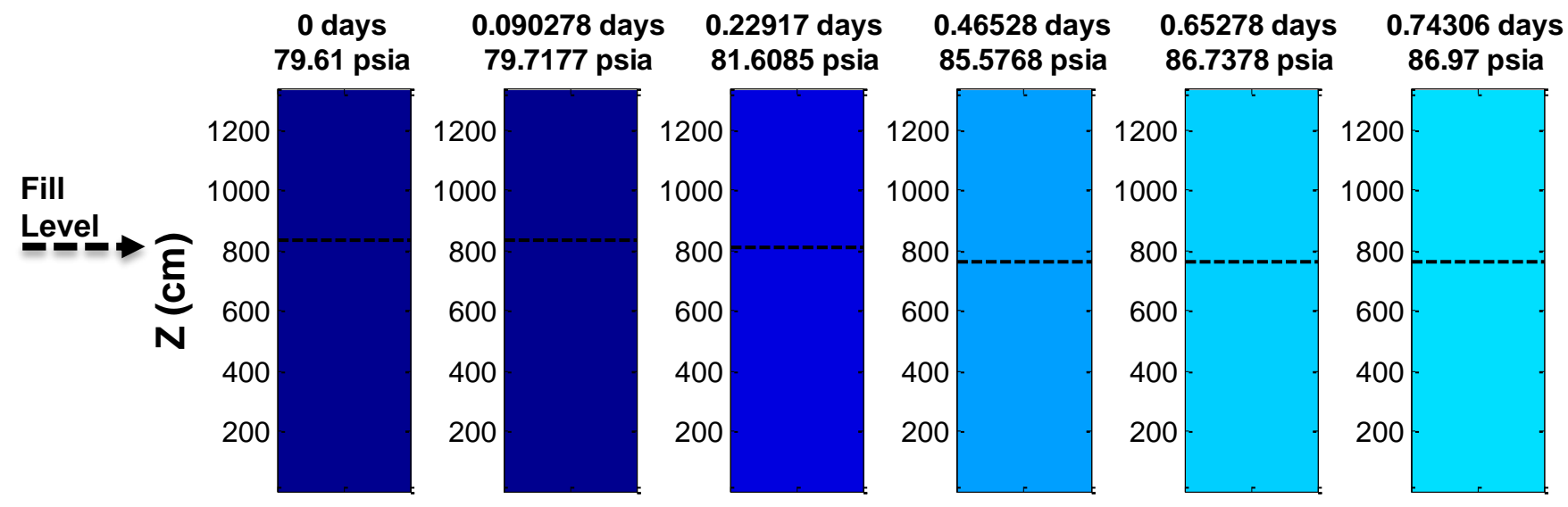

0.84028 days
88.1775 psia

0.93056 days Temp.
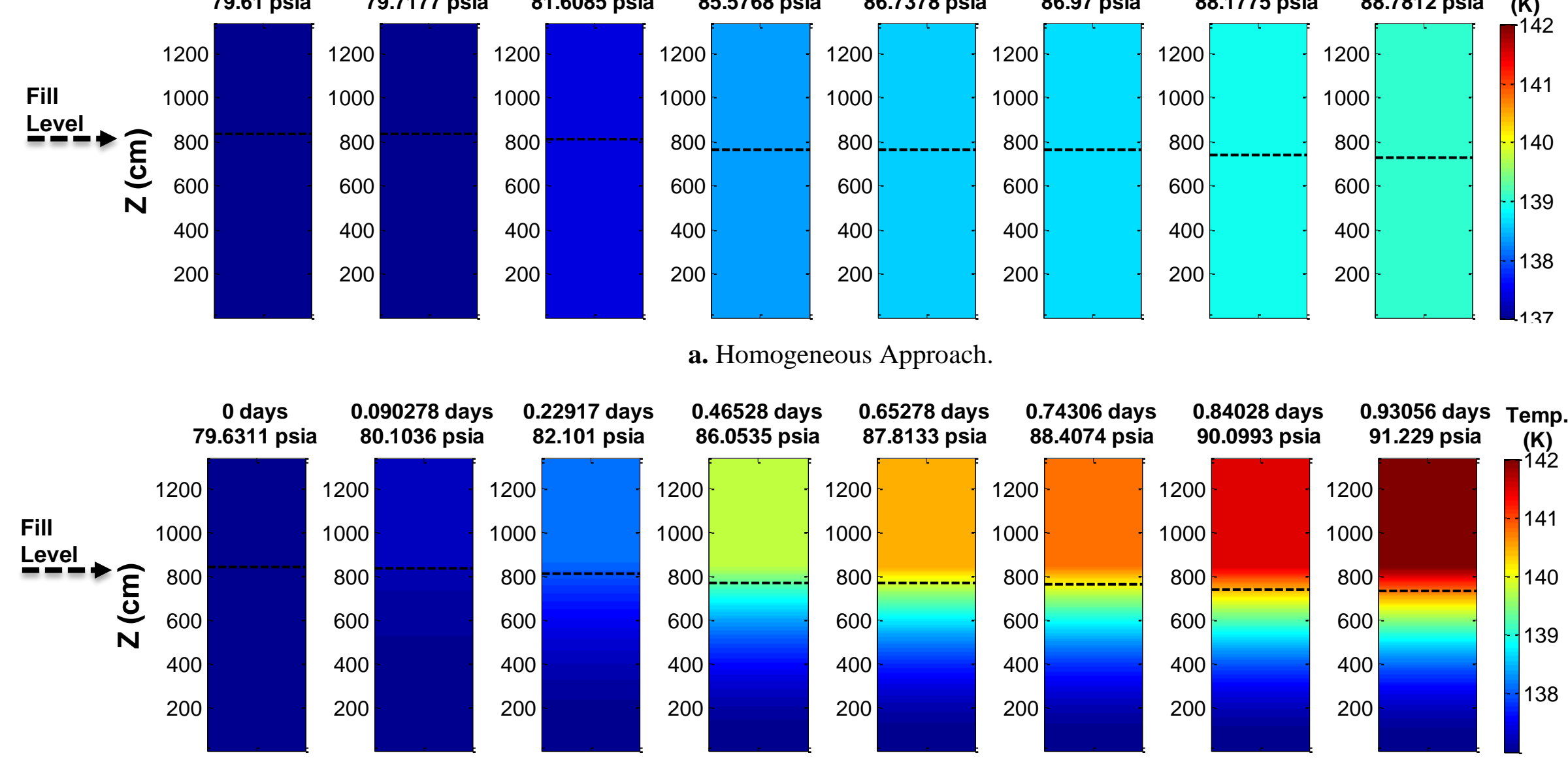

a. Homogeneous Approach.
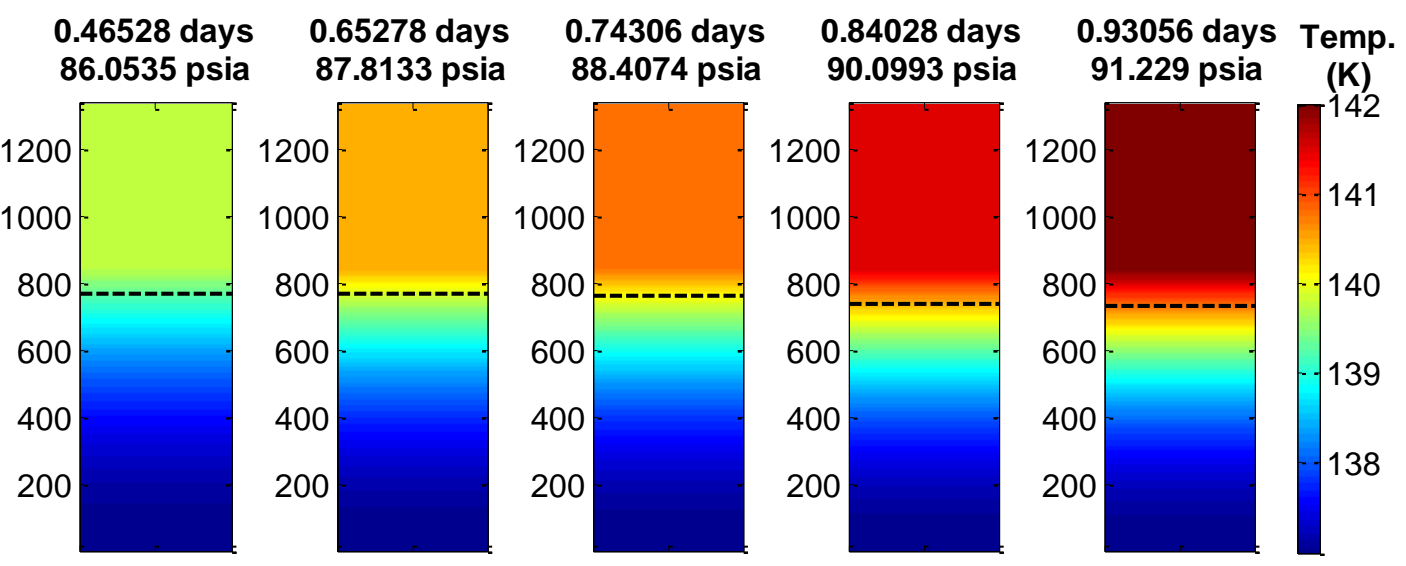

b. Stratified Approach.

Figure D.12. Fueling Station 2 in Utah. Segment 2. GenSet: On. Initial Homogeneous Fill Level: 62.83\%. Temperature Map Comparisons. 


\section{APPENDIX E:}

Saturated Properties for Methane $\left(\mathrm{CH}_{4}\right)$

\begin{tabular}{|c|c|c|c|c|c|c|c|c|c|c|c|c|c|}
\hline \multirow[b]{2}{*}{$\begin{array}{l}\text { Temp. } \\
\mathrm{T}\left({ }^{\circ} \mathrm{K}\right)\end{array}$} & \multirow[b]{2}{*}{$\begin{array}{l}\text { Sat. Press. } \\
\text { Psat (psia) }\end{array}$} & \multicolumn{2}{|c|}{$\begin{array}{l}\text { Density } \\
\left(\mathrm{g} / \mathrm{cm}^{3}\right)\end{array}$} & \multicolumn{2}{|c|}{$\begin{array}{l}\text { Entropy } \\
\left(\mathrm{J} /\left(\mathrm{g}^{*} \mathrm{~K}\right)\right)\end{array}$} & \multicolumn{2}{|c|}{$\begin{array}{c}\text { Const. Press. Specific } \\
\text { Heat }\left(\mathrm{J} /\left(\mathrm{g}^{*} \mathrm{~K}\right)\right) \\
\end{array}$} & \multicolumn{2}{|c|}{$\begin{array}{c}\text { Thermal Coeff. Vol. } \\
\text { Exp. }\left(1 /^{\circ} \mathrm{K}\right) \\
\end{array}$} & \multicolumn{2}{|c|}{$\begin{array}{c}\text { Kinematic Viscosity } \\
\left(\mathrm{cm}^{2} / \mathrm{sec}\right)\end{array}$} & \multicolumn{2}{|c|}{$\begin{array}{c}\text { Thermal Diffusivity } \\
\left(\mathrm{cm}^{2} / \mathrm{sec}\right)\end{array}$} \\
\hline & & $\begin{array}{c}\text { Sat. Liquid } \\
\text { of }\end{array}$ & $\begin{array}{c}\text { Sat. Vapor } \\
\text { pg }\end{array}$ & $\begin{array}{c}\text { Sat. Liquid } \\
\text { Sf } \\
\end{array}$ & $\begin{array}{c}\text { Sat. Vapor } \\
\text { Sg } \\
\end{array}$ & $\begin{array}{c}\text { Sat. Liquid } \\
\text { Cpf }\end{array}$ & $\begin{array}{c}\text { Sat. Vapor } \\
\text { Cpg } \\
\end{array}$ & $\begin{array}{c}\text { Sat. Liquid } \\
\text { } \boldsymbol{f} \mathbf{P} \\
\end{array}$ & $\begin{array}{c}\text { Sat. Vapor } \\
\beta \mathrm{g} \\
\end{array}$ & $\begin{array}{c}\text { Sat. Liquid } \\
\text { kinvis_f }\end{array}$ & $\begin{array}{c}\text { Sat. Vapor } \\
\text { kinvis_g }\end{array}$ & $\begin{array}{c}\text { Sat. Liquid } \\
\quad \alpha \_f \\
\end{array}$ & $\begin{array}{c}\text { Sat. Vapor } \\
\alpha \_g \\
\end{array}$ \\
\hline 90.7 & 1.70 & 0.45138 & 0.00025 & 4.227 & 10.228 & 3.3684 & 2.1104 & 0.00299 & 0.01137 & 4.2875 & 143.4142 & 1.38895 & 166.18898 \\
\hline 92.0 & 2.01 & 0.44965 & 0.00029 & 4.275 & 10.171 & 3.3729 & 2.1145 & 0.00300 & 0.01121 & 4.1394 & 124.7431 & 1.38226 & 144.96532 \\
\hline 94.0 & 2.56 & 0.44697 & 0.00037 & 4.347 & 10.088 & 3.3807 & 2.1213 & 0.00302 & 0.01099 & 3.9347 & 101.5440 & 1.37122 & 118.48608 \\
\hline 96.0 & 3.23 & 0.44428 & 0.00045 & 4.418 & 10.009 & 3.3894 & 2.1287 & 0.00305 & 0.01080 & 3.7528 & 83.4962 & 1.35945 & 97.78975 \\
\hline 98.0 & 4.04 & 0.44155 & 0.00055 & 4.488 & 9.934 & 3.3988 & 2.1371 & 0.00308 & 0.01064 & 3.5892 & 69.3055 & 1.34707 & 81.43587 \\
\hline 100.0 & 5.00 & 0.43881 & 0.00067 & 4.557 & 9.863 & 3.4090 & 2.1462 & 0.00313 & 0.01050 & 3.4405 & 58.0310 & 1.33404 & 68.38607 \\
\hline 102.0 & 6.13 & 0.43605 & 0.00081 & 4.625 & 9.796 & 3.4198 & 2.1562 & 0.00318 & 0.01038 & 3.3038 & 48.9849 & 1.32054 & 57.87417 \\
\hline 104.0 & 7.46 & 0.43324 & 0.00097 & 4.691 & 9.731 & 3.4314 & 2.1671 & 0.00323 & 0.01028 & 3.1775 & 41.6628 & 1.30660 & 49.33214 \\
\hline 106.0 & 9.00 & 0.43043 & 0.00116 & 4.756 & 9.670 & 3.4435 & 2.1789 & 0.00329 & 0.01020 & 3.0599 & 35.6856 & 1.29220 & 42.33019 \\
\hline 108.0 & 10.77 & 0.42758 & 0.00136 & 4.821 & 9.612 & 3.4563 & 2.1918 & 0.00336 & 0.01013 & 2.9501 & 30.7671 & 1.27747 & 36.55161 \\
\hline 110.0 & 12.81 & 0.42471 & 0.00160 & 4.884 & 9.556 & 3.4698 & 2.2056 & 0.00342 & 0.01007 & 2.8467 & 26.6888 & 1.26230 & 31.74417 \\
\hline 112.0 & 15.14 & 0.42180 & 0.00186 & 4.947 & 9.503 & 3.4841 & 2.2206 & 0.00349 & 0.01003 & 2.7494 & 23.2837 & 1.24686 & 27.71460 \\
\hline 114.0 & 17.78 & 0.41885 & 0.00216 & 5.008 & 9.452 & 3.4992 & 2.2368 & 0.00356 & 0.01000 & 2.6573 & 20.4232 & 1.23113 & 24.31891 \\
\hline 116.0 & 20.76 & 0.41589 & 0.00249 & 5.069 & 9.403 & 3.5151 & 2.2543 & 0.00364 & 0.00998 & 2.5699 & 18.0020 & 1.21500 & 21.43784 \\
\hline 118.0 & 24.10 & 0.41287 & 0.00286 & 5.129 & 9.356 & 3.5320 & 2.2731 & 0.00371 & 0.00997 & 2.4870 & 15.9427 & 1.19863 & 18.97873 \\
\hline 120.0 & 27.83 & 0.40984 & 0.00326 & 5.189 & 9.311 & 3.5499 & 2.2934 & 0.00379 & 0.00997 & 2.4078 & 14.1817 & 1.18187 & 16.86916 \\
\hline 122.0 & 31.99 & 0.40674 & 0.00371 & 5.247 & 9.267 & 3.5690 & 2.3153 & 0.00388 & 0.00999 & 2.3325 & 12.6664 & 1.16495 & 15.04786 \\
\hline 124.0 & 36.60 & 0.40361 & 0.00420 & 5.305 & 9.225 & 3.5892 & 2.3388 & 0.00396 & 0.01001 & 2.2606 & 11.3567 & 1.14768 & 13.46929 \\
\hline 126.0 & 41.68 & 0.40045 & 0.00474 & 5.362 & 9.185 & 3.6108 & 2.3642 & 0.00405 & 0.01005 & 2.1919 & 10.2192 & 1.13012 & 12.09376 \\
\hline 128.0 & 47.28 & 0.39723 & 0.00533 & 5.419 & 9.145 & 3.6339 & 2.3916 & 0.00415 & 0.01011 & 2.1263 & 9.2268 & 1.11223 & 10.88929 \\
\hline 130.0 & 53.41 & 0.39397 & 0.00598 & 5.475 & 9.107 & 3.6586 & 2.4212 & 0.00425 & 0.01018 & 2.0635 & 8.3574 & 1.09401 & 9.83057 \\
\hline 132.0 & 60.11 & 0.39065 & 0.00668 & 5.531 & 9.069 & 3.6852 & 2.4532 & 0.00436 & 0.01027 & 2.0035 & 7.5926 & 1.07549 & 8.89533 \\
\hline 134.0 & 67.41 & 0.38729 & 0.00745 & 5.586 & 9.033 & 3.7137 & 2.4880 & 0.00448 & 0.01038 & 1.9459 & 6.9171 & 1.05670 & 8.06562 \\
\hline 136.0 & 75.35 & 0.38385 & 0.00828 & 5.640 & 8.998 & 3.7444 & 2.5256 & 0.00461 & 0.01051 & 1.8909 & 6.3185 & 1.03750 & 7.32728 \\
\hline 138.0 & 83.94 & 0.38036 & 0.00918 & 5.694 & 8.963 & 3.7776 & 2.5666 & 0.00475 & 0.01067 & 1.8381 & 5.7860 & 1.01800 & 6.66727 \\
\hline
\end{tabular}




\section{SATURATED PROPERTIES FOR METHANE $\left(\mathrm{CH}_{4}\right)$ (Concluded)}

\begin{tabular}{|c|c|c|c|c|c|c|c|c|c|c|c|c|c|}
\hline \multirow[b]{2}{*}{$\begin{array}{l}\text { Temp. } \\
\mathrm{T}\left({ }^{\circ} \mathrm{K}\right)\end{array}$} & \multirow[b]{2}{*}{$\begin{array}{l}\text { Sat. Press. } \\
\text { Psat (psia) }\end{array}$} & \multicolumn{2}{|c|}{$\begin{array}{l}\text { Density } \\
\left(\mathrm{g} / \mathrm{cm}^{3}\right)\end{array}$} & \multicolumn{2}{|c|}{$\begin{array}{l}\text { Entropy } \\
\left(\mathrm{J} /\left(\mathrm{g}^{*} \mathrm{~K}\right)\right)\end{array}$} & \multicolumn{2}{|c|}{$\begin{array}{c}\text { Const. Press. Specific } \\
\text { Heat }\left(\mathrm{J} /\left(\mathrm{g}^{*} \mathrm{~K}\right)\right) \\
\end{array}$} & \multicolumn{2}{|c|}{$\begin{array}{c}\text { Thermal Coeff. Vol. } \\
\text { Exp. }\left(1 /{ }^{\circ} \mathrm{K}\right)\end{array}$} & \multicolumn{2}{|c|}{$\begin{array}{c}\text { Kinematic Viscosity } \\
\left(\mathrm{cm}^{2} / \mathrm{sec}\right)\end{array}$} & \multicolumn{2}{|c|}{$\begin{array}{c}\text { Thermal Diffusivity } \\
\left(\mathrm{cm}^{2} / \mathrm{sec}\right)\end{array}$} \\
\hline & & $\begin{array}{c}\text { Sat. Liquid } \\
\text { of }\end{array}$ & $\begin{array}{c}\text { Sat. Vapor } \\
\text { pg }\end{array}$ & $\begin{array}{l}\text { Sat. Liquid } \\
\text { Sf } \\
\end{array}$ & $\begin{array}{c}\text { Sat. Vapor } \\
\text { Sg } \\
\end{array}$ & $\begin{array}{c}\text { Sat. Liquid } \\
\text { Cpf } \\
\end{array}$ & $\begin{array}{c}\text { Sat. Vapor } \\
\text { Cpg }\end{array}$ & $\begin{array}{c}\text { Sat. Liquid } \\
\beta \mathbf{f}\end{array}$ & $\begin{array}{c}\text { Sat. Vapor } \\
\beta \mathrm{g} \\
\end{array}$ & $\begin{array}{l}\text { Sat. Liquid } \\
\text { kinvis_f }\end{array}$ & $\begin{array}{l}\text { Sat. Vapor } \\
\text { kinvis_g }\end{array}$ & $\begin{array}{c}\text { Sat. Liquid } \\
\boldsymbol{\alpha} \_f \\
\end{array}$ & $\begin{array}{c}\text { Sat. Vapor } \\
\quad \alpha \_g\end{array}$ \\
\hline 140.0 & 93.23 & 0.37680 & 0.01015 & 5.748 & 8.928 & 3.8135 & 2.6113 & 0.00490 & 0.01085 & 1.7875 & 5.3108 & 0.99804 & 6.07522 \\
\hline 142.0 & 103.24 & 0.37317 & 0.01120 & 5.802 & 8.895 & 3.8526 & 2.6601 & 0.00507 & 0.01107 & 1.7390 & 4.8854 & 0.97770 & 5.54183 \\
\hline 144.0 & 114.02 & 0.36947 & 0.01234 & 5.855 & 8.862 & 3.8951 & 2.7135 & 0.00526 & 0.01132 & 1.6926 & 4.5033 & 0.95692 & 5.06033 \\
\hline 146.0 & 125.58 & 0.36568 & 0.01357 & 5.908 & 8.829 & 3.9415 & 2.7723 & 0.00547 & 0.01161 & 1.6481 & 4.1593 & 0.93574 & 4.62330 \\
\hline 148.0 & 137.97 & 0.36180 & 0.01489 & 5.960 & 8.796 & 3.9923 & 2.8371 & 0.00570 & 0.01195 & 1.6055 & 3.8487 & 0.91402 & 4.22587 \\
\hline 150.0 & 151.22 & 0.35784 & 0.01632 & 6.013 & 8.764 & 4.0481 & 2.9088 & 0.00595 & 0.01233 & 1.5645 & 3.5675 & 0.89178 & 3.86329 \\
\hline 152.0 & 165.35 & 0.35376 & 0.01787 & 6.065 & 8.731 & 4.1099 & 2.9885 & 0.00623 & 0.01277 & 1.5253 & 3.3119 & 0.86890 & 3.53067 \\
\hline 154.0 & 180.41 & 0.34958 & 0.01953 & 6.117 & 8.700 & 4.1782 & 3.0776 & 0.00654 & 0.01326 & 1.4877 & 3.0797 & 0.84547 & 3.22539 \\
\hline 156.0 & 196.42 & 0.34528 & 0.02133 & 6.170 & 8.667 & 4.2544 & 3.1777 & 0.00688 & 0.01382 & 1.4517 & 2.8679 & 0.82126 & 2.94410 \\
\hline 158.0 & 213.45 & 0.34083 & 0.02328 & 6.222 & 8.635 & 4.3398 & 3.2908 & 0.00726 & 0.01444 & 1.4172 & 2.6741 & 0.79633 & 2.68381 \\
\hline 160.0 & 231.49 & 0.33626 & 0.02538 & 6.274 & 8.602 & 4.4362 & 3.4195 & 0.00768 & 0.01514 & 1.3841 & 2.4968 & 0.77046 & 2.44271 \\
\hline 162.0 & 250.60 & 0.33151 & 0.02765 & 6.327 & 8.568 & 4.5456 & 3.5671 & 0.00814 & 0.01592 & 1.3523 & 2.3340 & 0.74362 & 2.21840 \\
\hline 164.0 & 270.82 & 0.32657 & 0.03013 & 6.380 & 8.534 & 4.6711 & 3.7380 & 0.00864 & 0.01678 & 1.3220 & 2.1842 & 0.71572 & 2.00909 \\
\hline 166.0 & 292.20 & 0.32144 & 0.03282 & 6.433 & 8.499 & 4.8162 & 3.9380 & 0.00920 & 0.01774 & 1.2928 & 2.0462 & 0.68657 & 1.81329 \\
\hline 168.0 & 314.75 & 0.31608 & 0.03575 & 6.488 & 8.464 & 4.9862 & 4.1748 & 0.00981 & 0.01880 & 1.2648 & 1.9188 & 0.65594 & 1.62957 \\
\hline 170.0 & 338.54 & 0.31045 & 0.03897 & 6.542 & 8.426 & 5.1882 & 4.4593 & 0.01047 & 0.01997 & 1.2379 & 1.8009 & 0.62371 & 1.45677 \\
\hline 172.0 & 363.60 & 0.30450 & 0.04251 & 6.598 & 8.388 & 5.4320 & 4.8074 & 0.01120 & 0.02126 & 1.2122 & 1.6917 & 0.58950 & 1.29370 \\
\hline 174.0 & 389.99 & 0.29820 & 0.04643 & 6.655 & 8.347 & 5.7328 & 5.2425 & 0.01199 & 0.02266 & 1.1874 & 1.5902 & 0.55299 & 1.13942 \\
\hline 176.0 & 417.76 & 0.29145 & 0.05080 & 6.713 & 8.304 & 6.1135 & 5.8011 & 0.01285 & 0.02420 & 1.1635 & 1.4958 & 0.51374 & 0.99299 \\
\hline 178.0 & 446.96 & 0.28416 & 0.05573 & 6.773 & 8.258 & 6.6116 & 6.5430 & 0.01379 & 0.02588 & 1.1406 & 1.4079 & 0.47112 & 0.85364 \\
\hline 180.0 & 477.67 & 0.27618 & 0.06136 & 6.836 & 8.208 & 7.2936 & 7.5754 & 0.01481 & 0.02771 & 1.1184 & 1.3256 & 0.42437 & 0.72030 \\
\hline 182.0 & 509.93 & 0.26729 & 0.06793 & 6.903 & 8.151 & 8.2880 & 9.1047 & 0.01591 & 0.02969 & 1.0969 & 1.2485 & 0.37231 & 0.59211 \\
\hline 184.0 & 543.87 & 0.25709 & 0.07580 & 6.974 & 8.088 & 9.8828 & 11.5941 & 0.01710 & 0.03185 & 1.0761 & 1.1760 & 0.31328 & 0.46768 \\
\hline 186.0 & 579.57 & 0.24488 & 0.08569 & 7.055 & 8.011 & 12.8853 & 16.3360 & 0.01838 & 0.03418 & 1.0555 & 1.1075 & 0.24450 & 0.34466 \\
\hline 188.0 & 617.20 & 0.22889 & 0.09936 & 7.153 & 7.910 & 20.7419 & 28.7787 & 0.01977 & 0.03670 & 1.0347 & 1.0421 & 0.16100 & 0.21785 \\
\hline 190.0 & 657.01 & 0.20074 & 0.12516 & 7.305 & 7.731 & 94.0274 & 140.8354 & 0.02126 & 0.03941 & 1.0108 & 0.9777 & 0.04988 & 0.06838 \\
\hline
\end{tabular}




\section{APPENDIX F:}

T-V DiAgRAM FOR METHANE $\left(\mathrm{CH}_{4}\right)$

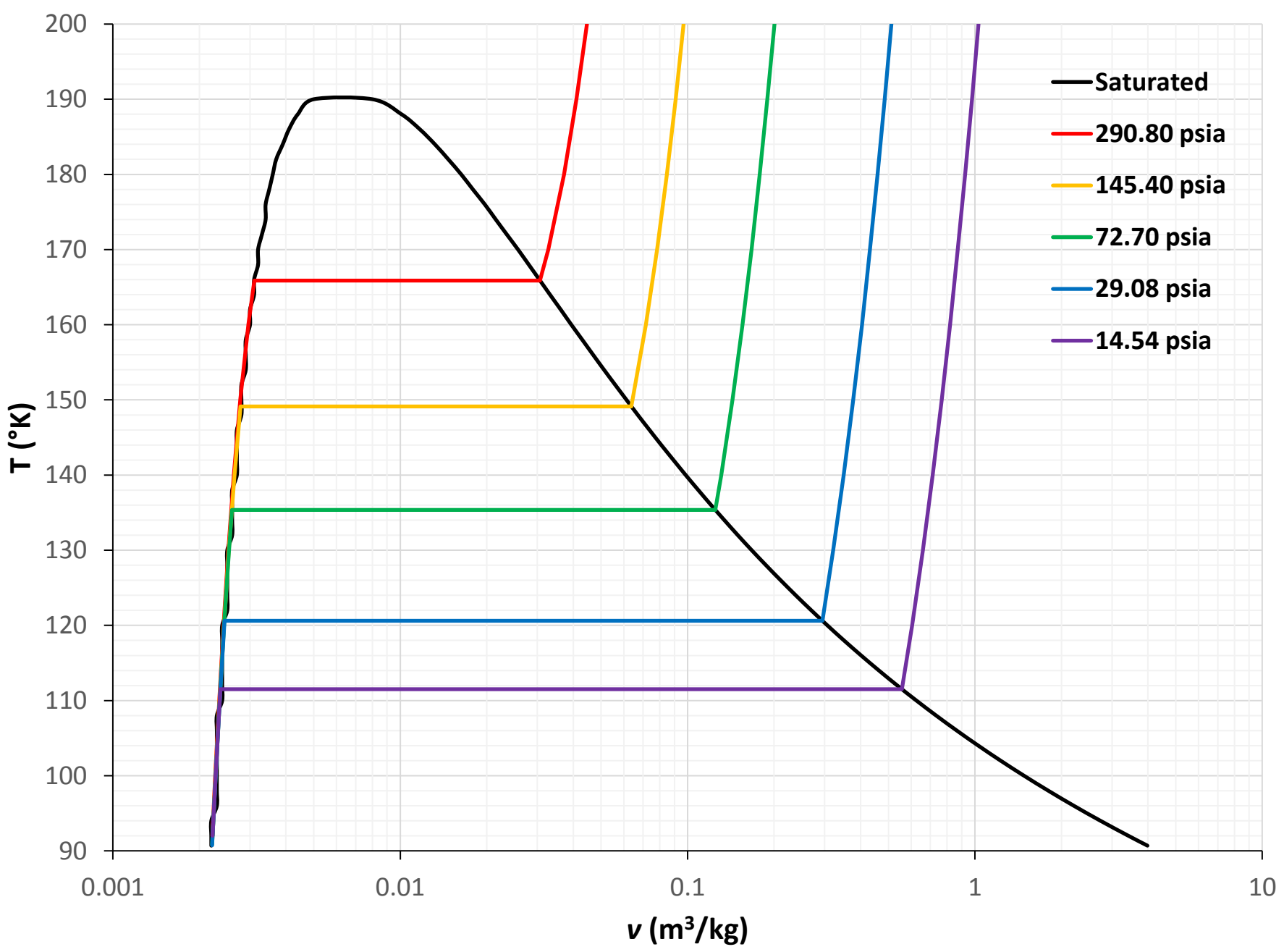




\section{APPENDIX G:}

T-P Diagram For Methane ( $\left.\mathrm{CH}_{4}\right)$ IN THE TyPiCal Pressure Range OF a LNG TANK

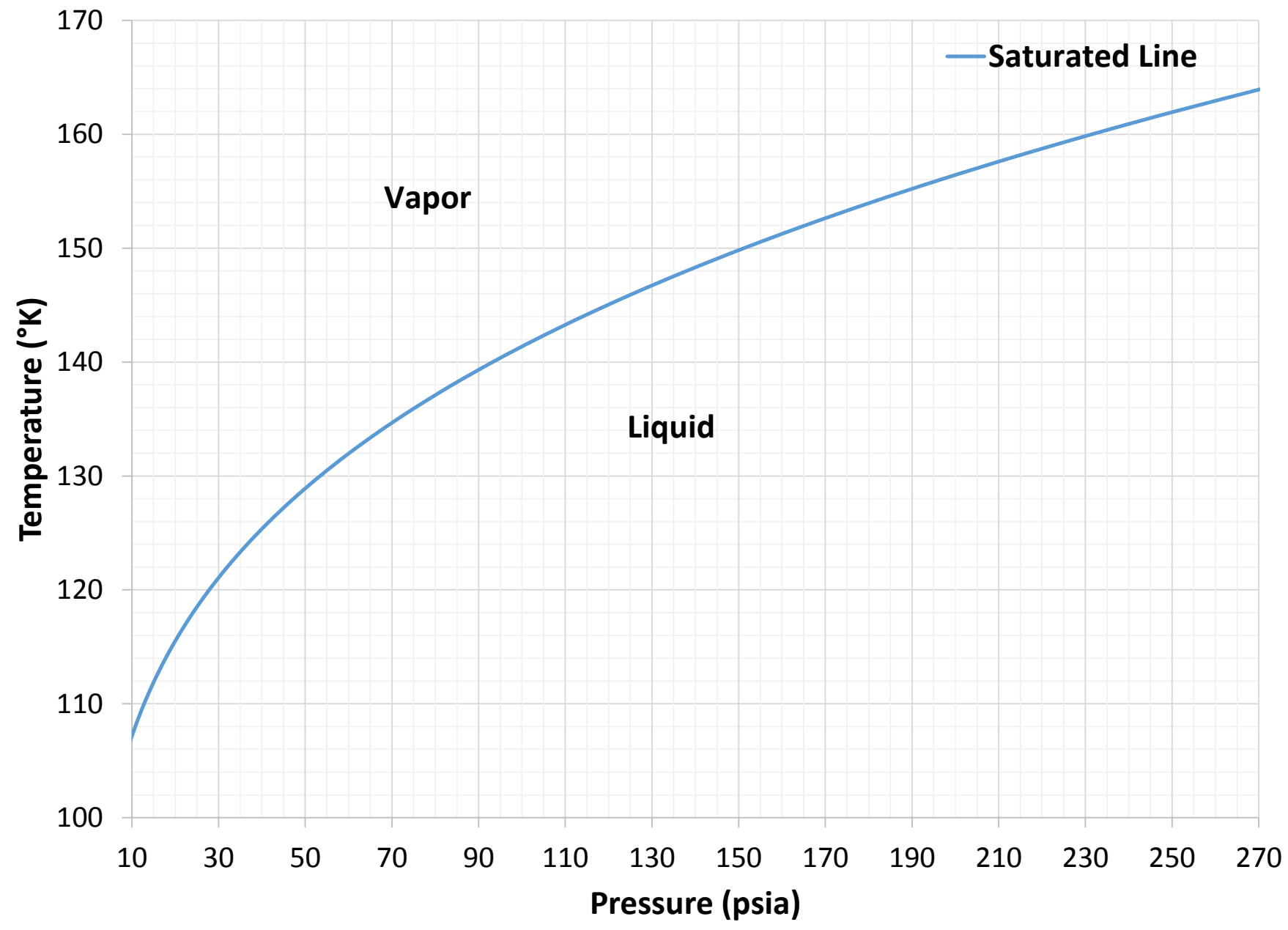

